


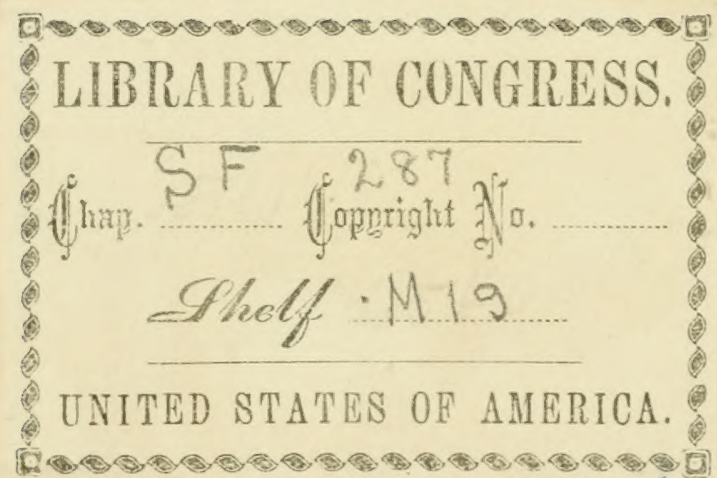






TH E

\section{NEW SYSTEM}

oF

\section{EDUCATING HORSES}

INCLUDING

INSTRUCTIONS ON FEEDING,

WATERING, STABLING, SHOEING, ETC.

WITH

J'RACTICAL TREATMENT FOR DISEASES.

I L L U S T RATED.

INCIUDING A

LARGE NUMBER OF VALUABLE RECIPES NOT BEFORE PUBLISHED.

BY D. M A G N ER,

Author of the New System.

ELEVENTH EDITION, REVISED AND ENLARGED.

\section{WITH AN APPENDIX.}

BUFFALO :

THE COURIER COMPANY, PRINTERS.

1876. 


\section{SF 287 M19}

Fintered according to Act of Congress in the yesr 18\%,

BY D. MAGNER,

in the Oftice of the Librarian of Congress, at Washington.

Inquiries for this book, or concerning other business, addressed to Prof D. Magner, Buffalo, N. Y., will receive prompt attention. 


\section{PREFACE.}

SiNCE publishing my first book in 1864 , comprising only 64 pages, I have made many important improvements, until it is now conceded that my system of Educating Horses, is the simplest and most practical in the world. To harmonize with my work, I have found it necessary to repeatedly revise and enlarge it, making it comprise many times the : mount of matter contained in the first.

My principles of subduing vicious horses constitute an entirely new feature of my success, wholly superseding the throwing-down principie, found to be so valuable by myself and others.

Included also will be found the most reliable and practical treatment for the care and cure of sick and lame horses, \&c. I have expended over $\$ 5,000$ in the study of Veterinary Practice alone.

My unquestioned experience and success, in addition to the value of my equipments, comprising the most beautiful and valuable troupe of Educated Horses in the world, is a guarantee of qualification and responsibility that entitles me to a confidence that cannot be accorded to those who, without reputation or experience, may engage in the business from motives of policy.

I introduce simple common sense principles that make the successful control of even the wildest and most vicious horses, not only possible, but easy for any one of ordinary strength and intelligence to do, which are as humane as they are effective and valuable.

D. MAGNER. 


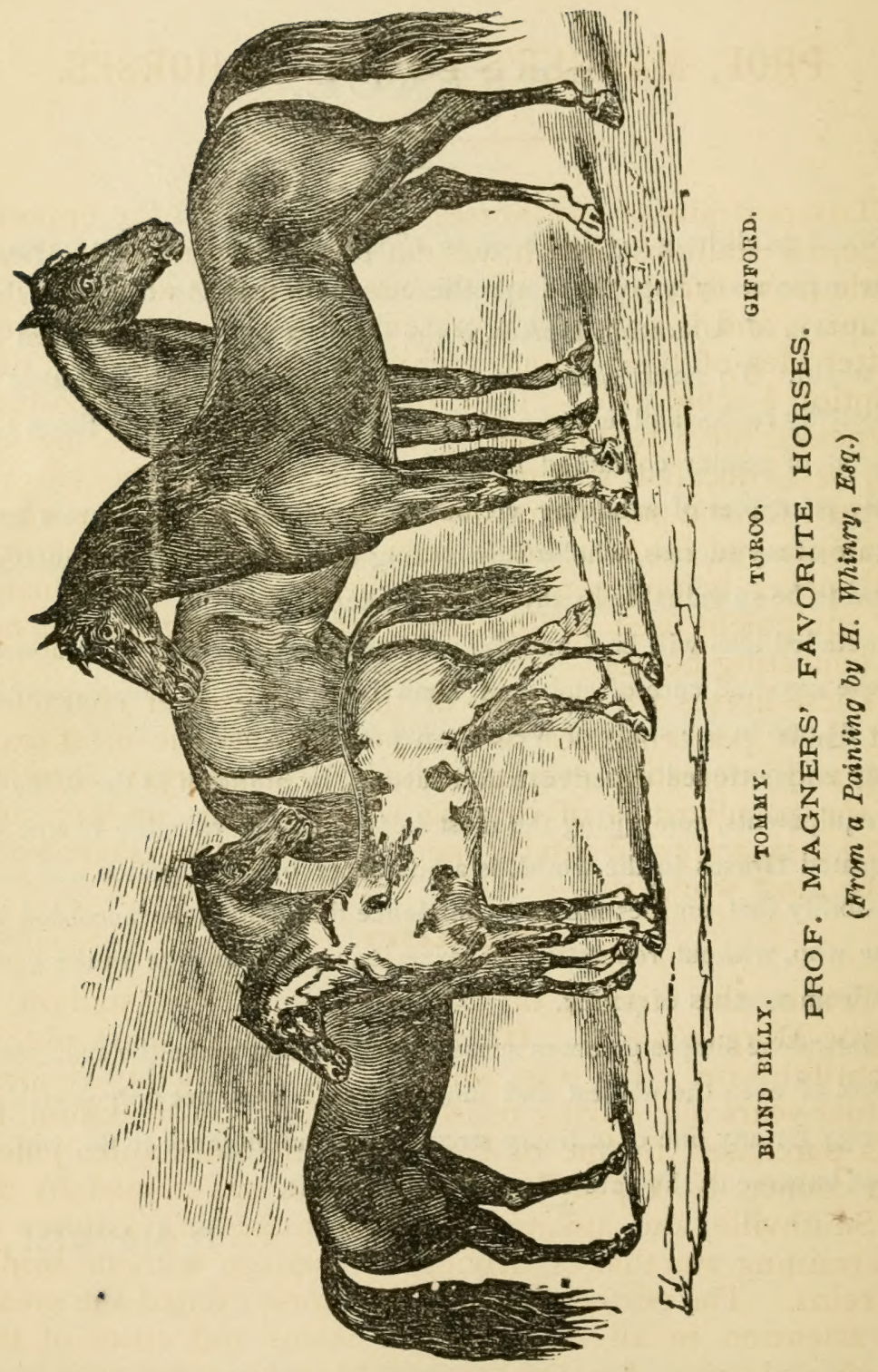




\section{PROF. MAGNER'S EDUCATED HORSES.}

ThF portraits of my horses and ponies, on the opposite page, all stallions, which was cut from a painting of them, made from life, by one of the most eminent artists in the country, and is a perfect representation of them, will give a better idea of their beauty and value than any worded description I could give. They are conceded by all who have witnessed their performances, to be the finest, most beautiful, best educated, and most valuable troupe of horses ever owned, for the purpose of giving free exhibitions by which to amuse and interest horse men and others in my efforts; and never before, perhaps, was there so fine and valuable an equipment used in illustrating and teaching the science of educating horses.

These horses are not only of the most varied character, but their performances are unquestionably the most exciting and interesting ever exhibited in this country, showing all the peculiarities of driving without reins or bits, and show a sagacity and intelligence in the ring that is conceded to be most wonderful.

\section{TUTRCOO.}

Turco, the farthest on the right, is a black stallion of Duroc-Morgan blood. He is nearly fourteen years old, of beautiful form. He was, when a colt, remarkably vicious; at four years old, having resisted all efforts to break him, he was purchased by me of Esq. Cole, of Smithville, Jefferson county, N. Y., in June, I86r. He was trained by me in Smithville, and among the most interesting features of his training was that of driving to carriage without bridle or reins. The performances of this horse excited the greatest attention in all the principal towns and cities of the north and east. I trained several horses to drive with him, and he has been driven and exhibited, double and single. by me, through the principal towns of twenty-three states. 
This ceasing to be a novelty, by the number of horses soon after so trained by others, who assuming the most extravagant pretensions, made it no better than a burlesque, I superseded it with other and more interesting features of performance under canvas, as now exhibited by me daily.

This fine horse has shown some peculiar features of sagacity. He will not allow a stranger to loaf around him, will allow any one to approach, feed, water and clean him, but curiosity seekers who may show any timidity in going near him, are soon reminded that he is not to be trifled with, but is perfectly docile.

\section{GIFEOID.}

Gifford, the black horse on the near side, is of Mor gan blood, ten years old, and is one of the most beautifully modeled, as well as one of the finest performing horses in the country. Have owned and exhibited him for nearly five years, both north and south. Among his most remarkable feats is that of acting vicious or gentle at will. $\mathrm{He}$ will play sick in the most natural and wonderful manner, even groaning from apparent intense pain.

\section{BIIIVD BIIIT.}

Next on the off side, to the left, is represented Blind Billy, which is acknowledged by all witnessing his performances, to be not only the finest modeled pony, but the most wonderful performing BLIND HORSE in the world. BILLY is now nine years old, mahogany bay color, fourteen hands high, and weighs nearly 900 pounds. He is as above stated, totally blind, and has been so for four years. He does everything by word of command only, and not the least interesting peculiarity of his performance is the attention with which he waits for and promptly obeys every command. He will run the ring, turning right or left, go lame, walk on his knees, kick on his knees, look for and find a handkerchief, jump clear of the ground and kick, walk on his hind feet around the ring, or turn right and left in circles while standing erect on his hind feet. He will sit down like a dog, turn right or left while sitting on his haunches. All this, and much more, he does in the promptest manner, at the word of command. He is acknowledged not only to excel all other horses, blind or 
not, by the difficulty and variety of his performances, but surpasses as well all horses known, by his wonderful performances of squealing and laughing, at the word of command. The sum of Seven Thousand Dollars has been offered and refused for this beautiful and wonderful animal. He is unquestionably, the rarest, finest, and most valuable performing pony in this country, if not in the world; and the witnessing of his performances the most instructive and interesting novelties of the day.

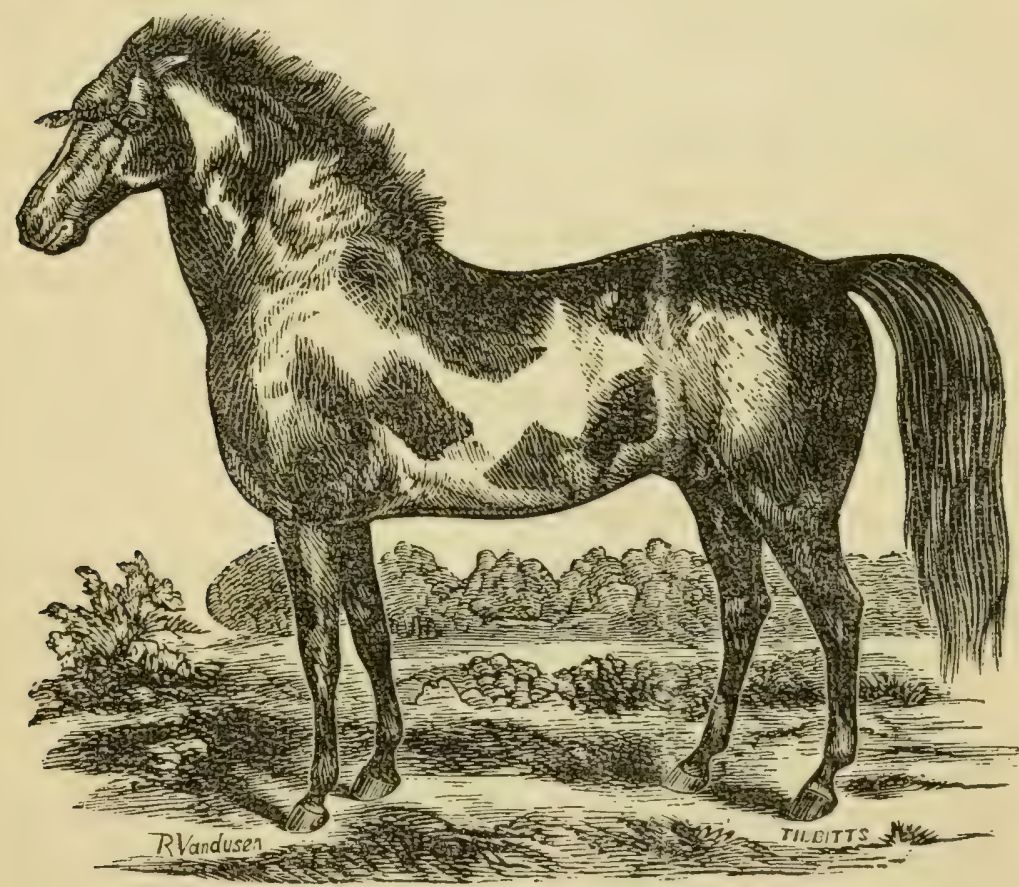

rompr.

The best Trick Pony in the World.

The nearest on the left is the Spotted Pony, Tommy. As his appearance shows, he is the smallest and most cunning of the group. He is eleven years old, weighs 720 pounds, bright bay color with white spots, extending back on each side of his body, and is a perfect model in form. 'Tommy is the clown of the lot. He is in himself a whole show, and the amusement he excites by his unique performances is really side-splitting; it is not so much what he 
dues as the way he acts out his performance that so intensely amuses. He is as apparently innocent and gentle as can be; even allowing a child to go under, around, or over him. Should a rider even fall under his feet, he will either carefully step over him or stand still until the rider gets up; yet in an instant by the merest signal, his whole nature seems to be changed to the character of a vicious, dangerous stallion, with ears back, mouth open, eyes flashing fire, and every hair on his body on end, he will clear the ring of all intruders. At such a time there are but few of the most courageous who will dare to enter the ring, so apparently dangerous does he appear; yet as quickly at command will he assume his former gentle appearance, and play with any one or go around the ring for presents. The sagacity he exhibits even in this is almost wonderful, for if given no attention he will pass by without apparently noticing a person, going directly to those of the sunniest nature by whom he delights being caressed, always showing preference for well dressed and good looking larlies, for whom he seems to have a great fondness, acknowledging a caress or a present with the politeness of a courtier, ly a bow of the head.

It is, however, in his great contests with riders that he shows the most wonderful sagacity and power, throwing or not a little boy easily and quietly as commanded, but sending the smartest and best riders flying at will from his back. It is in his great performance of "throwing the boys" that he brings down the house with almost insane applause. I have seen at such times the most habitually grave men and women laugh and scream with delight, until the tears coursed down their cheeks, and in many instances of persons lying down upon the seats, or rolling upon the ground, yielding in their paroxysm of excitement to the uncontrollable impulses which seized them. When the eloguent preacher and senator from Ohio, Mr. Garfield, who, with his friends and faculties of the Hiram College, attended one of my exhibitions in that place; so great was his pleasure while witnessing this great performance of 'Tommy's, that he rolled, clapped his hands, and shouted with delight.

The following from the Cleveland Leader, in speaking of 'Tommy's performance during one of my exhibitions in that 
city, will better illustrate the excitement and interest which his performance excites:

"But the most laughable scene took place when the spotted wild horse, Tommy, was introduced. He presented every appearance of a wild steed, and ran restively about with distended nostrils and fiery eye, his mane bristling like the quills of a fretful porcupine, but at the approach of his master he became as tame as a lamb. Every one was invited to try their equestrian skill on Tomsy, and all who tried were thrown to the ground, tenderly, but in the twinkling of an eye. Mr. Magner offered $\$ 500$ to any one who would ride Tommy one minute. Several tried, but

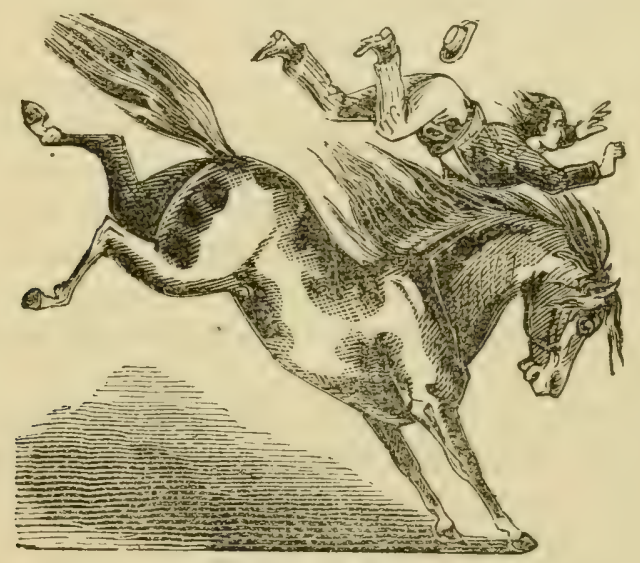

Tommy, in his famous act of throwing the Boys.

none were rewarded with success. One ambitious gentleman threw off hat, coat and vest, and said he 'would be $\mathrm{d}-\mathrm{d}$ if he didn't ride him.' Tommy was too much for him. He was thrown several times, and finally concluded that he had better let Tommy have his own way."

Thus it is seen I not only give the most interesting exhibitions free under canvas, but being the author of my own work, and handling and controlling the wildest and most vicious horses daily in illustrating my system, and devoting too, my whole attention to this end, that I am inaugurating an era of interest in the study and kind treatment of the horse, which is in the extreme, commendable and valuable. 


\section{THE NEW SYSTEM OF EDUCATING HORSES.}

THERE are so many who claim precedence as authors of the New System, etc., and that, too, in increased proportion to the ignorance and inexperience of those engaging in the business as a matter of speculation, that a few words of explanation, in relation to the part I have taken and of my success in this field, becomes necessary as a matter of duty and justice to myself and public.

I have now been before the public over eleven years, constantly employed in imparting a knowledge of such principles of edncating and managing horses as I found to be most simple and practical. I claimed and advertised a NEW SYSTEM from the start. In the winter of I 863-4 I wrote and published in Utica, N. Y., at the Herald office, an exposition of my treatment called "The New System," copyrighting the same under that title.

Sometime afterwards I sold to Mr. A. H. Rockwell, for three hundred dollars, the right to republish this work under his own name, a copy of the contract of sale of which I have still in my possession.

Mr. R. very unjustly, in the revision of this book, implies having taught me, of having trained the horse Turco I then owned, etc.; when the fact was, I was over a year on the road before I met or heard of him, I had trained and exhibited this horse nearly two years before he saw him. To Mr. Rockwell undoubtedly belongs the merit of giving public exhibitions of the feature of driving a horse in the strect without reins with a whip. But Mr. Bunnell, of Wellsioro, Tioga county, Pa., emphatically claims that his wife trained this horse to be guided and controlled by motions of a whip), and repeatedly exhibited him at County Fairs before selling him, and before being purchased by Mr. R. 'This is not, however, any discredit to Mr. Rockwell, being too simple a feature of training to be regarded a; much of an achievement; and besides, he has proved liimself a gentleman of 
too much skill and merit to have the admission now of this fact injure his standing or character.

I also gave a gentleman named R. P. Hamilton, the privilege of republishing one of the earlier editions of my book, which lie did under his own name, a copy of which edition I have in my possession.

[I met and cultivated the acquaintance of Prof. Hamilton in Ohio, in the winter of I866. Between this gentlemeri and myself, there had during our acquaintance been mantained the warmest feelings of friendship, contributing to a more than ordinary interest in each other's success and welfare.]

In March, I868, I started a resident of Batavia, N. Y., named O. S. Pratt, in the business, selling him two trained horses, one of them a gray trick pony called Billy, and a fancy advertising wagon. At the same time I sold another gray trick pony, named 'Tommy, to a gentleman named Graves, a resident of Lockport, N. Y. This pony was afterwards purchased of Mr. Graves by the said Pratt, and are the same he still uses in his business.

Mr. Pratt, who makes some pretentions to character, I learn, advertises himself as author of the New System, etc. He certainly was not identified as a horse man before the above date, having kept a grocery in Batavia previous to the above time, which he sold for the express purpose of buying his outfit, as stated, and engaged in the business as a mere matter of speculation.

I am known in the principal portions of twenty-three states, extending from Maine to Mississippi, including New Brunswick. I am the author of my own work, have TRAINED AND OWNED, AND DO OWN THE FINEST AND MOST VALUABle STUd OF Horses in AMERICA.

To illustrate and prove the interest I excited by my success in this field, years ago, I will insert here a few samples of the many flattering notices I received from the people and press of that period:

\section{From the Utica Morning Herald, Jan. 23, 1863.}

Horse Training.-In the afternom Mr. Magner gave a few persons an opportunity to witness his process of training horses, at the barn of Mr. Roberts, near the cemetery. Mr. R.'s stallion, Ethan Allen, which is known as the most vicious horse, in this part of the State, was taken in hand, and in 20 minutes, Mr. M. had him completely under control so that he could handle him precisely where and as he pleased, and manage him without bridle or halter. Anwng other apparently verv 
hazardous things, he passed beneath the horse between both fore and hind legs. An unbroken colt was also operated with, and was brought under complete subjection in considerably less time than the stallion. A committee of competent judges present, expressed great satisfaction with the result. Mr. MAGNer has a system of his own, which he conficlently thinks to be superior to any other known. He guarantees that he will subdue any horse, however vicious, and break them of all such bad tricks as balkiness, kicking, biting and running away. $\mathrm{He}$ is quite a young man, has a good address, and seems to possess much more than ordinary intelligence. We think he is likely to become famous in his profession. Of course we would not be justified in giving the details of his system.

The above mentioned horse harl bit and struck Mr. Rolverts six months before, so severely and so desperate was his fury, that it was with the greatest difficulty two men drove him off with rails, but not until Mr. Roberts had an arm lacerated and proken, and was insensible from his injuries, from which he had not yet recovered. The horse ran loose in a building, being fed and watered through a window, and so vicious that he had not been taken out or handled, nor could his owner or any one go into his room with safety. Indeed I was entreated by the committee comprising Mr. Butterfield, (now Genl. Butterfield or his brother,) Mr. Golden, (Merchant,) Editor of Herald and others, not to go near him-that they would do all they could, to interest the public in my favor, if I would not. But the success above stated, will show with what ease and quickness I made him obedient to my will. He was used and driven afterwards perfectly gentle, by his owner. The Utica Herald, Mr. Roberts, or other gentiemen named, can be referred to, for proof of this statement.

\section{From the Kennebec Journal, Augusta, Me., Feb., 1864.}

Mr. Magner, the author of this philosophy, and who proves himself to be one of the most expert and scientific horse tamers and trainers in the world, has, during the past week, delighted and astonished the good people of Augusta and vicinity by the admirable and perfectly successful demonstration of his system in subduing and controlling some of the most vicious and ungovernable specimens of the horse fraternity that could be found among us. The manifest and acknowledged importance of this art, and the desire of the public to understand and witness the results of its application, induced a crowded attendance of all classes on Mr. Magner's practical illustrations of his theory. All who attended came away fully convinced of, and perfectly satisfied with the correctness of the principles and workings of this new system. Even the members of the Senate and House of Representativ: ', and thie members of the Executive Council took a leisure hour, laid by the affairs of State, forgot their parliamentary squabbles, and found both amusement and instruction in witnessing the skill and consummate tact with which Mr. Magner handled the hitherto incorrigible subjects brought forward to test his new doctrine. Crowds of our most intelligent citizens were alse in attendance, and became decidedly and thorougly satisfied that 
Mr. Magner's system is all that he claims for it, and when applied, will be effectual in bringing the wildest and most stubborn horse into complete subjection and docility. A large class of pupils united in order to profit by Mr. Magner's instruction, and learn the best modes of applying his theory to practice, and as a matter of course, the hardest and most vicious horses that could be found in the neighborhood were brought in for him to subdue; all of which were completely tamed and brought into such a state of docility as to astonish those who saw it. So satisfactory and perfectly successful were his instructions and experiments to every one who attended, and so efficient and useful did his principles and modes of procedure prove themselves to be in training and subduing horses, that the officers of the Second Maine Cavalry were influced to invite him to give a course of instruction to those of the regiment who could be spared from duty to attend. In this, too, he was perfectly successful, as in all other instances. The most dangerous of vicious horses are those frisky, nervous, touchy kickers, whose heels are always ready to greet you whenever you approach or attempt to harness them. One of this class was brought forward, of so desperate a character that her owner cautioned Mr. Magner that he would expose himself to danger and probable injury if he was too familiar with her. In a very short time he had her so effectually subdued and conquered that he could do anything he pleased with her-jump upon her back, slide off behind her heels, handle her feet, and place himself in any position he pleased around her without her offering the least opposition or showing the least disposition to bite or practice her old tricks.

It may be thought that the practice of this mode would require great strength and size of body. On the contrary, Mr. Magner is a young man hardly of medium size, and of a very modest demeanor. But he is cumpact of form and muscle, resolute, prompt and decided, though kind and patient in action-requisites more essential in dealing with the many crabbed and cross-grained brutes that are often brought for him to tame, than herculean strength or size of limb and body. Ie was strongly urged to stay longer in the city and repeat his course to another and larger class, but his prior engagements prevented a compliance with the request.

In his tours through the country in the fulfilment of his mission of good to so useful an animal, we commend him to the friendly attention of farmers and horsemen, who will find his principles of great value, in this necessary art. We look upon this mode of horse training as an art wonderful for the sure and infallible results which follows its appliance.

\section{Maine Farmer, Feb. 24, 1864.}

His practice is guided and aided by common sense applications of most simple mechanical means and new principle of control, as will convince the most stubborn and willful horse that there is a power above him to which he is soon glad to submit. It is all done quietly, no whipping nor thrashing; no mauling, bawling nor swearing, as has too often heretofore been the custom in such cases. Herein is one of the great and invaluable improvements which Mr. Magner introduces 
in the art of bringing the horse under complete control of man. We make the remarks for the purpose of calling the attention of our farmers and owners of horses of Maine, to these new improvements of such vital importance to their interests. We have taken pains to give them a personal investigation. You will find Mr. Magner a modest, unassuming young man, and no humbug, and we cordially advise every one who can, to obtain his lectures.

\section{Portland (Me.) Tranecript-1864.}

Mr. Magner, the Horse Tamer and Trainer, has been in Portland during the past week, and has created a great stir among our horsemen. So great was the interest excited, that Mr. Magner formed a schuol, which was largely attended by those interested in such matters, including many of our best citizens who have fine horses, and seems to have been altogether satisfactory. Such success in so brief a period is quite unusual. His exhibitions have been very interesting and have satisfactorily demonstrated his ability to bring the most unmanageable horses entirely under his control. An innocent colt, fresh from the country, was introduced, and in a few minutes acted the part of a well trained horse; then came a spirited mare, whose stubbornness was not so readily but no less surely overcome; an old stager, which had for years defied every farrier in the county, but after five minutes training stood quietly as a lamb while his feet were handled and hammered in true blacksmith style; a splendid animal, whose principal fault seemed to be unusual fright at the sight of an umbrelia, in a very short space of time stood unmoved as one of those articles was placed before him and moved about his body, and when at last it was held above and dropped upon his head, he appeared to regard it with far more of complacency than fear; a puller on the bit was beaten at his own game and yielded handsomely. Whatever the tricks and eccentricities of which the animals brought forward were guilty, they found more than their match in the horse tamer, who did not in a single instance let a horse pass out of his hands till he could truthfully say, "I have you, sir." He was asked to test his skill still further on a vicious mule which was brought in and turned loose in the ring; he was indeed a villainous fellow, and not at all agreeable in his manners, refusing to be bridled or handled, and meeting every one who approached him with an undesirable display of his heels-but in less than fifteen minutes his whole demeanor was changed, and he remained perfectly quiet while he was again and again naltered, mounted on all sides, and handled from head to foot, andi finally was led out perfectly submissive. The change was wonderful and called forth great applause.-These exhibitions are, as we learn. foreign to Mr. Magner's custom and general purpose, which is, not io exhibit feats in lorsesmanship, but to make the people practically acquainted with his system, and thereby create increased interest in risising and managing horses. He is soon to start out into the towns of this State, and we hope farmers and horsemen will give him all the attention which his theory and his success merit. 
Mr. Magner is about thirty years of age, is rather below the ordinary height, has a stout, muscular body, a sprightly piercing eye, and speaks with a clear voice and convincing manner, and in deportment and appearance is altogether a gentleman; and it is only just to say in his behalf, that in Portland, as well as in several towns which he has visited, he has won for himself and his method of managing horses great favor, and many are now carrying out successfuly the instructions which they have received from him.

\section{Portland (Me.) Advertiser-1864.}

RAREy Nowhere.-Mr. Magner, whose equestrian feats have excited the wonder of our citizens, has left the city in order to fulfill numerous engagements in the country. It is yery fortunate for him that this is not an age when men are executed for witchcraft. Had he lived in Salem in 1692, and exhibited, as he has here, his power over refractory horses, he would have been hung, as sure as fate, for a wizard. Indeed, we are not certain that he does not practice some sort of witchery in his management of horses. No one can form an idea of his wonderful power over them until he witnesses proof of it. To see a horse furious, stubborn, defiant, with a very devil in his eye, in a few moments, by some mysterious power, calmed down, rendered docile, patiently submissive, and allowing every liberty to be taken with himin a word, the evil spirit which had possessed the animal, completely exorcised-you can hardly credit, although the marvelous transformation takes place under your naked eye. A knowledge of Mr. Magner's theory of subduing the horse must be invaluable to all owners of the animal. The horse has been the gentleman's special study. He has made himself acquainted with all his characteristics. He has but to look upon the animal to discover his faults, and straightway, by a miracle, as it were, he corrects them. It seems almost too much to believe, and people will not believe it until they see for themselves proof of the gentleman's success.

I WOULD MOST RESPECTFULLY REMIND, that whatever my success a few years ago, I have since then introduced new principles, and made improvements which enable me to produce results now in the education and reformation of horses, in many instances in a few minutes, which it would have been most difficult, if not wholly impossible for me to have done a year or two ago, the proper application of which will enable results in the reformation of vicious horses, that is even now wonderful and almost beyond belief. I have, during the past summer and fall, taken horses in hand, in Ohio and Michigan, that had resisted all efforts of the best horsemen, who practiced the treatment of all others who have traveled in the business, as well as that I uscel 
years ago, and in every case controlled and drove them easily and safely in less than an hour. I have now a conception of this great and important science, which long experience and careful study only will enable, the value of which I prove by the successful results exhibited, and the high appreciation of my instructions by all giving me attention.

I have devoted the best part of my life exclusively to the development of this science, besides expending a large amount of money in the study of veterinary practice, uncler one of the ablest Veterinary Surgeons in America, I)r. IVm. Somerville, of Buffalo, N. Y., whose certificate will be found below; thus insuring the undisputed reliability of my efforts and of making my work of great practical value for reference.

From Dr. Wm. Somerville, Froprietor of the Buffalo, N. Y., Horse Infirmary.

"This is to certify, that D. MAGNER, Esq., served under me nearly two years, during $\mathbf{s} 68$ and $\mathbf{1} 869$, as an apprentice to learn and be instructed in the Veterinary írofession. I consider him well qualified to treat successfully all Diseases in Horses, and able to practice as a skillful and competent Veterinary Surgeon.

Buffalo Horse Infirmary,

$$
\begin{aligned}
& \text { IVM. SOMERVILLE, } \\
& \text { Vet. Surgeon, Member of two Veterinary } \\
& \text { Colleges, and of } 36 \text { years practice. } \\
& \text { Infirmary, ,, }
\end{aligned}
$$
I 27 Erie St., Aug. I, I869."

No one desires more earnestly than I do, the success and encouragement of any one who may prove, even to a limited degree competent to teach reform in the treatment and care of horses. There is need enough of wholesome practical effort in this direction, and after the prolonged and arduous struggle which I have maintained during the best part of my life, in this trying field of professional enterprise, I feel more like retiring to the quietness and pleasure of private life than continuing in it longer. Hence I am above any feelings of envy. I have felt compelled, in this edition of my book, co make these explanations, but 
more for the satisfaction of those who have and may give me attention, than for the gratification of my feel.ngs.

The few following notices from a large number of a recent date, will show the appreciation of my system of treatment by the most critical horsemen in the country. From people too, who have given attention to all those who have traveled in the business, from Mr. Rarey, down to the present time, showing the great appreciation of my efforts over that of all others, proving that my principles of treatment are most effective and practical yet brought into use.

\section{From the Michigan Horse Breeders' Association of Jackson, Mich., May 6, 1871.}

We, the undersigned officers and members of the Michigan Horse Breeders' Association, and citizens of Jackson, have attended Prof. Magner's lectures.on the education of horses while in this city, and endorse him to the people of the State as a reformer of great merit.

His treatment reduces the education of horses to a definite and fixed science, ensuring not only the most humane, but the most wonderful results in the control of wild and vicious horses. We have witnessed the effect of his treatment in the control of a large number of vicious horses, and have no hesitation in saying his system is the best in the world.

S. S. VAUGHN, President.

J. A. ROBINSON, Secretary.

GEO. SHERWOOD, Treasurer.

DAN. B. HIBBERD,

C. C. TURNER.

Endorsed by the following eminent citizens of Tackson.

$\left.\begin{array}{l}\text { D. J. ROBISON, } \\ \text { A. J. PANTLINE, }\end{array}\right\}$ Proprietors of Hibbard House.

M. KNAPP, Livery and Horse Dealer.

B. J. JOHNSON, Member of City Council.

CHAS. MESEROLL, City Marshal.

W. L. SEATON, Postmaster and Member of City Council.

ROBT. KNOWLES, County Clerk.

JESSE HURD. Proprietor of Track.

JOHN GOODYEAR, Livery and Sale Stable.

C. C. POND, Broker, and 50 others.

From the Jackson, Mich., Patriot.

Prof. Magner gave his last exhibition and lecture in this city on Saturday afternoon last, and as usual, a large number were in attendance 
at the opening exhibition, and at least two hundred members of his class were present to listen to the closing lecture, and witness some of his wonderful feats of subduing and managing horses. At the close of the lecture, one of the members of the class offered the following resolution, which was received with applause, and adopted without a dissenting voice :

Resolved, That we, the members of Prof. Magner's class, hereby ex press to him our high appreciation of his instructions in his system for the reform and elevation of horses, which, in our estimation, is incom. parably superior to any system ever brokght before the public. By this system, the management of the horse is reduced to a definite and exact science, and we desire most heartily to commend Prof. Magner to the confidence of the public, and to express to him personally our thanks for his patience, his thoroughness, and his gentlemanly bearing, while engaged in his profession in this city.

\section{From the Adrian Weekly Times, April 13, 1871.}

During the present week, Prof. Magner, the celebrated horse tamer and educator, has conducted his classes in this city. He has created a genuine furore among all interested in horses in this city, and his reputation has extended to a circuit of country, and persons have attended his classes from over twenty miles distant. He has succeeded in subduing and rendering perfectly tractable some horses who have resisted all previous efforts of horse-breakers and others to reduce them to submission, and his wonderful power over horses excites the most astonishment from those best posted in equine care and treatment, and the exhibitions of the trained stud of horses which he owns and carries with him, are superior in interest to the choicest features of the best circus traveling. In every place he has been, the professor has received the most emphatic and cordial endorsements.

\section{From the Toledo Blade.}

As a practitioner and teacher of the science and art of training horses, the professor is without a rival, and has won the confidence and admiration of the public wherever he has been. No one can understand the seemingly magical power which this man seems to possess over the horse kingdom, until he witnesses one of his exhititions, and we are free to say that a knowledge of Mr. Magner's theory of training horses will be invaluable to every owner of the animal. Wherever he goes, his lectures should be heard and his experiments seen. While in Toledo he had for his classes many of our best citizens, and all feel not only fully satisfied, but endorsed him, as will be seen, in the strongest manner.

Ilappening into the tent one day, we saw the Professor training a noble, but desperately stuhborn horse, owned by Mr. R. Mott. After pperating with the animal but a brief time, his very nature seemed 
changed, and on being driven by his master, was kind and obedient as the best of horses.

The readers of the Blade can rely upon the fact that the Professor is an upright, honorable gentleman, possessing all the wonderful skill he claims.

\section{From the Toledo Commercial.}

Monday, the last lesson of Prof. Magner to his class in Toledo, was given. His success here has been unprecedented, and his teachings unparalleled in their line. What the members of the class have learned could not he bought of them for ten times the sum paid by them for the instruction. He goes to Adrian, Michigan, from here, and we bespeak for him there a hearty welcome and the usual success attending his efforts. The professor is a man of his word, professing no more than he performs, and doing good wherever he goes. In his teachings he not only learns his scholars, but benefits the horses, by introducing a more humane and gentle course of treatment, and therefore merits the name of benefactor to the brute race, or a niche beside the renowned Bergh. We congratulate the Adrianites on their acquisition.

\section{From the Cleveland Ieader, Feb., 1870.}

After the exhibition, the regular lesson and illustrations began by a lecture of about twenty minutes duration, wherein the professor explained the cause, symptoms and cure of many of the diseases to which the horse is peculiarly liable, and set forth the matter in so clear, forcible and simple a manner as to disarm any prejudice or want of confidence in the man, if any such prejudices had been previously formed. But the great sensation of the evening was yet to come, for which all were anxious, as many present knew the vicious nature of the beast to be subdued-in fact there were one or two present who had had good cause to ever remember the great runaway and kicker known as the "Malone Horse." He is a gray gelding, perhaps sixteen hands high, of great beauty and strength, and a will and determination rarely found in the purely American breed of horses. The horse was brought into the enclosure, and caused general comment by his magnificent style and grace of movement. His owner was present, and after looking at the animal for a few moments, and dreading to see him pass into wther hands to manage, hesitated at the last moment to give his consent to the application of the system. Mr. Magner, determined to have a subject for his class, asked the price of the horse, which was announced to be \$500. "I'll take him," said the professor, and at once handed over the amount. This movement on the part of Mr. Magner was unexpected, as must "horsemen" who have visited us generally preferred to "work up" other people's horses, rather than their own. But Mr. Magner knew the value of the animal before him, and knew the value of his system, and was further aware that $\$ \mathbf{r}, 000$ was ready for the horse the moment that he could be driven safely before a trotting wagon. 
At this stage of the proceedings the excitement was intense, and many speculations were indulger in as to who would prove the victor, the man or the horse. In less than twenty minutes from the time that Professor Magner laid his hands upon his subject, the horse was as gentle as a lamb, and as easily controlled as the most reliable family horse. Among other efforts to prove that the gray gelding was completely broken, the professor, without reins in hand, mounted the wagon, and catching the animal by the tail drove him around the ring at a fearful pace, drawing the wagon upon the heels of the horse in such a way as to strike them with a force that could be heard at the farthest end of the room. The class was astonished, declaring that they had already received more than the value in useful knowledge of the price of their admission.

\section{From the Cleveland Herald of Feb. 26, 1870.}

Professor Magner last night gave an exhibition at his hippotheatron, which was in every respect a success. A success in giving complete satisfaction to the large audience attracted, and in realizing a good sum for the Dorcas Society, a benevolent institution for the benefit of which the entertainment was given. This is the second donation the professor has made to charitable institutions of our city. When he leaves us his visit will not only be remembered on account of the skillful methods of training horses, which he has imparted to a large class of students, but also for deeds of charity done in our midst, which will make his name ever associated with pleasant recollections.

At the close of the last lecture of his course in Cleveland, the following resolution was moved by Hon. Silas Merchant, (President of City Council,) which was carried by acclamation of the entire class :

Resolved, That we, as members of Prof. Magner's class in this city, deem it but a just recognition of his skill and success in teaching us his system of educating horses, which we regard as the best ever shown us; and for his gentlemanly demeanor, that we are fully satisfied with his instructions, hereby endorse him and his system of educating and treating horses, to our friends and the public.

The following well known gentlemen and citizens of Cleveland, endorse Prof. Magner and his system, and can be referred to:

J. P. ROSS, Proprietor of American House.

II. NOTTINGHAM, Esq.

W. W. CRAWFORD, 5 I Euclid Avenue.

GEN. J. W. FITCH, Kennard House.

J. D. KEEGAN, Druggist, 3 Euclid Avenue.

R. P. WATERBURY, Akron Stove Co.

H. W. LUETKEMEYER, I 50 Superior street.

I. SCHRIBER, Tubacconist, II3 Water street.

GEO. E. ARMSTRONG, of Alcott \& IIortim, Wholesale Iry Goods, 149 Water street.

E. N. KEYES, Real Estate Agent, I Rouse's Block. 
SILAS MERCHANT, Iron Founder, River street.

L. B. FRENCH, of French \& Keith, Wholesale Dry Goods, Water st.

S. S. COE, Secretary of Cleveland Insurance Co., corner Water and Superior streets.

W. P. HIORTON, of Alcott \& Horton, Wholesale Dry Goods, Water st. A. S. ROBBINS, Wholesale dealer in Photographic Stock, corner Su perior and Seneca streets.

GEO. H. BURRITT, Collector of Customs, Custom House.

E. THOMPSON, Wholesale Grocer, Bank/street.

JAS BENNETT, Livery and Boarding Stable, Champlain street.

iV. D. CUSHING, Agt. Erie R. R., I3I Superior street.

WM. EDWARDS, Wholesale Grocer, Water street.

A.IOS TOWNSEND, Wholesale Grocer and President of City Council, City Hall.

H. COLLINS, Proprietor of Weddell House.

H. HURD, Wholesale Grocer, Water street.

GEN. D. T. CASEMENT.

O. STONE, Esq., Scovill Avenue.

F. W. BELL, Wholesale Lumber Merchant.

C. W. COE, Proprietor of Cleveland Mills, 268 Scovill Avenue.

T. ELWOOD, Livery Stable, St. Clair street.

H. P. WEDDELL, Esq., Banker, Bank street, and 500 others.

\section{Buffalo Commercial Advertiser.}

Horse that Killed One Man and Injured Several Others.We yesterday afternoon visited the amphitheatre of Prof. Magner, the noted horse tamer, on Carroll street. We found there a large number of our most prominent citizens and horse owners, and all manifested the greatest interest in the doings of the professor. By way of blending amusement with instruction, Prof. Magner exhibits before his class and visitors, his educated horses and ponies, who seem to possess a degree of intelligence absolutely marvelous.

After the exhibition of these animals, interpersed with remarks of an instructive character from the professor, a horse belonging to the Omnibus Company-a most vicious brute, with a disagreeable habit of biting, and striking with his fore feet; from which those in charge have not been able to remove the collar or bridle for over three months-was brought for treatment. We understand, by the way, that this horse (a large and powerful bay) once killed a man, by biting and trampling him under foot, and recently bit the hand almost off the person having him in charge. In twenty minutes, in the presence of between two and three hundred persons, Prof. Magner reduced this brute to perfect subjection, so that the groom and himself harnessed and unharnessed him, put their hands in his mouth, and handled him in every shape with perfect impunity, the formerly furious beast being as docile as a kitten. It was a wonderful exhibition, as we can bear testimony.

We can have no hesitation in recommending Prof. Magner and his mode of treatment to all interested in horses, as one who can and does perform all that he promises. 
The alove horse is now gentle, as shown by the following letter:

Prof. MAGNer :

Buffalo, Dec. 21, I869.

Dear Sir:-I consider myself in duty bound to drop you a few lines respecting our once vicious horse, "Man Eater," as we called him. I have often said what a good thing it was we did not shoot him. $\mathrm{He}$ was taken out of the stable twice for that purpose, when I, on both occasions, interceded in his behalf. He is now one of our best horses, as docile as a lamb, and the drivers all like him. We work him double and single, as required. All this was caused from your few minutes tuition. You are aware of his past history. For weeks previous to making your acquaintance we could not get a man to harness him, and two of our drivers were disabled by him. When you visit the city, please give us a call.

Believe me, yours very truly,

M. FORDE, Agent, Buffalo Omnibus Company.

At the close of Prof. Magner's lesson on Thursday last, all present, (nearly fifty,) among whom were the following well known gentlemen:

RICHARD BULLYMORE, Esq.,

C. L. WHITING, Esq.,

Z. BONNEY, Proprietor of Bonney's Hotel.

H. COURTER, Courter House,

W. C. SHERWOOD, Esq.,

E. UPSON, Carriage Manufacturer.

DR. GEORGE S. EVARTS,

J. O. ROBSON, Esq.,

it was unanimously resolved, that "we commend Prof. Magner to our friends as a reformer of more than ordinary usefulness; that his theory of governing and educating horses is the most practical, humane and valuable in its results we have ever witnessed; can be learned and practiced by any one of ordinary intelligence. He tamed a wild mare in our presence in ten minutes, and, among other feats, he made her sit down twice and lie down four times in a minute without touching her."

In his class on Monday, August gth, comprising nearly one hundred, among whom were the following well-known citizens:

GEORGE W. TIFFT, Esq.,

JUDGE MASTEN,

MAJOR DICKEY,

C. J. HAMLIN, Esq.,

F. W. TRACY, Esq.,

It was resolved by acclamation, that "we fully endorse Prof. Magner and his system, and believe every one owning or interested in horses 
will find it to their advantage to learn his system of treatment. In our presence he put a halter on the most vicious horse in the city without touching him, and, by its use and that of a whip, made the horse lie down and get up three times, then stood off ten feet, and, with his hands in his pockets, laid the same horse down ten times in a minute. In les than twenty minutes from the time he commenced his treatment with his horse, he took off and put on repeatedly the collar and bridle, without exciting resistance or any indication of viciousness from the horse. The same was done by the driver, to do which before would have been at the hazard of his life. 


\section{PRELIMINARY HINTS - CONDITIONS OF SUCCESS, ETC.}

IF horses could be guided and controlled in their education by the use of a bit and reins, it would not be necessary to resort to any other treatment.

But as this cannot be done excepting in the training of those of the mildest and most docile disposition, it becomes essential to success to know what to do to insure the perfect docility and obedience of any and all horses of any extremes of viciousness, in harness or not.

We see, too, that horses of energy and pluck are often easily spoiled by the most trifling causes exciting their fear and resistance, and that unless stibjected to proper treatment, they are liable to become unpleasant, dangerous or worthless thereafter, for use.

Overcoming all those possible difficulties with ease and certainty implies a knowledge of those conditions and principles of education and subjection by which the horse can be easily taught and guided into perfect docility and obedience at will.

This, it is seen, by the principles taught, and herein explained, can be easily done, and it is for the purpose of directing special attention to some of the more important conditions influencing the application of my treatment that I am induced to write out such preliminary hints, forming this chapter, as my experience suggests, the careful perusal of which I would urge.

The Horse by nature is averse to the control of main, and as he cannot know the various ways it is intended he is to serve the wants of man, he must be taught, and to success fully teach him implies making him passive to contro.. without exposing him to injury or abuse, requiring-

FIRST, That the nervous system is not so disturbed and perverted by fear and excitement as to rouse the fears and vicious part of the nature into controlling action. 
SECOND. That there is a clear understanding of such principles of addressing the reason as will convey to it most clearly the idea of what is required to be done.

THIRD. That there is a knowledge of such principles of subjection as will enable guiding and controlling the animal in such ways and to such extremes as may be desired in his education.

In a word, the superior strength of the horse must be fully and unconditionally held or made passive to control, any excessiveness of the fears and passions prevented, while the reason is addressed and won to a perfect understand ing of what is required to be done. Experience proves that horses resist control to the degree they learn it possible to do so.

\section{EXCESSIV巴 FEAR NIUST BE PREVENTED.}

That excessive fear, even, of a few moments' time, from any cause, may so derange and excite the mind as to spoil and pervert the character for life. That the excitement of the passions only stimulates resistance and confuses the understanding. That almost any horse can be taught and made to do anything of which he is capable, if properly shown and treated kindly and patiently. On the contrary, if excited and abused, his whole nature is stimulated to resistance. Hence, if we would not excite resistance or excessive fear, of objects or other causes, we must bring them to notice in such a manner as to both prevent exciting the fears and convince the horse of their harmless character until fully reconciled to their presence.

Fourth. The inability of the horse to understand articulated language, implies the necessity of conveying to the mind clearly the idea of what is recuired to be done.

FifTH. That the great strength of the horse is so nentra. ized and controlled at will, as to make prompt submission to man a necessity.

Now while my principles as I have illustrated and proved will enable avoiding all those supposed great difficulties in training and handling horses, and cause results that in many instances appear wonderful, it must be evident they are, as well as all other principles, only rules, by the use of which certain results are to be secured, and their chicf value in practice must depend upon the jurlgment used in 
applying them. But if as I have shown, and as the ordinary observation of daily experience clearly proves, fear is excited and the will aroused in securing obedience, the resistance of the animal is stimulated, the legitimate authority and control of the trainer or driver weakened or neutralized, and the necessity for force greatly increased, to a degree very often that wholly spoils the animal.

\section{FIRST IMPRESSIONS ARE STRONGEST.}

The first impressions made upon the mind or nervius. system of the colt, are the strongest and most lasting. I colt or horse of even a good disposition, it is seen, may be made a reckless, foolish, kicking maniac, by being greatly frightened, from some cause in itself, perhaps trifling, but forced to notice in such a way as to excite and derange the nervous system. And when it is seen that even the life of a sensitive horse may be destroyed by being greatly frightened, we can see to what a degree the nervous system can be deranged at times by causes which, if the animal were subjected to the precautionary treatment shown, would excite no fear, and hence no resistance, thereby preventing as well as overcoming easily, what would appeitr to be an almost insurmountable difficulty.

Equine nature is so constituted that it will submit passively to conditions of resistance or restraint, it cannot successfully resist or overcome, or by producing such impressions upon the mind as will prevent an inclination to resist.

This is the law of natural government or stipremacy to which all the lower animals yield, the smaller and weaker submitting to the stronger, and indeed, this is the fundamental basis of successful human government. Hence, the resorts of military power or studied scientific application of restructive force as shown in war and its penalties, and hence the effort to attain a knowledge of more destructive means to repel or overcome resistance.

\section{HORSES SHOULD BE EDUCATED-NOT BROKEN.}

But we see, as in the successful education of the horse, this principle must be so modified, that he will not be injured or abused, not even excited to any extreme, as this 
would neutralize and destroy the very object of our efforts to make a strong, gentle, submissive servant to our wants, which is our real object to attain.

But the common plan of doing this by attempting to hold and force a horse in harness, and whipping if there is resistance, is from the nature of things, inadequate, defective and cruel, since there is not necessary physical power to do this with any degree of certainty, and the aggravation of the whip, in conjunction with the natural fear of the animal, stimulates resistance, and thus without adequate precaution or power, the difficulty to be overcome is so greatly increased as to cause failure and trouble, the cause of which is usually attributed to a bad disposition. But if the animal is first made passive to restraint by proper treatment, control becomes simple and easy, since the mind can now be easily won and guided without fear or resistance into such habits as may be desired without exciting resistance or subjecting the animal to injury.

Now this is exactly what my system enables doing, developing to a practical basis those principles of necessary power, while there is a clear understanding of what is required to be done impressed upon the mind, which is at the same time aided and encouraged by the most powerful appeals to the better part of the nature, until prompt willing obedience is secured and fully established. This has been the object of Schristian, OFFUTT, RAREy, and others, to accomplish, but in vain, as shown by the simple method of throwing shown by all those including Rarey, by reducing vitality, as shown by South Americans, the Indians on our western plains, and the Chilians. Of course, very remarkable and satisfactory results were and can be often shown by these methods of subjection, but from necessity, coming far short of those essential points aimed at, and so necessary to that perfect success, which we are able to do by my treatment, which enable results in many cases in less than an hour, entirely impossible to accomplish by such or any other treatment heretofore in use.

\section{SUBJECTION-OLD METHODS OF.}

The rudest and most iniurious methods of subduing horses are those which tend directly to lower the strength or 
destroy life. Hence the different methods of taming or breaking horses in general use from time immemorial. 'The first account we have of any horse being suldued was that of Bucephalus, in the time of Alexander the Great, about 300 years before Christ. A subject, we are told, presented this horse to the Emperor as a gift, but he (the horse) showing a very vicious disposition, Alexander ordered him to be taken away, when young Alexander stated what a pity to lose so fine an animal for the want of a little address. adroitly mounted him and rode him off at the top of his speed. The greatest alarm was manifested for the safety of the P'rince, and the joy of all was great when he returned, the horse perfectly gentle, and he safe. This horse became famous for his wonderful sagacity. We are told that when he died he was buried with honors, and a city was given his name. The same principle of subjection, with slight variations, is still practiced on the pampas of South America, and on our western plains. They catch the horse with a lasso, throw him to the ground, saddle and bridle him, and ride him with whip and spur, until completely exhatsted and perfectly submissive. South Americans square wif the ends of the hair of the tail, after the horse submits, to indicate that he is broken and again turn him loose. The same principle is in use among the Indians on our western plains, and with equal success. The Chilians tie a chractory horse in the stable and whip him until he lies lown or falls down, usually requiring about forty-eight mours. He is then tried, and if refractory the process is ontinued until he becomes gentle.

Bleeding, physicking, want of sleep, starving, want of wrier, intense pain, choking, \&c., \&c., will enable this end; but, as will be seen, this treatment is not only dangerous but injurious, often breaking down the animal to such at degree as to become comparatively worthless, or male so treacherous as to require being broken over again almost eve y time used. There is a belief among many, cven of intelligence, that a certain peculiar something in the way of medicine, will make a horse gentle, following a man anywhere. Catlin, an Indian traveler, states with knavity, in his account of Indian customs, \&c., that after an Indina brenthes into the nostrils of a horse, he becomes his siave, following him like a log, \&e. I have handled 
all sorts of horses, and have shown results in the way of successful control of mustangs, mules and vicious horses, which I defy the ability in any one to produce by any such treatment. My experience tells me that breathing into the nostrils or giving any medicine of which we have any knowledge, will fail to make the mind of a wild or vicious horse passive to control, to any marked degree. The oslets which grow upon the inside of horses' legs, ground and blown into the nostrils in connection with oil of Cumin, Rhodium, Anise, either or all, constitute this great secret; but as good an effect can be-produced by giving apples, sugar and salt in equal proportions, oats, or in fact anything of which the horse is fond. This is however only in part an illustration of the value of some of our most essential treatment in the successful management of certain peculiarities of disposition.

\section{KINDNESS-ITS IMPORTANCE.}

I will call more special attention in another part of this chapter, to the importance of kindness as an essential to true success in making horses of a naturally wild and nervous disposition safe and gentle. We see that a horse of a sensitive, plucky nature, may be excited and roused into the most determined resistance or viciousness by a little exciting abusive treatment. That the more the bad part of the nature is excited, the more determined and reckless the resistance. Excitement heats the blood, blunts the understanding and stimulates the passions, and as a consequence, increased nervousness and resistance is the result.

Under such circumstances a horse will go beyond his natural strength in resistance. Hence, the mustang, or other horse, broken by exciting, exhausting force, such as running, extreme whipping, \&r., is not only liable to be seriously injured constitutionally, but soured in temper. Good illustrations of this are shown in high strung mares and horses, which may be whipped severely for kickingr. Though perhaps weak and broken down from abuse, they will squeal and kick with the true recklessness of malignant hate. 'The very expression of the eyes shows kick. So with the balker; the whole nature is intensified in rebellion. But how different if the better part of the nature is won by 
kindness. The expression is softened. there is a matural willngness excited to do whatever is poperly and carefully shown; but if in addition to this the mind can be helrl and controlled at will, thus lessening the confidence and powers of resistance, obedience can be secured and won with a quickness and ease that is surprising.

This is the true principle, as I have shown, as it enables addressing and winning the full coöperation of the understanding and better nature, without exciting resistance, or to so limited a degree as to be easily overcome, and really implies teaching the horse in a reasonable practicable manner in accordance with the laws of his nature.

\section{PECULIARITIES AND EXTREMES OF DISPOSITION}

The extremes of intelligence, temper, size and texture of body demands attention, when attempting to train or subdue a horse. And here this apparently threadbare subject reveals an apparently new and most interesting field for the careful student.

We are told in Genesis, that after all the lower animals were created they were brought before Adam to receive their names; and whatsoever he called any animal, whether beast, bird, fish or reptile, that was the name thereof. In a word, all representing the different stratas or modifications and extremes of his own higher or lower nature. Hence, in understanding his own nature, he could readily comprehend that of theirs. There are not only classes but modifications in each family, each representing some type or modification of others becoming clearer to the observation in the domestic animals. For though each family, in a general sense, preserves its own peculiarity of identity in size, color, disposition, \&c., yet no two of any family are exactly alike, each showing some peculiar phase of distinction. Hence, one ox, cow, dog, or other animal, is seen to be more vicious, wild, or difficult to manage than others of the same family, and vice versid. The horse shows these peculiarities of extreme sometimes to a most marked clegree. Hence we see there are horses so clocile, fearless and manageable that they can hardly be made to do anything mean, submitting to being handled or driven.in harness from the start without trouble, while others are so Highty, foolish or 
vicious as to be scarcely manageable by the most skillful prudence and effort.

Now if you will look closely, for example, at the head and eyes of any horse showing a marked trait, you will find, confining your observation to even the eye alone, a corresponding peculiarity of it to that of the animal the horse most similates in character or disposition. To illus-

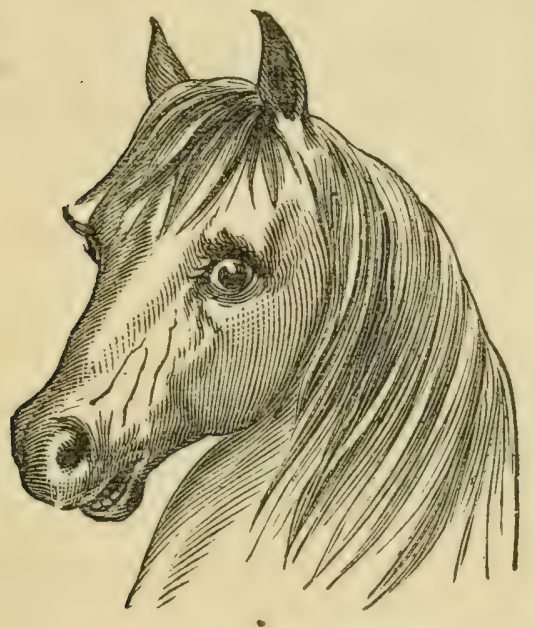

Naturally Intelligent and Gentle. trate - a large brown eye rather flat set well out in the head, eyelids thin, expression mild, but sensitive, which is peculiar only to the naturally gentle horse, you have the counterpart of the sheep or gazelle, the most innocent and gentle of all the domestic animals. The same is noticeable in the dog of mild, gentle character, as well as other animals. A small, round, clear eye, set well into the head, or eyelids heavy, expression stolid or learish, you have indicated a sulky, unreliable, mulish or bull-dog disposition. Notice the head of such. You will usually find it rather narrow between the eyes, long from eyes to ears, ears inclining to lop back, head rather low between the ears, and nose rounding. Rouse this temper and the sulky unrelenting pluck of the bull-dog, hog or bear is shown, which they most similate in form and expression. The first, though greatly excited, remains plastic, yielding readily to control, hardly resisting the most severe abuse by attempting to do more than try to get away. Whereas the second becomes so stubborn, as the blood becomes warmed, as to stand stolidly in defiance of the most severe whipping, or plunges madly forward, regardless of consequences. As kickers or balkers they will contest every point stubbornly if warmed up and excited, though submitting readily to restraint if the blood is permitted. to become cool, and the better part of the nature is appealed to. 
When the eye is large, even, full, but clear or dark in color, restless and sensitive in action, a flighty unreliable character will be exhibited-Is a free driver if a bright bay or sorrel, liable to pull hard on the bit as the blood becomes warmed by exercise and excitement.

If the eye is good, round and clear, scintillating as if it were fire, the eyelids drawn

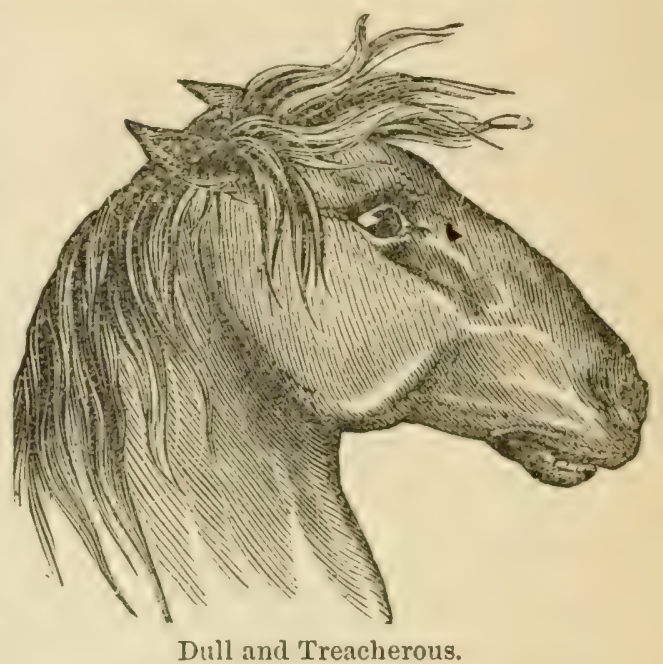

Dull and Treacherous. down, or the eyes partly closed, a kind of listless expression of the head, you have the unusual but possible temper of the tiger or feline character, the temper of which if you

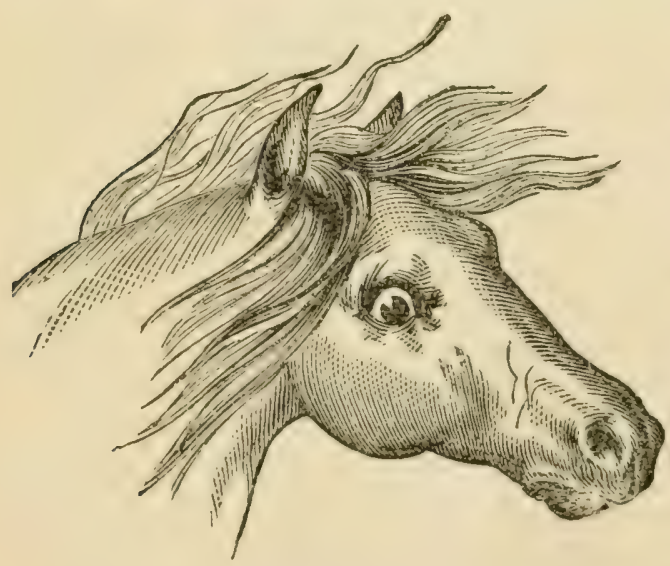

Sensitive and Flighty. rouse and excite, above all others, will be the one which will almost set at defiance your most persevering efforts. You can throw him a hundred times, he will lie down easily but jump up promptly; he will: barely yield to the next principle of subjection, which is by far the most simple and powerful, but in defiance of all you can do, when a little rested, he will perhaps kick or run away as recklessly and determined as ever, all the whipping and pounding your temper, if aroused, may cause you to inflict will do no good, and only make the matter worse.

I would here say that as soon as you discover this dispn. 
sition, stop exciting coercive treatiment, subject at once to passive treatment. As soon as there is submission, work slowly and quietly, and the difficulty you were by the prerious treatment only intensifying, you will soon find to ¿isappear, and the animal become perfectly gentle, but must not be whipped. [See cuts of illustrating natural extremes of disposition.]

NOTE.-I have had many illustrations of the wonderful resistance that may be excited in horses of this disposition by treatment that will heat the blood and rouse the temper, and showing the value of treatmont that is wholly passive in their management. A few of the most marked cases I will refer to in this connection: An eight-year-old bay pony, by bad treatment made to kick, resisted all efforts to break, and was an incorrigible reckless kicker; was entirely passive, but if touched around the flanks or hind parts, would squeal and kick most desperately. As a means of illustration, subjected to first and second methods of subjection. Quickly throwing would do no good, and as predicted, only roused resistance. She yielded readily to the second method, submitting to being touched around with a pole in any manner, and I proceecied at once to carry out control by restraint upon the mouth, and drove her successfully, preventing her kicking. But as soon as she got over the surprise and effect of this treatment, she resented all effort to control i:er, kicking in the most desperate manner. I knew that while irritated and excited she would resist all effort to subdue, and bought her to make a satisfactory experiment. I subjected her the next day, privately, to the same treatment in the most careful and thorough manner, but all to no purpose. She proved incorrigible, the most desperate animal I ever saw.

I worked this mare with great care and thoroughness, as a matter of trial, but all to no purpose. Never before did I see such reckless determined resistance. I carried coercive treatment to its utmost limit, and for the first time in all my experience, found a horse that by sheer pluck would resist it; yet yielded readily to the milder and more flattering course, which though working slow, made a radical reformation. The whole aspect of her nature became changed as the blood became cool, and ulitmately proved one of the most docile, manageable ponies in the country.

SECONu CASE.-A four-year-old colt, a natural kicker; would kick any body or any thing. Had resisterl all efforts to break her, and was worthless; was brought twenty miles for me to handle; would kick and balk, and was one of the worst I ever saw - an interesting case.She resisted the usual regular treatment, resisting all effort, compelling finally, a resort to the slower and less exciting course, and as she became cool grew out of all resistance, becoming a safe and gentle mare.

Both of these cases resisted so determinedly in illustrating my regular treatment, that I purchased them to enable me to handle them in private, with the results above stated. Have had many cases of this temperament that were regarded as invincible, having resisted all $[2 *$ 
The milder and more sensitive, the less abuse and excitement will be borne. The more stubborn and combative nature, the more force, and even abuse will be borne, but mingled with the wild character, force that will heat the blood, will excite resistance. Hence, a mild, sensitive dog or horse can be managed best by gentle flattering treatment. The bull dog, mule or stubborn cart horse will take the whip and care but little about it. But a little excitement and punishment would only rouse to aggression the lesur or hog, and animals showing the intense courage and pluck common to the more untamable nature will resist all but the most intense means of pain. Hence we see that grentleness and kindness is the course, and the only course alvisable with the horse, dog, or other sensitive animal. Those of a more positive disposition call for both force and encouragement, while the lion, tiger, elephant, \&c., must be made to feel the most intense means of pain. Hence, those of the wild class, such as tigers, \&c., are subdued by burning and pounding with red hot rods. The elephant is suljjected by having spears stuck into his body, and hooks stuck into the ears, Sc. But it is seen the effect of carefully encouraging or kindly treating is, with rare exceptions, very marked, and is only to be superseded when force becomes necessary.

As a rule, the larger and finer the brain is in texture, the more docility and intelligence will be exhibited; and the smaller the brain the less the intelligence, and the more determined the resistance to control. In proportion as there is predominance of the lower and more savage characteristics of animal nature, there is more natural resistance and difficulty to subdue, but proportionately more vitality and powers of endurance may be anticipated. To the degree that the animal intelligence and :sensibility are in excess of the coarse and stubborn traits, there will be proportionately more tractableness and docility, though, perhaps, the hardiness and vitality may be somewhat less. The sheep and llama, for example, having but little of this coarse, combative nature, will not bear abuse. We are told the

others, but in every instance have succeeded by the usual course of disconcerting or passive treatment. All these bad cases require the most gentle and encouraging after treatment, to fully wear out of the mind all impulse of resentiment and enmity previously excited. 
llama, ii overloaded, will lie down discouraged and die, not resenting the cruelty in the least. 'The camel, of a less sensitive nature, will toil patiently under the heaviest burthen, submitting meekly to almost any extreme of abuse; while the ass, mule and mustang, having a larger share of the combative disposition, are more obstinate and willful, and are usually more difficult to subdue and manage, and always call for more force in their subfection than is called for in the control of those of a mild, sensitive disposition. More vitality and endurance may, however, be always anticipated in proportion to the predominance of the wild, combative disposition. They are the horses, above all others, that call for great skill in their early training especially, and any imprudence or abuse by which the fears and passions are much excited, is almost sure to excite a proportionate degree of resistance and trouble.

\section{IMPORTANCE OF PREVENTING FEAR AND RESISTANCE.}

One of the essentials of true success is that of vigilance in guarding against accidents or preventing resistance. $\Lambda$ little carelessness or imprudence under favorable circumstances is liable to precipitate a degree of resistance, or a calamity it is often difficult if not impossible to prevent or overcome after being excited. The dropping of a lighted match carelessly in a heap of shavings, led to the burning of the city of Portland, a few years ago. The burning of a little straw in a corv stable, caused, it is supposed, by the upsetting of a lamp, led to the burning of Chicago. Nearly every great and lamentable accident involving great destruction of property. and loss of life, is usually traceable to some minor defect or carelessness.

That delicacy of judgment which detects danger and takes measures to prevent accident, gives a great advantage in attaining success, but when this is combined with skill which enables overcoming the difficulty easily and effectually, the most perfect success must result with anything : ke ordinary effort. 


\section{HORSES SHOULD BE PROVED BEFORE USING,}

Hence, if a colt is wild or vicious, or learned to run away and kick, making control hazardous and doubtful, it is essential to true success to subject him to such necessary treatment as will assure of his perfect docility and safety in handling or driving under the most exciting and dangerous circumstances, as it is then that perfect docility becomes most valuable, and is as much a true necessity in guarding against accident, as the making of steam boilers so strong and testing them by such increased pressure as will insure against the possibility of exploding under the pressure necessary in use. It is no excuse to claim that the horse got suddenly frightened, kicked, and ran away, making control impossible. Such a possibility should be guarded against by subjecting the horse to treatment which will both prevent and overcome such a possibility, which can be easily done by the ordinary course of subjection. Hence, when a horse is impulsive and dangerous, liable to kick or run away, or is at all doubtful, he should not be driven until subjected to this necessary precautionary treatment, and is not to be hazarded until made thus safe. 'There is no more necessity or sense in hazarding an accident by the use of horses that are so unsafe that they will not submit to the most ordinary causes of excitement, such, for example, as being touched by the wagon or cross-piece of shafts, fear of top umbrella, refusing to be obedient to the most ordinary restraint and guidance of the bit when pulled upon, no matter how excited, than there is in hazarding a boiler known to be so weak as to give way under any greater pressure than is barely necessary for ordinary use.

But in tracing back causes of unusual derangement, we should look back, too, to those of a constitutional character, inherited from the sire or sires by causes which excite or derange the mind or nervous system, as the condition of the mind at the time the sires were brought together, must largely influence in forming the character of the colt. Hence the stallion, though of a gentle character, if excited and maddened at the time of so using, will almost with c.rtainty cause the colt to be naturally vicious. So in relation to the mare; if subjected to exciting, abusive treatment, the disposition of the colt must be affected by it. Many 
interesting statements of facts, proving the truth of these assertions, have been made to me by farmers and bręeders at different times, after attending my lectures, to such causes of possible derangement, and which it is essential to guard against.

\section{REMARKABLE ADAPTATION OF HORSTS FOR DIFFERENT USES.}

Marked extremes and modifications of size, disposition and character, show fixed laws of adaptation. We see this is not only true in the adaptation of different classes of domestic animals for special uses, but even in those of the same family. Thus

\section{THE ESQUIMAUX}

have not only a dog, but a dog of peculiar nature, exactly adap.ed to their wants. No other domestic animal could endure the intense cold of that region, or could live so far North with man, and this dog must and does perform the different duties of guard, assistant, hunter, fisherman, etc., and, in extremity, supplies, both by his body and his skin, both food and raiment for his master.

\section{THE LAPLANDERS}

have the reindeer, which is also singularly adapted to therr wants, the most reliable and only beast of burthen capable of enduring the rigors of so cold a latitude, supplying them with milk, butter and cheese, their flesh making the best of food, and their skin the best of clothing.

THE PERUVIANS

have the llama, or alpaca, which is accustomed to climb the mountains, carries heavy burthens over the Andes, and furnishes them with milk for their children, wool for clothing, but best of all, meat for food. The

\section{INHABITANTS OF THE DESERT}

have the camel, or dromedary, for crossing the arid, sandy plains, carrying heavy burthens, and bearing within themselves a supply of water to last them for a week. They have also the horse, lithe, active and enduring, capable of traveling with great fleetness for days, on the most scanty fare. 


\section{NATURAL ADAPTATION REGARDED.}

This remarkable adaptation to climate and condition; as seen not only in the animals named, to the wants of the people among whom we find them, is also wonderfully exemplified in the horse, showing great size, weight and strength, mild, docile and patient disposition, exactly alapted for the slow, slavish drudgery of the plow or cart. His anatomical structure and coarse, heavy muscle show him to be fitted for and adapted only for strong but slow action. The fiery, quick, active horse, on the contrary, hias not only a form adapted for speed and great endurance; he has a more oblique and thinner shoulder, longer arm and hip, and more lung power. His whole structure is of a finer, lighter and stronger character. He does not put on fat easily, and is more sensitive, intelligent and active, simulating the grey-hound in appearance and action, compared to the heavy, slow Newfoundland dog of an entirely contrary conformation. From these extremes there is an endless variety of modifications, showing not only marked traces of distinction of family, for strength, activity, endurance and action, but in disposition, ranging from the smallest Shetlander to the large Norman or Flemish horses, in size, intelligence, temper and density of texture from that of the quick, fiery barb, to the slow, dull, sluggish cart horse. Hence the necessity of selecting the larger, slower and more patient character for slow, heavy, slivish work, and the light, active, hardy, enduring character for great fleetness and endurance, as, for example, shown in the use of light, hardy, lithe, active horses used on the desert or plains of our own country, for speed and endurance, and the large, slow, Norman or Flemish horse for slow, heavy work. In a word, anything of an ordinary discrimination should designate the necessity of selecting horses for the work they are by nature best adapted. Want of regard to this law is the cause of not only much annoyance, but of great loss to farmers and others.

This is not only true in the selection and use of light boned, sensitive, delicate constitutioned horses for slow, heavy work, or subjecting high-strung, nervous-tempered ones for such a purpose, when slower, stronger and more patient animals should be used. So, in relation to using 
slow, heavy horses for fast driving or riding, and so, also, the greatest and most unpardonable want of judgment and prudence is shown by gentlemen in the selection of horses of the most unreliable character, for a purpose requiring the greatest docility and perfection of character.

The most lamentable and common causes of accident and loss, result from the want of exercising proper descrimination and judgment in the selection of horses more especially adapted by nature for their use.

Thus, if a horse is not or cannot be made perfectly reliable for carriage or family use, or for any purpose involving much danger to life and property, he should be discarded or changed for one that is safe and reliable. But as these naturally excitable, hardy, plucky horses are really the best and most valuable horses when properly educated, the great value of my treatment can be appreciated, as I conclusively prove. I can even reform and make perfectly gentle the wildest and most vicious horses that can be found; and that it must be the fault of the reader if he cannot be equally successful. I see and handle horses almost daily, that are used for carriage driving, so unreliable and dangerous in character, that it would be true economy to shoot or give them away, rather than hazard accident by their use.

\section{NOT BEING AFRAID OF HORSES.}

This is a common expression, and is most always prompted by fool hardy ignorance. A wild mustang or mule would strike or kick without regard to being firm and courageous in manner or not. A determined horse that has learned to kick and run away, can do so in defiance of any control that can be exerted upon the mouth by the strongest of men with reins. If there is danger of a horse kicking or resisting control from excessive fear or other cause of resistance, being recklessly venturesome, without having taken adequate precautionary measures to prevent or overcome such viciousness, is only incurring risk; it is the part of true success to guard against or break up, before taking any doubtful chances which can be easily done by my treatment. It is assuming too much for any man to attempt driving and controlling a wild, reckless, kicking, runaway horse, by the control of reins and bit, as a strong, 
retermined, runaway horse can run away in defiance of the power of several men by pulling on reins with any bit in usc. I could refer, if necessary, to hundreds of horses of so bad a character as to resist all control in double or single harness, by any means that could be used, to two of the worst cases of which I will refer to here, out of a large number I have handled, even during the past season.

An eight year old bay horse, owned by Mr. Grates, a livery keeper of Garrettsville, Ohio. This horse was raised by Mr. Gates, had a right to trot fast, but in defiance of all that he could do up to the time handled by me, he could no be controlled in harness. The united strength of ten men, the owner stated, could not hold him if in the least excited or touched with a whip; yet in twenty minutes was driven by me gently, and so thoroughly gentle and manageable as to stand by word of command, regardless of any cxcitement, even whipping, and has been driven in double and single harness by Mr. Gates. and others for nearly a year, (Nov., I87I,) and drives safe and gentle. One of the most remarkable however, was a six year old colt, owned by I. P. Collins, Esq., proprietor of track in Toledo, Ohio. 'This colt resisted all control in harness, pulling so recklessly against the bit, that control was out of the question; yet was driven perfectly gentle by me in forty minutes, and remains so. These horses could run away with any horse hitched with them in double harness; it was considered as impossible by any means to drive them in single or double h.ur:ess without running away; yet the once handling to which each was subjected by me, proved sufficient to make them quiet in single or double harness.

I stand ready to handle and drive horses of the wildest and most desperate character, and take such in hand almost daily in illustrating my lectures, yet I never have an accident or get run away with. Now, although I do this as a matter of business in the pursuit of which I take in hand some of the most desperately reckless horses in the country, I would not think of hitching up and driving a horse of even ordinary bad character as is usually done, knowing my control to be too doubtful and limited to do so safely. This is the prudence I would urge upon you to exercise when necessary, as it is one of the essential points of true suc. cess as well as in guarding against and preventing accident 
Of course there are circumstances, and they are almost of constant occurrence, that call for courage and firmness of the highest order, to divert the attention, and hold a disposition to aggression in check. Horses of courage and intelligence are sometimes wonderfully acute in their perceptions, and the least expression of weakness or want of confidence would encourage them to resistance if not dangerous aggression. This is seen most clearly in stallions.

The horse always reveals his intentions by the actions of the ears and muzzle, and the expression of the eyes, as plainly as could be done by words. If they are thrown back, the lips curl, eye half closes and glistening with an expression of defiance, there is danger. In approaching such a horse, the better way is to stand still just beyond the reach of the animal, looking straight at the eye, showing undoubted conficlence and power in the actions and expression of the features and language, authoritatively commanding to get round or take care. The degree of attention and submission to command, will enable determining with great certainty, how far it is safe to venture, but under any circumstances is the eye, in such a case, to be taken off that of the horse. The firmness and delicacy of judgment often necessary in approaching and handling some horses, must necessarily be of a high order to prevent resistance, if not aggression and injury.

\section{GREAT THOROUGHNESS NECESSARY.}

An important requisition is being thorough in what is attempted to be done, and never to feel that there cannet be success. The worse the horse, the more careful and thorough must be the efforts. Want of reasonable perseverance will, I imagine, be the principle cause of failure it there is failure.

Fifteen out of every twenty men, who may attend my lectures, would toil arduously and patiently for days and even weeks for the pittance of a dollar or two a day, who would scarcely submit to the patience and effort necessary to break or reform a valuable horse, for example, of balking or kicking, if it required a half day's continuous effort, though the effort would enable increasing value of the ani. mal from one-fourth to one-half. 
There are also many who are disposed to sneer and find fault with the writer, should they fail to even a limited degree in accomplishing those marked results illustrated, and which have been shown to be so easily accomplished by his treatment as to be beyond comparison with any other treatment in simplicity and effectiveness.

The consideration of an hour or two's time and a few dollars' cost, seems to be an equivalent that demands such effectiveness in the treatment given, as to scarcely require an effort to reform horses of the most vicious character. Like the conceited, ignorant, laboring Irishman, who managed by years of the most severe labor and rigid economy to save enough to take him to America, had such a hallucination impressed upon his mind of the ease and luxurious plenty to be found in this great, free country, that after landing in New York he would not deign to pick up a five dollar gold piece which happened in his way in the street. It was not worth stooping for. Be Gorra, he would go to the whole heap which he imagined somewhere beyond, and when he found it necessary to work at fourteen shillings a day, which was just twelve times more than he ever received for a day's labor in Ireland, he cursed the freedom and sneered at the privation, suffering and loss by which this grand, free country, with its illimitable resources, were won and given for the use and benefit of the poor and industrious of all nations, for little more than the cost of coming to it. So many ignorant, conceited men who have not the experience, discrimination or judgment to appreciate and use with becoming patience and effort, the knowledge which I have made available to them for virtually almost nothing, which has cost me the best part of my life to develope, at a cost of labor, anxiety, danger and money, that with reason would appal those of the most stern resolution, energy and strength, and but few, indeed, who would have the courage even to attempt, would succeed in passing through without failing. The truth is, more or less failure and difficulty is necessary to become skilled and successful in the performance of any important duty, and the same is, to some extent, true in the application of my system. When I tell the reader that the ability to write these pages, and whatever of skill and success I have attained, has been grown into me by the hard, stern attrition of an unaided 
floating life among strangers, almost continually subject to those perverting influences which are its natural concomitants. And yet I am made only the more mindful by experience that I am wholly indebted to those necessities of my condition, which seemed to call continually for the exercise of my greatest energies, not so much to attain succes as to prevent and overcome the trials and failures to which I was almost constantly liable. This is the lesson which true success. in any channel must teach, and in no direction is it taught more forcibly than in the proper exercise of this great and important duty.

Human nature is so constituted that it calls for great trials to develope its great and profound resources. Every difficulty, rightly considered, only stirs into still greater action its latent powers. Every act of dissimulation and dishonesty discovered leads to a closer perception of the actions and intentions animating others under like circumstances, but they are rightly considered only the elements necessary to brighten and strengthen the mind to steadier, stronger, more uniform and successful action. As the steady wielding of the hammer by the blacksmith developes more size and strength in his arm, and proportionately more strength and powers of endurance.

\section{MORAL BEARING.}

In its true significance, this duty is really one of the most interesting and instructive we are called upon to perform, constantly revealing to the mind the true latitude of its powers and responsibility. In studying the instincts and habits of the horse, we are reminded of many of the laws, aptitudes and peculiarities of our own nature; for, while we are trying to control and regulate the actions of the horse, we are bringing into play certain principles of order, command and control in our own minds.

The more we observe this the more true and important it will be made to appear to us. We soon find that we first need to control ourselves to be able to control the horse, and we see, too, that the more perfect and reasonable the control which we are capable of exercising over ourselves is, the more perfect and reasonable the control we are capable of exercising over the horse. Hence we see that the 
scientific study and training of the horse is almost continu ally leading the mind to an insight of the most striking laws of our own minds.

Now, when we proceed on fixed laws, this exercise begins, and the more we see and understand that skill is involverl, the more we feel that real responsibility and skill are demanded to insur success. We see that certain elements are necessary: oolness, firmness, steadiness of purpose, energy, perseverance. We have brought all these qualities into exercise; we have cultivated and strengthened them in ourselves; we have seen the importance of not showing fear, the impropriety of exhibiting anger, hastiness, revenge, etc., and the importance of keeping uppermost feelings of kindness, forbearance, etc. 'Thus, when we proceed on right principles and according to the real laws of the case, we are all the tirne cultivating the better side, and restraining the worst side of our own nature.

View the subject as we will, it excites strong incentives to self-improvement, offering the most frequent suggestions, and presenting a repetition of motives for the cultivation of all our highest and best powers. 


\section{THE WILD COLT.}

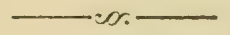

WHEN we remember that the first impressions on the mind of the colt are the strongest and most lasting; that his resistance is prompted by fear and an ignorance of what he is required to do, we see that the first point to be accomplished, is to make him so gentle that he will not try to resist being handled without frightening or abusing him. Imagine yourself in place of the colt ; a timid, innocent, suspicious child, and realize what the treatment of any one should be to enlist your confidence and obedience, and you will see that gentleness, kindness and prudence in not exciting the fears are paramount considerations. If the colt is afraid of you and resists your control, it is because he apprehends danger from you. Now the quicker you force him the more you must abuse and excite him, hence you must make up your mind to be patient-take your time, following up carefully, one point after another, until there is entire docility, allowing being touched or handled behind as may be desired without exciting fear or resistance.

If possible, have a room or yard, about twenty-five or thirty feet square, or even larger. See that all causes of injury are removed, and get the colt into this enclosure very quietly; if he is wild and nervous, see that no hens, dogs, etc., are in the room. Say to your friends, it is necessary to your success, and is a condition of your instruction, that you must be alone.

Of course the colt must first be haltered. If not very wild, this will not be difficult to do. But if very wild or vicious, this may be difficult and perhaps dangerous, and you should always carefully guard against injury to yourself as well as your horse, and at the same time you may accomplish your object just as surely, if not as easily. Titlie a light pole ten or twelve feet in length, or as much lo: ? as you can use to advantage, if the colt is very wild or 
diangerous, and drive two nails into it, about eight inche; apirl, tue first about an inch from the end, with the heads bent a little outward from each other. Take a common

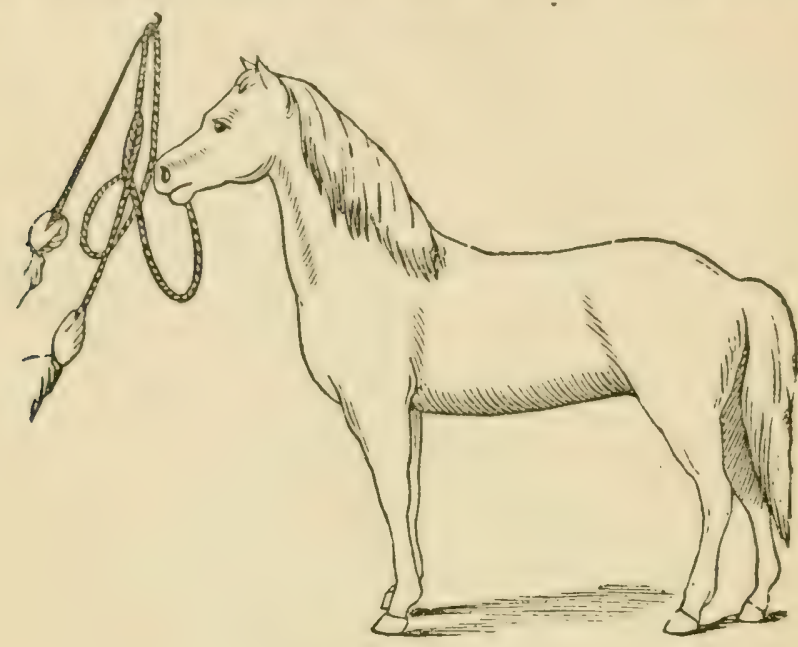

Haltering the-Colt.

rope halter with a running noose, pull the part which slips through the noose back about two feet, and hang the part that goes over the head upon the nails on the end of your pole nicely, keeping hold of the hitching part, which must be as long as your pole. Your halter is now so spread and hung upon the stick as to be easily put on to the head. If the colt is not excited or frightened, as you extend the halter towards him he will reach out his nose to smell and examine it, and while he is gratifying his curiosity in this way, you can bring the slack part under his jaw and raise the pole high enough to bring the halter over and back of the ears, when, by turning the stick half way round, the halter will drop from it upon the head. This will frighten the colt a little and cause him to run from you, but this will only cause the slack part passing back of the jaw to be pulled up, and the halter will be securely adjusted.

Being haltered, the colt must be taught to submit to its restraints and control. Take a position at the side on a line with the shoulder, and give a quick, strong pull towards you, instantly letting loose on the halter until you get the same position again. You have the greatest advantage from 
this position, and by adroitly repeating the pulls as he will bear, until he will come without being pulled upon. Should you pull slow and steady, he will resist and pull against you, and may even attempt to throw himself down; this you will avoid by giving a quick pull, and letting loose instantly. As soon as he will yield and come round promptly, get on the other side and repeat in the same manner, until he will follow you readily on either side without pulling. Be careful not to pull ahead until there is prompt submission sidewise. You can then gradually pull a little more on a line with the body until the colt will come promptly in any direction, to the slightest pull upon the halter. If the colt is of a quick, gentle disposition, he will soon learn this lesson thoroughly; but if very young, or of a slow, sulky disposition, great resistance is likely to be shown for some time. If the resistance is very obstinate or reckless in character, you may resort to the simple course of subjection, which will soon compel obedience. This you have been taught how to do; if there is not prompt obedience to the second method, (being careful not to tie too short,) resort to the first, then again to the second, until submissive.

When there is submission you should encourage by appealing to the affections. Rub the head and neck, and give presents of something of which fond, until all excitement and irritation subside. The eye will gradually grow mild in expression, and there will be an apparent inclifference to being handled. A coarse, harsli or loud voice is terribly irritating to a sensitive or spirited horse or colt, and must by all means be held in check. Speak in a gentle natural tone, softened by kind expression, which will do much toward securing the confidence of the animal and repressing his fear. With some colts it will be necessary to repeat the lesson in leading two or three times, to ensure prompt obedience.

\section{HITCHING.}

When the colt will lead kindly and promptly, he may next be taught to stand hitched. To prevent his learning to pull at the halter, take a piece of strong cord, about a third of an inch in diameter, twenty-two feet long; double it, and place the centre under the tail; bring both ends 
forward, cross and twist them three or four times over the back, knot them in front of the breast, and pass them

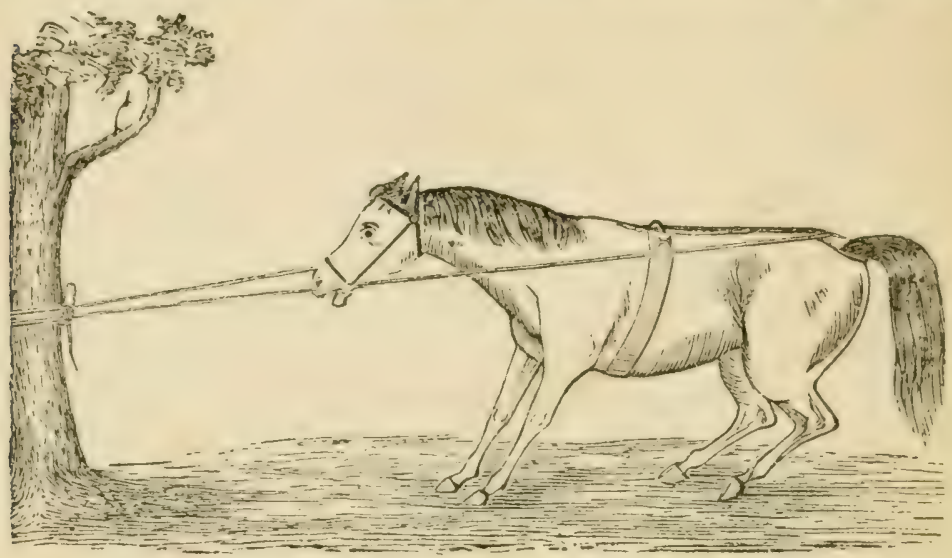

Hitching.

through the ring of the halter and tie to the manger or post. Hitch in this way until the colt refuses to pull back, even if frightened a little; after learning to submit in this manner, which he will soon learn to do, he will stand hitched by the common form of halter.

\section{BITTING}

Is the next step in educating the colt, and implies teaching the colt to submit to the restraint and control of the bit, giving as much style to the carriage of the head and neck as the form and temper of the animal will bear. Put on a common bridle with a smooth snaffle bit, without reins, and allow him to go as he pleases, in a yard or field, for half an hour or more, which may be repeated once or twice, to make the mouth accustomed to and hardened to the bit. Next put on a surcingle with check and side reins, buckling the reins at first so long as to bring but little restraint upon the mouth. After being on thirty or forty minutes, take it off. At each repetition buckle the reins a little shorter, until the head is submitted up and back freely to the check.

It seems needless to introduce details of a bitting harness. Any simple construction of the ordinary kind will answer very well, and the style is so gemerally molerstood that a 
description here is unnecessary. The object being to bring such restraint upon the bit that the head will be held up and back most natural and easily, without giving freedom to the head except in the direction of the reins. Care should be taken to have the throat latch so loose, that there will be no pressure of it upon the throat when checked up.

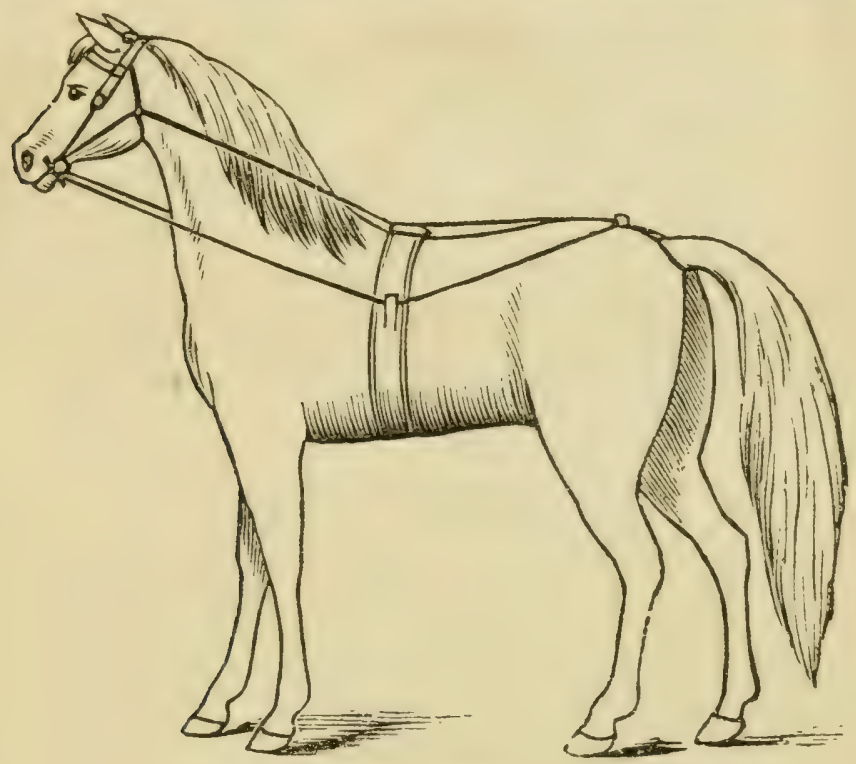

Bitting the Colt.

The gag-runners should be well up near the ears. Care must be taken not to bring too much restraint upon the bit by buckling the reins so short at first, as to endanger causing the colt to throw himself over backwards and break his neck. It is bad policy to keep a colt checked up too long at a time, as it becomes tiresome, which would cause a resting of the head upon the bit and thus form the disagreeable habit of lugging. If, however, the colt should fight the restraint of the bit or check, it should be left on till the fit exhausts itself and he shows a disposition to submit to its restraint.

Short lessons at first, and gradually keeping on longer as the mouth becomes hardened by the bit and the colt will bear it without fatigue, is the best course.

After the usual course of checking up in this manner, 
take a piece of cord about eight or ten feet in length, of the common sash or clothes line size, as strong and pliable as you can find. Tie a large hard knot in one end, and about twenty inches from this knot make another tie, passing the knot end around the neck as near the shoulder as possible. Pass the other end of the cord through both rings of the bit, back of the jaw and back through the loop around the neck, and draw up the slack. Now stand in front of the head, holding the cord tightly with both hands; give a quick, short pull down and back, which will cause the head to be thrown up and back. Repeat, until the head is given up and back freely at the slightest pull. Now, when the reins are attached to the bit and pulled upon, the restraint is precisely the same as before; and after repeating this lesson a few times, the head will be freely submitted to the control of the bit, and a beautiful carriage of the head secured, even without a check.

\section{DRIVING IN HARNESS.}

I would say here in this connection, that there is an almost unaccountable stupidity exhibited in the usual method of training colts. 'There is the greatest care taken not to frighten by having the heels touched for fear of exciting resistance; whereas, this is the very point that should be accomplished most thoroughly in the first place. The hinder parts should be broken, as it is term, until there is no fear of being touched by anything. This is the first point I look to and accomplish most perfectly, safely and quickly by my second course of subjection, and which is one of the real secrets of my success in driving wild or kicking colts so quickly to shafts without breeching. Look to this point in the first place, then teach the colt to summit to the guidance and control of tbe bit, and you accomplish by two movements, quicker and better, what it takes so long, and is done so unreliable by the usual course of treatment.

When the colt is gentle and taught to submit the head to the bit, the next step should be to teach submission to the guidance and control of the bit with reins. I would state here that if the colt is well bitted, submitting the head to being checked high, there will not be much inclination to kick or resist, hence, the custom of putting on a bitting 
harness on a wild colt, checking the head up tightly. This treatment will work well in most cases; being a powerful means of subjection, the majority of colts or those not very bad, will work to harness quite well by checking up tightly for a while. Colts of a sulky, plucky nature are liable to resist it, and throw themselves over backwards. If the back part of the head should strike the ground heavy in thus falling, there is great danger of the animal being killed, as the back part of the head under where the bridle and halter comes, is where the first bone of the cervical vertebrae (atlas) unites to the head or oxipital; an apparently very slight concussion or injury at this point will break the neck and destroy life. This must not be hazarded, and besides it is needlessly cruel. The course I advise in the first place, enables making the colt perfectly gentle with perfect safety in a few minutes, enabling, if even desired, putting the colt in harness and driving with perfect safety, especially if the precaution is taken of driving around a few minuutes in harness before attaching to wagon; but if the greatest certainty is desired at the expense of a little patient care, subject to the mild course of bitting in addition, but little more is necessary to do than drive him in harness a few minutes, turning right and left, and stopping until obedient, when he can be easily driven to shafts.

The proper course is to put on the harness with smooth snaffle bit in bridle, tie the tugs into the breeching, run the reins through the shaft lugs instead of the terrets, now getting directly behind the colt you can easily rein and keep him before you in driving until obedient and gentle to reins. Of course there must be patience and care in proportion to the temper and natural resistance shown until successful.

\section{HITCHING THE.COLT TO POLES.}

If the colt is at all uncertain, it will be policy to work slowly and carefully, as one mismove while attached to a wagon might cause damage to wagon and injury to the colt. The simplest, cheapest and surest plan of teaching the colt to become safe in shafts, is to drive first in poles. GET THREE SLENDER POLES, two of them about twelve feet long each, the third about seven feet in length. Lay down the poles 
small ends forward in the form of shafts, about twenty inches spart, the back ends about six feet apart. Lay the short piece across about six feet six inches to seven feet from the forward ends, and tie on with pieces of cord. Hitch the colt into these poles, attaching the tugs to the cross piece by tying with cord, and drive around until there is perfect submission to them, guiding promptly to the reins and submitting to the poles striking the flanks or heels without exciting the least fear. But in the early driving of colts, great care must be used not to force too freely to back, as this may cause the habit of backing too freely, turning around and running back from the slightest causes of fear of anything in advance, in driving to wayon or sulky. Great care should be taken not to drive the colt too much at first, and at no time sufficient to produce exhaustion. Neither should his strength be taxed too much by drawing heavy loads, until he has become accustomed to the noise and restraint of the wagon and learned to use his strength as required. Let his drives be moderate at first, both in gait and distance; gradually increasing the distance as he will bear without fatigue. After learning to walk well, let him trot a little, gradually letting him out faster and a little farther, as smooth pieces of road give opportunity; restrict these little outbursts of speed at first to the limits of a few rods. I.et him dash out a short distance, then gradully slacken to a walk, speaking kindly and encouragingly. After a while, let him out again, pushing, perhaps, a little faster and farther, being careful not to crowd to breaking. It must not be expected because your colt is perhaps a good mover, that he will be a fast trotter. But if he does show a loose open gait, do not by any means spoil him by attempting too much at first. There is usually too much anxiety to try a colt's speed and bottom, and he is often pushed, overdone, and spoiled perhaps, before his powers are half developed.

A colt must not be crowded too much in educating to harness. He cannot be expected to submit quietly to the irritation and excitement of harness and wagon, or drive like an old horse, without experience and practice. He must grow into the position as it is were, and a reasonable patience and effort is necessary to ensure this. The great trouble with most people in training colts is, they attempt 
too much, and thus make haste slowly. The quickest and surest course is that I give. It will always enable working a colt safely at most in a few hours.

\section{DOUBLE DRIVING.}

It is generally the custom to drive the colt at first in doubie harness by the side of a gentle horse aecustomed to harness; the colt should be put on the off side. The whip should be held over the old horse, to keep him up to the movements of the colt in starting, but the gait should be kept moderate.

After driving well on the off side, he should be reversed to the near side, there being less danger of becoming frightened from getting into or out of the wagon, or of secing things while being passed to or from the wagon, by being more from view on the off side, therefore to lessen the probabilities of being frightened, it is preferable at first.

I,et the driving be moderate, and the load light, and, by all means, if the colt is of a sensitive or nervous temperament, the greatest mildness must be observed. Loud "yclling" or cracking of the whip should not be permitted. A little imprudence of this kind is often the cause of very serious mischief with timid, young horses.

\section{BACKING.}

After learning to drive well, teach the idea of backing by pulling on the reins steadily, and saying "back." If there is resistance give a quick, sharp, raking pull, which will move the colt by the pain and force of the bit backward, repeating until there is prompt obedience. If there is much resistance put on breaking bit, which will soon secure obedience, but under any curcumstances do not make the colt back too freely, especially if the mouth is sensitive.

\section{RIDING.}

If the colt is not of a very bad character there will be no resistance to being rode after the first lesson of subjection. If there is, attach a short strap or a piece of rope to the off fore foot, throwing the othet end over the back. 'Take a 
short hol:l of this strep with the right haml. while the 1 ff grats the near rein of the bridle firmly. As the heart is fulled around, the horse is made to step sidewise, and the instant the foot is relaxed it is held up by the restraint of the right hand on the strap, which is instantly drawn upon. 'The colt is now on three legs, and unable to resist. Jump lightly on the back, press the feet against the belly and flanks. As there is submission release the foot, taking a firm hold of the reins, which should be held short. Move the colt forward, and as there is an indication of resistance pull upon the strap and reins, which will disable and disconcert the horse from further

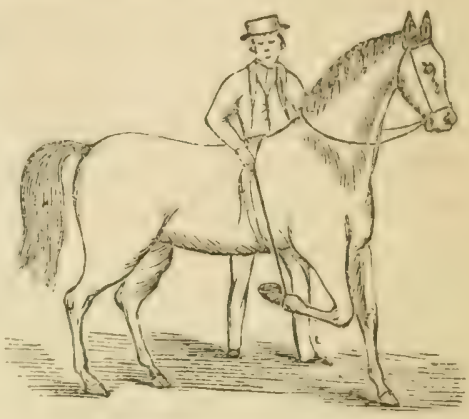

(Mounting the Colt.) opposition to being rode. If the colt will not move forward, request an assistant to lead him by the head for a short time. So long as there is any indication of resistance, keep on the strap. One thorough lesson is usually sufficient, though some colts may require a repetition of the lesson.

When it is desired to mount, let the left hand rest lightly on the mane, a little forward of the withers, holding the reins between the thumb and fingers. Throw the right hand lightly on the back, the body close to the horse. Now spring lightly upward and forward. The instant of doing so, let the right hand glide forward until the elbow strikes the back bone, when the weight of the body is to be instantly balanced upon the right arm, which will enable sufficient strength to make the spring continuous, and the body is easily brought into a sitting posture. This is slight undertaking, and a little practice will give the ability to mount the highest horses with apparently wonderful ease. T'o mount on a saddle, stand by the side, a little back of the stirrup, the face towards the horse's head. 'Take a short hold of the reins between the fingers, grasping into the mane at the same time, put the left foot into the stirrup, throw the right hand over the saddle and press it against the off side, throwing the weight of the body on the left foot, and you can lift yourself into the saddle easily. 


\section{HANDLING THE COLT'S FEET.}

If the colt is of an ordinary good disposition this can be done without resorting to special means. Stand well up to the shoulder, put the left hand on the shoulder, pressing forward gently, which will relax the muscles controlling the leg, with the right hand, instantly grasp the foot below the fetlock and lift it up, removing the left hand and bring under the foot to aid the right hand. To handle the hind feet, let the right hand glide gently from the shoulders back to the hip. At the instant it passes the point of the hip, bring the left forward upon the hip. While doing this, the right hand is being glided down the leg gently, until it strikes the fetlock, when the left hand should be pressed firmly against the body at the point stated, which will relax the limb, and the foot can be easily brought up by the right, the left is lowered and passed down the limb on the back part of the fetlock. Or the foot can be raised and lowered a few times with the right hand, while the left balances the body by pressing against the hip until there is perfect submission.

If there is resistance, take up the fore foot, request an assistant to hold it up for you, while he at the same time holds the colt by the halter or bridle. Tie the end of a rope or strap around the hind foot, above the fetlock, at the instant of doing which let the hand glide along to the opposite part, until six or eight feet from the foot. At the same time request the forward foot to be let loose, the assistant holding by the halter. Now pull upon the strap, which will bring the foot forward, and at the instant of attempting to kick, let go, and so repeat until the foot is submitted to the restraint of strap. Then slip behind and pull the foot back, and as before yielding at each effort to kick, let go, until the foot is submitted freely. Now take the foot from the control of the strap to the hand and handle gently.

If there is very determined resistance, tie the end of your long strap around the neck, near the shoulders, pass the other end back between the fore legs, around the hind foot, but under the strap around the neck, and draw up on it, at the same time holding him by the bridle or halter. The colt may be frightened and jump to get clear of the resstraint. Should he act very much frightened, slack up on 
the strap until the foot is almost back to its natural posi. tion. 'Then as he will bear, again pull a little shorter, at the same time pulling him round in a circle by the head, until he ceases struggling to get the foot loose. You may now pull the foot farther forward, and hold it as before, until he will stand quietly. Now step back a little and pass the hand down the hind leg. Slap the hand upon the leg a little until there is no resistance, then take it in the hands. If there is no resistance, undo the end of the strap and allow the foot a little more freedom; at the same time while holding the foot by the strap, pass the hand from the hip down the leg quietly, rubbing and caressing until able to take it in the hands.

Handle the opposite leg in the same manner, until there is perfect submission. Should the colt resist having the feet handled with much determination, or prove very vicious, the regular subjective treatment will be necessary. Those of a wildish mustang disposition are the most obstinate; there is once in a while one of this class that will call for pretty thorough and patient treatment to make gentle. They are not only so plucky, but so strong and enduring that they are disposed to resist control of the feet at all hazards. It is of great importance that colts are treated with great kindness; giving apples, a little oats, etc., after submitting the feet or being otherwise handled, as the real cause of trouble is fear, and winning the confidence by a little flattery in this way has a powerful effect in disconcert ing the attention and winning the confidence, and thus of teaching obedience. All this is now so easily done when necessary by the ordinary subjective course, that it seems needless to dwell on minor conditions and details; you must bear in mind that bad cases call for a little work and patience, and that you must be not only thorough, but prudent, to be successful. 


\section{EXCESSIVE FEAR-CAUSES AND TREAT- MENT OF.}

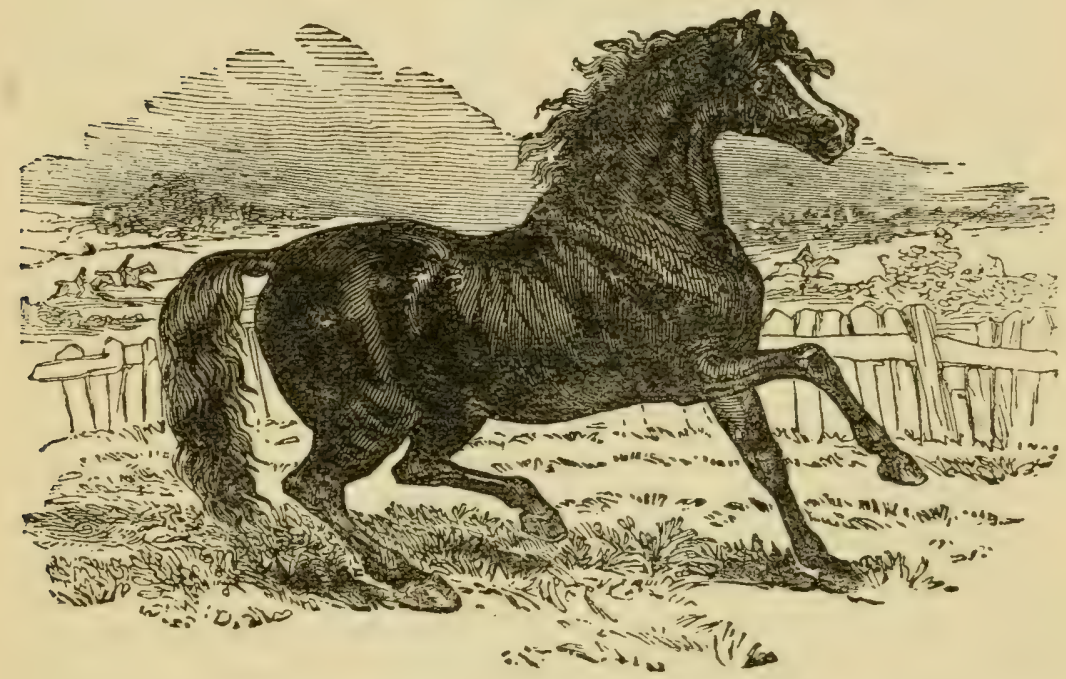

FEAR requires more than a passing notice. It is the cause, or principle one, of the most dangerous and difficult habits to break up, showing a disease of the mind, or mania, and as such its consideration is at the foundation of the principal bad habits to which horses are subject. Fear causes the colt to resist control, to kick, run away, resist an umbrella, robe, cars, and all unusual objects and sounds. These marked derangements are often the result of causes in themselves of a trifling character.

Thus, a colt is suddenly excited by the appearance of an umbrella, and it is afterwards an object of terror to him. A horse may be driven for months, or even years, but at some unlooked-for moment the breeching perhaps breaks, allowing the shafts or cross-pieces to strike the heels, perhaps causing the unsuspecting animal to spring, kick and run away. 'The impression by this one act makes a wagon an object of terror, and he refuses contact with it afterwards. and thus $3 *$ 
through all the ramifications of character, the same intensity of fear and resistance is shown to a greater or less degree, in proportion to the sensibility of the animal and the intensity of impression made upon the mind. The intensity of the impression may be even so great as to destroy life. Several instances of such a fatal result have been brought to my notice. In Lignonier, Ind., a few years ago, a fine horse dropped deal from excessive fear of the cars. Such an occurrence took place in Chicago a few years since, and during the burning of that city one such instance has been authenticated.

All impressions, it is supposed, are made upon a series of concentric nerves in a certain location of the brain, called ganglize, which retain and throw them off by reflex action under like circumstances. Being of a primary character, when excessive in strength, they subvert and control the reason, and thus the character is strongly marked, if not controlled by them.

Hence the many instances of insane fear and resistance resulting from being once frightened.

I could refer to many instances of such insanity coming under my own observation. A bay mare, owned in Green Castle, Pa., in I $\$ 65$, was entirely fearless of all objects but a robe, the appearance of which would make her furious. When seen at a distance of thirty feet, she became so reckless as to break away from all restraint, plunged against a heavy door, breaking it down, and ran away. When brought back, I took her in hand. When shown even a corner of the robe at a distance of twenty feet, she would plunge, squeal, strike and kick in the most reckless manner. The shock to her nervous system was so great that I feared she would not bear it, and it was only by the most careful treatment I was able in forty minutes to bring it near and throw it upon her, and ultimately she did not care anything about it. When in Cleveland, an interesting case of this character, owned by Dr. Keegan, was brought me. Many years before, when standing in the street, the wind blew a blanket from the horse's back, falling under him, and it so frightened him that ever afterwards a blanket could not be brought near him. This horse was entirely fearless of all other objects, could be driven up to cars, but a blanket was to him an object of the greatest terror, resisting its appearance by 
kicking, striking and even squealing, in his phrenzy to get away from it. With a little care I succeeded in breaking up the impression so effectually, that he allowed a blanket or him afterwards. We see, in all cases, that excessive feat is excited by forcing or bringing the object to notice tou quickly or unexpectedly, causing so intense an excitement of the fears as to derange the understanding. If, in the first place, these derangements are the result of shocking the nervous system by the suddenness and violence of the impression, the preveution of such derangements can be secured by bringing objects and sounds liable to excite, to notice slowly; and, SECOND, in overcoming them, that there is power to control physical resistance at will, to enable convincing the reason of the harmless character of the object or sound. The feelings become blunted by the presence or repeated contact with the object or sound. The greatest causes of danger cease to attract notice by familiarity with them. The family living on a by-road in the country, who would notice every one going by in their isolated position, in a city where people pass almost constantly, would soon become unmindful of even greater causes of excitement. The principle is the same with horses. Hence, omnibus, hack or other horses that are almost constantly in the vicinity of the cars soon become unmindful of them, the exception being those of a very sensitive character, or by being greatly frightened at first. Hence, military horses that are forced to submit to the firing of small arms, cannons, drums, etc., soon become regardless of such excessive noises and excitement, and soon become perfectly gentle and obedient to control under such circumstances. It is common, too, for horses that are very sensitive in the country when subjected to the constant bewildering excitement of a city to become as unmindful of what is passing around them, as others accustomed to use in such a locality. The change of character, too, that may be produced by proper subjective treatment, is remarkable, many marked proofs of which I have illustrated in my own practice. To one marked case I will here refer:

In October, I868, a six year old horse, owned by A. Smawley, of Petroleum Centre, Pa., was brought to me for treatment. This horse was of so remarkably wild and desperate a character that he was known by the name of 
"Wild Pete." He would scringe and jump at the least touch or appearance of anything strange; he would not stand to be cleaned, could not be harnessed, and to attempt putting him in shafts would excite the utmost desperation, jumping and kicking clear of restraint at all hazards. He was one of the most desperate acting horses of the kind I ever saw. Indeed, anything touching him behind, even a touch of a whip, would make him jump and kick regardless of consequences. Yet, after subjecting him to two energetic lessons of less than an hour each, I could drive him to my buggy with perfect safety, and he could not be made to kick or resist control. So perfectly docile did he become, that he was let for driving in the livery, and has proved a very superior and safe carriage horse. As a rule, however, constitutionally timid horses yield slowly, and require careful as well as thorough treatment. I could refer to many interesting illustrations of this character did space permit.

The rule should be, not to excite the mind excessively from any cause, and to gradually, as the animal will bear, bring the object to notice, at the same time associating with such causes of fear the greatest kindness by giving presents of anything of which fond.

If there is much resistance or danger, physical control is to be made undoubtedly by the course of subjection, holding your point until perfectly successful, repeating the treatment until all resistance ceases. The better to give a practical understanding of details, I will include in this connection the treatment in accustoming to a few of the most common objects of fear, which will enable an understanding of the treatment necessary for anything else.

\section{A ROBE.}

While held under careful restraint, let the robe be brought up gently to the colt's nose. After smelling and feeling of it in his own way until satisfied, rub it gently against the head, neck and body, the way the hair lies, as he will bear. 'Jhen stand off a little and throw it across the back, over the neck and head, gradually stepping farther, until you can t'irow the robe upon him as you please. Repeat the lesson sc:veral times. 


\section{AN UMBRELLA OR PARASOL.}

While holding the colt by the halter or bridle, as may be necessary, bring the umbrella to his nose gently, rub it against the head, neck and body, as he will bear, spreading it a little, repeating the process of rubbing, and so continue gaining little by little, until you can raise the umbrella over the head, and pass it around the animal as you please, without exciting fear or resistance.

\section{SOUND OF A GUN.}

First, commence by snapping caps a short distance from the horse, gradually, as he will bear, approaching nearer, until you can snap caps while the gun is resting upon the back, over the head, etc. Then put in a little powder, and at each repetition increase the charge until you can fire off a heavy load without exciting fear.

\section{RAILROAD CARS.}

Let the animal see them at rest, then gradually lead or drive him up to them, even to smelling them with his nose. Now, as you have an opportunity, drive the horse around while they are moving, working up nearer as you can, and at the same time turning him around so that he can see and hear them from different directions. This lesson should be often repeated, being careful not to crowd beyond what the colt will easily bear, until they cease to attract his serious attention.

\section{OBIECTS EXCITING FEAR WHILE RIDING OR DRIVING.}

Should the horse show fear of a stone or stump, or anything of the kind, he will naturally stop and stare at the object in an excited manner. Should the cause of fear be great and sudden, he may attempt to turn round and run away. This is to be guarded against, by sitting well forward on the seat, and taking a short hold of the reins, at the same time speaking calmly and encouragingly to the horse. Bear in mind the horse has a great advantage over you, that his excitement is liable to precipitate his whole. 
strengtl against you at the least sense of freedom, or additional cause of excitement; that once resisting control in this position, he will try to do so again at all hazards, under like circumstances.

Speak encouragingly to the horse, but keep a close watch upon his actions. In a short time the extent of his alarns will not only be perceptibly lessened, but he will become calmer, and almost disregard the object. Then drive nearer as he will bear, exercising the same patience and care. At each effort to get nearer, the horse will become apparently as much frightened as at first. Keep pushing a little at a time in this way, as the horse will bear, until you can drive. up to the object, or by it, and you not only leave no bad impression upon the mind, but gradually overcome the disposition to become frightened.

Sometimes a horse will dislike a wheelbarrow, baby wagon, turkeys, etc., but the treatment is the same. When the excitement is not so great as to endanger successful resistance, and the horse is disposed to "play off, or soldier," it may be advisable to apply the whip a little sharply, but this is to be avoided when it is seen the resistance is wholly induced by fear, and the animal is not lazy.

Some horses while driven to carriages, will not bear the noise and excitement of other horses being driven up behind. This is principally on account of the horse's inability to see and understand the cause of the excitement, or it may be owing to the fault of the driver. Some one drives up rapidly behind, perhaps wishes to "go by," to prevent which the colt is hallooed at and whipped up to prevent such a result. This may be repeated a few times, and the consequence is, if a spirited horse, the habit is acquired of rushing ahead to avoid the punishment expected under suct: circumstances, and very often, too, a horse is forced into this habit by being run into from behind.

\section{USING BLINDERS.}

It must be remembered that the blinders in general use so cover up the eyes as to make it impossible for the horse to see things plainly sidewise, or at all from behind, which tends to increase the fear, as we are convinced, when we see that to overcome the animal's fear of any object, the 
first and most obvious point is to give him an understanding of its appearance and character. Blinders are admissible only when there is a desire to conceal the defects of a large head, and to cause a naturally lazy horse to drive steadily, by preventing him from seeing when the whip is about to be applied.

\section{MUST SEE THE OBJECT FROM DIFFERENT POSITIONS.}

It is one of the peculiarities of the horse to understand and be reconciled to an object or cause of excitement only from its position and circumstances as brought to his notice. 'This seems to be on account of the horse's reasoning powers being so limited as to be unable to retain the same understanding of the object beyond the position from which it is brought to notice.

Every progressive change of position requires almost the same care and patience as that preceding. For example, if in teaching a horse to submit to an umbrella, if it were shown only from the near side, upon carrying it to the off side, would inspire nearly as much fear as at first from the near side, or there may be an aversion to some particular object, or resistance niay be inspired only under certain circumstances. You may succeed in getting a colt gentle to be rode from the near ride, but an attempt to mount him from the off side, world in all probability be resisted.

If a horse is afraid of an umbrella while in harness, he may be taught to care nothing about it out of harness, but if not taught to feel and understand its character in harness, would be apt to be as much frightened at it in that position, as if he knew nothing about it.

This seems to puzzle many well-meaning men, and is often the cause of much disappointment.

A horse that is afraid of an umbrella, is brought forward to illustrate the management of such habits. In a short time the horse will bear the umbrella over and around him in any manner, without seeming to care anything about it. The owner is pleased with the belief that his horse is broken, when in harness at some future time, he raises an umbrella behind the animal, and is astonished to find him almost as bad as ever, and he is disappointed. But when 
It is seen in the first place that it is often necessary to repeat the treatment, that expecting the animal to be broken of the habit by a single indirect lesson, only tends to defeat success. For without ability to control the horse, every attempt to force upon him the object of aversion only inspires greater resistance, because taught to a still greater degree to resist control, and a sense of freedom always tends to increase the animal's fear of the object. Now the efforts of the owner to control the horse directly in a position of so great disadvantage, may produce exactly this result, and then from an ignorance of the cause of failure, believes it is impossible to overcome the habit.

The lesson must be repeated, as long as may be necessary to the end of perfect success, or the horse once excited is liable to drift back to being almost as bad as before. 


\section{SUBJECTION .}

Educating horses successfully, implies showing and teach ing what is required to be done in such a plain, practica. manner, that the horse is made to understand clearly what to do. This implies showing by actions, when he does right or wrong, restraining or reproving for resistance or loing wrong; and caressing and rewarding for doing right, repeating with patience until the animal can understand the meaning and object of his restraint, that he is not to be hurt and only required to do what he is commanded. This is an absolutely necessary condition, as horses do not understand articulated language, and cannot understand what to do unless shown. Hence, we caress and reward by giving something to eat of which the animal is fond, learning him to associate kindness and freedom from pain, by yielding obedient to demands made upon him. But it is seen all horses are not gentle enough to be approached and handled to enable doing this. That a man has not strength enough to control or restrain a wild or vicious horse with any degree of safety or certainty. 'To make such so gentle and submissive to control, that they can be safely and easily handled and educated, constitutes the science of subjection.

\section{EXCITEMENT NOT ADMISSIBLE.}

There is one law in the subjection of horses requiring special attention, and that is, that the more excitement caused in forcing obedience, the greater and more persistent must be the resistance. The object being now to fix upon the mind such an impression of. power as to make the animal passive to control; at the same time not only intensifying the impression by such treatment as will cause the most pain, in exact proportion to the resistance made but appealing to the reason and better part of the nature as lirectly and forcibly by acts of kindness; but if in doing this the passions are excited, proportionate resistance must result, which may, in the more plucky peculiarities of 
dispositiun, endanger breaking down the animal to overcome; and even though there is submission to force, there is likely to be renewed resistance after the exhaustion, or the animal becomes cool, unless the better nature is immediately won into coöperation of the efforts by kind encouraging treatment. Hence, when it is desired to bring all the powers of the animal into play, we see the blood is warmed up either by stimulants or exercise.

Trotting horses are exercised before racing; if animals desired to fight are not in the mood, they are provoked until excited; men who are under the influence of liquor, or from any cause are excited, would fight with a recklessness they could not be induced to do when sober and the blood cool, consequently there must and will be increased resistance to the degree, the bad part of the nature is excited.

This is what Rarey and others tried to accomplish and evade by the different methods introduced, of controlling horses such as lever bits, checking the head high, tying up one or both legs and throwing the horse down. That shown by Rarey (disabling and throwing) being the simplest and valued most highly, the object being to exhibit physical power to the mind, but if the horse happened to be of a sulky, stubborn disposition, passively submitting to the force to which subjected, the impression of power would not be adequate, and if very vicious could not be made sufficiently positive to ensure anything like uniform success, especially in the breaking up of such habits as balking, kicking, running away, etc.

Were it admissible to subdue horses by lowering their strength, success would be easy, as this can be and often is done by any of the following means, such as bleeding, physicking, want of sleep, violent exercise, pain, starving, want of water, etc., that will lower the strength and depress the energies, will accomplish the same end.

\section{CHIIIAN AND SOUTH AMERICAN METHODS.}

It is on this principle that the people of South America break horses; they catch the wild horse with the lasso, throw him to the ground, saddle and bridle him, then ride the animal with whip and spur until exhausted and submis- 
sive, they then square off the ends of the hair of the tail to indicate that the horse is broken, and again turn him loosc. The Indians on our western plains practice the same plan. The Chilians tie the refractory horse in the stall and apply the whip right and left until he lies down or falls down from weakness; the horse is then tried, and if refractory the process is continued until he becomes gentle. The same process is practiced by certain traveling horsemen in this country; turning the wild or green colt loose in a small enclosure and applying the whip until submissive. Of course a horse must be whipped terribly to force obedience in this way, and in the treatment of some is liable to sour and spoil the temper. The farmer has learned that if he can tire and exhaust a colt he is much less sensitive, not likely to kick or attempt resisting control. Horses that are worked hard or after a hard journey are much less sensitive or excitable than after being idle for some time. The exceptions being (for there are exceptions) those of peculiarly excitable, hardy nature, that seem to increase in energy as they are warmed up.

The usual course in this country is to put the harness on the green colt, after perhaps being bitted by checking up tightly, which is repeated a few times. The colt is attached by the side of a gentle horse, allowed to go and wear in to becoming accustomed to the harness and obedient to the control of the bit. The excitement and possible resistance induced by this course without adequate ability to control by the reins or bit, leads to the many habits of balking, kicking, running away, fear, etc., in harness. Should the animal become frightened or resist violently without adequate precaution or power to prevent resistance, some one of the many bad habits to which horses are subject is produced. These results, it is seen, I can easily prevent and overcome by my treatment, which enables accomplishing the end desired in the simplest, most practical and humane manner, thereby enabling me to control even almost at will, horses of the most vicious and desperate character 


\section{IMPRESSION UPON THE BRAIN.}

As it is the impression that is made directly upon the mind that controls and moves the animal; it is not only necessary to control the animal at will, showing exactly what is required to be done, but that the coöperation of the better part of the nature is won by the kindest and most encouraging treatment, and which constitutes the next most powerful lever of making horses docile and manageable. Indeed, a proper application of the efforts with the advantage only of kind, encouraging treatment will enable of itself to show very successful results, and is absolutely indispensable in the treatment of sensitive or naturally wild horses. I show not only just how to guide and control the horse to any extreme desired, but hold this control with scarcely an effort, by encouraging obedience through the feelings in the most powerful manner. Now throwing or any of the treatment in general use will not enable this with any certainty; but throwing is a valuable auxiliary, and properly done, enables creating a very strong impression upon the mind of some horses. I will here give the details of the proper method of doing it.

First, have made a strong leather surcingle, long enough to go around the body of the horse, to which have attached a strong back strap and crouper. On the off side of the surcingle, about eight inches from the back, have a twoinch ring; from this ring to the back strap at the hip have a strong double strap extend. Now put on this harness, which will be like a bitting harness.

Next take a common hame strap, pass around the near fore leg and over the surcingle, buckling only short enough to allow the foot to come in a horizontal position, or the strap can be tied around the arm and foot. This done, take a cord eighteen or twenty feet long, of the strongest kind you can get, about $3 / 8$ inch in size, if strong enough; tie the end into a knot; about twenty inches from this end make another simple knot, but do not draw it tight. Now pass this end over the neck, put the end knot through the tie, or other knot, and draw close. The object is to have the cord fit around the neck some distance from the head Pass the other end of the cord through the ring in the side 
of the surcingle; at the same time let the cord at the other end extend through the mouth. When the cord is now drawn tight it will be seen to pass from the neck through the mouth back through the ring, and by pulling on the end held in the hand the head will be drawn to the side. 'Tiic leg on the opposite side being tied up, when the cord is pulled upon the horse must roll over on his side. This plan will enable throwing a horse very easily, and will enable doing all that is possible to do by this principle of subjection.

This principle of subjection does not work well in the control of horses of a naturally sulky, mulish disposition. Hence it will be found, balkers, very determined kickers, and especially those showing the positive reckless temper of the mustang nature, will resist it, and constitutes only one good step in exhibiting physical control, though not so reliable or effective as the other treatment (shown and illustrated in my lecture.)

\section{WORST HORSES.}

The dull gray, bright sorrel, and nervous tempered black, and sometimes a bay, if showing much of the wild nature, will exhibit the most plucky resistance. If the eyes are small, set well into the head, ears long, inclined to lop back, head flat or nearly so between the ears, head rather narrow and long, you will find if wild or vicious, the most determined

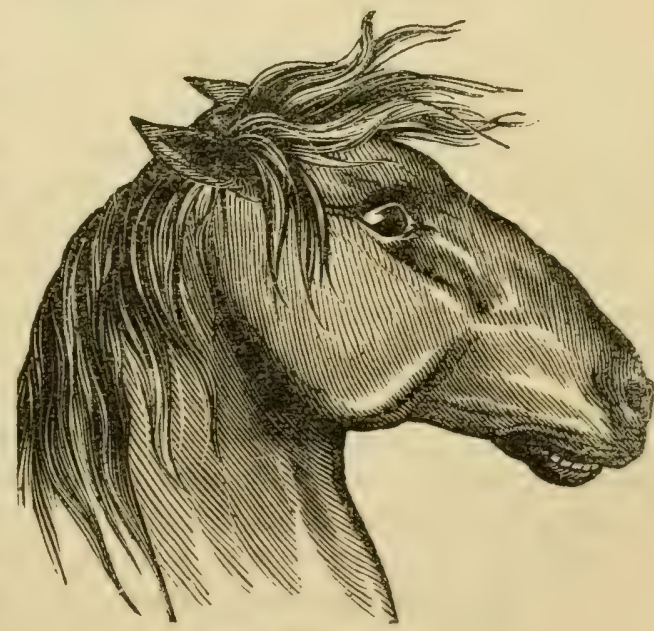

Bad Disposition. resistance, usually acting very sulky and indifferent to the whip or other means of pain, as the blood becomes warmed up.

The second course of subjection works best in the control 
of this temperament. The first may be tried, but in the event of great resistance and the animal becoming very warm, give sufficient rest to permit the blood to become cool, when you will easily succeed by working carefully and thoroughly, encouraging obedience by kindness.

The naturally sulky, wild, desperate disposition, very rare, but always shown by a middling large eye, well formed nead and countenance; the ears are thrown back, the eye

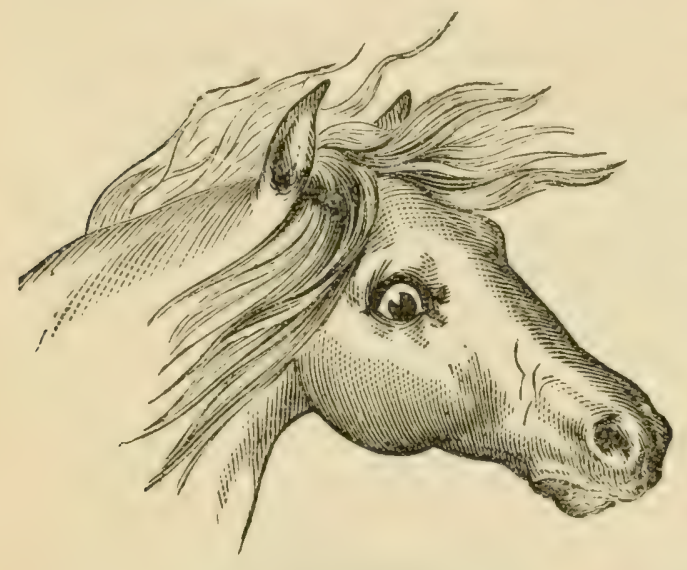

Sensitive and Flighty. sullen, requires the most care and thoroughness, and must not be hurried too much, and not at all if greatly warmed up, as such, under such circumstances, become intensely reckless. If kickers or balkers, perplexingly sullen and determined, passive treatment will enable controlling such easily, always encouraging all you

can for obedience by caressing and giving presents of apples, oats, \&c., \&c., and above all, you are not on any condition, to stop as soon as the animal submits. Keep at work now, treating in the kindest mannor until the nervous system becomes cool, and the horse is fully reconciled to your control.

You are not to consider a horse broken because submissive to control after being handled once. 'Test carefully after getting cool, and if necessary, repeating until certain of success.

Let me impress upon you here the necessity of being thorongh. It is not by any means safe to be otherwise. Make it your business to do well what you attempt to do. A man of much less than ordinary ability can accomplish almost wonders by trying and being thorough. The man who will not try, and not only try, but be persevering, is not worthy of success. 
The greatest cause of failure, will be want of care and patient perseverance. If we can force and win the obedience of a horse in a given time, that is the treatment to pursue to insure perfect success in the reformation of that animal. Like the doing of anything else, work enough must be done to secure the end aimed at with certainty. A horse may submit to control in the most perfect manner after a course of treatment, yet not be half broken. More or less repetition of the treatment, with careful, prudent, encouraging management will be necessary to insure that uniform success in the performance of this great duty, which its delicacy and importance demands. 


\section{BREAKING HORSES, ETC.}

\section{RUNNING AWAY.}

THis habit may be induced by a great variety of causes-frincipally by becoming frightened in some way, though often by the horse learning to pull against the bit so hard as to defy control, and therefore at the least cause of irritation disposed to pull ahead and run away. When actuated by fear, the resistance is usually so sudden and violent as to induce a degree of resistance to the restraint of the bit we have not power to prevent or control. Sometimes, too, the horse will spring sidewise, or turn around in doing this, and will so learn the trick that at the least excitement he will spring into a sharp run. All this resistance, it is seen, results from defective training of the mouth, and is virtually surmounted when able to force so great a degree of control by the bit as to break up all disposition to resist restraint when excited.

Running away is a very serious and dangerous habit, and all such predisposition should be thoroughly broken up when manifested. If very bad, tone down resistance by subjecting the animal to a course of subjection; after which fut on the breaking bit and force the most thorough submission to the slightest restraint of the reins.

let this be very thoroughly done. Then hitch to wagon, making the horse stop whenever called upon or pulled upon by the reins, until there is no disposition to resist, though subjected to the greatest excitement, as there is once in a while a horse that will try with all the courage and pluck of clesperation to run away after once learning the habit, and it is so important that the greatest docility and submission of the animal is in this position secured by the control of the bit. I will allude more especially to the details necessary to success. After the animal submits to the primary course of subjection and control by the bit is attempted, 
work slow. Let the horse move on a slow walk at first. Call whoa sharply and instantly after surge with the quickness and energy of the crack of a whip, with the reins upon the mouth; repeating and increasing the speed of the animal as there is submission, making one point after another, until the animal can be put on a run and will stop instantly at command. Even then you are not to feel too sure of having accomplished your purpose. Test carefully when cool, and assure yourself of the most perfect submission and docility before incurring any risk. This is really the important point in assuring of success, not only in the breaking of horses of this character but in all others of a bad character. Some horses subject to this habit will yield readily to the use of the four ring bit. The foot-strap is also a valuable auxiliary, but the breaking bit is in advance of anything else in doing this.

\section{TURNING AROUND.}

If the horse turns around, drive first with harness, whip up sharply, then make him stop, always pulling in the opposite direction from that the horse usually turns, until there is not only the most prompt obedience to the commands in going ahead, but ready submission to control, right or left, or in stopping, as may be required. Sometimes the habit is contracted of pulling so hard on the bit as to resist control. In this case all that is necessary to do is to train the mouth once or twice with breaking bit, or use the four ring bit, and the habit will be broken up. If one rein is pulled upon, pull sharply on the opposite rein, and repeating at each indication of such a purpose until the head is yielded freely and evenly.

In reviewing the common causes of this habit, we see that two objects must govern the efforts. First: To overcome or neutralize the exciting cause of resistance-usually some cause of fear. Second: To make the mouth perfectly submissive to the most delicate restraint of the bit; it being essential that the exciting cause should be removed, while the power to control resistance must be increased.

I will in this connection add, that there is no part of the training of horses which should be done more thoroughly, or tested mor a carefully, than this of teaching proper 
submission of the mouth to the bit. Yet I will venture to assert none is more imperfectly or ignorantly attenpted; and that the more experienced and intelligent horsemen should regard doing this difficult, when there is so much to indicate to the most ordinary observer the method of doing it with ease and certainty, seems strange. And yet, perhaps, this is not so strange, since it has been very much of a puzzle to do this at all, and really in its true aspect shows more real science than can be illustrated by any other feature of my treatment, since upon this must depend ultimately the readiness and success with which horses can be guided and controlled in harness.

It is essential in training a horse well to the bit, that the idea is given correctly of submitting the.head up and back when pulled upon. Also, that the horse should be made to understand exactly the meaning of every signal of guidance and restraint. In training the mouth, the exact idea can be conveyed by being particular in repeating the same kind of reproof, by pulling sharply whenever there is an attempt at pulling hard. There is soon not only prompt obedience to restraint of the bit, but there is no disposition or confidence to resist control. Remember a horse cannot understand the object of such restrant, if there is not uniformity of action and language. Yet most people talk to their horses in the most careless manner. If there is an intention of approaching a horse, the usual word is "whoa!" In driving, when it is desired to make the horse go slow, "whoa" is the usual word, and the consequence is the animal does not know what is meant by "whoa." Every action and word should have a special meaning, and they should never conflict, that the understanding may not be confused. "Whoa" should be an imperative command to stop. To go slower requires the use of some other word. Even every motion of the whip should have a special meaning. If the horse is managed with care in this way, he becomes almost a machine, that yields submission to the slightest touch or word of command.

RUNNING BACK.

To break up this habit, there must be established a thorough fear of the whip), so as to induce going ahead when 
commanded. Put on harness, and tie the tugs into the rings of the breeching rather short. Drive around with the reins, giving a short cut with a good bow whip around the legs once in a while, if not prompt. As the horse learns to spring ahead when commanded, pull a little on the lines, gradually repeating until he will pull quite hard on the bit to go ahead. Niake this as thorough as possible. In driving repeat and carry out this, going ahead promptly, whipping up sharply once in a while if necessary.

The main point to make with horses of this character, is to create a thorough fear of the whip. To do this well while driving with harness, whip around the hind legs sharply, until the horse will start ahead promptly when commanded. Now, attach to wagon and gradually work up with whip until there is prompt obedience. The foot strap may be put on if there is any possible danger of the horse running back when hitched.

\section{KICKING IN HARNESS.}

This is apparently the most dangerous and difficult habit to overcome, to which horses are subject; yet it is a habit that yields readily to my treatment, but requires care and thoroughness and a large share of common sense in determining how much must be done and when to stop. This cannot be learned by any fixed rule, since there is such a great difference of extremes shown in this habit that it is not safe to venture a limit of what and how much must be rone. I have often broken horses of kicking, of apparently the worst character, in twenty or thirty minutes. Then again, one scarcely confirmed in the habit may require very much more time; and a few extreme cases, of apparently a mild character when not excited, would call out all my resources for hours, to make the subject yield safely to control. I broke a horse in Maine of the worst character, of kicking, by a few pulls upon the war bridle. At all events, the owner informed me, months afterwards, that the animal remained perfectly docile. This horse would kick at any body or anything.

But I found a horse in Mississippi, which was perfectly gentle to ride or handle, would only kick when to wagon, yet he was the most terribly persistent kicker when in harness 
I ever saw, or ever expect to see. All ordinary treatment was only as play to this horse. Circumstances made it necessary to break up the habit, and I felt compelled to do so, and succeeded only after three lessons. Never did a horse resist more bravely, but I succeeded in making the animal so gentle as to submit the wagon against the heels going down hill, and he was driven by me a week after being broken, in the presence of a large concourse of people, proving safe and gentle afterwards.

Breaking of kicking, as with most other habits, requires thoroughness in what is attempted. If there is more fear than willfulness, the fear must be thoroughly overcome. If based upon willfulness, that must be mastered at any hazard. In either case, put through a careful but thorough course of subjection, exciting resistance by rubbing a stick of some kind against and between the legs until there is no resistance; now put on harness and breaking bit, and compel perfect submission to its restraint. Let the hind legs be touched as before, and at each indication of resistance, punish sharply; with the reins back the animal against a rail fence or anything convenient. If there is perfect submission, back into the shafts of the wagon, or bring the shafts over the back gently. This is a step requiring much caution and firmness. Stand at the left shoulder, grasping the rein near the bit firmly, and as the shafts are brought forward, and the cross-piece comes in contact with the legs, if there is much sensitiveness shown, give him a sharp, quick jerk upon the reins, which will at once disconcert the horse, and at the same time throw the head so high as to make it difficult for him to kick. Force this point well, until the contact of the wagon is borne, when the harness may be attached. Now drive around gently, stopping and starting repeatedly, carefully observing how much forcing the horse will bear. If there is no indication of serious resistance, follow up by driving around, until there is perfect submission. At each repetition of being hitched to a wagon for a few days, let the horse be backed against the cross-piece several times until it is borne without flinching.

This precaution of testing repeatedly is absolutely essential to prevent and overcome any growing sensibility or confidence of ability to kick when driven, until there is not discovered any disposition to indulge in the habit. 
If this will not do, repeat the lesson of subjection which the reader has been shown, and if there is any doubt about submitting to the shafts without danger of an accident, get TWO POLES about twelve feet each in length; lay them down on the ground so that the small ends will be about twenty-two inches apart, and the large ends are six or seven feet apart. Next get a piece of pole of the same size, lay across and tie firmly to the side poles just far enough from the forward ends so when the horse is hitched in the tugs are tied to this crosspiece with pieces of cord. Hitch to this without holdbacks, and drive around, repeatedly stop)ping and backing the horse against the cross-piece until there is perfect submission. This driving in poles may be repeated if thought necessary, remembering that it is absolutely necessary to make every step sure before the next is attempted.

A great advantage of repeating the lesson is, that the sensibility of the mouth is so greatly increased that the most plucky horse will scarcely dare resist the bit after being severely punished a few times. If the horse yields, but is doubtful or appears touchy and sensitive once in a while, you may be able to make your point by putting on the FOOT STRAP, which is an excellent means of controlling a doubtful horse, in making this step.

This is simply disabling and controlling one of the fore feet, by a strap which is passed over the belly-band and back to the wagon as a third"rein. Simply pulling upon this at the instant there is an attempt to kick, throws the horse off his balance and disables him from doing so. It must be borne in mind that much depends in making subjection thorough; no mat-

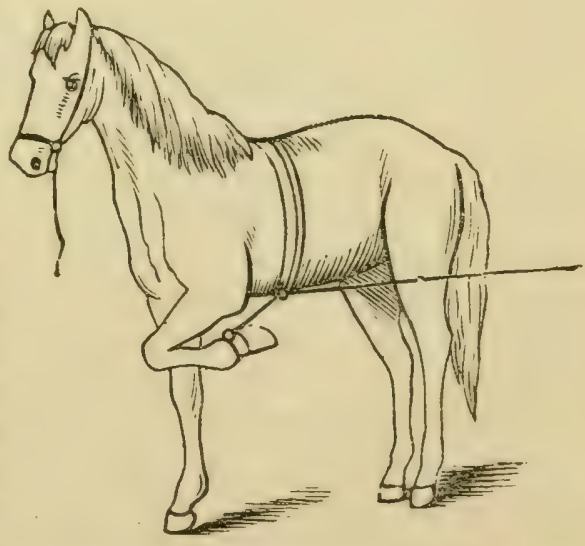
ter how good or proper the treatment, the horse must be made to yield unconditionally, or failure is not only probable but almost certain. 
Kicking straps if properly put on, are powe ful means of reproof upon the kicker. I have had excelient success with this means years ago. They will not work well on a slow determined horse, and in any event should be kept on until all desposition to resist is overcome.

\section{KICKING STRAPS.}

Have made four straps, like common hame straps; two long enough to buckle around the hind legs above the gambrels, and two a little shorter, so as to be in proportion. to buckle around just below the gambrel. The straps should be an inch and a quarter wide, good thick leather, and the buckles should be heavy. Now have made two D's, just twice as long as the straps are wide. This D should have the straight part a little rounding, and the corners not quite to a sharp point. Put

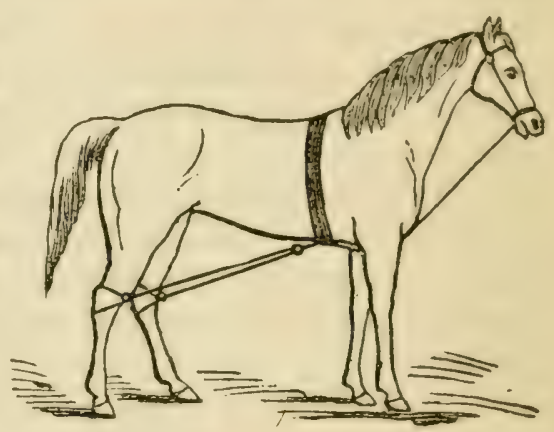
a long and short strap on each D, and buckle them around the hind legs of the horse; the long strap above and the short one below the gambrel, bringing the $\mathrm{D}$ in front of the leg. These we designate KICKING STRAPS.

Put a strong well-fitting rope halter on the head, tie a strong two-inch ring on the end of the hitching part, which should be of a length to extend between the fore-legs, over and just back of the belly band. Then take a piece of strong manilla rope, long enough to extend from the ring on the end of the halter back to each hind leg. Pass the end of this through the ring to the center, and tie each end carefully into the D's on the straps, the whole so arranged in length that the horse can travel easily and naturally. Now as soon as the horse kicks, the most severe punishment must result upon the nose. If the horse is sulky the connection may be made direct to the bit; there is however danger if the horse kicks recklessly, if so attached, of greatly bruising the mouth, or of even breaking the jaw; have known too such results from this cause, hence I have dis. 
carded it. No quarter is to be given until there is perfect submission. The harness may be put on after the horse ceases kicking, and drive around as before. These straps should be kept on until there is no disposition to kick.

If the mouth is hard, use breaking bit and force as before, with the reins, until there is perfect submission. The horse is to be treated with the utmost kindness when he yields. Bear in mind this rule must not be disregarded, of addressing and winning the coöperation of the affections as soon as there is submission. The foot strap may be used as a precaution when hitched to wagon, until submission is made sure.

If the mouth is naturally sensitive, and the horse is docile but quick and irritable, a different policy must be adopted, as the horse may drive gently for hours, or even days, and yet may kick at a real or fancied cause of annoyance. This mode of treatment would not work well with such, as they soon become cautious by throwing the head down when there is such an intention, and there is not persistence enough to make reproof sufficiently positive to cure the habit.

The OVERDRAw CHECK will now work well. But care must be taken to apply it right, or there will be cause for disappointment in its use. The object is now to simply disable the horse from his purpose at the least attempt to kick, which we can easily do, especially while in single harness. Probably the best way to do this is as follows:

Get a small steel bit and hang it loosely above the driving bit in the bridle. Put the bridle on the head; now provide yourself with a fine, strong piece of hemp or cotton cord, about three-eighths of an inch in diameter, and sixteen feet in length. That kept at hardware stores for hanging windows, will do. Put the center of this cord back of the ears, run the ends back through the rings of the small bit and through the gag runners, which should be close up to the ears. (See cut.) Pass them now through the terrets and back through a ring, which must be attached as far back upon the crouper as possible, and attach the ends to the shafts on each side of the hips. At first this check should be drawn short, to bring the head as high as the horse can bear. The head is now not only high, but the least effort to kick will thwart itself by drawing the check tighter, 
thereby preventing the horse from doing any mischief. As there is manifested less disposition to kick, give more free-

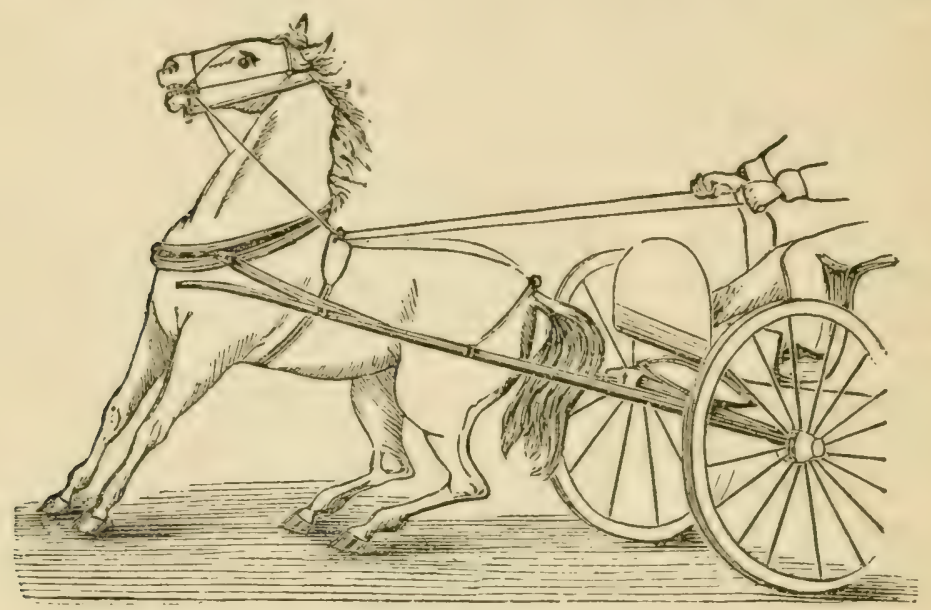

Over draw Check for Kickers.

dom to the head. When the animal proves safe, change and use the common check rein, at first rather short. A nicely rounded strap may be used instead of the cord. It requires very careful and thorough treatment to reform a slow, reckless kicker, especially if the nervous system is much weakened in this direction. I have the best success by the second and third methods of subjection in conjunction with the control of the mouth, and unless you cannot make your point by this treatment, your success will be doubtful. OLD SQUEALERS of this character are to be discarded. I know there are so few who will be necessarily thorough in carrying out obedience, and treating afterwards with prudence and kindness requisite, that I do not wish to encourage success in making such safe and gentle. It is seen I can drive any such in a few minutes. The same treatment will enable breaking up the habit if applied with care and thoroughness.

Look first for the cause of resistance, second for the type of disposition, and try to make the treatment such as will prevent and overcome the habit in the most direct and positive manner, always striving to be cool and careful. Treat the horse kindly, as soon as there is submission. 


\section{KICKING WHILE HARNESSING.}

Put on the war bridle (small loop,) and work up with it sharply right and left a few times, then pull down tight, and tie into a half hitch. While holding the cord in the left hand, step back and pass the hand from the shoulders to the hind parts gently. If this is borne, take the harness in the right hand and work it back gently over the back. As this is borne, untie the cord and tie down, so as to give the mouth a little more freedom. Now go back and handle as before, being careful to be gentle; if there is resistance, punish sharply, tie down short again, and put the harness on. When there is submission, untie, then work back as before; at the least indication of resistance, tremble on the cord until the horse will bear the harness while free from restraint.

\section{KICKING WHILE GROOMING.}

Some horses are so thin skinned that they can scarcely bear a currycomb on the flanks or legs, and when excited by rough treatment and too severe use of the currycomb, are easily made vicious to handle or groom. Put on the war bridle, and after working up with it, hold tightly, and with the left hand use the currycomb on the back, gradually working to the sensitive part; as there is submission, give a little more freedom to the mouth, and work back lightly. If the horse seems unable to bear the currycomb, use the brush instead, and that, if necessary, lightly. Work lightly and indirectly to the sensitive part, at the same time speaking gently. It is almost impossible to overcome this habit if there is not gentleness and kind treatment.

The currycomb is used too much by most grooms. A sharp toothed, brass currycomb, must not be used on a thin skinned horse; use a brush. I should want a horse to kick a man out of the stall who would use a currycomb with needless severity, or be otherwise needlessly harsh.

\section{KICKING WHILE SHOEING.}

Some horses have a peculiar aversion to having their feet hanclled, and if once aroused to resistance, from any cause, are apt to become pretty determined in the habit. If the 
foot is pulled away when taken up, or the horse is excited and injured in some way while the foot is held, fear of injury is produced and associated with the requirement, which, by the usual pulling, hauling and kicking practices of the shop, makes the horse worse. The least indication of ability to resist control of the foot, inspires to greater resistance, hence, the horse by persistence in such a course is confirmed in the habit. If only a little irritable and restless at being shod, put on the war bridle, draw tight, and tie in a half hitch. The foot can now be handled. Untie in a few minutes, and let the cord be pulled upon a little when (iisposed to resist, which will distract the attention and cause submission. If the resistance is determined, take up the fore foot and have it held by an assistant; tie the end of the long web around the hind foot above the fetlock. 'This done, request the assistant to let go the foot and hold by the head; while standing opposite the shoulder, pull upon the strap until the foot is brought well forward, giving loose the instant there is an effort to jerk or kick. Repeat pulling and letting go, until submitted freely. Now step directly behind and pull back, giving, as before, until submissive; then bring the web over the back around across the breast, pulling short enough to bring the foot well forward; pass the end back under the part over the back, and pull tight.

Let the assistant now grasp the web, holding firmly as ever, with the left hand holding the head by the bridle. This brings the leg forward, where it can be handled at will. If this will not do, tie the end of the web or rope around the neck, near the shoulders, in the form of a running noose; pass the other end back between the fore legs, around the hind leg, below the fetlock and back through the loop, around the neck, drawing it through short enough to bring the foot well forward. Pass the end back under to prevent slidirg, and retain in the hand. The horse will now be very likely to struggle to get the foot loose. Should his resistance be so great as to endanger injury, you can give loose on the end of the rope. When the horse ceases trying to get the foot loose, rest the left hand upon the hip, with the right pull upon the foot forward and outward. If there is great resistance, pull around by the head, which will enable you to keep him in such limits as you wish. 
When the struggle ceases, go back and handle as before. When the foot is submitted to the hand, while held to the restraint of the rope, put the cord well back upon the neck, draw it down tightly, and tie it into a half hitch. Then pull upon the foot with the hand as before. If not resisted, untie the strap and take the foot in hand gently. Put it down and take it up, rubbing and handling until there is entire submission. Then carry it back with the right hand, keeping well forward out of danger, by resting the left hand upon the hip, and pulling and yielding to the foot until manageable. Now pass the left hand down the inside of the leg, take it from the right and carry it back gently; put it down and take it up once or twice. Harnmer upon it lightly, gradually increasing, until the foot is submitted as required. Now untie the cord and tie it a little longer; go back and handle the foot as before. If submitted, untie the cord, holding the end in the left hand, and handle as before. If there is an intimation of resistance, tremble on the cord, which will keep attention on the mouth, and remind of the previous control until the foot is submitted without restraint. Manage the other hind foot in the same manner, if necessary. If the horse is very bad to shoe he must be subjected to the regular treatment for direct subjection, and the smith shop is no place for this. Such horses should be first handled at home until thoroughly submissive, when simple treatment will enable easily forcing the animal to stand quietly to be shod. Horses of this class, rank with the very worst, and should be at once subjected to the most positive means of subjection. Passive treatment will enable control very easily, but must be used with care. 'The feet of such horses should be taken up and pounded upon repeatedly in the stable, until submission becomes habitual. When taken to the shop, if necessary, simply remind that submission must be yielded, and treat gently-caressing and rubbing head and neck the way the hair lies. Colts should not be taken to a shop to be shod until accustomed to have the feet handled. 


\section{BALKING.}

'This habit is usually caused by confusing and overloarling, or trying to force too much by whipping when exhausted, or when the draught from some cause becomes too great for the horse to manage, thereby exciting and discouraging the horse before able to settle down to a steady, determined pull. When a horse, and especially a young one, becomes mad, and will not pull when commanded, there should not be a word or an action that would betray an understanding of the resistance. Change position-take up time in some way by fixing the harness or walking around, whistling or singing, if in the mood. There must not be any appearance of anger. Give the horse time to get over the irritation and become willing to use his strength against the collar. Any characteristic of willfulness denotes sijirit and sensibility, consequently not disposed to submit to being rudely and injudiciously forced in harness. If double, get both horses to start evenly. This can be done best, and greatly lessen the weight of the load in starting, by standing directly in front of both horses, catching the bits with the hands. Now move the horses gently to the right or left, until the wheel almost strikes the side of the wagon-giving them time to become steady. When you see they are ready, speak with cheerful, encouraging voice, "come boys." If this precaution is taken, there will be no further trouble; but bear in mind that the horses must not now be permitted to go to the limit of their strength. When they are still pulling with energy, at the first favorable place stop them. After ample time to recuperate, speak to them gently to go. It seems to be natural for a horse to go ahead and draw all he can, and it is only when confused, excited and abused in the most unreasonable and imprudent manner, that the disposition is excited to balk. When once the habit is acquired, it is liable at any moment to be persisted in if excited or much force is used.

If there is any treatment to which horses are subject in educating to harness that is unreasonable and needlessly harsh, and should be corrected, it is that of pounding of whipping to make them go, when perhaps the animals are confused and discouraged, and not in a condition to malie much of an effort. 
The principal cause of this habit is harnessing horses and attempting to drive them, and make them draw heavy loads, before they can know what is requirer of them, or learn to use their strength in pulling.

The whip is too irritating, without giving sufficient power to force obedience, and as the will is stimulated to increased positiveness and sensibility is blunted in proportion to the degree the blood is warmed, this advantage of force by the whip decreases, while the resistance is increased, and hence is often a direct cause of failure.

If the whip is to be depended upon, the horse should be driven around in harness only, when it should be made to crack keenly around the hind legs the instant after "get up.' is spoken, until the horse learns to spring ahead when commanded. When there is perfect obedience, attach to the wagon and move gently, stopping and starting often, until obedience becomes habitual. To prevent this habit the colt should be driveu around in harness, touching up with the whip, until the idea of starting at the touch of the whip, and guiding and submitting to the bit, becomes prompt and habitual. Then drive slowly and gently for some time after being attached to the wagon.

If the habit is formed, and especially in single harness, it is usually more from resistance to the bit than collar, and if the horse is young he will yield readily to simple treatment. Put through the second course of subjection. Then put on harness. Drive around, whipping sharply the instant the horse does not start when commanded, guiding right and left, and stopping at the control of the bit. If there is a habit of LUNGING AHEAD, regardless of the bit, or of not standing as desired when hitched, be positive and thorough in requiring instant obedience to the command whoa, which can be easily done with breaking bit. Drive around unti\} there is perfect obedience. Then hitch to wagon, gently start and stop the horse repeatedly, until the obedience is made certain. The lesson of driving to harness should be repeated, if there is any disposition to resist. 'The war bridle will enable working an ordinary balker very easily First, make follow promptly with harness on, when the horse will soon yield to it in harness. There must be kindness and flattery for every art of obedience. Talk kindly, give apples, oats, or anything the horse likes. 


\section{EFEECT OF KINDNESS.}

The impression of kind treatment, gradually showing and encouraging the animal to yield obedience, is certainly very effective, when carried out well in practice. During my early experience I traded horses very often. In this way I became the owner of a pony mare, eight years old. She proved balky, and on inquiry I learned that she had been traded round for years, and had been owned by nearly all the sharp jockeys in the country, being entirely unmanageable. She would neither go down hill or move on a level in harness. Neighbors advised me to prosecute for being imposed upon with such a good-for-nothing animal. Making it a rule not to find fault if cheated, I declared myself satisfied, and concluded to try what I could do with her. I first filled my pockets with apples, led the mare to a secluded piece of smooth, slightly descending road, hauling the buggy by hand; hitched her to the buggy, but did not urge her to go; read a paper the better to show indifference.

After a while she started on a run. To try to make her go slow by pulling, would be equivalent to making her stop, and so let her go until she wore off the sharp edge of her ambition. I now gradually pulled her back, as I could see she would bear, when I reached a descending piece of ground, made her stop, got out of the wagon, talked gently, gave her an apple, then moved forward a little, saying "come Jennie," (her name,) gave her another apple, rubbing her head, as before, and so repeated, for about half an hour. Then would get into the buggy and make her start; after going a few feet or rods making her stop, but always getting out and rewarding her with an apple. The result was, that Jennie soon not only would start and stop when commanded, but became anxious to obey me. Drove her home; treated her with the utmost kindness; next day hitched her up gently; made her start and stop a few times before getting into the buggy; got into the buggy; soon made her stop, but rewarded her as before. The result was that I soon could depend upon her starting and stopping when commanded. Of course I carried this treatment from a descending to an ascending grade, teaching the mare gradually to use her strength. The result was that she be rame one of the most willing and pleasant little working 
animals I ever owned. Sold her in a few weeks. She became the property of a rough, bad man to horses, who, by needless abuse, marle her balk on his way home, and she became spoiled. This mare was of a sanguine nervous temperament, naturally willing to do all she could when shown and treated kindly, but would not bear whipping and abuse. Her will was so strong that she would stand bravely, regardless of the most severe whipping. I struck her with the whip but once, when she threw herself down in the harness. There cannot be too much care and patience with young horses that are learning to drive. If a little stubborn, putting through a short course of subjection and teaching to move forward, as before explained, will soon produce perfect submission. If, however, the habit is thoroughly formed, it must be counteracted by direct means. To do this best, hitch the balker by the side of a gentle horse. Attach a strong piece of cord in the form of a crouper, under the tail of the balker, bring forward through the terret and tie to the hame ring of the gentle horse, just short enough to give freedom so long as the horses are even, but the instant there is a disposition to refuse, the whole power of the gentle horse is brought to bear upon the tail, which will cause the horse to jump forward instantly. Stop and start repeatedly, until there is no disposition to refuse moving forward when commanded. Should pulling on the tail irritate and cause kicking, at once remove the cord; tie the end of the hair into a knot; tie the cord to the hair by this knot; bring forward between the legs and attach the cord to the hame ring or collar of the gentle horse, as before. The restraint is now on the tail lengthwise, which has a remarkably disconcerting influence, with great power to force the horse forward when the gentle horse starts. If this should fail, there is but one resource left, which I can here describe, but which is very effective and valuable if properly applied.

Put the war bridle on; bring the part over the neck forward to the ears; now jerk sidewise and ahead, and finally ahead as there is submission, until there is prompt obedience in coming ahead when pulled upon. Hitch to wagon by the side of a true horse. Have prepared a smooth stiff pole about the length of the wagon tongue. Bore a hole a few inches from the large end, and about a foot or more for- 
ward of the head bore another. Lay this pole over that of the wagon, the end uver that of the true horse's whiffletree, and tie firmly on top with a piece of cord. Now step for.

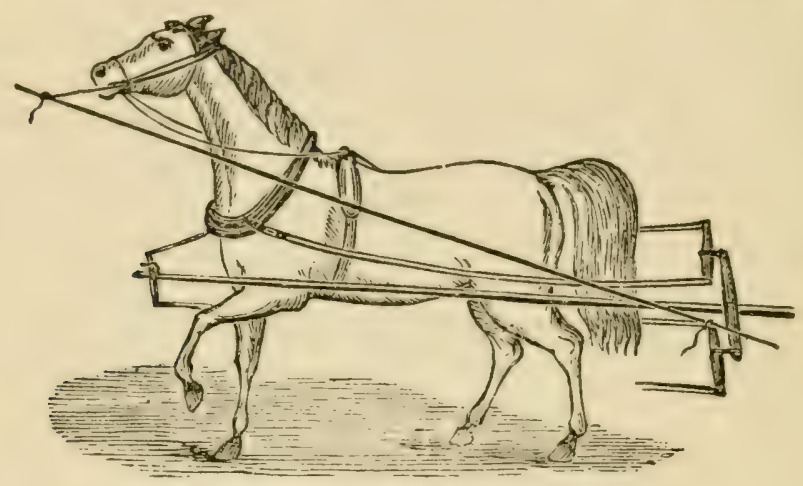

Pole applied to Balker.

fard and tie a piece of small rope from one hame ring to the other of the horses, under the pole, so as to be just taut when in position. Pass another piece of the same sized cord around the pole and tie it into the true horse's hame ring short enough to hold the pole in the center. Tie the cord on the head now to the pole through the hole, just long enough to give freedom, so long as the horses keep even; but as soon as there is refusal to go, the strength of the true horse is brought by the pole on the head, which will compel going ahead, (see cut.) Start and stop the horses often, until obedience is secured. This pole may be used so long as there is any disposition to balk.

The horse should not be required at first to use much strength in drawing. Let this be required gradually, as there is obedience and willingness inspired to work. It is a grave fault to try to make the horse work immediately This must not be attempted. First, create a willingness to start when commanded, then gradually increase the load until it becomes habitual to draw when commanded. I am aware very many will have much trouble, and may wholly fail with horses of this character. It is presumed that there is tact and intelligence enough to appreciate and understand the necessity of being patient, prudent and thorough in zlapting the efforts skillfully. Those who will not have or have not mind enough to feel the responsibility and value 
of being governed by reason in the treatment of habits, not only of this type but of any other, must expect a possibility of failure with some very bad horses.

A very good way to work a single balker is to drive first by the side of a gentle horse with the pole, then hitch to single wagon, using two small poles instead of reins to the hit. Now, if the horse does not move promptly when commanded, a little push on the poles will cause him to start, and soon cause prompt obedience. But I would remind again that patience, delicacy and skill in carrying out the principles taught, are the primary and grand essentials to insure success. I would therefore remind, that great firmness, skill and patience should be used in directing and controlling the efforts, since without a judicious application of the efforts the advantages may be so far neutralized as to prevent or greatly diminish success.

\section{KICKING IN THE STALL.}

This is one of those habits that require great caution, judgment and care in guarding against danger. Let the horse know by some signal or command, of your presence and intention to approach. Many horses of the gentlest character would kick if approached suddenly and unexpectedly; and again, many horses that are gentle but a little peevish, will not bear being approached without a little care in attracting attention. The motion of the ears and lips, and expression of the eye, will always notify of danger. And here let me warn the reader that however careful he may be in not going too near the horse, there must not be a semblance of fear shown in language or actions. The commands must be low and positive, indicating power. If the horse will not move round and seem to be distracted from a positive intention, stand still, and if the animal does not yield, walk off, carelessly whistling, in such a way that the horse does not see that you feel defeated.

If you have his attention, repeat the words "get around, or over," with a positiveness that must be obeyed, looking at the eye as if you could and would overcome all opposition. When you see the horse shrink from your gaze, glide up to the shoulder, before the mind can be made to act, and the next instant let the left hand be passed along the neck 
and down the head to the nose piece of the halter, and you are safe, as the horse cannot now kick, strike or bite you. I have repeatedly got tc the shoulder of horses in this way that would kick and strike the stall just after I passed, yet not be struck; it is a feat, however, that must not be attempted unless necessary. In going out, the rule is the same-pull the head towards you, looking at the eye sternly; this will throw the quarters from you, and at the instant you let go, glide out and you are safe.

If the horse is very dangerous, the best and safest course is subjective treatment, following up witl the war bridle, sharply until mindful of your commands, or if you wish to work dead sure, leave the war bridle on. Lead the animal into the stall, then step back opposite the hips and say, "get around." If there is not prompt obedience, give a sharp jerk, which will throw the hind part from you. Repeat this, and in a short time the horse will learn to step around promptly when commanded, and allow being approached. If the horse is persistent, leave the cord on, the small loop being left larger and passed through the rings of the halter. As you now step out, retain the cord in the hand and hang or tie the end to a nail on the post, leaving sufficient length to permit the horse entire freedom to the halter. Now when you desire to go into the stall, if the horse does not step around when commanded, untie or unhook the end of the cord and give a jerk upon it, which will bring the animal to his senses. Leaving this on a few days, caressing and giving presents of sugar, apples, or anything of which the horse is fond, will soon not only break up the confidence, but so enlist the attention that your approach will be looked for, and eagerly invited to him by stepping around, and endeavoring to reach toward you for the present.

I would here observe that there are very many men who are not fit to have anything to do with a sensitive, well-bred horse. They are either so coarse and harsh as to excite resentment, and hate. or so dull and ignorant that they cannot or will not see that they must both conceal fear and avoid danger. They will not do either. 'They abuse and show so much fuar as both to excite and encourage resistance, and without the genius or tact to correct the cause of mischief they attribute all the trouble to the natural viciousness of the animal. 
Sensitive horses should not be teased in the stali, or while cleaning, by pinching, pricking or whipping, to "show off," as the term is. Gentlemen who own fine horses should be very particular about this, and a man who would in any way persist in such treatment, should be kicked out the stable.

\section{PULLING ON THE HALTER.}

It is the disposition of the horse to persist in what he learns, and this is remarkably so where the habit is one of resistance to the restraint of the halter or bit. If the halter strap is broken once or twice, there is a determined purpose to pull loose at all hazards when hitched. This is sometimes only in the place the habit has been learned. Thus a horse learns to pull loose in the stall-he will resist being hitched in stall, but will submit to be hitched anywhere else; or the horse has learned to pull loose in the street and resists there, but will submit and not pull in the stall. 'This habit is taught either by being tied by the halter before knowing or being taught to submit to being tied, or accidentally breaking the tying strap. If from the first cause the animal becomes frightened, pulls, and if successful in breaking loose, the habit is established; or the halter strap is so weak that the least jerk upon it causes it to break, the habit becomes fixed.

Put on the war bridle, and trair the horse about until he will come to you readily. Now bring the part over the neck forward to the ears, and pull more on a line with the body, repeating until there is prompt obedience to the least pull forward. Wind the cord once around a post, keeping the end in the hand, so as to let it loose a little if necessary. Excite the horse to pull a little, which he will soon fear to do, as there is great pain induced by the purchase of the war bridle in this way. Repeat until he will stand, and let the whip or any other means of excitement be used, without trying to pull.

Should this fail, try the following method:

Get a strong half-inch cord twenty-two feet in length; put the center under the tail like a crouper; twist them a few times as you bring them forward over the back; pass forward on each sic'e of the body, knot them across the 
breast, then pass them forward through the halter below the jaw. Tie firmly as you would a halter, to manger or post ; excite by any means that will make the horse pull until the

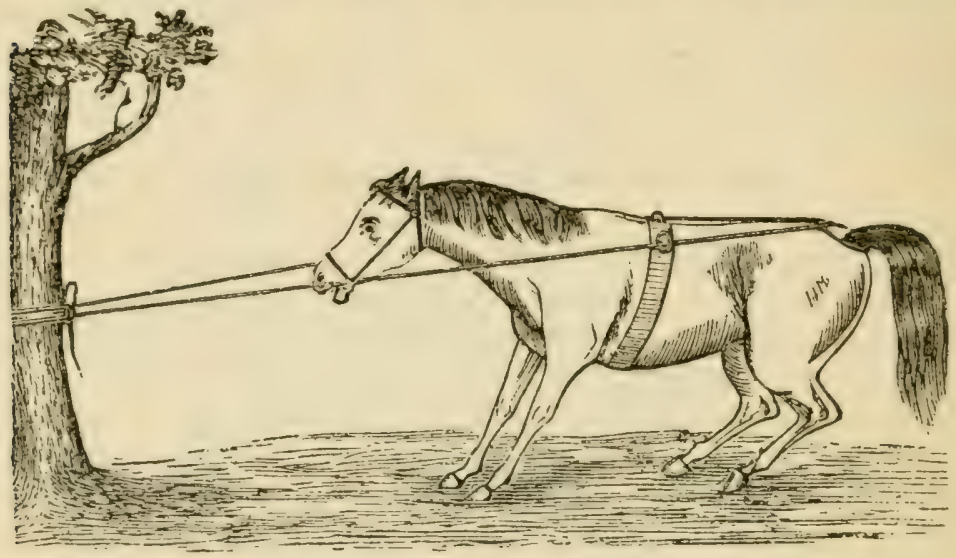

Treating a Halter Puller.

habit is overcome. I whip across the nose keenly, until there is perfect submission, when I can soon make even a bad one stand up without attempting to pull. To insure safety, would hitch so for a few days, or so long as there is any jredisposition to pull on the halter. Same treatment for pulling on the bridle.

\section{BITING AND STRIKING.}

There are many habits which to break up successfully refuire not only good judgment but the highest order of nerve, and this is not only one of that class, but one that requires perseverance and caution. The least want of watchfulness will encourage this propensity; and however thorough the training, if there is not this care, the horse will be encouraged to become aggressive, and once allowed to do so successfully the point gained is lost. Hence the necessity of being able to see the intention at a glance, and risconcert the mind from its purpose before being fully leveloped. The horse must be made to yield the most jerfect submission, (by the first or second methods of -ubjection.) If a stallion this is an absolute necessity. Follow up with the war bridle, punishing sharply. In ap- 
proaching afterwards, speak sharply "get round!" or any signal that will attract attention. Let the left hand be put on the shoulder, (near side,) glide it up the neck to the head, then down to the nose piece of the halter. If there is an attempt to bite now, the hand is carried up before the head and held out of reach, while you can keep the head from you with the greatest ease.

An old horse subject to this habit must be watched closely. So long as there is disposition to bite, the horse must not be regarded safe. Carelessness and timidity, especially if subjected to harsh treatment, may be regarded as the primary cause. I have known horses to beconic inveterate biters by being whipped once or twice.

A gentleman informed me lately that a horse he formerl! owned became terribly vicious by being struck once with whip in stall. He was, up to that time, as gentle as any horse could be. Mr. Roberts' horse, a notice of which I include in referring to my treatment in the first chapter - from the Utica Herald. This horse had been of a very docile character. A rough, drunken groom, who was employed to take care of him, by irritating and abusing the horse got him vicious. Mr. Roberts now took him in hand; one day while in harness the horse acted a little stubborn and vicious; Mr. Roberts struck him with the whip, when instantly the horse struck and bit him, knocking him senseless under his feet, and would have killed him if not driven off by two men, who happened at the time close by. $\mathrm{He}$ had run in his stall seven months, and would jump at any one with the ferocity of a desperate dog. As was stated, I took him in hand and made him gentle in less than twenty minutes, and he remained of a good character afterwards. If the horse is young and thoroughly treated, there will be but little trouble in reforming the animal. If old and bad there is no hope of success, unless there is unusual nerve, and genius to make every move just right, and follow up the treatment until the mind relaxes from the purpose, and the affections are won. The habit is clearly a mania when once thoroughly formed.

If the horse is allowed to bite without instant and positive reproof, after training, no matter how thoroughly the training, the predisposition will be again so strongly developed as to make the anımal watch for an opportunity to 
bite. After forcing obedience, encourage every act of do. cility. Be continually on the watch for danger and punish energetically for aggression, but immediately encourage obedience by kind, affectionate treatment.

\section{CRIBBING.}

Cribbing, so far as we are able to learn or judge, is a habit. There may be constitutionally predisposing causes, but it is certain, whatever the pretentions of any one, I have never been given any proof of ability to break up the habit with medicine. Horses will not crib on anything that is lower than the knees. Hence the treatment of tearing away the manger and feeding on the floor, or in a basket. Sometimes sawing between the teeth will stop the habit.

There is but one practical plan of breaking up this habit, and the success of that will depend very much upon the skill displayed in making the adjustment.

The act of cribbing induces considerable contraction of the muscles of the neck, and the larynx is forced down much beyond its natural position. This then is the key through which we must act. Have the throat-latch of the halter hang on a line with the top of the head to the junction of the neck with the head. Take a piece of strap, (good firm leather,) about five inches in length, and as wide as the throat-latch. Drive ten ounce tacks in a row along the center of this strap, three-eighths of an inch apart. File the points sharp and of an equal length. Lay this strap on the inside of the throat-latch where it crosses the larynx, wind a piece of waxed thread around both, at the center and ends of the short strap. Buckle the throat-latch just long enough so that it will not touch the neck when eating or drinking, but will press sharply at the least attempt to crib. The result is that at every attempt to crib the tacks will stick into the neck, which will hurt and disconcert the horse from doing so.

The point of success will really depend upon the perfection and care with which this is kept adjusted. If there is large muscular development on the neck or thick necked, the strap must be buckled shorter than when the neck is well cut out, as it is termed. Make the reproof severe at 
first. Then keep it so as to touch sharply when a repetition is attempted. If the throat-latch is not on a line with the top of the head, the tacks will rest against and cut the jaw, a little below the junction of the head with the neck. If this is kept on a few days or weeks, and then put on carelessly or taken off, there is likely to be failure; for if the horse finds he can crib once after this is put on without hurting himself, he will try to repeat the effort at all hazards, and will punish himself severely to do so. But if punished at first and this kept where it will sting at the least attempt, it will be likely to cure the habit. It is to be kept on from a few weeks to as many months, according to the age and persistence of the habit.

\section{GETTING CAST IN STALL.}

Drive a staple into a beam, or the floor directly over the horse's head, as he stands in the stall, to which attach a strap or piece of small rope of sufficient length to extend within fifteen inches of the floor. Before retiring for the night, attach the other end of the cord or strap to the top? of the halter, making it just long enough to allow the horse to put his nose to the floor. Being now unable to get the top of his head to the floor, he is prevented from rolling.

\section{PUTTING THE TONGUE OUT OF THE MOUTH.}

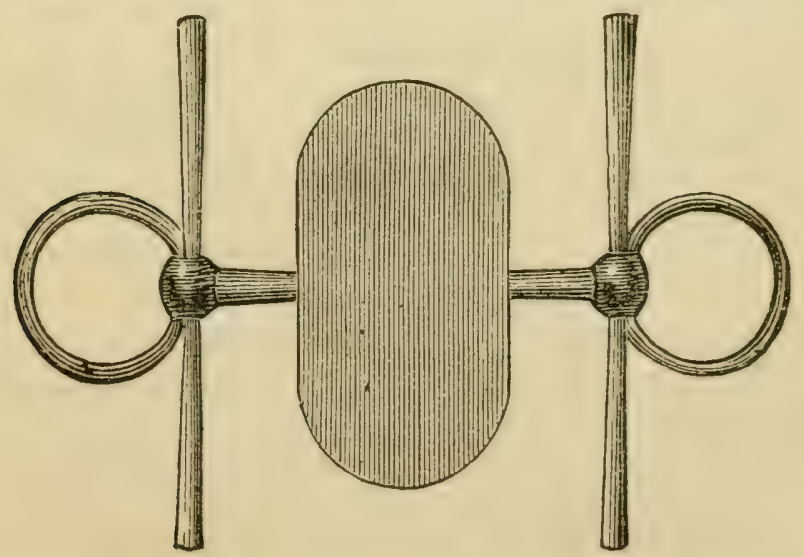

Have fitted a piece of thin sheet iron, about two and a half inches wide, and five inches long, with the ends made 
rounding, and the edges filed smooth. Drill two small holes about half an inch apart, near each edge at the center. Fasten it through these holes on top of the bit with a piece of small annealed wire. Shorten the cheek pieces of the bridle, so that the bit is drawn well up in the mouth. This piece of iron is now over the tongue, making it impossible for the horse to get the tongue over the bit. Keep this on the bit for two or three weeks, when the horse will become habituated to carrying the tongue under the bit and keeping it in the mouth. The tongue is sometimes, but not often put out under the bit, which indicates a confirmed persistence in the habit, and is sometimes impossible to prevent. The following treatment will work admirably in most cases, and is the only treatment worth explaining:

Get three middling sized bullets and hammer them out to about an inch and a half in length. Drill a little hols. through the end of each. Tie one to the center of the bit by a little piece of wire through the joint. Attach the others to the bit about an inch from the center, (one on each side,) so as to play loosely. (See cut.)

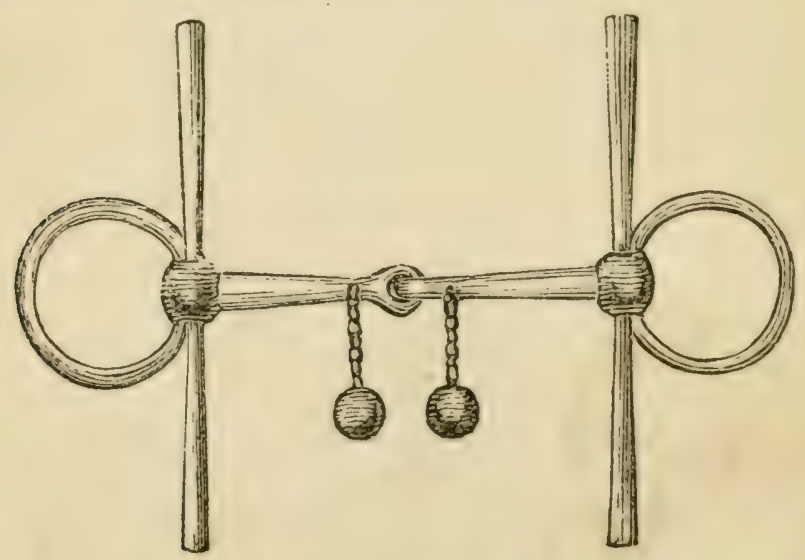

When this bit is now in the mouth, these extra arrangaments will so disconcert the horse that in his struggles to get them out of the way, he will forgot to put the tongue out.

\section{JUMPING OVER FENCES.}

Many farmers assert that this alone is worth the entire expense of the lesson. Certainly if this will prove so valua- 
ble, the instruction on Taming and Changing Habits rust be invaluable. If a horse or mule, put on a halter that fits well to the head-a five ring halter is best. Next find a piece of thin leather, (an old boot-leg will do, ) about as long as the head, and from four to five inches wider than the head is at the eyes. Form it same as cut, with a string attached at each corner. Attach the upper corners by the strings to the halter where the brow-piece is attached to the cheek-piece. Tie the cords attached to the lower corners back of the jaw (being careful to leave just freedom enough to masticate easily.) Let the ends now pass over the throat-latch, and make fast. The horse is simply disabled from looking ahead. He can look sidewise and back, but cannot look ahead or over the nose forward, which will disconcert suffi-

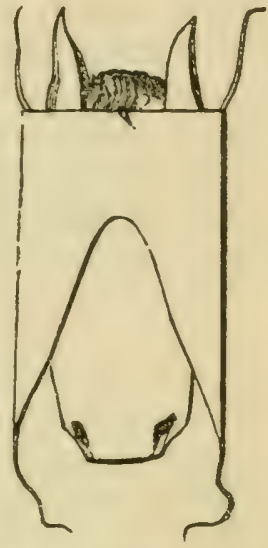

The Jumper before adjusting. ciently to prevent the animal not only jumping, but throwing the fence down. If an ox or cow, attach the upper corners to the horns, and pass the strings around the neck instead of over the throat-latch. I find that cows will not attempt to jump after this has been used two or three weeks. Horses and mules a much longer time, and in some cases must be used for months. Of course farmers should keep fences in good repair to keep

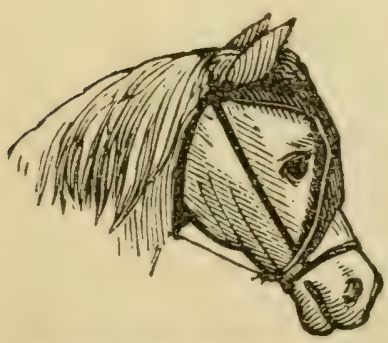

The Jumper Adjusted. stock from being tempted to jump them. It is fallacy to suppose that means, however valuable, can be wholly relied upon for success, so long as the cause is permitted to continue. The leather should be at least four inches wider than the head at the eyes, but five or more will be much better. This will bring the leather outside of the eyes when on, from two to three inches, and around the side of the face to prevent working over the nose. There may be failure with this, but if properly ap. plied exceptions will be rare, as it has proved so far almost infalible. 


\section{PAWING IN THE STALL.}

Get a piece of chain about ten inches in length-run a short strap through one of the end links, and buckle it around the foot above the fetlock; or a piece of light chain can be fastened to a small block, and attach it to the foot in the same manner. When the horse attempts to paw, the clog or chain rattles against the foot, and prevents a repe tition of the practice.

\section{KICKING THE STALI.}

The same treatment used for preventing pawing may be used; or a piece of plank may be attached across the stall over the hips about an inch higher than the hips. At each effort to kick now, the hind part will strike this plank and prevent ability to do so. If the kicking is with one foot against side of stall, attach some brush to the side of the stall, or hang down loosely over the part kicked at.

Pullinc too Hard on Bit, Turning Around while DRIving, OR RUNNING BACk, were sufficiently explained in the article on Running Away; which, with the illustration given in teaching, will give sufficient knowledge of the treatment necessary for these and other habits not specially mentioned.

\section{IICKING COWS.}

Put on the war bridle, (small loop,) and pull a few times, right and left, then go back gently and attempt to milk. On the least resistance, hold with the bridle and punish sharply, so repeating as may be necessary until the cow learns to stand quietly and becomes afraid to kick. Effectual in every instance.

Of course due attention must be given to the condition of the animal. Sometimes the teats are sore, and the pain caused by milking is very severe. Scolding, kicking, or pounding with the stool should not be permitted, as it only increases the mischief it is desired to avert. One or two lessons have proved effectual in every instance used. 


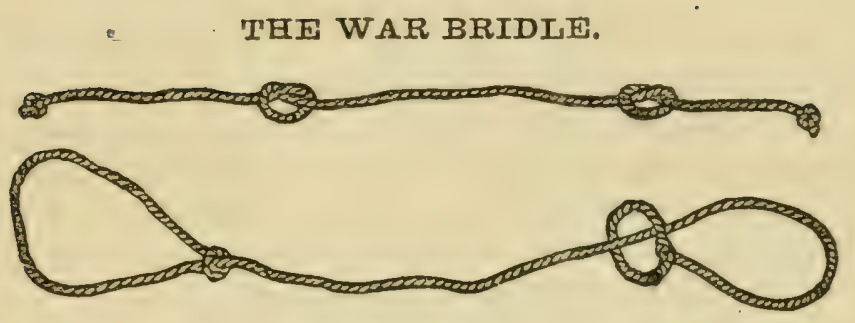

'This is simply a cord of the best material, twisted hard, of about three-eighths of an inch in diameter, and twelve or fourteen feet long. Tie each end into a hard knot, just as you would do to prevent its raveling, with the difference of putting the end through the tie twice. Then pull down tight and hard close to the end. Now tie another knot about twelve inches from the end, but before drawing it tight, put the end through. (See cut.) This will make a loop that will not slip or draw through. The great simplicity of this form of knot, and the ease with which it can be untied, gives it preference to me over all other forms of knot I have ever used, and is, in my judgment, the best form of knot, all things considered, to be recommended for general use. The peculiar power given by this means upon the mouth is liable to cause accident, when used upon a quick, sensitive horse or green colt, with too much energy in such a manner as to bring the restraint directly back upon the mouth. which would in many cases cause the horse to rear up and possibly fall over backward upon the head. Of course a horse is liable to get killed by such an accident, and it must and should be guarded against. This loop should be just large enough to go over the lower jaw, back of the bridle teeth of the horse it is intended to be used upon. The other end can now be formed into another loop in the same manner, with the difference of being large enough to go over the head and fit tightly around the neck well back to the shoulder.

\section{APPLYING THE WAR BRIDLE.}

There are two ways of applying and using the war bridle: Ist. While standing forward of the shoulders on the near side of the horse, throw the small loop over the neck and 
take in the left hand. Then with the right put the large loop through from the top side. Now pass the left hand forward to the mouth, adroitly spreading the loop in the same position over the thumb, second, third and fourth fingers, at the same time the right hand is to be passed under the neck, around the head, upon the nose, which is to be grasped gently but firmly, while the loop is put over the jaw back of the bridle teeth with the left.

By standing near the shoulder and giving a sharp pull, you will find the horse will come to you easily, by repeating which he will soon learn to follow. This is a powerful means of controlling by the head; is particularly valuable in teaching to lead, controlling the head in bridling, harnessing, grooming, or even in shoeing, if simply a little irritable. Drawing down tightly and tying into a half hitch, will sometimes have a powerful effect. This is the most powerful and valuable means ever discovered of teaching colts to lead, and will enable handling even very bad horses easily. It is not, however, suitable or powerful enough to control horses of a decidedly bad or stubborn character.

2d. Take the large loop between both hands, and while standing directly in front of the horse, slide it over his head well back upon the neck, about where the collar rests. The loop should be made in size to fit tightly around this part of the neck. Now put the other end down between the loop and neck. Put the loop this forms into his mouth back of the bridle teeth, then draw down upon the end until the slack is taken up. This method of using the war bridle, enables more power sidewise than the first, but does not like the first give power to pull ahead.

\section{FOUR RING BIT.}

This peculiar form of bit will work in the control of some pullers with great success. It is made and used as follows:

Take an ordinary short steel snaffle bit, heat and bend in the form of a link one of the rings, now slip over this ring two one inch rings, when the ring previously bent is to be straightened out as before. You have now a snaffle bit, with two rings on the mouthpiece. (See cut.) Buckle into 


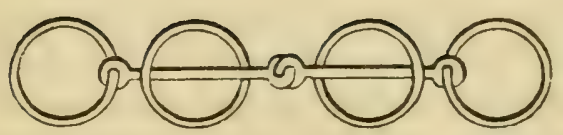

a common bridle. Get made next two straps, one two feet in length and three-quarters of an inch wide, made like a hame strap; the other about three feet in length, narrower and lighter. Run the short strap through both rings and buckle double, in the form of a nose-piece, buckling just long enough to fit around the nose closely. Bring the long strap around the short one at the center, pass up and through a little loop left in the bridle between the ears and buckle, just short enough to let the nose-piece come straight across the nose. It will now be found by standing in front of the horse, putting both thumbs through the rings and giving a little jerk down and backwards, that the head will be thrown up and back easily. The strap across the nose will act as a fulcrum when the rings on the end of the bit are pulled upon, the two inside rings slide towards the center, forcing the joint upwards against the roof of the mouth, which causes so much pain that the horse will not try to resist after being pulled upon a few times. As a driving bit this is very powerful. After being pulled upon a few times, there are but few horses that will try to resist it. It overcomes pulling on one rein or throwing the nose upon the breast. The effect of this bit on some horses is very great. It does not cut or make the mouth sore like other bits, and would be especially valuable on horses that pull hard and get the mouth sore, as it does not touch the lower jaw, yet forces perfect submission.

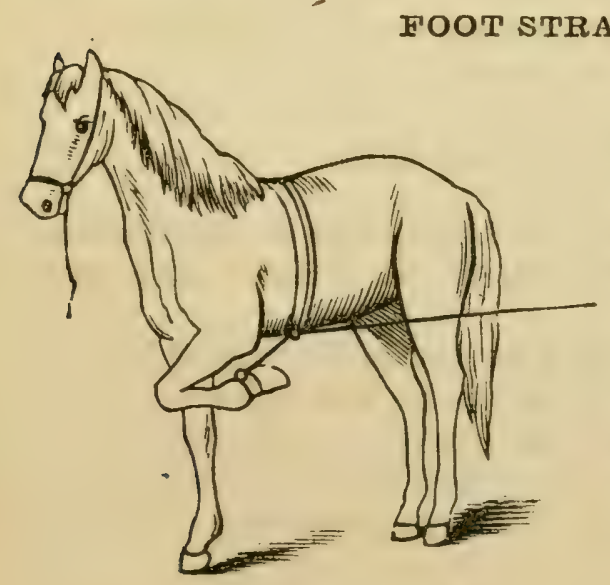

Any piece of strap or rope of about twelve or fourteen feet in le $\mathrm{ng} \mathrm{th}$, simply tied around the fore foot in most any manner, will answer on an emergency. But simply tying or knotting around the foot is objectionable on account of the danger of chafing 
and preventing cirrulation, or possibly untying at some critical moment. When necessary to use a foot-strap much, it should be specially adapted for the purpose by making as follows: Have a smooth strap made, about twelve inches long and an inch wide, with a buckle on one end and buckle holes punched in the other. About one inch from the buckle should be fitted, under the lap passing around the buckle, a ring or D stitched in nicely. 'I'he elgres of this strap should be dressed down smooth; or much better, cover the part coming in contact with the foot with a piece of soft leather. This strap is intended to buckle around the foot below the fetlock. Into the ring fasten the end of a strap or web fourteen feet long and an inch and a half wide.

Buckle the short strap around the near fore foot below the fetlock, then pass the long strap over the belly-band on the near side back to the wagon, and hold as a rein. This gives control of the foot at will, by which the horse can be disabled and disconcerted instantly, while driving. If the horse attempts to kick, simply pulling the foot up throws him off his balance. He can neither kick or run back, and if he attempts to go ahead it must be on three legs, in a manner that makes resistance quite limited. It is especially valuable when training colts to drive, by neutralizing the animal's power to resist should he become frightened and attempt to kick or back. The foot-strap is also valuable as a means of cnabling control of horses that will not submit to being rode, and is very effective.

\section{TROTTING.}

A good walking gait should be the foundation of the training. Continue this walking lesson until the colt is thoroughly gentle and submissive, and has learned to walk with energy. Now sradually let out on a moderate trot, holding up often, gradually letting out a little faster, as the strength and education will bear, but never so as to cause fatigue. Those muscles that are brought most into use are most largely developed, and bear in mind also that a colt has neither the strength or bottom of an old horse, to beas either much exertion, or to be pushed in his gait, and can not at once act the part of a fast going well trained horse. 
Let this jogging be continued, gradually as there is ambi. tion and the road is smooth and descending; but let out only so fast, or to the point that the gait is held even and square; and at first should be pushed only a short distance, after which pull back to a walk and speak encouragingly. This is to be repeated, gradually going a little faster, but never to the point of exhaustion, always encouraging with a kind word or two after doing well. I would here caution against hitching the colt to a heavy wagon or sulky. The weight must be reduced as much as possible, and the better to facilitate the object, always let the bursts of speed be on a smooth, slightly descending piece of road. By this precaution you will remove all drag, and the horse is able to use all his powers to the best possible advantage.

This careful driving and gradually teaching the animal to push forward when commanded is to be continuer, but however promising, the risk should not be hazarded of trotting a race, or a long distance, before the system is thoroughly matured and hardened to bear prolonged exertion. The gait of many fine trotters is ruined by too much haste and harshness in training. A horse has not his growth until five years old, and should not be put to severe work before six or seven years old. It is proved by experience that much greater age is necessary to attain great speed. Flora Temple made her fastest time of two minutes nineteen and three-quarter seconds, when she was fifteen years old, at Kalamazoo. Dexter is constantly increasing his speed, we are informed, by age and practice; and so it will be found with all the best trotters. They were grown into great speed by careful, persevering work, by which the system is highly developed, the muscles are strengthened and hardened, and useless foul matter that would obstruct the free action of the heart and lungs, and increase the weight, is removed.

Should the horse break when pushed in his gait, he should not be pulled up too suddenly, which would slacken his specd. Rather encourage him to go faster, and by gently and firmly pulling right and left bring him to the trot. The horse has now no disposition to resist control, and he must be taught to rely upon with confidence, as well as yield submission to the control and restraint of the bit. 


\section{TO FORCE ON THE TROT.}

There are many promising steppers that will break and run, and will not come down to work again, when much excited; and unless there is power to prevent such a habit and force on the trot, the horse cannot be relied upon in a race, at perhaps the very instant pushing is necessary. There is not power to do this by the bit, and consequently horses that step freely in private become foolish and unreliable when urged in company with other horses. There is but one way of overcoming this trouble, and that is by the use of the following means, the conception of which has been original with myself, and brought to the notice of trainers by me for several years, and has proved in skillful hands a valuable adjunct, to the end of making flighty, nervous horses come down to fast, reliable going.

Have made first four straps long enough to go around the hind legs above the hocks, and from three quarters to an inch wide. Obtain next two D's or rings, in size to admit two each of these straps to be run through. Step in front of each hind leg and buckle these straps around the leg, one above and one below the gambrel, the ring

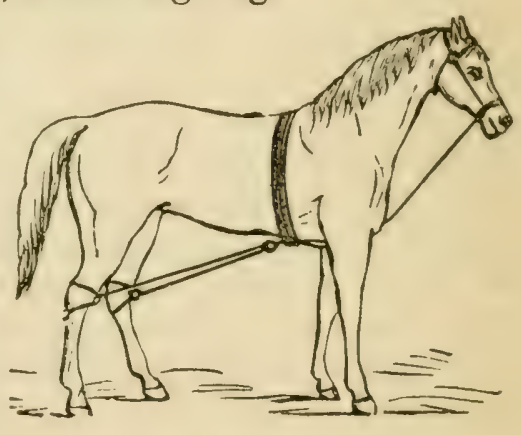

Cure for Breaking. or $\mathrm{D}$ in front, bringing the straps to an acute angle. Put on the head a light well-fitting halter. Attach a strap to this, which must be in part double to regulate the angle, and must be long enough to extend from the head to the back edge of the girt. On the end is to be attached a small, nice, easy running pulley, fitted to run a half-inch cord. The strap is to pass back from the halter, between the legs, over the belly-band, just back of which must come this pulley. Take next a piece of firm, hard cotton or hemp cord, from three-eighths to half an inch in size. Run it through the pulley to the center, and tie the ends into the D's or rings attached to the hind legs; the whole to be so regulated in length that the horse can walk or trot easily. This is similar to the kicking straps described on page 78 . 
(See cut.) One leg going forward to the degree that the opposite one goes back, brings no restraint on the cord or head, but the instant both feet go back as in the act of running, the cord is shortened, the head is drawn back, and the horse is taught that he is helpless. He soon learns this and becomes afraid to break, though subjected to any reasonable excitement. With this "rig" on, move the horse on a walk until accustomed to it, which will usually require but a very short time. Then let out on a moderate trot, and when thoroughly accustomed to it pushing to a fast gait. This must be repeated. In fact this arrangement should be kept on until the horse is made reliable. Should be driven and thoroughly practiced with other horses, and excitement made as if in a race. Of course all this requires ingenuity, patience and care.

This will work best on some horses by attaching to the collar, or around the neck. The restraint is simply more positive by this change.

One gentleman in Ohio, two years since, came one hundred and fifty miles to get this treatment of me, and in three months afterwards he informed me that he had since sold a mare for fifteen hundred dollars which he had bought for three hundred and seventy-five dollars. She would break when in the least excited, and could be made nothing of, though a fast stepper. He bought her, made the experiment, and in less than a month had her down fine, and could hold her under the whip regardless of yelling and the excitement of competing horses. This gentleman informed me he then had a horse that promised equally good results by this treatment. 


\section{BREEDING.}

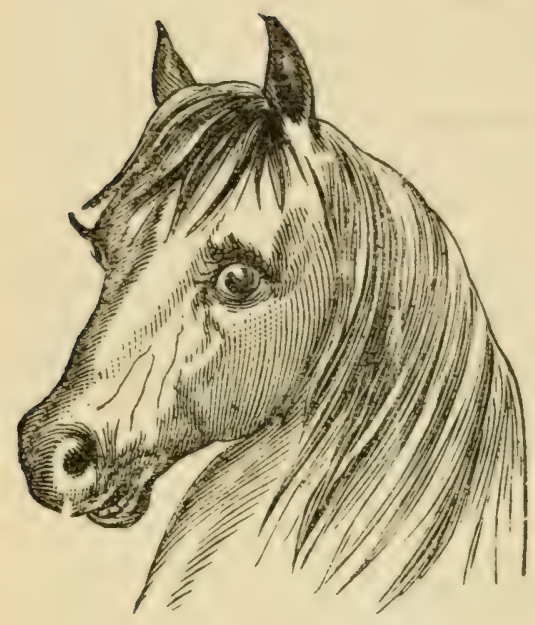

Intelligent and Gentle.

One of the primary points of success is to start right, and in no respect is this more essential than in breeding. The law of like producing like is inexorable; consequently it is seen that to raise good horses, good horses must be bred from. Many farmers who are otherwise keenly alive to their interest, are singularly thoughtless and imprudent in this. If a mare is broken down and unfit for labor, no matter how coarse, badly formed, or what the evidence of constitutional unsoundness, she is reserved to breed from. Again the cheapest horse, no matter how coarse if sleek and fat, is selected and employed to breed from. The most ignorant farmer is particular to select the largest and soundest potatoes, the cleanest wheat and oats, for seed, etc. He has learned this is true economy. Yet there seems to be the most utter disregard of this law of prudence in the breeding of horses and farm stock in general. During my long experience before the public, I have endeavored to impress upon farmers, when I could, that this sort of economy is like paying a quarter for a chicken, and giving a

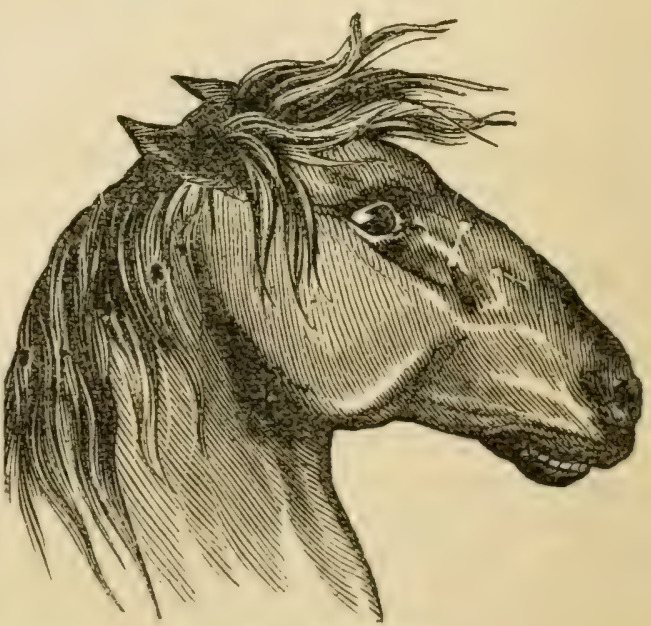

Dull and Treacherous. dollar to have it taken home. 
It costs just as much to raise a poor, coarse blooded colt, as a fine blooded one. The cost of feeding and care is really the same, the only difference in cost being in that of the use of the horse. 'The first will possibly sell when five years old and trained to harness, for from a hundred to a hundred and fifty dollars. The other is worth from three hundred to a thousand, and possibly more. The first will scarcely sell for the cost of feeding and care. The second ensures a large profit, and this for a little additional first cost. And then the satisfaction of having fine valuable animals, that can go along if necessary,

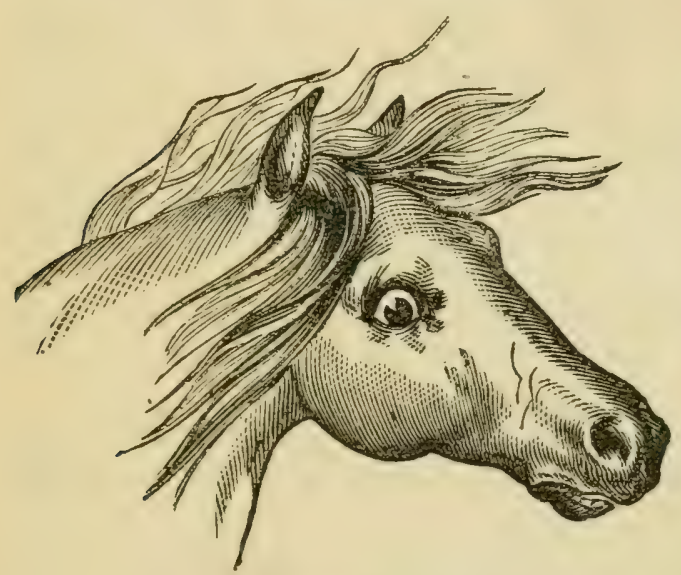

Naturally Sensitive and Shy. able to do any kind of work easily, and saleable for a larger price, is a source of no ordinary pleasure and encouragement, if from no other feeling than that of contributing so largely to increased economy and wealth. The fact is, breeding from poor, unsound horses is so much a detriment, that it would be a damage to any one to be compelled to breed from such stock, if given for the purpose.

\section{IN RUSSIA, PRUSSIA AND AUSTRIA,}

the breeding of horses is controlled by the governments, each one having large breeding establishments, where those wishing, can procure sound stallions, devoid of all hereditary diseases. Each stallion is furnished with a certificate from the government. No other stallions are allowed to serve mares, under a penalty. The result is, that you will scarcely find an unsound horse, except by accidents, etc. Hereditary diseases, such as ophthalma, roaring, rupture, spavin, ringbone, curby hock, spongy feet, etc., scarcely known. It would be a source of undoubted economy and benefit to the breeders, if the legislature of each State would 
enact such laws, by appointing competent inspectors to grant licenses to those free from blemish or hereditary diseases or unsoundness.

- A few years' breeding, under such restrictions, would materially increase the value of horses in each State, and thus be a real blessing to owners and the country.

In selecting a stallion, look first carefully at his head. The nostrils should be large and well defined; eyes, that they are full, bright, and clear; good breadth between the eyes; the ears lively and rather short and tapering, and the head high between the ears; next, that the throat shows no enlargements of the glands, showing a disposition to be a whistler or roarer; next, the shoulder should be oblique, strong and high; then the fore leg, see that it is not tied in (as it is termed) under the knee, for such are liable to spring; then the feet should be of good size, sufficient depth to be strong in the quarters; spongy and flat feet should be rejected; next, the loin should be strong, the back should be well coupled, quarters broad from point to point of hips, and running nearly straight out to root of tail; stifle should stand low and well out; hocks broad and strong; no puffs or wind galls, as it indicates weakness. As a colt from such a horse at an early age, may show indications of blood spavin or thorough pin, look at the inside of the hock, an enlargement at the point of what is called a jack spavin or curb, enlargement on the back of the leg; next, at the foot, that there is no enlargement at the edge of the hoof, known as ringbone; weak eyes, or blindness, poll evil, fistula of withers, or in fact any cause of unsoundness should discard a stallion. I need not remind that the mare should be selected with the same care. Heaves, broken wind, and marked contraction of the feet should discard a horse, and I would by all means discard a bad tempered one. The horse should be in good health or condition. This implies that he has been subjected to moderate but regular exercise during the season. A horse that is driven hard and hurried from place to place, perhaps overheated and made to cover from two to four or five mares a day, should be regarded as unsafe, and the colt liable to lack vitality.

To be successful in breeding any particular variety of horses requires first decision as to the purpose for which 
intended. To be particular requires first, intention as to purpose for which intended. If heavy draft horses, evenly trotting roadsters, or ponies are required, select both dam and sire with special reference to the kind of stock wanted. If the mare is light boned or defective, select a heavier boned horse, one that possesses the contrast of greater strength or better points in that respect. But to ensure much certainty of what you would have, the mare and horse should be as nearly the type desired as possible, though not related. I would be very particular about disposition and intelligence. The head should be broad between the eyes, muzzle small, short or middling short from eyes to ears. The smaller and rounder the eyes, the more positive will be the temper. (See cuts.) To have a horse sensitive, intelligent, courageous, and naturally docile, there must be large brain, the eye must be large, standing well out, and mild in expression.

Of course it is understood that BAD TREATMENT WILL SPOIL THE BEST TEMPERED HORSES, AND GOOD TREATMENT WILL MAKE GOOD SAFE ANIMALS OF THE WORST.

\section{THE MARE.}

The mare is said to go with foal eleven months or three hundrea ciays; but it is not uncommon for mares to have fully developed foals in much less time, and in many instances mares have been known to go four or five weeks beyond this time. Time should be so arranged in putting mares, that the colts will come at a time when there is some grass, as the mare will do better not to be confined to dry feed. The virgin mare, or one that has not had a colt, for one season, must be put when she is found in season. The mare that has had a colt will be found in season, and should be put on the eighth or ninth day after foaling; some prefer the eighth, others the eleventh. Good judges claim that it is dangerous to go beyond the tenth, as the mare is apt to come off her heat soon after, and if allowed to go to a later period, the sucking of the colt is likely to reduce the mare too much to allow conception to take place, and thus a year's service of the breeder is lost.

After putting a mare, the days for trial are the ninth after service, the seventh after this, the fifth after this again. 
Some commence again, commencing with the nirth day and follow up as before, making forty-two days. Twentyone days being the period elapsing between a mare's going out of heat, and coming in again, making her periodical term thirty days. Twenty-one days is claimed to be sufficient to prove a mare.

The mare and colt should be well fed, and protected from storms. The theory of working a mare hard, and half starving the colt, is the poorest kind of economy, since the mare needs generous feed and rest, to renew her strength and make her milk, by which of course the colt is nourished and made to grow. When size and strength will indicate that it is time to wean, which is usually in five or six months, put the colt in a quiet pasture, away from the mare, where it should be closely looked after. A little oats, (better if bruised,) should be given daily.

The conclusion of careful breeders is, that it is much better for a colt to run in pasture, than to be confined in a stable. If the colt is intended for farm use, castration may be performed when six months old; if, however, the withers are light, it should be postponed until the head and neck fills up to the degree required, and this may require from one to two years, or even more. If the head is large and heavy, early castration is advisable. Colts should be generously fed, and protected from the inclemency of the weather in winter. They should be treated gently. May be broken early to harness, if treated gently and with care. This, however, is hazardous, as there is danger of overdriving young colts if they are driven at all. Many seem to take pride in trials to which they subject two or three year old colts. It is not what they can do, but what they ought to be required to do.

\section{STABIING.}

Pure air is not only an absolute essential in securing and retaining the perfect health of horses, but is the cheapest and most easily available. The stable should be so located and constructed as to enable this most perfectly, as well as afford the greatest convenience and comfort, thus ensuring health and economy. It should be built on a dry, airy location, facing the south, large enough to give ample 
soom, warm and well lighted, yet well ventilated. The stalls should be at least five feet wide for work horses, and if fine horses that are worked but little, they should be large enough to enable stepping around freely. If there is room, a box stall is the best, but it should not be close. The door, at least, should be made of slats, and a window above the head, so arranged that it can be thrown open to give light and ventilation. The door should be large, to preclude injury by striking the sides or hips against the posts, and there should be a reasonably large yard, which should be well fenced. If a manger and rack of the common form across the stall is used, I would suggest an improvement upon that in general use.

First. It should be so constructed that the horse cannot waste the feed while eating, yet should not be very highthe top about three and a half feet from the floor.

The rack, instead of sloping out over the head of the horse, should stand straight, or perpendicular, which will prevent hay seed and dust from falling upon the horse's head, and enable catching and pulling the hay more easily from the rack, and the back so inclined forward that the hay will all the time be in the horse's reach. The bottom should be open like the front, so that the dust can drop through to the floor.

The best form of manger I have seen, both for convenience, safety and health, is that so constructed that there is an alley in front of the head. The place for hay is a sort of box, on one side of which is a feed box, which should be large enough to prevent throwing the feed out while eating. The hitching ring should be on the off or farther side, to prevent the strap being caught by the foot. The manger should be about on a level with the shoulders. The nearer the horse is made to imitate his position when eating in the field the better. But this is not admissible in the construction of the manger, since the horse would waste the feed. This form of feeding box and manger is cleaner. There is not that temptation to give more hay at a time than the horse may need. The manger can be reached easily and safely; in feeding the hay is easily thrown upon the floor, where it can be easily shaken up, and thrown fresh and palatable to the horse. It obviates the usual temptation of a receptacle under the manger, in 
which to pack, during the day, a lot of poisonous bedding, and finally there is the best of ventilation, as the air can freely circulate in front of the manger. Every stable should have a sort of chimney, or opening at the top, to allow of the bad air to pass out freely. The windows should be so placed as to admit light enough that the ordinary work of the stable can be done without opening the doors, which should have shutters to enable darkening the stable if necessary, when flies are troublesome, or to permit sleep in the day time, which is often necessary. The walls, if any, in front should not be whitewashed, as is often done, as pure white would injure the eyes. The color should be made neutral by adding some brown or other coloring matter. A cellar stable, unless so constructed as to enable at all times the most perfect ventilation, is dangerous; yet one of the best stables I have seen was what would be termed a cellar stable, which was simply a series of box mangers running across the whole size of the building, with a passage-way running lengthwise through the centre, thus giving free access to each range from the end, from which was a run-way to the floor above; but there was a series of little open grates around the entire room near the ceiling, which gave perfect ventilation. A special point I would call attention to, viz.: not having, on any condion, a stall so constructed as to have a stone or brick wall on one side, or have the naked wall form one side of a stall. The temperature of one side is so much lower than that of the other, that derangement of the circulation must result, causing cold and injery that is often the cause of spoiling a valuable horse. If a stall is so located, line the wall with plank. The construction of farmer's stables is generally bad, the stalls being too narrow and short, the hay rack too high, and the top part standing too far forward over the head. In many cases they are but little better than a rlose dark Dox, without any adequate means of ventilation wren the doors are closed, and if they are open there is usisaty so much draft of air as to cause cold, just as those ocrunving a close, warm room are made to feel keenly anv smiden current of cold air that may be admitted into the roam by too suddenly throwing the doors open while warm 'The sudden influx of cold air would check perspiration and rlnse the pores of the skin, thereby endangering some acute is $\mathrm{m}$ of inflammation. 
Again, the stables are usually built over a cellar, which is perhaps half filled with water and manure that throws upward through the floor a deadly miasma that lays the foundation of disease. The rack is crammed with hay, the dust and dirt of which is forced against the horse's nose. The manger is half filled with filth and trash. The bedding; thoroughly impregnated with ammonia, is rolled under the manger in the morning, to saturate and poison the hay above it in the rack, or such other food as may be given the animal. The usual bad ventilation and high temperature of cellar stables make too great and violent a change in the temperature when taken in or out, and the consequence will be cold cough, with great disposition to attacks of pneumonia, or lung fever. Humanity and true self interest should prompt to looking to these errors being corrected in the construction of the horse's places of living, and as these ends can be attained without any extra expense worthy of consideration that is necessary for the construction of a poor one, it is a duty which is a really suicidal policy to neglect.

I would suggest, in conclusion, that the flooring of stalls or a stable should never be made of hard wood, such as oak, ash, chestnut, etc., as it wears smooth and endangers slipping and injury of the horse in getting up. The best wood for flooring is elm, spruce, hard pine, hemlock, or any wood that will wear rough and prevent slipping.

\section{FEEDING.}

Hay, corn fodder, oats and corn, constitute the principal food of horses in this country. Hay and oats in the Northern States, fodder and corn in the South. The food should be in quality and quantity to impart strength, vitality and elasticity, and this requires some discrimination and care, as the food should be harmonized both to the condition, and the severity of the labor to which the horse is subjected. As a rule, the stomach should not be distended with food when prolonged, energetic effort is desired, as the heart and lungs would thereby be much impeded in their action, and congestion and rupturing of or enlarging of the air cells of the lungs may result. This is to be especially guarded against in the feeding of hay. Greedy eaters can 
and will gorge themsclves by eating so much hay as to be unfit for active labor, and is usually shown to result in heaves or broken wind. Heaves are always found in the teamsters' or carters' stables, where there is no care in feeding. This disease is always found among horses of the above class, but never found among racing horses, from the fact that the utmost prudence and care is used in selecting the food, and feeding in smaller quantities, or in adapting the food more perfectly to the wants of the system.

It has been demonstrated beyond doubt that the reason horses improve so much in wind by eating prairie hay is,

" that it is so coarse that horses cannot eat it fast enough to overload the stomach. The quantity of hay should be carefully regulated, and never as much given as the horse will eat if at all voracious. The majority of owners pack a large rack full, allowing either liberty to eat too nuch, or making it unpalatable and unhealthy, by being breathed upon. From eight to ten pounds is about the average quantity for an ordinary roadster to be allowed in twentyfour hours, more or less, according to size, the kind of work, and the quantity of grain given. Dusty or mouldy hay should not be fed, as it is liable to produce various forms of disease.

All food should be clean, and in quality perfect. Hay is most perfect when it is about a year old. Horses would perhaps prefer earlier, but it is neither so wholesome nor so nutritious, and may purge. When it is a year old it should retain much of its green color and agreeable smell.* The blades of corn pulled and cured in the summer are unquestionably much better than hay. I should certainly prefer this kind of fodder to any kind of hay, for fine horses. It is strange that it is not prized more highly in the North.

Oats make more muscle than corn. Corn makes fat and warmth. Hence, the colder the weather, the more corn may be given, and the harder the work, the more oats. Oats should be a year old, heavy, dry and sweet. New oats will weigh from ten to fifteen per cent. more than old ones; but the difference is principally water. New oats are said to be more difficu't to digest, and when in considerable

- Note 1.-In packing or stacking hay. salt should be slightly sprinkled through it so as to detroy insects. It also aids in preserving it bright, aud makas it unore palatable and healthy for the horse. 
quantity are apt to cause flatulency and derangenent of the stomach and bowels. The same may be said of corn. If not sound and dry, it may be regarded even much more dangerous than oats, and should not be fed. Doing so will be at the hazard of the consequences above mentioned.

The quantity of oats given daily may vary from eight to sixteen quarts. If the horse is large, and the work is severe, a little more may be given. Corn should be fed in the ear, and like oats must be regulated in quantity to the size and labor of the animal; from five to twelve good sized ears are a feed. I give a larger proportion of feed at night, and less in the morning and noon. There is ample time for digestion during the night. There is not during the day, if the labor is severe. Experience proves that some mildly cooling laxative food should be occasionally given. A bran mash, made by pouring boiling water on eight or ten quarts of wheat bran, covered over until cool and fed at night, from once to three times a week, is the finest and best.

Carrots are a good laxative and alterative before frost, but are too cold and constipating during cold weather. They may be fed in October, November and December, but in the Northern States not later. (I am governed by the judgment of one of the best veterinary surgeons in the United States, based upon careful and critical observation of effects on a large number of horses, on this point.) I feed Irish potatoes, from one to three quarts, with the usual quantity of grain, from two to three or four times a week, and would recommend their use. Think their value cannot be over-estimated. Feeding a small quantity of roots and giving bran mashes, keeps the bowels open and the system in a uniform, healthy condition. Without them constipation is probable, and this is one of the primary causes of diarrhœa, colic, or inflammation of the bowels. If it is desired to make a horse fat in a short time, feed corn mea? and shorts, with cut straw, to which add a pint of cheap molasses. Nothing like this for recruiting and filling up a horse that is out of sorts or poor. If the horse eats too fast, put a few round stones in the feed box. He must now pick the food from among the stones, and thus he is compelled to eat slowly.

If the horse is exhausted, or when sufficient time canrot be allowed for him to eat and partially digest a full meal, 
he may be greatly refreshed by a draught of warm gruel, or in summer, of cold water containing a small quantity of meal. To give some idea of the routine of feeding and watering when great care is necessary, I include the system of feeding and watering Mr. Bonner's famous trotting horse, Dexter:

"At six every morning, Dexter has all the water he wants, and two quarts of oats. After eating, he is 'walked' for half an hour or more, then cleaned off, and at nine has two quarts more of oats. If no drive is on the card for afternoon, he is given a half to three-quarters of an hour of gentle exercise. At one o'clock he has oats again, as before, limited to two quarts.

"From three to four, he is driven twelve to fifteen miles; after which he is cleaned off and rubbed thoroughly dry.

"He has a bare swallow of water on returning from the drive, but is allowed free access to his only feed of hay, of which he consumes from five to six pounds.

"If the drive has been a particularly sharp one, he is treated as soon as he gets in, to a quart or two of oat meal gruel; and when thoroughly cooled, has half a pail of water and three quarts of oats, with two quarts of bran moistened with hot water.

"Before any specially hard day's work or trial of his speed, his allowance of water is still more reduced."

\section{WATERING.}

If a large quantity of cold water is taken into the stomach while the system is agitated and sensitive, by the circulation being so increased as to open the pores of the skin freely, it is liable to so chill the stomach as to derange the circulation and close the pores of the skin, and thus excite some one of the common alimentary derangements of colic or inflammation of the bowels. Hard water, especially cold well water, is more liable to cause mischief in this way than soft water. Hard water will derange some horses, so much as to show an almost immediate effect of causing the hair to look rough or stare, the appetite deranged, if not indeed preceded by colic or infiammation of the bowels; also, horses that are raised and worked in the country, where the water is strongly impregnated with lime, are troulled a 
good deal with intestmal calculi, $i$. e., stone in the bladder. Hence soft water should be given, if convenient; and if well water, especially while warm, it should either have the chill taken off or be given very sparingly.

The best time to water is about half an hour before feeding. While driving, the rule should be little and often. None, or only a swallow or two, should be given at the close of a drive, until cool. If very warm, the horse should be walked moderately where there is not a current of air to strike him, from ten to thirty minutes, as may be found necessary. If, then, any danger is apprehended, the chill should be taken off the water if very cold and given sparingly a few swallows at a time. The common custom is to give about a half bucket of water. The safest course would be to give less and repeat. The rule should be, for ordinary use, to give small quantities often during the day, and the animal to pursue his journey or labor immediately after. If allowed to stand, the system may be chilled. The absorbents are closed, which is the common cause of Laminitis or Founder, although this disease may not develop itself until twelve or twenty-four hours afterwards, and any cause which will chill the system-either cold winds or cold water-while the animal is warm, will be almost sure to produce the above disease. 


\section{TEACHING TRICKS.}

Do not hurry a horse too fast in his training. If you undertake to teach too much, or too fast in the start, or indeed at any time, you only confuse or discourage. Do only so much as the horse can comprehend, and make daily progress.

\section{TEACHING TO FOLLOW.}

If it is desired to simply teach the horse to follow promptly with halter or bridle on, apply the war bridle (small loop); when he comes round promptly, stand off a short distance and say, "Come here, sir." If he d es not come to you, give a sharp pull, gradually changing positions and going a little farther. If he comes to you promptly, caress him; if not, pull sharply, repeating in this way until you can make him come to you promptly, in any direction, at the word.

TO MAKE FOLLOW WITH THE WHIP.

The simplest and easiest way of doing this, is to work up sharply with the war bridle, and when the horse comes tu you promptly, take a short, blunt whip, step up to the shoulder, and while holding the bridle loosely in the left hand, pass the whip gently over the shoulder, and tap lightly with the end on the off side of the head. This will annoy the horse and cause him to move the head a little from it, toward you; instantly stop and caress, then repeat the tapping again; should he attempt to run from you, hold him by the bridle. Repeat in this way until the horse will step toward you promptly. Then touch the whip over the hips and say, "Come, sir." If he comes up to you, or shows the least disposition to do so, caress, and so continue until he will come up promptly. Now step a little sidewise and ahead and say, "Come, sir." If he should step after 
you, caress, if not, touch the lash over the hips. In a short time the horse will learn to step to you, and follow promptly When he will do this, stand him in a corner of the room, stand a little in front of him and touch him lightly with the whip on the fore-legs and say, "Come here, sir." At the least intimation of coming, stop and caress. Then repeat, touching with the whip. If he moves to you a little, stop and caress, and in this way repeat until he will come to you promptly. Then get a little farther from him and repeat in the same manner until he will learn to hurry up to you, to get away from the whip. Should he bolt away, put on the bridle, and hold the end in the left hand. You can now hold him by the bridle when he attempts to run, until he finds he cannot get away, and will come up promptly.

This lesson should be made very thorough before there is an attempt to take the horse out of doors, and then in a small yard. If this is not convenient, put on the bridle, having good length of cord, and hold in the left hand loosely.

If the horse is of a bad character, the following method may be used: Turn the horse into a room or small yard well enclosed. Provide yourself with a good bow whip. The horse will feel uneasy and look around at you, and then perhaps for some place by which to escape. Walk up to him, and as he runs into a corner apply the lash sharply under his flanks, following him up, making the whip sting keenly around the hind legs. When he stops or turns his head toward you, stop instantly, reach out the hand, at the same time approaching gently. Should he run or turn around to kick, whip instantly as before, and so continue until you can approach and caress the head and neck a little. Then say, "Come, sir," at the same time touching the whip lightly over the hips. If he comes, or shows the least disposition to do so, caress and speak encouragingly. If he runs, whip as before, and so repeat until the horse will come up promptly when touched by the whip.

As the object is to make the horse honest in following, it is necessary to make him feel that you whip him only for resistance, encouraging and flattering for every intimation of obedience, until he realizes his safety from the whip to be in coming to you. 
TO LIE DOWN.

Tie the bridle reins into a knot back of the neck. Throw your strap over the back, under the body, and tie to the near foot, below the fetlock. Now pass the right hand well over the back and take a short hold of the strap. Cause the horse to step toward you and pull the foot up. Then pass the left hand around the reins and pull back and down upon them in such a manner as to turn the head a little to the off-side, at the same time pulling down steadily but firmly on the strap over the back with the right hand. As the horse goes down, gradually pull the near rein, so as to bring the head to the left, at the same time pressing down and from you firmly with the right, until the horse will lie down. Pass the end of the strap now through the ring of the bit and draw through gently, step over the neck, and as the horse attempts to get up, pull him back, until he lies quiet. Rub and caress him, and after lying a few minutes, say, "Get up, sir." Repeat in this way for a few times until the horse will lie down readily. Then while holding him on or near the knee with the strap, hit him on the skin of the other with a little whip, until he will bring it under and lie down. After awhile he can be made to come on his knees and lie down by simply pulling the head down a little and hitting the skins with the whip, at the same time saying, "Lie down, sir," repeating until the horse will lie down to the motion of the whip. This is about the easiest ard most practical way of teaching a horse to lie down.

\section{TO STT UP.}

When the horse will lie down promptly, put on him a common collar, and while being down take two pieces of rope, or anything suitable, about ten feet each in length. Tie the ends around the hind feet, carry them forward between the fore legs and bring them once around the collar.

Now step on his tail, take the bridle reins in the right hand, while you hold the ends of the ropes firmly in the left. Give a little jerk on the reins and say, "Get up, sir." When the horse throws out the forward feet and springs to raise himself on the hind feet, he finds himself unable to complete the effort, on account of the hind feet being tied 
forward under him, and so he brings himself in a sitting position. Instantly step forward, holding the ropes firmly, rub and caress the head and neck a little for a few seconds, then as you see the effort to keep up becoming tiresome, let loose and say, "Get up, sir." By repeating in this way a few times the horse will soon learn to sit up when commanded without being tied.

\section{TO MAKE A BOW.}

Take a pin in your right hand, between the thumb and fore-finger, stand before, but a little to the left, of your horse, and prick him on the breast lightly. This produces the sensation of a fly biting, to relieve which he will bring down his head, which you will accept as yes, and reward for by caressing and feeding as before. Then repeat, and so continue until he will bring his head down the moment he sees the least motion of the hand toward his breast, or you can substitute some signal which he will understand readily.

\section{TO SAY NO.}

Stand near the left shoulder, holding the pin in your hand, with which prick him lightly on the withers, which will cause him to shake his head. You then caress as before, and so repeating, until he will shake his head at the least indication of touching him with the pin; you can train your horse so nicely in this way in a short time as to cause him to shake his head or bow by merely turning the hand a little, or moving it slightly toward him.

\section{TO KISS YOU.}

Teach him first to take a piece of apple out of your hand. Then gradually raise the hand nearer your mouth, at each repetition, until you require him to take it from your mouth, holding it with the hand, telling him at the same time to kiss you. He will soon learn to reach his nose up to your mouth ; first to get the apple, but finally, berause commanded to do so. Simply repeat until the horse understands the trick thoroughly. 


\section{TEACHING A HORSE TO DANCE.}

Put on the war bridle; hold the cord some four or five feet from the horse's head, and with a whalebone whip tap him on the shin or ankle until he lifts his foot, then caress him, and do the same with the other, making him raise first one foot, then the other, then stop and caress. Next, make him raise them several times, until he moves his whole body by the motion of the whip to the time of music. Caress and encourage frequently.

\section{TEACHING A HORSE TO WALTZ.}

After he has learned to dance, put a surcingle around his chest and fasten the bridle-reins to it, the left rein much the tightest, bringing his head well around to the left side. Then make him move forward, when he follows his head, and every time as he is turning his head from you give him a sharp cut with the whip, which will make him jump round quickly until his head comes around to you again. Then you should caress and encourage him by talking kindly, patting and feeding him. He will then be slower to move his head from you, but you must continue with the whip every time the horse's hind parts are toward you and his head from you, caressing every few minutes until he understands to move at the motion of the whip. Patient and careful practice in this way will make your horse prompt and graceful in his movements. 


\section{SHOEING.}

THE hoof of the horse, in a state of nature, is adapted only to a grassy surface. Here the natural wear and tear of the hoof is just compensated by its growth. When the wear is made greater than this, by driving on hard roads, the horn is worn down so rapidly that the vascular part of the foot would soon be exposed, and the horse would in consequence become lame.

Shoeing includes, first, the duty of preparing the feet for the shoes; second, forming the shoes to the feet, so as to be most exact in size, weight and fitting to that part of the hoof, and that only, that is shown by experience to be best able to bear the pressure and strain of the shoe without injury, and preserve its form and bearing best; and, third, that when injury and lameness result, the cause, at least, should be removed, and a reasonable effort made to restore the parts to a state of health.

That part of the foot which is visible, and to which the shoe is fastened, is called the hoof. It is simply a thin covering of horn to the delicate but powerful mechanism of the internal structure of the foot, and for convenience of description is divided into three parts, the wall, sole and frog.

\section{THE FOOT.}

There are other minor points, a full description of which is not essential to our object here, such as the toe, heels, bars, commissures, etc. The outer crust, or wall, is a simple piece of horn, of from a quarter to three-eighths of an inch in thickness, increasing in thickness from the quarters to the toe, where it is thickest and grows fastest, in order to bear the increased wear upon this part. If this horn were cut into and examined with a microscope, it would be found to be made up of a large number of little tubes, or hairs, cemented together; that they can be split apart like the fibers of wood, and that the horn increases in hardness and density from the inner surface to that of the outer, the inner 


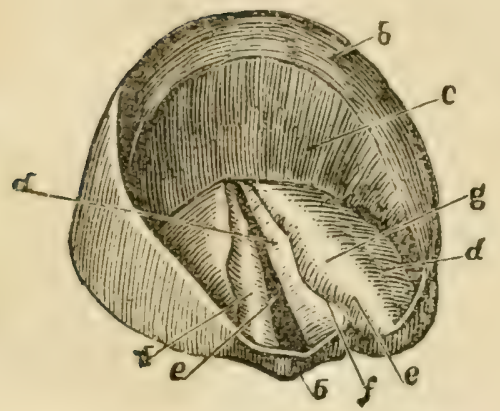

( No. 1.)

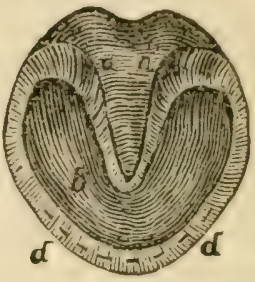

(No.2.)

a a The frog.

$b$ The sole.

$c c$ The bars.

$d d$ The crust.

lining the crust. $d$ The sanio continued over the hars. e e The two concave surfaces of the inside of the horny frog. $f$ That which externally is the cleft of the frog. $g$ 'The bars. $h$ The rounded part of the heels, belonging to the fros.

surface being quite soft, while the outer surface is hard and smooth.

If we now look at the sole, we will find it from one-eighth to three-sixteenths of an inch thick, a little arched, of a dense yielding texture, joined firmly to the lower and inner

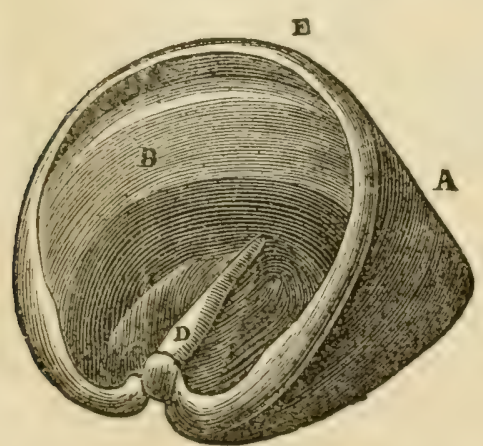

(No. 3.) Interior of a Healthy Foot.

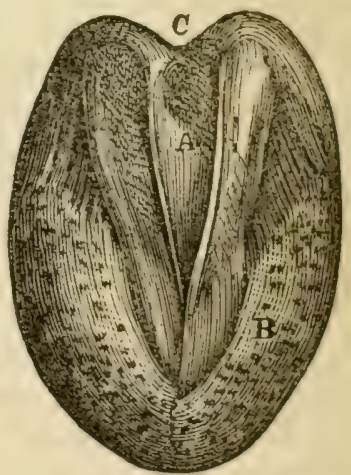

(No. 4.) Sole of Hind Foot.

edge of the wall. At the center, occupying the space between the heels, and extending well forward to a point towards the toe, is a softer and thicker formation of horn, admitting of great elasticity, which is the frog. (See cut No. 2.) Between the frog and its connection, with the sole, on each side, is a little strip of hard horn, extending from the hecls forward, called bars, which are a continution of 
the outer wall. From the outside there seems to be a deep notch, on each side, cut down between the bars and frog, which are called commissures, the whole showing the most admirable arrangement for strength and elasticity. The frog, being of a soft, elastic nature, acts as a cushion in protecting the sensitive parts over it from being bruised or injured, while the direction of the bars make them braces for keeping the heels in place. Connecting the internal parts of the foot with the hoof, is a strong muscular structure,

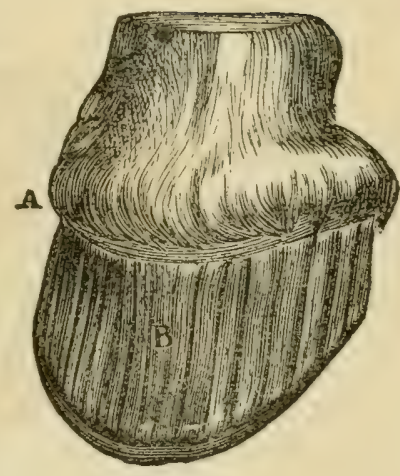

(No.5.)

$a$ Coronet.

$b$ Sensible lamellae. arranged so as to afford great expansion, as well as strength. That connecting with the wall of the hoof is named sensible laminæ, and that between the coffin bone and sole sensible sole and frog. This mus-

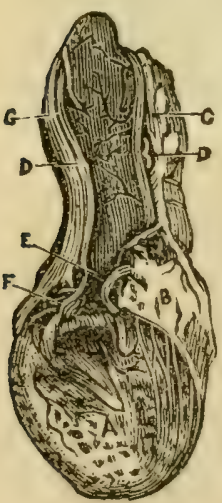

(No. 6.)

View of the veins of the Frog and Sule, injected.

cular structure has mingled through it a complete network of nerves and bloodvessels. Hence we see that in any way producing pressure or restraint upon the wall or sole, so as to bruise this soft structure, will cause inflammation, and result in soreness, change of structure and lameness, to a greater or less extent, in proportion to the extent of the injury.

The healthy foot is the best model for guidance, and the object should be in preparing the foot for the shoe, to simply bring it back to its natural form and bearing. If the toe is too long, or the heels too high, or there is an unusual accumulation of old horn on the sole, remove so much as will restore the foot to its natural proportions and bearing.

If the shoes have been on a month, cut

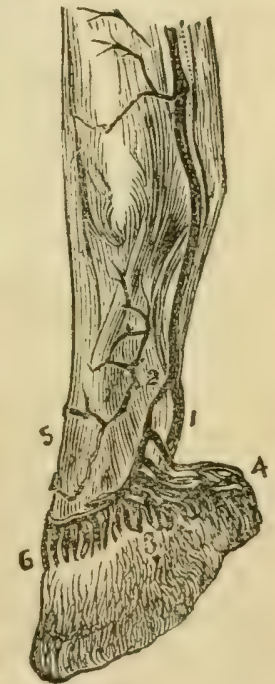

(No. 7.)

View of arteries of the Foot.

1. Vein.

2. Plantar artery.

3. Branches to the coronary substauce and laminge.

4. Posterior division of plantur artery.

5. Perpendicular branch. 
away the horn grown more or less, according to the length of time the shoes hare been on and the quantity of horn grown. If the foot is in a healthy condition, It is seldom necessary to interfere with the sole and frog. The sole and frog throw off horn by a natural process of expoliation; but sometimes the shoe extends so close and so far over the sole as to prevent this old horn from either wearing or scaling off. When this is the case, it should be dressed out, particularly at the heels, at the angles formed between the bars and crust. The buttress is usually so large and square edged as to make it unsuitable for doing this. Even with the greatest care, it is difficult, with such an instrument, to prevent cutting away too much at some points, while there cannot be enough cut away at others. An English shave, with the end turned back, like that of an instrument with which to mark boards, is just the thing for this purpose. While the object, in the first place, should be to reduce the hoof to its natural size, care should be used not to cut away too much of the wall; for, bear in mind, cutting away too much must bring the shoe against the sole, and forces driving the nails too deep into the wall of the hoof, if not into the vascular part inside, which would not only cause lameness, but be liable to induce the secretion of matter, and very serious consequences would follow. (See Causes of Lameness.) And besides, forcing so many nails into this thin

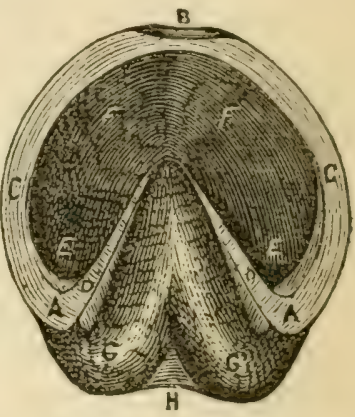

(No. 8.)

A Sound Fore-foot, preparer for the Shoe.

$a$ The heel of the crust. $b$ The toe cut out to receive the clip. $c c$ The quarters of the crust. $d d$ The bars as they should be left, with the full frog between them. $e e$ The angles between the heel and bars, where corns appear. $f f$ The concave surface of the toe. $g g$ The bulbous heels. $h$ The cleft. horn weakens it so much that by a few repetitions of such shoeing it becomes difficult to nail on shoes with any certainty of being held to the foot very long, and, of course, the more re-nailing the more the mischief is increased.

The bearing surface should be leveled down carefully and left a little higher than the sole, so that there can be no bearing of the sole upon the shoe. If the foot is flat and will not bear this, then the shoe must be lowered inside of 
the part coming under the wall, so that the sole will not touch it. No definite rule can be giv by which to explain just how much to cut away, or the limit. If the heels are strong and upright, they should be cut down so that the bearing will be level and the hoof appear natural. (See cut 8.)

Thenext aim is to form and fit the shae so as to approximate it to the size and bearing of the foot and work of the horse. If the hoof is thin shelled and the horse is not worked much, the shoe should be light; but if the work is hard, more weight will be necessary. No general rule will apply here. The shoer is to understand that if the foot is properly prepared as directed, the shoe must be made big enough to just come out even with the edge of the hoof from the toe to the turn of the heels, becoming a little wider at the extremity of the heels, for as the foot enlarges by growth, the shoe is brought forward under the heels until it loses its original proportion and becomes too short and narrow, to allow for which the shoe should be as much wider and longer than the foot at the heels (about a quarter of an inch) as it is supposed the foot will grow in the time it is intended to keep the shoes on before being re-set. The bearing surface of the shoe should be perfectly level, and only so much of the shoe as comes under the

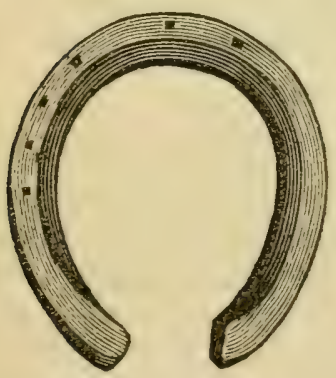

(No. 9.) Shoe, inner surface beveled to prevent contact with sole of foot. wall of the hoof should touch the foot. Either the foot must be prepared so that the shoe cannot come down to the sole, or that part of the shoe coming inside the wall of the hoof must be so hammered down that the sole cannot possibly touch the shoe. (See cuts 8 and 9.)

This requires being exact, no guessing or coming "pretty near" the thing and nailing on. The shoe should be so fitted that when laid on a level surface every part of the bearing surface would touch, and it should fit equally well to the foot. 


\section{SHOES ARE MADE CONCAVE,}

If the shoe as usually fitted is examined, the bearing surface at the heels will be found concave or the inner edge of each heel much the lowest; not only this, but often the heels are carried back too far, or the shoe is so wide that the heels rest on the seating inside of where fitte to support the heels.

It is evident that if the bearing surface at the heels is concave, there is a natural tendency as weight is thrown upon the foot to have the heels crowded together.

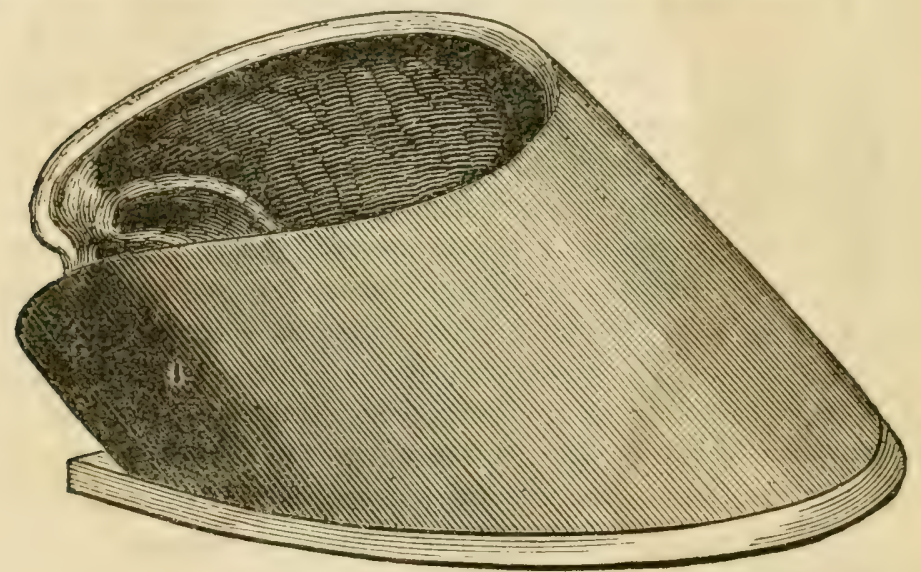

(No. 10.) Shoe Properly Fitted.

With the foot properly prepared and the shoe properly fitted to it, the next important consideration is nailing it to the hoof. As the hoof is continually growing and becoming proportionately larger than the shoe, this must be done if possible so as not to bring lateral restrain " upon the quarters, and this implies attention to the location of the nail holes. If the smith were to examine the thickness of the hoof of an ordinary well-bred horse, he would perhaps be surprised at its thinness, and he would see the importance, in the first place, of making the holes near the edge weil forward in the toe, and of not putting the shoe so far under the shell as to compel his driving the nails too deeply into it, or of having the nails so large as to split and shatter the hoof. If the nail holes are made well into the shoe, and the shoe should be a little narrow or short, and be set 
well under the hoof, the nails must be driven very near, or into the quick, which must result in serious lameness or injury. Two points, therefore, must be kept in view by the

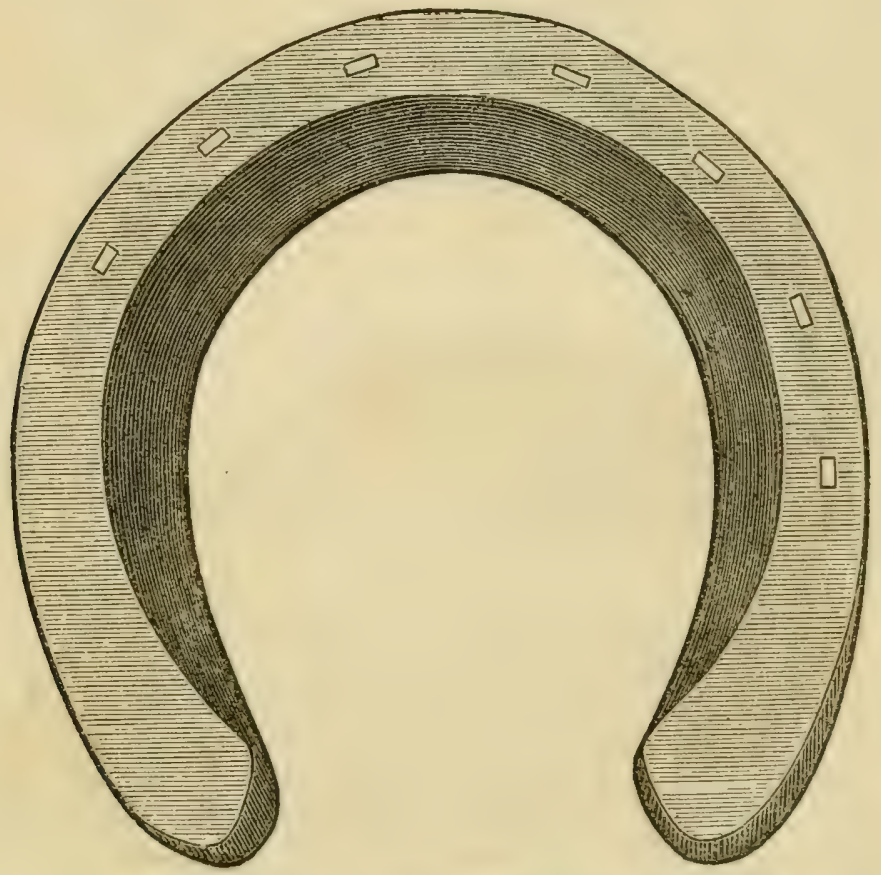

(No. 11.) Bearing Surface Level.

smith in punching the nail holes. First, making them so far forward in the toe as to prevent needless restraint upon the quarters. Second, so near the edge of the shoe as not to endanger driving the nails too deep in the crust. The nails should not be large, nor a greater number driven than is barely necessary to retain the shoe.

It must be remembered that, at best, the hoof is greatly shattered by the nails; that the horn is thickest at the toe, and the nailing well back to the quarters not only exposes to greater danger of pricking, but causes an injurious pressure upon the heels. If the horse is not used much, and the heels are rather square and upright, the quarters must be kept free. Hare the nail holes made well forward on both sides, three on the inner and four on the outer side, or nail well back on the outside quarter, but well forward in . $6^{*}$ 
the toe 1nside. As the foot now grows, the shoe will be carricd that side and forward, leaving the inside quarter free, thereby making both quarters as independent of the

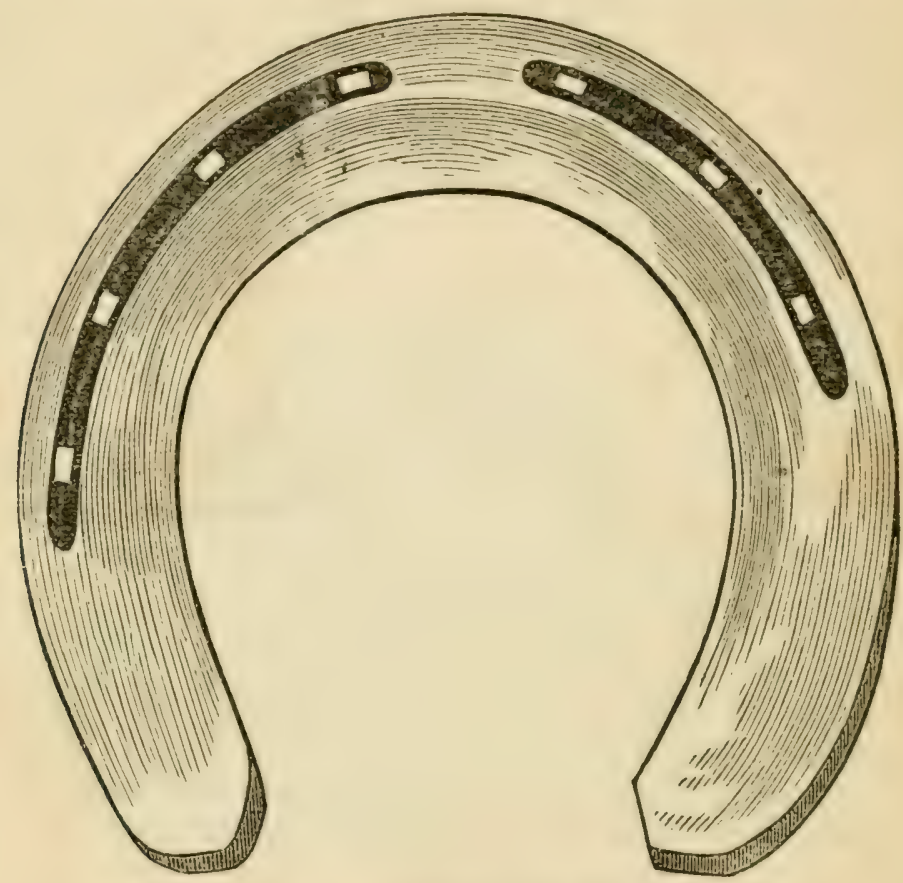

(No. 12.) Ground Surface-Position of Nails.

restraint of the shoe as it is possible to do. Any increase in the number of nails to retain the shoe more firmly must not imply freedom to drive them back in the quarters. Let the holes be punched closer together in the toe.

\section{EXCESSIVE RASPING BAD.}

Care should be used not to file too deeply under the clinches, as is common; and in finishing off, the file should not be touched above the clinches, and below only enough to round the toe a little. There is a penchant in most smiths to improve the shape of the foot by rasping and filing the whole surface to the hair. 'The outside of the hoof is much more dense and hard than the inside; the small spuces between the fibres of the horn are filled with a soft 
substance-the better to prevent a too rapid evaporation of moisture. If the whole surface of the hoof is rasped, the best part is not only likely to be cut away, but too rapid evaporation takes place, and the hoof is not only thereby weakened, but becomes dry, hard and contracted. If the horse is not used much, and stands on dry plank, this condition must be produced.

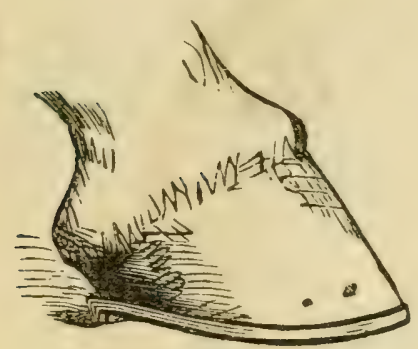

(No, 13.)

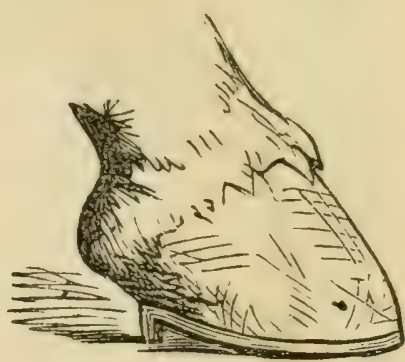

(No. 14.)

Foot Properly shod, and a foot that has been rasped down too much, in order to fit the shoe, which is too swall for it.

There is a very grave fault in the fitting and nailing of shoes, namely: if they happen to be too short, of setting them well back from the toe, which not only necessitates rriving the nails so deep into the hoof as to prick and lame the animal, but also destroys the proportion of the foot by cutting down the toe too much. (See cuts $x_{3}$ and 14.) Smiths seem to think it necessary to cut the hoof down to the shoe, no matter how far under the shell it may be. This is wrong, as the shoe is now pressing upon and nailed to the inside or soft part of the shell, which of itself leads to soreness and derangement. (See cuts 9 and IO.) In the first place the hoof should not be cut away too much in preparing for the shoe, but should leave plenty of strong, hard horn, through which to nail. In the second place, the shoe should come out even with the hoof; and third, the nails should be driven deep enough to hold firmly. Some shoers have a faculty of going from one extreme to the other by driving the nails so near the outer edge of the crust that there is almost certainty of breaking through. (See cuts I5 and I6.) Illustrative of this see cut I5; the hold of the nail is not deep enough; whereas in 16 the nail is started deep and comes out low, getting a good, strong 
hold, and not endangering driving into the quick. There should be no effort to cut down the hoof in any away that would weaken it, or destroy its natural appearance and bearing

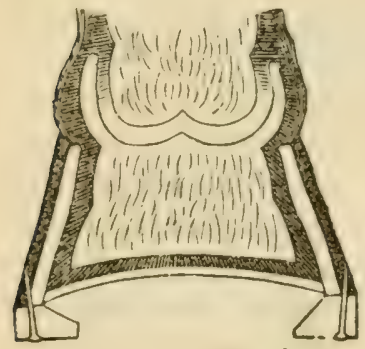

(No. 15.)

Nails driven too straight.

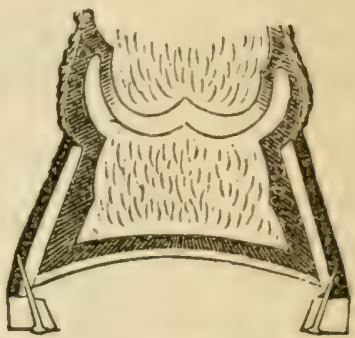

(Nö. 16.)

How to nail the Shoe.

\section{CONTRACTION OF THE FEET.}

If we cxamine the foot in its natural, healthy state, it will be found almost round, and very elastic at the heel. The frog broad, plump, and of a soft, yielding character. The commissures open and well defined, and the sole concave. 'The outside of the crust, from the heel to the toe, increased from a slight bevel to an angle of about forty-five degrees. In a state of contraction the heels are narrow and high, the commissures closed and the frog small, and from bad shoeing a marked change in size and form. Corns, or bruising of the sole at the heels, or any difficulty causing lameness, is induced by inflammation. Now, any cause by which the sensible sole or muscular structure uniting the coffin-bone to the wall of the hoof is bruised and inflamed, leads to either decomposition and the formation of matter, thickening of cartilage, or growth of bony formation.

The most common cause of inflammation, producing change of structure and lameness, is contraction. It is evident that the more horn is grown the wider and longer the foot becomes, and the more cut away the narrower and shorter it is made. If a shoe be fitted accurately to a foot after being trimmed and prepared carefully, it would be found in a few weeks to be much too short and narrow or too small for the same foot.

The foot is continually growing and losing its original 
proportions with the shoe, which, in four or five weeks, becomes at least a quarter of an inch wider and longer than it was when dressed. Now there must be not only special provision made in nailing for this increased enlargement, but the greatest care should be used not to permit any lateral, mechanical pressure upon the quarters that would restrict their freedom.

It must be observed that shoeing first raises the frog from contact with the ground, which, of itself, removes an important auxiliary to health in the foot; second, that nailing the shoe to the sides of the hoof brings direct restraint upon the quarters with increased force, and to the degree that this nailing is extended to the heels and the foot increases in size by growth, is the foot contracted by the restraint thus unavoidably produced.

\section{SHOES CONCAVE INJURIOUS.}

There is also another cause of derangement requiring special notice, namely: the bearing surface at the heels is usually inclined inward, or the inside edge is much lower than the outer edge, often quite or more than a sixteenth of an inch, which alone is sufficient to cause serious contraction. In addition to which the increased absorption of moisture, induced both by inflammation and by keeping the feet dry, tends directly to this end, since the dryer and harder horn becomes, the more lessened in size. Of course, if direct pressure is brought upon the foot, by which the vascular structure beneath the shell is bruised and inflamed, lameness and ultimate change of structure must ensue, which, if permitted, may cause serious or even incurable lameness.

There is one peculiarity about contraction that seems to puzzle even good practitioners, which is the increased growth of the heels. The heels grow down rapidly, and the shell becomes very thick, while the frog becomes small and hard. If cut No. I 6 is examined, the sole will be seen to be arched. Now it is evident if the quarters are pressed together, this bending of the sole upward is increased, bringing increased pressure upon the suspensory ligaments and coffin-joint, and force the coffin-joint upward and forward against the hoof at its upper edge. 
Now if you look at cut No. 7 , you will discover an artery passing down each side of the leg, which divides above the hoof into two branches, one forward around the edge of the hoof, and another back to the heel, which again throw off innumerable branches. The office of these arteries is to supply material for the growth of horn. Now the pressure induced upon the coffin-bone by the pressing of the sole against it as before explained, forces the coffin-bone against the upper edge of the hoof, and thus presses directly upon this artery, thereby obstructing the flow of blood to this part, and forcing it back into those supplying horn at the heels. Hence the forward part of the hoof grows slowly and becomes thin, while the heels grow down rapidly, becoming high and thick.

The first and important object in curing disease is, to remove the cause. We must do more than this in the cure of contraction by removing the surplus horn accumulated and applying mechanical pressure in such a way as to gradually spread the foot back to its natural form, so far as it will bear.

To do this we must first thoroughly soften the feet by poulticing. Next cut down the heels to within an eighth of an inch or more of the sole. Cut down carefully between the bars and frog. If not careful, you will cut through and bring blood at the extreme of the heel, while you have not cut deep enough farther forward. Follow the curve of the sole, aiming to cut out an average depth until the heels will yield easily to a little pressure.

The next object is to gradually force the heels outward. There are three ways of doing this:

First, (this is the treatment, I am informed, used by Mr. Robert Bonner of the New York Ledger, who is undoubtly one of the most careful students of the foot, and of the conditions necessary in shoeing to keep it in a healthy condition, in this country,) form the shoe of an equal thickness all the way round, with nail holes punched well back in the heels, and fit accurately to the foot, so that it will come out even with the edge of the hoof. Now drive the nails carefully, so that they will be deep enough into the horn to hold firmly without endangering pricking, leaving the points stick down straight After all are driven down, pull them out again. Heat the shoe and spread it about ont-eighth 
of is inch, more or less according to what the foot will beas, and put on again. Now, drive the nails again, each a little at each time until driven home, and clinch firmly. It is seen that the shoe must now exert an outward pressure upon the heels equal to the increased breadth of the shoe. Keep the foot reasonably soft. In a few days or a week the clinches can be carefully drawn, the nails pulled out, the shoe made wider and nailed as before, which can be repeated so long as the nails will hold well.

A simpler method is that of the convex shoe, (cut I 7.) The foot is prepared as before, with the difference of not cutting away the bearing surface so much at the heels. The shoe, instead of having the bearing surface level, should be made convex, the outer edge from an eighth to one-fourth, or even more, of an inch lower than the inner edge, running out at the toe. This surface should be filed down carefully, and so fitted to the foot that the heels will rest on these in. clined surfaces, the shoe being a little wider than the heels, and nail on. Now there

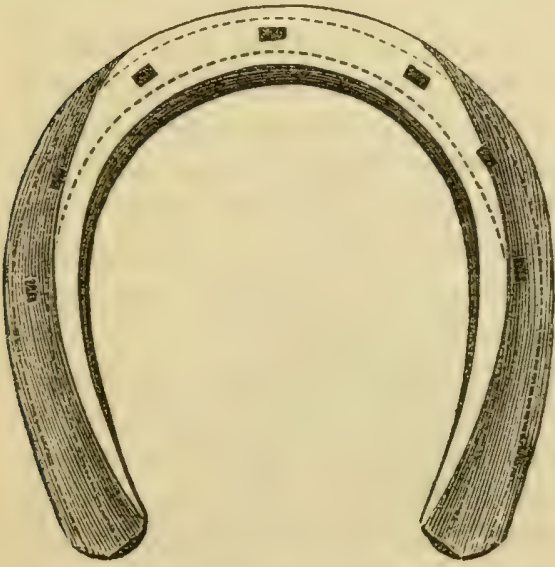

(No.17.) Convex Shoe for the cure of Contraction. is a continued slipping outward of the heels when weight is thrown upon the foot. Remember one point here. Do not commit the error of cutting down the heels very close. You must have horn enough to keep the shoe from coming in contact with the sole. If it does, the inner edge pressing upon the sole forms a shoulder which will not only prevent expansion, but bring pressure upon the sole, bruising it, and thus be the cause of injury and lameness.

The third, is that of Tyrrel's patent shoe, (cut I8.) By this shoe, if properly fitted and applied, the foot can be expanded as little or as much as may be desired. It will also enable expanding one or both heels as may be desired, and is the best form of shoe I have seen 


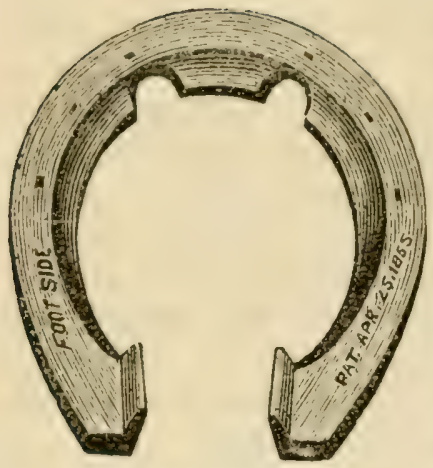

'No. 18.) Tyrrel's Patent Shoe for the cure of Contraction.

for the cure of contraction. The only difference there is in this shoe from the common form is: first, the inside edges of the heels are turned up into little clips; second, the shoe is so cut out at each side of the toe as to enable bending the quarters outward, by putting the tongs or a screw between the heels and pressing them outward. The clips at the heels extending up inside of the bars at the extreme of the heels press the heels outward just so much as the shoe is spread, which can be done every few days at will until the foot is expanded as much as may be desired. This is the great consideration in the cure of contractions so far as mechanical pressure is concerned. It requires nice mechanical judgment and skill to fit and put on any form of shoe, both in preventing contraction and for its cure, and especially so in my judgment in the use of this. As before explained, the foot should be carefully dressed down to its natural form. The excessive horn preventing expansion of the heels cut away, implying especially the thinning out well of the part between the frog and bars. The foot should be softened by poulticing previously The shoe should then be carefully fitted, the clips resting accurately against the bar inside. The shoe should never be spread enough at a time to cause inflammation and soarness. If this is carefully persisted in, so far as the contraction, cure must be certain. This shoe of $\mathrm{Mr}$. Tyrrel's has been used with great success for this purpose. The right to use it with special directions for its use can be obtained by addressing H. B. Fern, Batavia, N. Y.

\section{CORNS}

Appear in the angle of the hoof near the heel. They are generally caused by the shoe being worn too long, causing the shell of the hoof to grow over the shoe, which throws the weight upon the sole, or the angles between the bar and crust are not properly dressed out. If the descending hee? 
of the coffin bone meets with too much resistance by want of elasticity in the sole at this place, the sensitive sole is liable to be so bruised and injured as to produce corns, which are simply a contused wound of the sensitive sole. Contraction is also an actively exciting cause of corns which should be overcome by expansion shoes. If of an ordinary character, upon cutting away the horn, there will be found a red spot; if very bad, the color will be a dark purple and deeper seated.

- If in this condition it is neglected, matter may be formed, or the inflammation may cause the lateral cartilages which are attached to the heels of the coffin bone to become ossified, or even the accumulation of large, bony deposits, which would destroy the mobility of the foot and cause considerable deformity.

All pressure must be re-

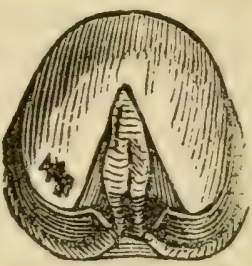

(No. 19.)

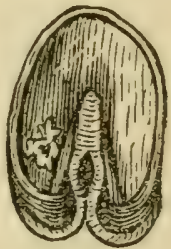

(No. 20.)

New Corn.

Situation and appearance of an old corn. moved from the part. First, dress down the part bruised until quite thin. Put a little sulphur on, and burn in pretty well with a hot iron, or put on butter of antimony, which will stimulate a healthy growth of horn.

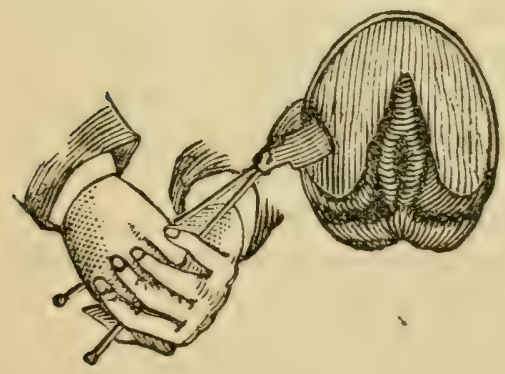

(No. 21.)

Testing for Corn.

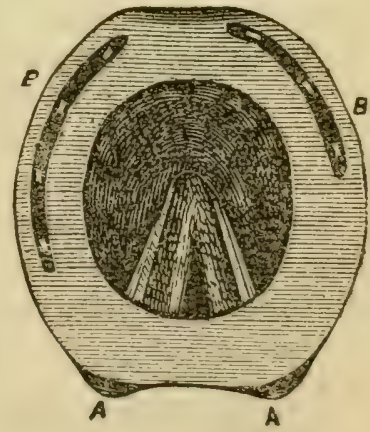

(No. 22.)

Bar Shoe for Corns.

If there is much inflammation, poultice; and if ther is a cavity or the sensible sole is exposed, put on a little $\mathrm{p} c \mathrm{ch}$ and tallow, over which spread a little tow. Put on the s.roe 
so fitted there will be no pressure on the part. To do this a bar shoe will often be necessary. (See cut No. 22.) The shoe should be re-set frequently until cured.

\section{QUARTER CRACK.}

When the hoo' is dry and hard it is easily split. A piece of glue when very dry splits and breaks very easily if pounded upon, vut if softened by moisture would only bend and be vruised. 'The hoof partakes of the character of glue. If very dry the fibres become dense and hard. If while the feet are in this condition the horse is driven fast on hard roads, the hoot is luable to burst. If the hoof is thin and contracted, there 15 great danger of the inside quarters splitting.

Cut down the hool back of the crack, so that there is no pressure of that parc of the bearing surface upon the shoe, put on a bar shoe, cut across the split deeply at the edge of the hair with a tiring iron. Next cut down the edges of the hoof so far as split extends, to the quick. Then soften and grow down the hoof rapidly by applying any good, stimulating ointment. A mixture of equal portions of tar, lard and turpentine, is excellent for this purpose. The fitting of the shoe should be carefully attended to, the hoof grown down as rapidly as it is safe to do, and the part kept clean by covering it with a little tar, or a mixture of resin and tallow. There will not be a cure until a new hoof is grown down, which will take about six or eight months.

\section{INTERFERING.}

Some horses travel so close that the least neglect of having the shoe well under the quarter, and the part nicely dressed down, would cause a bruising and cutting of the

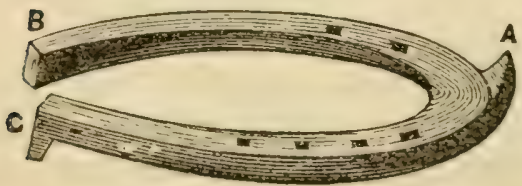

(No. 23.)

Interfering Shoe. opposite ankle. The shoe should be so formed and fitted as to come well under the hoof. To do this well, that side of the shoe should be made rather straight, with the web narrow, and the nail-holes well forward 
in the toe; at all events there must be no nails driven into that part of the hoof that strikes, as the clinches will be likely to cut. If the toe cork is set well round, on the inside of the toe, and the foot is so pared, or the shoe is so formed that the bearing of the inside of the foot is raised somewhat, there will be a tending in the ankle to be thrown out when borne upon. But the great object is to have the shoe fitted and filed smoothly, and set well under the part hitting, so that after the hoof is rasped off all it is prudent to do, and rounded down care. fuily, the shoe sets far enough under not to endanger its cutting, yet supports the hoof, and gives a natural bearing to the foot. The chief

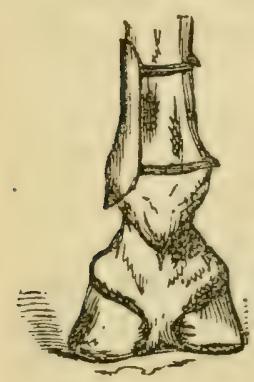

(No. 24.)

danger will be that some portion of this part of the shoe, will be made to extend beyond the hoof, and the shoe be fitted and put on so roughly that it can scarcely be said to be fitted any smoother or better than is usually done, without regard to such a purpose. It Interfering Pad.

is always best to keep the bearing natural by trimming

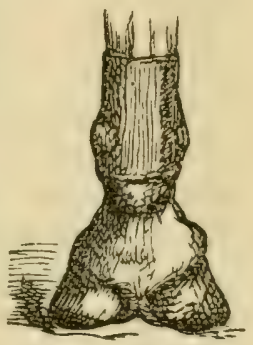

(No. 25.)

A Leather Boot to protect the Ankle.

the foot level, and making the shoe of an even thickness, but set it under and file smoothly. If this will not do, raise the inside a little. Driving young horses to sulky will often cause interfering; getting a horse in good condition will often overcome the difficulty. If the ankles are cut or sore, they should be protected with pads until well. If the owner values the animal highly, he should give such shoeing his personal attention.

\section{WEAK HEELS.}

Cutting down too close and fitting the shoes roughly, so that the horse wears and breaks down the heels, will cause them to be low and sensitive. Such feet should be simply leveled down with the rasp carefully, and the shoe fitted to touch every part of the bearing surface at the heels. 


\section{SHOES.}

It should be borne in mind that that form of shoe which accords with the foot in making the bearing natural, pre-

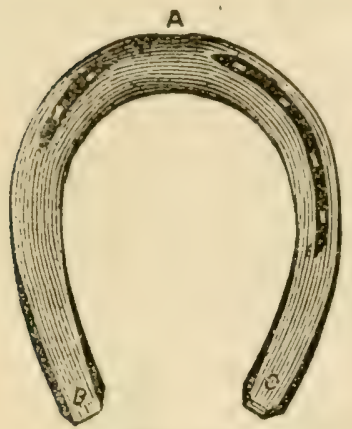

(No. 28.) serves its elasticity and protects it from injury, is best. If we examine the foot it will be found concave. This is the best form to enable a fulcrum that will prevent slipping. If we would imitate and carry out in the form of the shoe, that of the foot, it should be also concave, or thick at the outer edge and beveled upward to the inner edge on the ground surface. Such a shoe will not ball, prevents slipping, is lighter, and would certainly enable more speed on a track if at all wet. Amateurs who have an opportunity should see my models of shoes of different patterns.

Shoes for summer wear should be level, of an equal thickness from toe to heel. If the roads are soft, this is certainly advisable, to give the frog pressure. If shoes are made with corks, the inside ones should be rounded, so as not to cut the feet. The outside ones will prevent slipping. My "Maine Snow Shoe" is undoubtedly the best for winter use; will not ball, and prevents the feet most effectually from being bruised or injured.

The bearing surface of all shoes should be level, and come exactly under the wall of the hoof all the way round. The nails should be as small, and as few, and as far forward in the toe as will retain the shoe safely, the object being to wrotect the foot and keep it healthy. When, from any cause, there is an undue absorption of moisture, making the frog and hoof dry and hard, either from inactivity by standing on a dry floor, or driving on dry hard roads, or both, it must be supplied by artificial means. Stuff or fill the feet with flax-seed meal, to which has been added a little wood ashes mixed with water. It will stick. Or wet cluths may be tied around the hoof.

If there is soreness of the feet, put them in water as hot as can be borne, to which should be added a handful of salt, for an hour each day, for one or two weeks, or blister mildly around the coronet, repeated two or three times. 
If there is a dry, hard condition of the feet, apply moisture around the coronet by tying wet cloths around the hoof, or poulticing, stopping the feet with flaxseed meal, as before explained; after which, apply some of the preparation for softening the feet and stimulating the growth of horn.

The usual palliative means of rubber cushions and such means, put between the hoof, to cure soreness and lameness, are of no account, since they do not reach the cause of difficulty. The nailing of the shoe must necessarily be so tight as to press out all the elasticity there is, and, in addition, the heels cut through such means so quickly that they will not prove of any real value.

\section{RE-SETTING OF SHOES}

Shoes should be re-set once in from four to six weeks. For light, occasional use, not more than seven nails should be driven-four on the outside and three on the insidewell forward. The shoe should come well out under the toe, so that there is no necessity for more than touching the edge a little to reach the shoe, and by all means do not allow that reckless rasping of the outside of the hoof so general with shoers. If the shoe is short it should not be a reason that the hoof must be cut down to it. Even rasping under the clinches should not be permitted. A thin shell can be easily ruined in this way; besides, this rasping of the whole surface of the hoof not only removes the strongest and hardest part, but permits too rapid an evaporation, which causes the horn to become hard and brittle. It is much better, easier and cheaper to keep the feet healthy than to cure them. It is wise in shoers to be patient and do the work well, and owners should remember that extra care and skill deserves extra compensation. It is hoped that the few explanations given will aid in a better understanding of this duty.

If the horse shows sudden lameness in the foot, especially after being shod, examine it carefully; strike the hoof lightly with a small hammer; put the hand first on one foot and then on the other, that you may discover any increased heat. If a nail has been driven too deep, remove the shoe. If much inflammation, poultice-usually necessary for 
twenty-four hours or more-when cover the part with tow and a preparation of tar and resin, or pitch and commou grease. If a nail has been driven into the foot, get the horse to the stable as quick as you can, take off the shoe, poultice the foot, and give a sharp dose of physic, and let the animal stand quietly. The object is to keep down inflammation. No hot oils or anything stimulating is to be applied.

A little of the digestive ointment may be used after the inflammation goes down to excite a healthy granulating process, or any cooling astringent. There is liable to be tenderness if the sole should strike the ground afterwards, as there may be inflammation of the periosteum, to relieve which, put on a high-heeled shoe and blister around the coronet. The sole is sometimes bruised by the shoe pressing upon it, causing much inflammation and lameness. Take off the shoe, poultice for twenty-four hours or more; fit the shoe so as to remove all pressure from the sole; if sore yet, continue the poultice; if matter is formed, treat as you would any such ulcer, with a healing astringent. Several good preparations are given in another part of this work.

The difficulty of getting sketches made of the illustrations needed in this and other articles, induced the necessity of copying many of them from Mayhew and others. 


\section{DISEASES AND THEIR TREATMENT.}

THE treatment and remedies here given will be found very valuable. I have, at great loss of time and money, subjected myself to a practical course of study under one of the best educated and successful English veterinary surgeons in this country, (Dr. William Somerville, of Buffalo, N. Y.,) whose certificate will be found below, and aim to give such practical treatment as I know to be most reliable and practical. Many of the remedies included have been obtained by me at much trouble and great cost, and are worth much more than the cost of this book and my instructions. I have no desire but to benefit my patrons, and the utmost assurance may be felt that the greatest care has been used in discarding remedies not known to be reliable and valuable.

\section{DR. WILLIAM SOMERVILLE'S CERTIFICATE.}

"This is to certify that D. Magner, Esq., served under me nearly two years, during 1868 and $\mathrm{x} 869$, as an apprentice, to learn and be instructed in the veterinary profession. I consider him well qualified to treat successfully all diseases in horses, and able to practice as a skillful and competent veterinary surgeon.

\section{"WM. SOMERVILLE, "Veterinary Surgeon. "A member of two Veterinary Colleges, " and thirty"six years' practice.}

"Buffalo Horse Infirmary, 127 Erie St.,

"August Ist, $1869 . "$

I would urge the necessity, at least, of ordinary prudence in preventing colds and sickness by guarding against unnecessary exposure, or mercilessly driving until in a profuse perspiration, and then leaving the horse in some cold, bleak place without more, perhaps, than a poor blanket, and that 
thrown on carelessly, while the driver is perhaps enjoying himself with his friends in some drinking saloon, toasting his shins while the poor animal stands shivering at the door. 'The effect of such bad treatment will not then have time to develope itself, but will be seen in a few hours, or at farthest on the following day. This is the common cause of acute laminitis (founder) and of pleuro-pneumonia (pleurisy). 'The three principal points in the health of a horse are feeding, air and exercise. In the first place, irregularity of feeding will certainly produce disease. (See article on feeding.) Ventilation - the stable should be neither too hot nor too cold. The animal will show the effect in a few days by coughing or having slight irritation of the mucous membrane of the throat.

A horse can take cold as easily by going out of a cold air into a hot stable, as he can by going from a hot stable into cold air, and vice versa. It is the sudden change of temperature which produces the change on the mucous coat of the larynx and throat.

The clothing of the horse in the stable should be neither too hot nor cold. But if kept too warm, he will be more likely to take cold when he goes out to exercise on a cold or chilly day. The stable should be well ventilated with pure air at all times, and all poisonous air and gases, particularly the ammonia, which is formed from the urine, should be allowed free egress from the stiable, as the animal cannot be expected to keep in good health while compelled to inhale such malaria.

L.et me tell you, one of the great points in keeping horses in good health and condition, is regular feeding and good care, being careful, after a sharp, hard drive, especially if there has been exposure to wet and cold, to blanket warmly -anticipate and look for a chill, or being off of food. If so, a little fever medicine and a warm bran mash should be given at once, and a serious attack of pneumonia may be thus averted. Men who talk and slash horses around recklessly, I have a low opinion of as horsemen. To keep) horses doing well, even though worked hard, requires attention to little things. If the road is heavy or up-hill, and the horse shows fatigue or is warming up excessively, hold up and shove, if necessary, on good road and down grade, aiding and nursing along by watering often but not inuch at a time. 
A very little driving without regard to this prudence will soon get even a good, hardy horse off his food, if not cause sickness, and then Providence, or something else, is the supposed cause. Use all the care and prudence you can in guarding against and preventing sickness; it is your safest and best rule. I give the very best treatment in the following pages you can use with most success. The medicine is easily obtained and administered. Indeed there are single remedies in this book I would not be without for one thousand dollars.

\section{SPASMODIC COLIC.}

Colic is one of the most common as well as most dangerous diseases to which the horse is subject. There are two forms of this disease, namely, Spasmodic and Flatulent Colic.

The first is wholly of a spasmodic nature, and if not relieved, will, in severe cases, run into inflammation of the bowels, causing speedy death.

The second, while exhibiting the same general symptoms, shows marked enlargement of the belly, from generation of gas, which, if not checked and neutralized, results fatally by rupturing the diaphragm, causing suffocation and death.

The common causes of colic are, application of cold water to the body, drinking cold water when in a heated condition, costiveness, unwholesome food, etc.

Premonitory symptoms, are sudden. 'The animal paws violently, showing evidences of great distress, shifting his position almost constantly, and manifesting a desire to lie down. In a few minutes these symptoms disappear, and the horse is easy.* But the same uneasiness soon returns, increasing in severity until the animal cannot be kept upon his feet; the pulse is full, scarcely altered from its normal condition; a cold sweat breaks out over the body; temperature of legs and ears natural. As the disease advances the

* Notr.-He may also act as if he wanted to make water, which he cannot d", there being a spasmodic contraction of the urethra. Hence the desire to give diuretic medicine. Straining in this way is usually prompted by a desire to reliere the muscles of the belly. No diuretic medicine should be given as the horse cannot pass urine until the attack of colic ceases, or it is taken from him with at catheter.

It is very seldom, even necessary to use a catheter. In fact, it is not necessary to pay any attention to this symptom. As soon as relieved of the colir, the horso will pass water freely. 


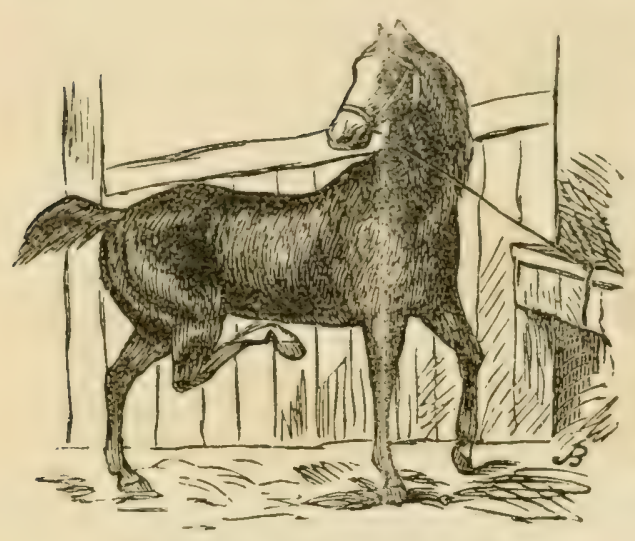

First Stage of Spasmodic Colic.

symptoms become more severe, the animal at times throwing himself down with force, regardless of consequences, looks anxiously at the sides, sometimes snapping with the teeth at the sides, looking anxiously at the belly, and striking upward with the hind feet, showing almost the same symptoms as in inflammation of the bowels. There are, however, strongly marked characteristics peculiar to each. The better to point them out, I will tabulate them, by which the difference and peculiarities of each can be easily determined.

\section{COLIC.}

Sudden in its attacks.

Pulse, in the early stage of the disease, not much quickened or altered in its character.

Legs and ears of a natural temperature.

Rubbing the belly gives relief.

Relief obtained from motion.

Intervals of rest.

Strength scarcely affected.

\section{INFLAMMATION OF BOWELS.}

Gradual in its approach, with previous indications of fever.

P'ulse much quickened, small, and often scarcely to be felt.

Legs and ears cold.

Belly very tender and painful to the touch.

Motion increases pain.

Constant pain.

Rapid and great weakness.

This disease being wholly of a spasmodic nature, it must be counteracted by antispasmodic treatment; and laudanum being the most powerful and reliable antispasmodic it is here indicated.

Treatment.-Give from two to three ounces of laudanum and a pint of raw linseed oil. If not better in an hour, give two ounces of laudanum and the same quantity of oil.

If there is not relief in a reasonable time after the second dose is given, take from six to twelve quarts of blood from the neck vein, according to the size of the horse and the 
severity of the attack. Always in bleeding make the orifice large, and extract the blood as quickly as possible. As

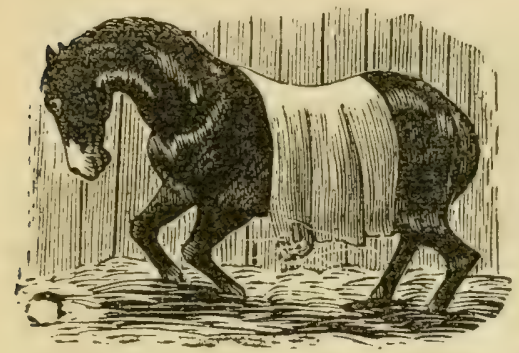

Second Stage of Spasmodic Colic.

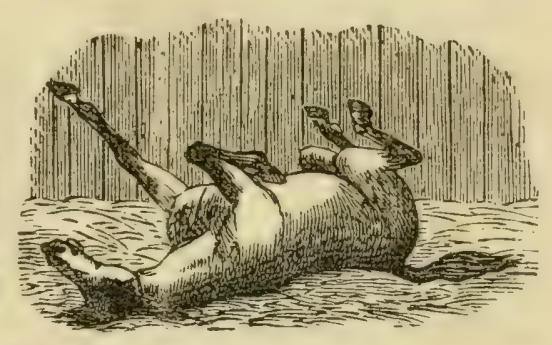

Third Stage of Spasmodic Colic.

bleeding is the most powerful and reliable means of relaxing the system, it can be always relied upon in the cure of this form of colic. There will be no relapse after bleeding.

The following remedy given me by Dr. T. Burton of Fultonville, N. $\mathrm{Y}$., is one of the best, if not the very best in use for the cure of either form of colic. The Doctor assured me he never knew it to fail if given in a reasonable time. In every case it has been used under my own observation and by myself it has given prompt relief:

\section{FOR COLIC IN HORSES-DR. BURTON'S REMEDY.}

Sulph. ether I pint, aromatic spirits ammonia I pint, sweet spirits nitre 2 pints, opium I/4 lb., asafœetida (pure) $\mathrm{r} / 4 \mathrm{lb}$, , camphor $1 / 4 \mathrm{lb}$. Put it in a large bottle, let it stand fourteen days, with frequent shaking, and it will be fit to use. Dose: One ounce, more or less, according to the severity of the case; once in from thirty minutes to an hour. Should be given in a little water.*

I could give a great variety of remedies for this difficulty, but the more I would include, the more confusion to the reader. The first remedy in connection with bleeding can be relied upon as one of the very best. Bleeding alone will give sure relief, but sticking a knife into the mouth is not the way to do this. A little blood from the mouth may seem a large quantity. There is liability to cut the palate artery and have trouble. Should you be so imprudent, and

\footnotetext{
* Note-The same proportion of tincture may be substituted for the gum which will enable its immediate use.
} 
cannot stop the bleeding, touch the artery with a hot iron, or hold a sponge filled with cold water between the ears. An ordinary styptic will not do. Always bleed from the neck vein, (directions for which are given under that head,) which is one of the simplest and safest of operations.

\section{FLATULENT COLIC, (TYMPANITES.)}

Symptoms same as spasmodic colic, with the difference of there being so great an accumulation of gas in the stomach and intestines that the belly is swelled. This disease will often prove fatal in from one to three hours. It is generally very sudden in its attack, often occurring while the animal is at work, particularly during warm weather or changeable weather from cold to heat; but is generally caused by indigestion, producing gases in the bowels or stomach.*

If to terminate fatally

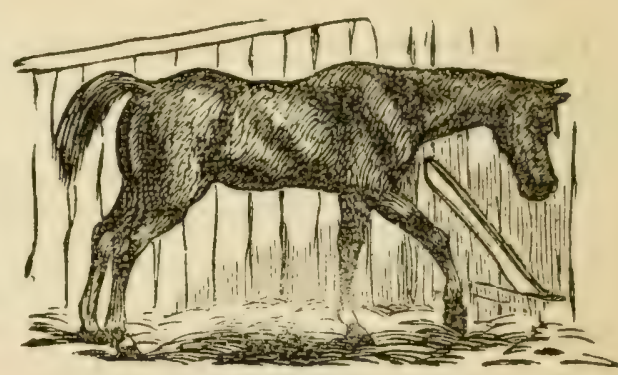

First Stage of Flatulent Colic. it will become weaker and slower until it is almost imperceptible. If the animal is allowed to fall down suddenly while pressure of the gas upon the walls of the stomach is very great, there is probability of rupturing of the diaphragm, which would cause almost instant death from suffocation.

Treatment.-In the first place do not commit the error of bleeding for this form of colic, as it would be almost sure death. Second, keep up evaporation of the body as much as possible by sweating with blankets. What would be still better, if available, would be a hot bath. If you have any of the remedy comprising ether, ammonia, asafotida, etc.,

\footnotetext{
* Note.-There are two locations for this disease, but in either it requires the same treatment, as it is generally produced by the same causes-the stomach, colon and coccum. When in the stomach it will be distinguished by eructations or belchin $y$ s of gas through the esophagus or gullet. If from the cocum or colon, the horse is violently swollen along the belly, flanks and sides generally. Pulse is rarely disturbed until the disease advances, when it will become quickened, run. ving to its beight quickly, and receding as rapidly, if futal.
} 
given for spasmodic colic, give it at once as directed. If this is not available, give a drench of the following:

Peppermint, 2 oz.; sulph. ether, 2 oz.; laudanum, I Oz.; soft water, I pint.

Be particular to keep the composition in motion while administering; to be repeated in half or three-quarters of an hour if not better. There is great danger of this disease ending fatally by rupturing of the diaphragm, through the great distention of the intestines, and contrary to the regular rule of scientific veterinary surgeons' practice. To prevent these violent falls and rolling in the stall, to keep the animal on his feet as much as possible, and to avoid all irritation or action of the bowels, it would be advised that he be walked as slowly as possible, led by the head to prevent falling or rolling, until such time as the treatment has had the desired effect.*

\section{PLEURISY-INFLAMMATION OF THE LUNGS- CONGESTION OE THE LUNGS.}

All these diseases are only extremes or modifications of one disease. I will include their treatment under one head, first describing the symptoms peculiar to each.

[All diseases of the chest take the scientific name "Pnenmonia," and are called Pleurisy, or Pleuro-Pneumonia; Typhoid inflammation of the Lungs - Typhoid Pneumonia; Congestion of the Lungs, or Congestive Pneumonia; and lastly, a disease known as Dropsy of the Chest-(Hydrothorax)-which last is generally the result of the former disease. When the word Congestion is spoken of, it means in common phrase, that one or the other (right or left lobe) of the lungs, are so engorged with blood forced into them that they are either unable to reccive or discharge any blooit, become hard, and almost black in color. When in this stage the disease is called Congestion, and often terminates at this period in death.]

* NotE.-The ether disturbs the breathing, making the horse apparently distressed, breathes laboriously, which will pass off again in a few hours. I could give more of a variety oi treatment for this form of colie, but all things considered, I think this is the safest and best, if not the most reliable for use by those not skilled in practice.

It is well to bear in mind also, that if the horse is small and the case not severe, less is to be given, while if very large and the attack severe, even more may bo given. 
The most common causes of lung fever, as it is termed, are, exposing the animal while warm to a cold wind, or becoming chilled from driving fast against a cold wind. washing with cold wa:er immediately after exercise, changes from heat to cold, or from cold to heat, removing from a warm to a cold, or from a cold to a warm stable, or cold applied to the surface of a heated animal, by which the blood is driven from the skin and extremities to the internal organs, or any cause by which the circulation is obstructed and deranged, may excite any of these forms of inflammation and congestion.

When the pleuro- a watery or fine membrane covering the external surface of the lungs, and lining membrane of the cavity of the chest)-is inflamed, the disease is called pleurisy.

When the inflammation is located in the lungs, it is called pneumonia, or inflammation of the lungs. When the action of the capillaries is greatly lessened from their being weakened, or the blood being so forced through them that they are obstructed and clogged, the difficulty is called congestion of the lungs.

There cannot be inflammation of a part without there being more or less inflammation of the other parts surrounding, and there cannot be inflammation without congestion, as there is always more or less obstruction of the circulation where there is inflammation.

\section{PLEURISY}

may be sudden or gradual in its attack, the horse showing indisposition sometimes for days previous. The horse wili be dull and heavy in action for a day or two, unwilling to lie down, pulse not much disturbed, or there is a chill, or slavering fit, which lasts from one to three hours, when fever sets in; breathing at flanks a little accelerated, cuuntenance is anxious, tlie head is sometimes turned towards the side, does not lie down. As the disease advances the symptoms become more marked. 'The ears and legs become cold; the pulse, from being a little accelerated, grows quicker, hard and full; the head is hung forward, stands. up persistently, breathing hurried, the membrane of the nose and eyes red. Turning the horse round, or hitting against the chest, back of the shoulder, will cause a kind of grunt. 
CONGESTION OF THE LUNGS

is first noticeable by the horse having a severe chill or shivering fit. He refuses his food, hangs his head between

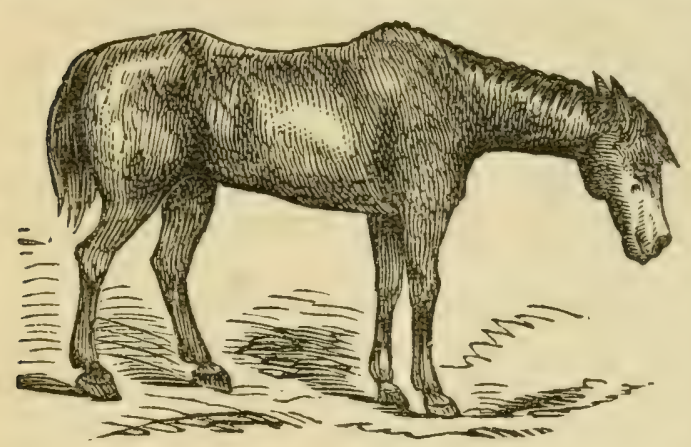

The Commencement of Inflammation of the Lungs. the fore legs or upon the manger, will not move or lie down, brea,thing quick and short, panting like. The nostrils are expanded, the head thrown forward; the countenance expresses pain and great prostration. (See cut.) The pulse is sometimes full and quick, but generally quick and weak, scarcely perceptible; the membrane of the nose and eyes bright red, tending to purple; ears and legs very cold; with a cold clammy sweat at the extremities.

In this case the inability of the horse to take air into the lungs causes great and rapid prostrition, (and will often, from extreme pain, lie down and get up, resembling colic, but the coldness of extremities, prostration and condition of pulse will, if carefully examined, enable an understanding of the real cause,) a choking noise sometimes coming from the throat. In some cases a little blood may be thrown from one or both nostrils. Extreme prostration and laborious breathing and bleeding from the nostrils shows severe congestion of the lungs.

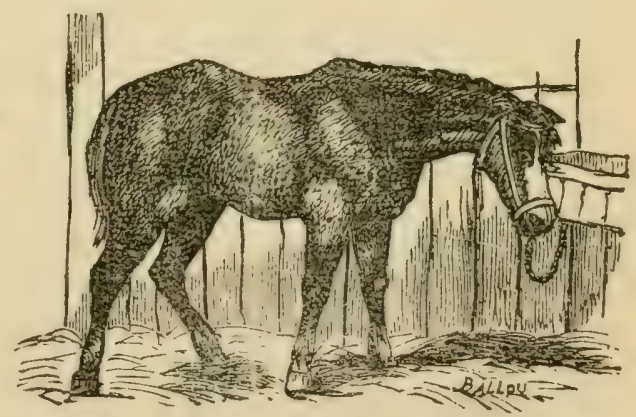

Second stage of Inflammation of the Lungs.

\section{TYPHOID PNEUMONIS.}

First symptoms. - Tle horse is off 1 is feed, disinclination to move, appetite gone, pulse weak and low-will some- 


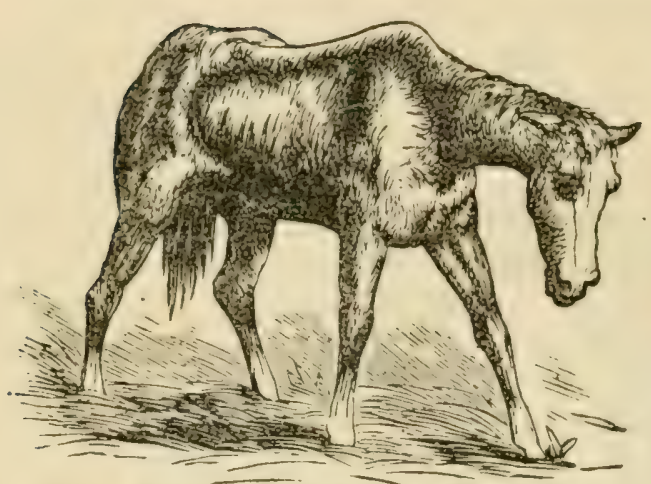

Third stage of Inflammation of the Lungs.

times eat a little, will not lie down, not much cough, rarely any discoloration o: the membrane of the nose or eyes - urine scanty and high colored-fæces hard and coated. After two or three days the mem brane of the nose and eyes a little discolored or red, pulse quicker, 65 or 70 , breathes quicker. About the fourth or fifth day there is usually a discharge from the nostrils, of a blackish brandy color cerumen.

Treatment.-Experience proves that sedative treatment is the most effective for cure of inflammation of the lungs, which is greatly assisted by counter irritation. The sedatives proved to be most effective and reliable are aconite, veratrum and belladonna. Veratrum exhibits great power in lowering the action of the heart, while aconite is not only a powerful sedative, but seems to act as a stimulant to the capillaries, thereby causing profuse perspiration.

There is so little judgment or attention given to condition in giving medicine and its effects upon the system, that I shall be compelled to limit myself to the most effect. ive simple treatment. There are but few who seem to know anything about the pulse; this of course should be under. stood, directions in relation to which, find in anothes chapter.

Take of tincture (radi) aconite I oz.; veratrum $1 / 4 \mathrm{Oz}$; soft water $4 \mathrm{oz}$. Dose from $\mathrm{I}_{5}$ to 30 drops on the tongue, every thirty or forty minutes, more or less, and at longer or shorter intervals, according to the severity of the case. In ordinary cases the veratrum may be omitted. If the case is found to be obstinate the veratrum may be added or given separately in about the same proportion.

\section{FOR AN ATTACK OF PLEURISY.}

Blanket warmly, and put in a comfortable stall, where there will be pure air, and give of the above fever medicine. 
from 15 to 30 drops every twenty or thirty minutes, on the tongue. If the case is severe apply some strong stimulant to the legs and on each side of the body and breast, such as mustard made into a paste and rubbed in thoroughly, or a liniment composed of aqua ammonia, reduced one-half with water; or any strong stimulating liniment should be applied. The legs may also be rubbed and bandaged warmly but not tightly, or some stimulating preparation may be used before bandaging.*

\section{INFLAMMATION OF THE LUNGS OR CONGESTION.}

Treat as for Pleurisy. - If there is much congestion, it is necessary to give prompt relief, which can be done best by taking four to six quarts of blood quickly from the neck vein, stimulate the sides and legs, and give fever medicine as for pleurisy. I wish now to call your attention to what you must not do. First, you must not give physic or oil for any of the forms of inflammation of the lungs. Cathartic medicine in any form is poisonous, such as aloes, oils, or tartar emetic. There is so much nausea attending the operation of these medicines and debility from their effect. There being also such powerful sympathy between the bowels and the lungs, that they hasten the cause of the inflammation of the lungs, often producing death in a few hours after administering them. Second, do not bleed for pleurisy, as so doing would cause debility of the capillaries of the part that would induce hydrathorax and death. In a severe attack of congestion, bleeding cannot only be resorted to with safety, but is the quickest and surest treatment to give relief, but must not be carried too far, merely to assist the lungs to throw off the load of blood forced upon them, and to give the medicine prescribed a chance to operate.

\section{TYPHOID PNEUMONIA-TREATMENT.}

As the word typhoid means low, it is necessary to watch it carefully in that stage, which will last as described in the symptoms, the first four or five days, when in many

\footnotetext{
*Note.-If you give a few doses of aconite as above propared, about the time fever sets in, or before, the horse will be relieved next day A few swallows of water should be given occasionally. Improvement will be denoted by the puliet becoming full and regular, and the expression and actions being lively. $7^{*}$
} 
rases the pulse may run down to thirty. Stimulants should be used at this stage, such as a little brandy and water or whisky and water. A gill or two of liquor to be given as a drench, or what is much better, is, take carbonate of ammonia, from one to two drachms; powdered ginger root, one to two drachms, made into a ball with honey or molasses and given twice a day. It should be remembered that this treatment alone is intended only for the low stage of the disease. When the pulse seems to rise to fifty or sixty about the fifth or sixth day, the patient should then be treated as for pleurisy, with fever medicine. Under the influence of the latter treatment, the pulse will recede and resume its natural number of beats (forty). In this form of disease it is extremely prostrated at first, the whole system being inactive. The pulse may run up in time to seventy, or even eighty.*

The reader may take up veterinary works, and those too by good authority, in which he is told to bleed for pleurisy and lung fever; bleed until the pulse falters. I have only to say that I give you what I know from experience to be safe, reliable treatment, and you are safe in following implicity the treatment given. Indeed, for all ordinary cases, a few doses of aconite, to which may be added, if desired, a little belladonna and veratrum in the proportion given, including same proportion of belladonna there is of veratrum, given promptly, will in almost every instance give relief quickly.

J)r. Somerville of Buffalo, puts up a preparation for the cure of lung fever, colds and chills, which is specific. It will cure every case of chills or fever. A bottle of which should be kept in every stable. If available at your druggist's, get a bottle by all means. It is just the thing, and cheap at any price.

See also introductory chapter to treatment of diseases before treatment for colic.

\footnotetext{
* Note-In all eases in fecding while the animal is lahoring under any of the forms of pneumonia, the aninal should be kept moderately warm, have plenty of pure air, cold water in small quantities, a hand full of wet hay, a carrot or two, an apple or a potato or more; anything of an alterative form. Be careful not to exercise too soon.
} 
CATARRH, OR COLD.

Cold is of common occurrence, and may lead to very serious consequences if neglected. If looked to in time, with a little rest and nursing, the system will soon resume its normal condition.

The usual symptoms are, a little increase of pulse, a slight discharge from the nose and eyes, the hair roughed, not much appetite, and some cough, which is sometimes severe.

Blanket warmly, give aconite as for

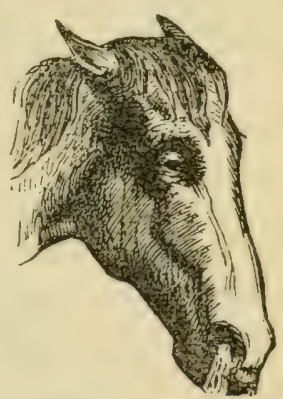

Effect of a Cold. fever. Nurse by giving bran mashes, etc.

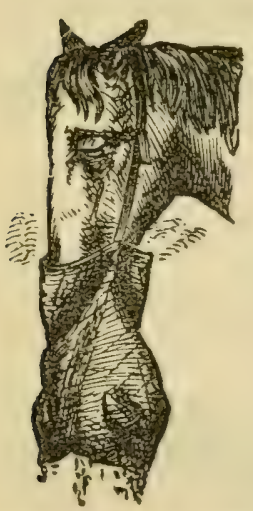

Steaming the Nose of a Horse having Cold. If the case is serious it may run into general inflammation of the air passages, as bronchitis or laryngitis. Would aim to keep up the strength, giving fever medicine, alternating with belladonna. Put on a bag, made of coarse, loose cloth, into which put some bran on which throw. an ounce or two of turpentine. Hang the bag on the head, same as in cut, being careful not to have it so tight around the nose as to heat or scald and be oppressive. A few repetitions of this will cause the nose to run freely. Rest and care will usually do the rest.

If there is obstinate inflammation of the throat and air passages, any good liniment

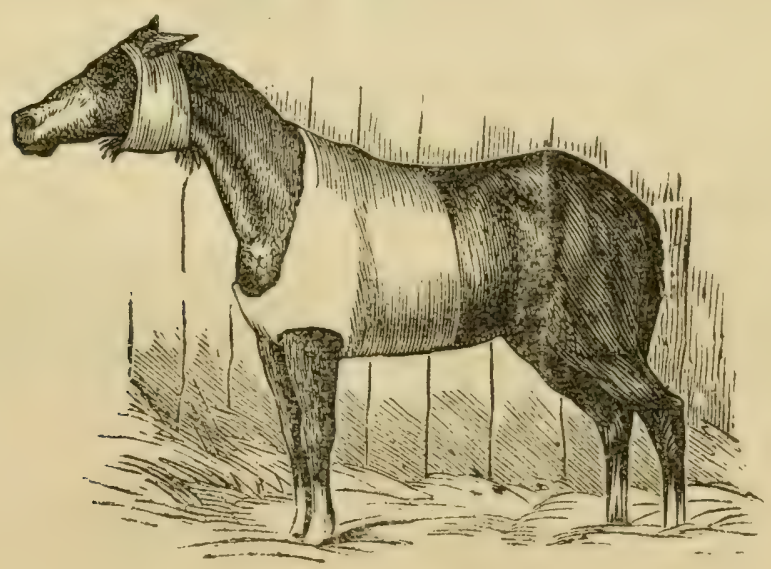


may be applied around the chest and throat and bandaged, as shown in the cut. The object is to stimulate the surface, and this would be an easy, practical way of doing it.

\section{STRANGLES OR DISTEMPER.}

This is another form of sore-throat, familiar to every one. Its design seems to be to throw some poisonous matter from the system, and the object should be to keep the strengtt: of the animal up and hasten suppuration.

The horse is out of sorts; the neck becomes sore and stiff; an enlargement appears which is first hard and tender; there is some discharge from the nose. The case usually grows worse, if very severe, often threatening to cause suffocation; horse unable to eat or drink but little, and strength is lost rapidly.

Use freely a poultice made of wheat bran and warm vinegar, changing as often as the poultice becomes dry, using the eight-tailed bandage, until the enlargement becomes soft and can be opened, when relief will be prompt. Or the following treatment may be adopted, which is similar, and if the alteration is not good, is preferable: Take spirits of turpentine, two parts; spirits of camphor, one part;

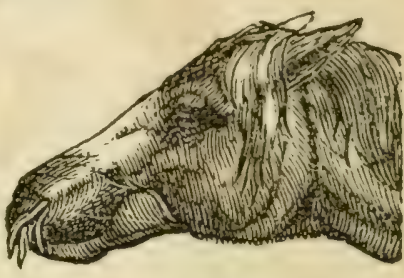

Severe attack of Distemper.

laudanum, one part. Put this on the neck with a brush, if convenient, or any way to apply it without exciting pain, three or four times a day until soreness is crused. After each application have ready three or four pieces of flannel, which should be a good thick article; put these over the parts

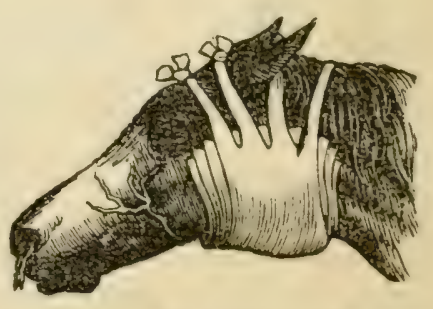

Applying an Eight-Tailed Bandago in Distemper.

and bind on with the eight-tailed bandage. When the tumor points, open it, and be sure that the matter has a 
thorough outlet. Sometimes the inflammation is so deep as to cause serious soreness and swelling of the throat. In this case the horse must be nursed carefully by feeding with

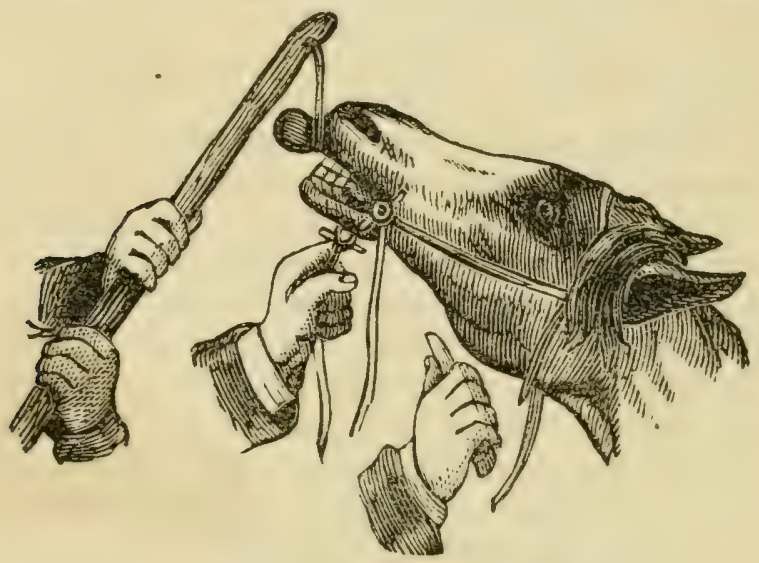

Opening the Abscess in Distemper.

warm gruel; the drink should be warm; grass or anything that will tempt the appetite should be given. Simpler treatment would be rubbing on the enlargement an ordinary fly-blister, to bring the enlargement to a head. Physic must not be given.

\section{INELAMMATION OF THE BOWELS.}

This disease is generally caused by constipation of the bowels, hard driving, over-purging or looseness of bowels, or drinking cold water when warm. Constipation is, however, the principal cause of the disease, and when this is the case, the first and most important condition of relief is to get an action of the bowels.

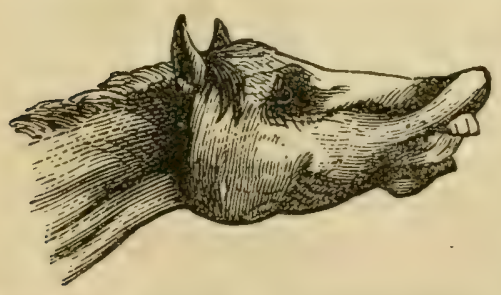

Symptoms of Intestanal and Abrominal Irritation, as shown in Inflampation of the Bowels.

Symptoms. - For the first few hours the horse is uneasy, paws, looks around at the side, the pulse is slightly accelerated and wiry. As the disease ad. vances the intermissions between the attack become less, pulse quicker, running from seventy to eighty beats in a minute, in some instances even 
faster; lies down and gets up, shows much pain, no swelling of sides. Now begins to exhibit fever, bowels constipated, urine highly colored and scanty.

Remedy.-Give a quart of raw linceed oil.

Note. - If constipation is very great, add from four to six drops of croton oil.

If scours or over-purging, give an ounce and a half of the tincture of opium with six ounces of water. But in order to suppress the inflammation it is necessary to bleed immediately from the neck vein from six to ten quarts of blood, according to the strength and size of the animal. In extreme cases bleeding may be repeated to the extent of four to six quarts in three or four hours. If much pain exists in constipation, give from one to three ounces tincture asafoetida. Feed lightly for a week at least, giving gruel, roots, grass and bran mashes, and keep quiet. No exercise for several days if there is danger of a relapse. This a dangerous disease and requires prompt treatment.

\section{INFLAMMATION OF THE KIDNEYS.}

Inflammation of the kidneys is generally caused by hard work, by slipping, throwing the hind parts so suddenly under the belly as to produce undue tension of the lumbar vertebræ, or from sudden colds by being exposed to rain and cold, the eating of musty hay or oats, or unhealthy food of any kind. Too powerful or too often repeated diuretics produce inflammation of the kidneys, or a degree of irritation and weakness of them that disposes to inflammation, from causes that would otherwise have no injurious effect.

Symptoms. - Less or more fever of the system generally, and unwillingness to move, particularly the hind legs, dung hard and coated, very sensitive to pressure on the spine. The horse looks anxiously round at his flanks, stands with his hind lrgs wide apart, straddles as he walks, shows pain in turning; the

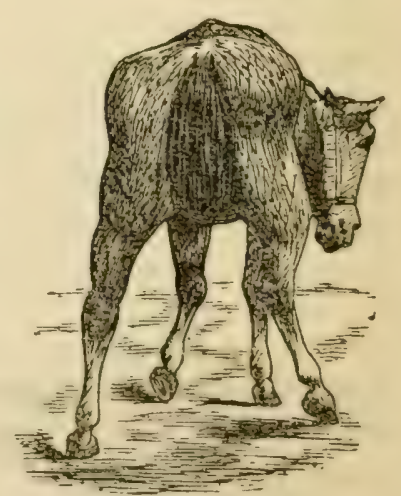

Appearance of a Horse Suffer. ing from Diseases of the Urinary Organs 
urine is voided in small quantities, and is usually high colored, scmetimes bloody; the attempt to urinate becomes more frequent, and the quantity voided smaller, until the animal strains violently, without being able to pass any or but very little urine. The pulse is quick and hard, full in the early stage of the disease, but rapidly becoming small, though not losing its character of hardness. Introduce the hand into the rectum. If the bladder is found full and hard under the rectum, there is inflammation of the neck of the bladder. If the bladder is empty, yet on the portion of the intestimes immediately over it there is more than natural heat and tenderness, there is inflammation of the body of the bladder. If the bladder is empty and there is no increased tenderness and heat, there

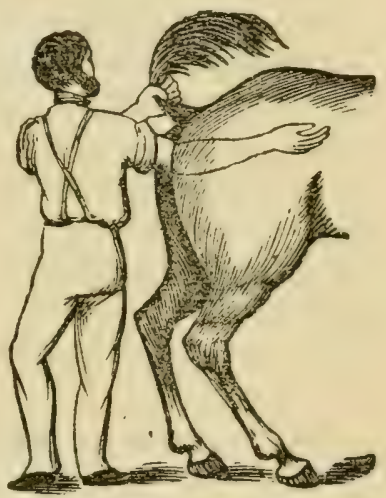

Test for Inflammation of the Kidneys. is inflammation of the kidneys.

Treatment.-If the pulse is high, about sixty, take five or six quarts of blood and give a fever ball; to be repeated in three hours if not better. Fever ball: 4 drams Barbadoes aloes, I dram tartar emetic, 2 drams ginger, calomel about the size of a bean, molasses sufficient to make into a ball. Counter irritation must next be excited over the seat of the disease. The loins should be fomented with hot water or covered with mustard poultice, or, better, heat a peck of salt in an oven, place it in a bag, and put it over the part affected. If the case is severe and protracted, a sharp blister may be used. No diuretics are to be given, as they would simply aggravate, and make the disease worse. After the bowels are open, give aconite, and treat as for fever. After recovery the horse sbould be kept very quiet for a month, and if in season, turned out to grass. If in winter, feed with light mashy diet; exercise lightly by leading, if the animal be valuable and it is desired to aid recovery by extra care. 


\section{INFWAMMATION OF THE BLADDER.}

Symptoms almost the same as those of inflammation of the kidneys. Frequent voiding of urine in small quantities, quick pulse, looks frequently at flanks, paws violently, tender when pressed upon under the flanks.

Here the principal object is to lower inflammation and relax the muscular contraction of the neck of the bladder. Bleed largely, almost to fainting; give physic as for inflammation of the kidneys, or a quart of linseed oil. A dram of powdered opium, made into a ball, or given in drink, every two or three hours, and blister over the loins. Give aconite, as for inflammation of the kidneys.*

\section{INFLAMMATION OF THE BRAIN, OR STAGGERS,}

Is first noticeable by dullness or sleepiness of the eyes, an unwillingness to move, general heaviness of the system. This disease is frequently called megrims, fits and mad staggers; but in part only one disease, according to the extent of such disease as the animal may be affected with.

The cause of staggers, is, an undue flow of blood to the brain, which rarely or never occurs in any animals except those in a plethoric (fat) condition.

Some writers and practitioners assert that there is a disease known as stomach staggers. I have never seen a case where it was necessary to treat the stomach, but always direct attention to the brain, as being the seat of this disease, which may be properly called head staggers. (In his lecture on this difficulty, Dr. Somerville was emphatic in this conclusion.)

In cases of megrims or fits it is merely a lesser attack, or pressure of the blood-vessels on the brain, and mad staggers is a greater pressure of the same vessels on the same part. The brain is divided into two parts, namely, cerebrum and cerebellum, which occupy a horny box in the head. The blood-vessels passing over the brain and coming in contact with the skull, become distended by an increased quantity of blood, and produce the feeling, which is thus exhibited.

* If possible call a vetcrinary surgeon who will introduce a catheter whicb will relieve the animal immediately. 
There is but one cure for this disease, and that is, remove

(c) cause. Bleed largely from the neck-ten, twelve (: warteen quarts, or until the symptoms of fainting. Aftes e horse is convalescent a sharp dose of physic should i) given to regulate the bowels. I would advise owners of such horses to dispose of them. Once taken with the disease, they are subject to a repetition of the attack when the bloodvessels become filled again.

Note.-Small doses of aconite (of the quantity for fever) may be given three or four times a day as a good preventive. Turning horses to pasture that may be liable to this disease will prove both injurious and dangerous.

\section{FOUNDER, (LAMINITIS.)}

There are two stages of this disease, acute and chronic. The first produces a high state of excitement and inflamma. tion of the sensible laminæ of the foot. The second, a morbid or insensible feeling of the parts generally. The first is invariably cured if properly treated. "The second is not curable, but may be palliated to a limited extent. Acute founder is easily detected. The animal invariably extends the fore feet as far forward as he can, and brings the hind ones in the same position under him. There is so much pain in the fore feet that he endeavors to throw his weight on the hind ones. (See cut.) The common causes of founder are exposing the animal when warm to sudden changes, usually produced by the following means, namely: Standing in cold air when warm, after being driven, driving through a river while warm, or giving cold water to drink while warm, washing the feet when warm and neglecting to dry them, \&c. It is generally supposed that feeding a horse while warm will produce founder. This is an error, unless it is such food as will chill the system, which may be done by giving a large quantity of rold wet mixed feed, whereby the circulation would be checked, as before explained.

Founder is simply inflammation in the feet, whatever general disturbance of the system is caused by the pain and soreness in them, and the correct principle of cure is to lower and remove this inflammation befare change of structure or sloughing can take place. 
Treatment.-As soon as the discase has develojed itself, bleed from the neck, according to the size and condition of the animal-from six to twelve quarts. Then give a sharp cathartic ball ( 7 drams aloes, 4 drams bar soap, I dram ginger). Make into a ball and give immediately. After the

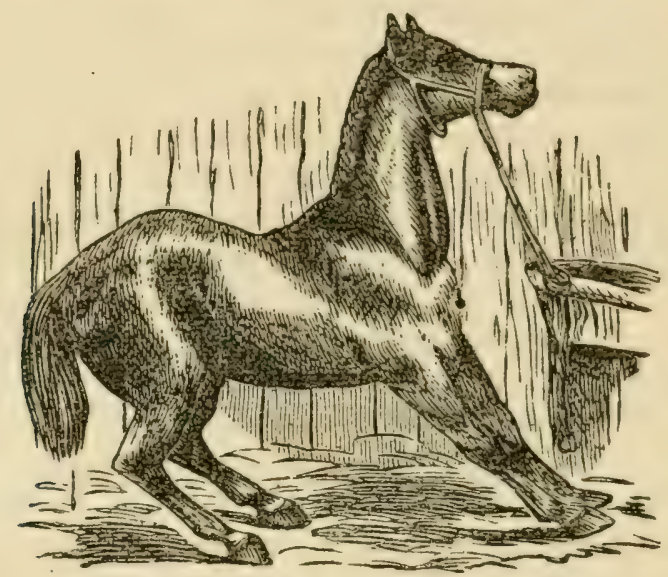

The Horse as he Appears when Suffering from Inflammation in the Feet, or Founder.

fore shoes have been removed, poultice thoroughly with bran wet with cold water. This poultice may, while on the feet, be kept wet by dipping the poulticed foot into a pail of cold water, or pouring some on. This poulticing should be kept up from four to five days, when the shoes may be tacked on, and the animal exercised a little. Cloths wet with cold water should be tied around the coronet and the soles stuffed for a week or two. The horse should have tepid water to drink and warm bran mashes during the operation of the medicine. If the disease should be stubborn, which is rarely the case, a second ball may be given after an interval of five days.

Nothing can be done for a sub-acute founder, or case badly treated. If the sole is broken down do not pare the sole. Fit the shoe so as not to press on the sole. Stuff the whole bottom with oakum and tar, and apply leather over. Put on the shoe carefully. Cure is impossible. If warm fomentations are used, instead of cold, a relaxation of the sensible laninx on the wall of the foot is liable to take place. 
The great trouble with most farmers and horsemen is, they do not know either how to bleed or give a ball of physic medicine.

In that case you must do all you can by poulticing the feet and the use of sedatives. Take a large tub or part of a barrel; put in some blue clay, upon which pour hot water. (The mixture should come half way to the knees when the horse stands in it.) See that it is not hot enough to scald. Stand the horse in for several hours, after which poulticing as before, at the same time give aconite as for fever. You can also give a pint of raw linseed oil. It would be also conducive to success to bleed from the toes, which can be easily done by cutting through the sole at the toe.

If, however, you can treat as first advised, your success will be certain, as this treatment I know will cure any case of acute founder, or laminitis.

\section{HEAVES, OR BROKEN WIND.}

Heaves produces increased action of the flanks. The inspiration is natural, but the expiration requires two $\mathrm{m}$ \%tions to expel the air. There is always a short cough, or grunt, and at the same time expels wind while coughing. Heaves are never found in the racing stable, where horses are properly fed. They are always found among cart or team horses, where the owners suppose they must feed a large quantity of coarse food or hay.

The seat of the disease is located in the air cells of the lungs, causing enlargement and sometimes a rupture of these cells. A result of bronchitis, or inflammation of the small air passages of the lungs, is the lodgment of mucous fluid in those passages of the lungs, causing inability to breathe, (wheeze,) and leads to this result. But in all cases of heaves we find the horse to be a greedy eater,-stuffs the stomach with coarse food, causing the lungs to be greatly restricted in their action, causing an enlargement of or rupturing of the air cells.

An important and necessary auxiliary to the successful treatment of heaves is restricting the quantity of coarse food or hay, and increasing that of condensed, nourishing food, thereby giving the lungs increased room to act. Horses fed on chopped stuff, corn fodder, etc., improve, and get worse by being fed on coarse food or hay. 
Heaves disappear by feeding prairie hay or grass, because It is so coarse the horse cannot gorge the stomach with it. Hence there is improvement by feeding corn stalks or fodder, as they contain more saccharine matter and do not engorge the stomach. I have given the tincture of rosin weed, which is claimed to be the curative principle of prairie hay, without satisfactory results, and can produce equally satisfactory results by other treatment that is claimed for that of feeding prairie hay.

First give one of the following balls: Ginger, powdered, I/2 oz.; capsicum, $1 / 4$ oz. Form a ball. This ball to be given three nights in succession; then omit two or three nights, and one or two balls may be given again in succession. The horse should have regular exercise, be watered often, (small quantities at a time,) and have straw instead of hay to eat, (corn fodder would be much better.) Under this treatment heaves will disappear.

FAVORITE REMEDIES FOR HEAVES.

I. Spanish brown, 2 oz.; tartar emetic, 2 oz.; resin, 4 oz., ginger, $2 \mathrm{oz}$. Mix and give two teaspoonfuls twice a day in the feed.

2. Vegetable tar, in mass, $1 / 2$ oz.; gum camphor, $1 / 2$ Oz.; tartar emetic, I dram. Form into a ball, one of which is to be given once a day.

3. 'Take indigo, I oz.; saltpeter, I oz.; rain water, I galIon; mix and give a pint twice a day in the feed.

I could include a great many pretended "sure cures" for heaves. I have used in my practice almost everything for this purpose, comprising sulphuric acid and corrosive sublimate, etc., as experiments, and find them comparatively or wholly worthless. If the horse shows heaves after a severe cold or inflammation of the lungs, there will be wheezing from a filling of the air passages with mucus. Hence gentle exercise, stimulating medicine to the air passages and lungs, and condensing the food, will give relief, since the lungs are thereby stimulated and freed from mucus, as well as giving freedom to act, and there is, in consequence, relief.

You will find the above treatment to work splendidly in most cases. They will give relief in all cases with proper attention to feeding, and will in many cases possibly make a cure. 


\section{TO CURE ROARING, OR WHISTLING.}

The following treatment for the cure of roaring, or whistling, as it is termed, has been used by Mr. E. D. Conklin, and others, in Cleveland, Ohio, and they claim the $\mathrm{m}$ st satisfactory results. Mr. Conklin, who is a large uwner of horses, and perfectly reliable, stites that he cured une very bad case; could not pull a luad two rods up-hill without howing and choking duwn; was completely cured in six weeks. II as tricit it in a number of cases, and always with satisfactory results. The treatment was introduced by Mr. Johnson, of Cleveland, who clumns he c.r: cure any case. As there is no really satisfactory treatment for this difficulty in regular practice that I know of, I give this remedy and st:ite my authority. It can be tried with safety.

Treatment.-From ro to 20 drops of sponga fosta on the tongue in the morning. At night the same proportion of Fowler's Solution in the same manner, to be repeated alternately for from four to six weeks, yiving more or less and for a longer or shorter time, according to the severity of the case, until a cure is effected.

\section{TETANUS, OR LOCKED JAW}

This disease is wholly of a nervous character. A description of the symptoms is scarcely necessary, but in the first stage there is a disinclination to move; then the tail becomes erect and quivers, the ears set back, and the conjunctiva is thrown over the pupil of the eye, and the head is elevated.

As the disease advances, the muscles all over the neck and body become stiff and rigid, and the legs have the appearance of a four-footed stool. The animal has little or no power to move.

For the first few days the teeth remain apart, but as the disease advances, the muscles of the jaw become so contracted as to bring them close together. Hence the name of locked jaw.

The causes of this disease are numerous, but it is generally produced from a wounded nerve or bunch of nerves, pricking the tail, and very often from docking, punctured wounds in the feet from glass or nails, and sometimes from severe exposure to cold, and I have known one case to occur from fright. As to the pulse, it is almost normal - for the first few days. As the disease advances the pulse quickens, 
and the animal is compelled to stand on his legs unt.2 death, if it terminates fatally. If favorably, a relaxation of the muscles begins from the fifth to the seventh day. This disease is more common in the extreme South than in - the North.

Treatment.-First, as the disease is of a nervous character, quietness is of the greatest importance. The animal should be put into an isolated place or box, by himself, and the cause of the disease found. If from docking, the next joint should be taken off the tail. If from a wound in the foot, the wound should be opened up and made new, and an application of digestive ointment inserted, so as to produce a healthy flow of matter. When the irritation has ceased from the wound, a pail of gruel should be placed before him, in which is mixed half an ounce of tartar emetic. This medicine should be given daily, and the spine rubbed well with a strong liniment, composed of one part of aqua ammonia and two parts of sweet oil. This embrocation should be employed daily until the back becomes sore.

Tetanus never arises from a wound until about the period that it may be considered healed. Bleeding about four quarts daily for four or five days has cured several bad cases. Think if the bowels can be regulated, quietness has more to do in producing a cure than all other remedies.

\section{POLL EVIL AND FISTULA OF THE WITHERS.}

These difficulties are of the same character, though in different locations, and the treatment of one will be sufficient for both. Poll evil is sometimes caused by striking the poll against a beam or floor, being struck or otherwise injured, or it may be the result of constitutional predisposition.

When the inflammation and enlargernent are first discovered, you may be able to disperse it by giving a dose of physic and applying cooling applications to the part.

If the inflammation does not abate, clip the hair and ruk on some blistering ointment. When the swelling enlarges, open and allow the pus' to escape; cut down to the bottom, making a good large orifice. 
In treating all ulcers, there is one point that must be kept in mind, and that is to make an opening at the bottom if you can, to let the matter run out, as matter always burrows to the bottom. This should be done by running a seaton through, bringing it out a little lower than the bottom of the wound, or what is termed a dependent opening. Wash the sore out clean. It is afterwards to be washed clearly with any of the healing preparations for ulcers, given in another page.

If pipes are formed requiring caustic medicine, you can use either chloride of zinc, corrosive sublimate, or any strong escorotic to destroy such growth, after which treat as before. These are very serious difficulties to treat, requiring proper dressing daily.

Fistula of withers to be treated in the same manner. The principle of treating these difficulties is really the same as that of any ordinary deep seated ulcer, more special directions for the treatment of which will be found under that head.

\section{SWEENY.}

Sweeny is really a fictitious disease, discarded by all reliable practitioners. They claim, and how justly I am not prepared to say, sweeny is the effect of diseases of the feet, such as corns, navicular diseases, ossification of the lateral cartilage, contraction, etc., producing atrophy of the muscles of the shoulder, and their treatment would be to remove the cause, and the effect would cease. If you wish to pursue a local treatment of sweeny or filling up of the shoulder, you can do it by the application of most any stimulating treatment. One of the simplest and best, which will work in every case, and which most horsemen will regard as of more value than the price of this book, is the application of soft soap. Add a little salt to soft soap and rub on the part thoroughly four or five times in the course of a week. Four applications will fill up the depression of the worst case. The regular treatment would be seatoning and blistering, but this will do all that is required so far as local treatment.

In addition, by all means, if any difficulty is discovered in the foot, treat it also, as explained in another chapter. 


\section{SPAVIN AND RINGBONE,}

There are two kinds of bone spavin, namely: Jack ard occult, or consolidated joint. 'The first is located at the upper portion of the metatarsal bone at its juncture with the cuboid bones. The second is usually located higher up, and more on the inside of the astragalus bone at its junction with the cuboid bones.

Spavias of either of the above classes have the same origin and same causes, namely, inflammation of the cartilage of the joint in the first instance, and extending to ulceration of the bone, consequently bony matter is thrown out, uniting more or less of the bone of the hock and excess of matter and ulceration of the bones from the enlargent.

The causes of spavin are numer-
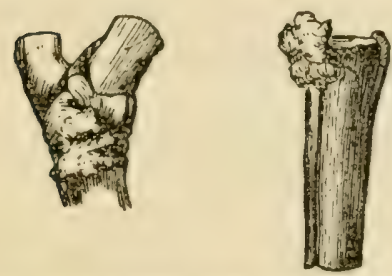

Showing the Changes of Structure Caused. ous, but principally of one class, such as sprains, hard work, blows, and, in fact, any cause exciting inflammation of this part. But a common cause and a great fault lies in the breeders of horses, as very often the colt is bred from spavined sire or dam, or both, and the colt is certain to inherit the same predisposition.

The symptoms at the commencement are treacherous. Very often horses are treated for hip lameness before any enlargement makes its appearance. 'The horse, at first, is very lame while laboring under acute inflammation of the hock joint. He will not wear out or the lameness as he does in the more advanced stage of the disease. The tumor generally makes its appearance from the fifth to the eighth week. Sometimes, however, the lameness is very gradual - scarcely perceptible at first-getting worse until there is marked lameness at starting, which will soon wear off as the

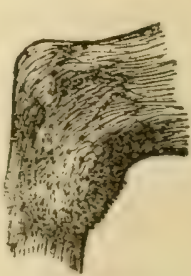

Bone Spavin. horse warms up.

The method of curing is varied, as there are hundreds or different remedies and applications. Some men go so far as to pretend they can remove spavins. To a skillful practitioner this is absurd. It will be seen that if such quacks can remove the external tumor, they cannot separate the bones 
which are united, and horses may be spavined without any visible enlargement.

I can simplify all this to gentlemen interested, by illustrating with my specimens, the location, nature, changes of structure, \&c., in spavin, a large collection of which I carry for the purpose. Sublimates, muriatic, sul-

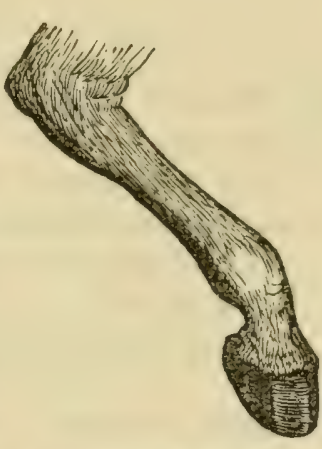

Natural Action.

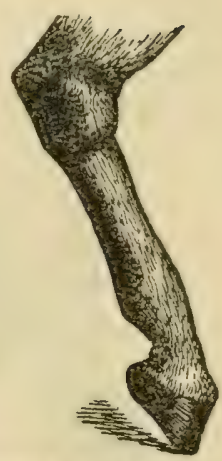

Effect of bad Sparin Forward. phuric, and nitric acids form the basis of the different ointments that are applied to remove this formidable disease. 'They always make a bad sore, and blemish the animal for life.

The only reasonable treatment for bone spavin is counter irritation and rest. If there is heat during the first few days, apply cooling applications, such as an ounce of sugar of lead to half a pail of ice water. Keep the leg wet for about two weeks, when it may pass off. A dose of physic should be given. If this stage has passed, repeated blistering with a preparation of iodine or cantharides will be necessary; but much better would be the actual cautery in an operator's hands. Clip the hair closely over a large surface four or five inches above and below the enlargement, and then out to the middle of the back and foreparts of the leg. Any of the strong blisters recommended for spavins, for which formulas 2ie given below, are to be used. If a blister, rub it in well with the hand for ten minutes or more. In two days put on some grease. When the inflammation goes down, wash with warm water and castile soap, and when dry put on more blister, and so repeat, keeping up just as much irritation as you can without destroying the hair. In the meantime, the horse must be kept in a comfortable stall, for one of the conditions of cure is rest. Keep up the inflammation in this way for four or five weeks, after which give a run to grass. It is sometimes necessary to blister lightly, if the lameness does not disappear, in six or eight weeks, which may be repeated a few 
times, with iodine oirtment in the proportion of one part of iodine to four of lard.

Work should be light, if any, within

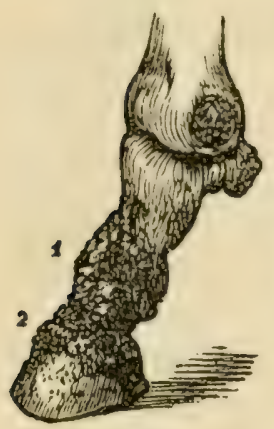

Ringbone. three months. This treatment will usually cure without leaving a blemish.

Treat ringbones on the same principle. Trim off the hair and blister in the same manner, observing the same condition of rest. As regards taking off the enlargement, this treatment is as effectual towards that end as can be used.

Several of the very best recipes for the cure of spavins and ringbones will be found below.

Bear in mind, you must always clip the hair off of the part to be blistered, and that the medicine must be rubbed in well with the hand for ten minutes.

VERY STRONG BLISTER FOR SPAVINS, RINGBONES, CURBS, ETC.

Finely powdered cantharides, I oz.; powdered euphorbium, 2 drams; lard I oz.; tar, 2 oz.

A VERY ACTIVE BLISTER FOR SPAVIN, RINGBONE, ETC.

Two drams corrosive sublimate, I oz. lard, I/2 oz. tar, 2 drams cantharides. Rub and mix well together.

A GOOD BLISTER FOR SPAVIN, RINGBONE, ETC.

Biniodide of mercury, $1 / 2$ dram; cantharides, I dram; lard, I oz.

A fine blister for any purpose requiring counter irritation and absorption, will take off curbs, splints, \&c.

POWERFUL ABSORBING BLISTER FOR SPAVIN AND RINGBONE.

Equal parts of beniodide of mercury and cantharides, three parts of tar and lard each. Rub in well with the hand for three mornings, and use lard after to soften and take off the scab, when it may be repeated if necessary.

SWEATING LINIMENT FOR WINDGALLS, ETC.

Strong mercurial ointment, 2 oz.; camphor, $1 / 2$ oz.; oil of rosemary, 2 drams; oil of turpentine, $\mathrm{I}$ oz. Mix. 
VERY STRONG SWEATING BLISTER, FOR WINDGALLS, CURBS, SPLINTS, ETC.

Biniodide of mercury, $x / 2$ to $\mathrm{I}$ dram; powdered arnica leaves, I dram; soap liniment, 2 oz. Mix.

\section{A FINE ABSORBEN'T FOR TAKING DOWN ENLARGEMENTS} OF ANY KIND.

One ounce beniodide of mercury; from I to 3 ounces of lard, according to the strength desired.

The following remedy for the cure of spavin and ringbone is regarded as one of the best used. It is sold in the Mohawk Valley, (where I obtained the prescription,) for $\$ 5.00$ a box, and Fifty Dollars has been paid for this receipt. It is, I think, the best of this class of prescriptions published.

\section{FOR SPAVIN AND RINGBONE.}

Five ounce euphorbium, $2 \mathrm{oz}$. Spanish flies (fine), I oz. iodine, dissolved with alcohol, $1 / 2$ oz. red precipitate, I oz. corrosive sublimate, $1 / 2$ oz. quicksilver, $6 \mathrm{oz}$. hog's lard, $6 \mathrm{oz}$. white turpentine, $1 / 4 \mathrm{lb}$. verdigris. Melt the lard and turpentine together, then while hot add all together. Mix well; when cold it is fit for use. Rub it in thoroughly on the spavin every day for three days; then wash clean with soap suds; omit for three days and then repeat for three days again, and so on until a perfect cure is produced. Should it blister, use it more cautiously.

This medicine will get up as much inflammation as you desire, and must be applied cautiously or it will blemish.

The following remedy for the cure of ringbone and spavin, and taking off enlargements, has been peddled through the country as a remedy of the greatest value. As high as one hundred dollars has been paid for this receipt. $I$ give it as given me.

Take alcohol, I 4 oz.; iodine, 304 grains; bichloride of mercury, 150 grains. Let stand in a sand bath twenty-two hours, then add 230 drops croton oil; let it stand in sand bath twenty-two hours longer, then bottle for use.

Next take quicksilver, I 4 oz.; nitric acid, 7 oz.; stir one minute; cantharides, 7 drams; stir five minutes; sulphuric 
acid, 7 oz.; stir three minutes; 50 drops of the above liniment. Let stand five hours, stir every half hour, then add 7 oz. prepared chalk.

First shave the hair off the "bunch," then apply the liniment with a lather brush. Sprinkle a little of the powder on paper, and rub on, after washing with the liniment. When the bunch is reduced two-thirds, wash with warm water and castile soap. In Eiventy-four hours grease.

This is one of the very strongest remedies used for spavin and ringbone, and if not used with great care is pretty sure to blemish. I will here state that educated practitioners use the milder treatment, immediately following the description of spavin. Properly done, the actual cautery or firing is undoubtedly the best and most reliable treatment. This is the treatment I use for these difficulties. Dr. Wm. Somerville frequently charges \$I $\$ 00$ for curing spavins, \&c., on valuable horses by firing, guaranteeing not to blemish. While the operation of itself is simple, it is one that requires rare practical skill, and is done successfully only by a few of the best practitioners.

Youatt, one of the best of the old English authors, says in regard to

\section{FIRING.}

Whatever seeming cruelty may attend this operation, it is, in many cases, indispensable. The principle on which we have recourse to it is similar to that which justifies the use of a blister; by producing superficial inflammation we may be enabled to remove a deeper-seated one, or we may excite the absorbents to take away any unnatural bony or other tumor: it has also this additional advantage, that, while it raises intenser external inflammation than we can produce by other means, it is the most powerful agent that we have at our disposal. Humanity, however, will dictate, that on account of inflammation which it excites, and the pain which it inflicts, it should only be had recourse to when milder means have failed, except in those cases in which experience has taught us that milder means rarely prove successful.

The part which is to be submitted to the operation is shaved, or the hair is cut from it as closely as possible with the trimming scissors. This is necessary to bring the iron into immediate contact with the skin, and likewise to prevent the smoke that will arise from the burned hair from obscuring the view of the operator.

The details of the operation belong to the veterinary surgeon. The grand points to be attended to are to have the edge of the iron round and smooth; the iron itself at, or rather below red head; to pass it more or less rapidly over the skin, and with slignter or greater pressure, 
according to the degree of heat; to burn into the skin until the line produced by the iron is of a brown colour, rather light than dark, and by all means avoid penetrating the skin. Leaving the additional cruelty of deep firing out of the question, we may depend on it that, if the skin is burned through, inflammation, and ulceration, and sloughing will ensue, which will be with much difficulty combated; which will unavoidably leave unnecessary blemish, and which have destroyed many valuable horses. It may happen, nevertheless, that by a sudden plunge of the animal, the skin will be unavoidably cut through. The act of firing requires much skill and tact, and the practitioner cannot be always on his guard against the struggles of the tortured beast. It will, also, and not unfrequently occur, that the skin, partially divided, will separate in two or three days after the operation. This must not be attributed to any neglect or unskillfulness of the surgeon, and the ulceration thus produced will be slight, and easily treated, compared with that caused by the actual burning through of the skin.

Some practitioners blister immediately after firing. As a general usage, it is highly to be reprobated. It is wanton and useless cruelty; but it may be required in bony tumors of considerable extent, and long standing, and interfering materially with the action of the neighboring joint. Spavin, accompanied by much lameness, and ring-bone spreading round the coronet, and involving the side cartitages, or the pastern-joint, may justify it. The inflammation is rendered more intense, and of considerably longer duration. In old affections of the round bone it may be admitted, but no excuse can be made for it in slighter cases of sprain, or weakness, or staleness.

On the day after the operation, it will be prudent gently to rub some neat's-foot oil or lard over the lines. This will soften the skin, and render it less likely to separate or ulcerate; a bandage would add to the irritation of the part. Any cracks of the skin, or ulceration that may ensue, must be treated with the calamine ointment already recommended.

It will be evident that there is an advantage derived from firing to which a blister can have no pretension. The skin, partially destroyed by the iron, is reinstated and healed, not merely by the formation of some new matter filling up the vacuity, but by the gradual drawing together and closing of the separated edges. The skin, therefore is lessened in surface; it is tightened over the part, and it acts as a salutary and permanent bandage. Of the effect of pressure in removing enlargements of every kind, as well as giving strength to the part to which it is applied, we have repeatedly spoken; and it is far from being the least valuable effect of the operation of firing, that by contracting the skin, it affords a salutary, equable, and permanent pressure. It was on this principle, but the practice cannot be defended, that colts which were not very strong on the legs, used to be fired round the fetlock, and along the back sinews, or over the hock, to brace and strengthen the parts. It is on the same principle that a racer or a hunter, that has become stale and stiff, is sometimes fired and turned out. For whatever reason the horse is fired, he should, if practicable, be turned out, or soiled in a loose box, for three or four months at least. The full effect 
intended to result from the external irritation is not soon produced, and the benefit derived from pressure proceeds still more slowly. In the thickened and tender state of the skin, and the substance beneath. for some weeks after firing, a return to hard work would be likely to excite a new inflammation, and cause even worse mischief than that which before existed.

Some weeks pass before the tumefied parts begin to lessen, and they only who have had experience in these cases would imagine how long, with gentle voluntary exercise, the process of absorption is carried on. $\mathrm{He}$, therefore, who whould expect that much good should acciue from the operation of firing, must be content to give up his horse for three or four months; but if he will use him sooner, and a worse lameness should follow, let him blame his own impatience, and not the inefficiency of the means, or want of skill in the surgeon.

The firing in every case should be either in longitudinal or parallel lines. On the back sinews, the fetlock, and the coronet, this is peculiarly requisite, for thus only will the skin contract so as to form the greatest and most equable pressure.

The operation of firing is one that I am thoroughly practiced in, competent to perform in the most successful manner.

BLOOD SPAVIN, THOROUGH PIN,

Soft enlargements upon the hock. If not of long standing, the following will be found very

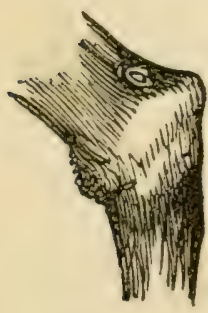

Thorough Pin. effective, though simple: Rub on soft soap, to which has been added a little salt, at night, and wash off in the morning. Two or three applications will cure, if recently caused. If of long duration, blister two or three times, as for bone spavin.

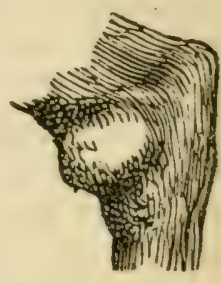

Bog, or Blood Spavin.

\section{SPLINTS.}

This is an enlargement between the cannon and splint bones, showing itself on the inside of the fore leg. The same treatment as for spavin.

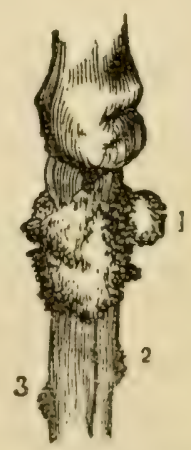

Changes that may be Produced.

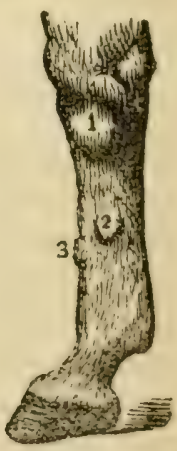

Splint. 
CURB,

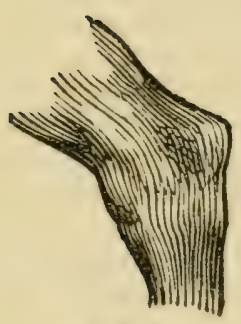

Clean Hock.

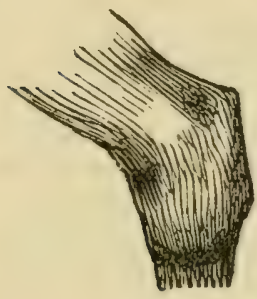

Curb.

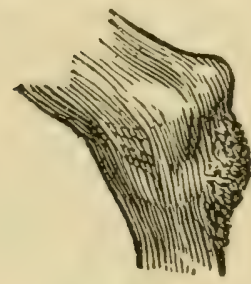

Curb.

This is an enlargement of the integument, and in some cases of bony deposit, usually caused by a strain. It is situated on the back part of the hock, just below the cap. Blister with remedy for spavin.

\section{SPRAIN OF THE BACK SINEWS.}

The animal becomes suddenly lame, and by use grows worse. Pass the fingers down on each of the tendons back of the knee. A little enlargeinent, if there, with considerable inflammation, will be discovered. Use cooling astringent liniment until the acute stage passes off. If not better then, blister, observing to give the animal rest. Firing is the most reliable treatment.

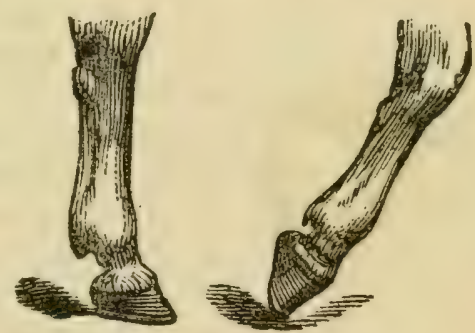

Enlargement caused by Sprain of the Tendons.

\section{COFFIN JOINT LAMENESS}

Is often mistaken by those who are not capable of locating the diseases of horses' feet to be lameness of the shoulder, from the fact that generally after the shoe is removed, and no external injury is discovered in the foot, some distant part is selected as the location of the disease. Navicular disease is dangerous and treacherous in its progress and development. It is commonly caused by violent sprains of the navicular joint, although sometimes, and, in fact, very often, may be induced by a contusion of the frog; and 
again, there is a disposition to have this disease from heredi. tary causes.

The coffin joint is composed of three bones: the os pedis, the navicular and small pastern bones. The navicular bones answer the purpose of a sup-

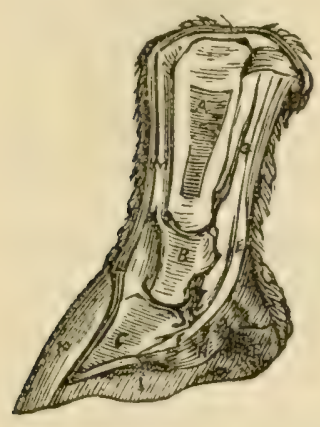

Section of the Parts Entering in to the Composition of the Foot, and the Fetlock and Pastern Joinıs,

$a$ Os suffraginis. $b$ Os corone. $c$ os pedis. $d$ Os naviculare. $e$ e The perforans and perforatus tendons. $g$ Inferior sesamoideal ligament. $h$ Cleft of frog. $i$ side of frog cleft. $j$ Sole. $k$ Crust. $l$ Coronary substance. port in allowing great elasticity of motion. The flexor tendon inserts itself into the os pedis, and passes immediately over the navicular bone, so that at each step the navicular bone is thrown upon one part of the os pedis and small pastern at the same time. It will be seen that in all cases of lameness of this joint, as well as in any other joint lameness, that the cartilage of the bones is inflamed, and as the disease progresses ulceration takes place, and consequently ancholosis. It is almost striving against hope to be able to explain to the general reader the symptoms to enable ability to locate the disease with any degree of certainty. Corns or bruises of the sole, contraction, or almost any cause exciting inflammation in the foot, may cause similar lameness, and to an ordinary observer there cannot be that fine judgment necessary to trace from certain peculiarities the location of the trouble.

Horses having navicular disease invariably travel more on the toe than on the heel, consequently the shoe is always worn more at the toe than at the heel. The hoof rarely or never is malformed, but the disease commonly occurs in healthy looking feet, contraction of one or both heels, which will in many cases interfere with the outer cartilage of the joint. In the cases of long standing the frog appears to recede, and does not have a natural appearance. If the horse is taken suddenly lame, sometimes scarcely putting the foot down, and only presses upon the toe, feel of the foot carefully. If there is heat around the top of the hoof and tenderness-even a little at the heel-there is probably strain of the coffin joint. In incipent cases (first stages) there is fever and tenderness to motion of the joint, which 
is noticeable by catching the foot in one hand, the ankle in the other, and twisting a little. The animal will show pain and resist.

As to treatment, in the first stage, the shoe should be removed, and have the toe of the shoe hammered down. The heels should be raised, and applied again so as to remove all pressure from the frog, and a cloth or rug saturated with cold water applied to the coronet. The bottom of the foot should be stuffed with oil meal or some adhesive substance. If this is done for a few days, with rest, the first attack will geñerally pass off.

In the more advanced stage of this di ease it will require thorough treatment. The shoe should be formed and applied as before, and a severe blistering applied to the coronet, which should be continued for from one to three weeks, with rest. At a still more advanced stage the frog seaton may be used, but this must be done by an experienced practitioner.

In all cases of this disease the animal will require consider able rest.

I would here remark that in an advanced stage of the disease the horse is a little lame, sometimes worse, at others better; rough road and down hill worse; is no worse to be at work; usually no apparant change in the hoof; will go better when the heels are raised by using high-heeled shoes; worse by bringing heels to the ground.

\section{LAMENESS.}

In treating lameness successfully, it is necessary to be able to understand the peculiarities of joint from muscular lameness, - in fact, of the action and movement incidental to each.

The horse is, for example, lame in the fore foot, and without knowing just what the trouble is, something must be done, and the shoulder is furiously attacked, being blistered, seatoned or subjected to some needless form of cruelty which can have no effect whatever on the injured part.

In the first place, if the shoulder is strained or injured, the horse cannot raise or put the foot forward naturally. He will drag it like, giving it a sort of swinging motion, and does not bring it very far forward. On the other hand, 
if the injury is in the foot, the foot is raised up and pus forward easily and nasurally, but is put down tenderly.

Again, a case of muscular lameness, such as shoulder lameness, straining of the back sinews, (suspensatory ligaments,) the lameness will get worse by use. That of the foot, such as corns, coffin joint lameness, pricking with a nail, etc., remain abont the same; besides, if there is much soreness in the foot, from contraction, corns, pricking, strain of the coffin joint, the foot will be put forward or rested upon the toe. 'This will always be the case if there is much soreness of the heels, as resting upon the toe relieves the pressure and pain. Hence it is a marked symptom of coffin joint injury, of corns and thickening of the lateral cartilages.

Again, if there is nuch inflammation, increased heat can be felt in the foot.

FIRST, SHOULDER LAMENESS.

Symptoms. - The animal drags the leg, with the toe on ground, and cannot raise the foot.

Treatment.-Local bleeding from the plate vein on the inside of the leg is very effectual, with a purging ball. Fomenting the shoulder with hot water will be found useful. If, in a few days, fomentations do not succeed, and the case seems obstinate, rub on thoroughly soft soap and salt, which will be found a fine stimulant, and is easily obtainer. If any eruption should arise from the application of this dressing, apply a little sweet oil or lard, which will remove the scab in a few days.

\section{PRICKING.}

If the horse becomes lame after being shod, examine the foot carefully. If pricked by driving any of the nails too near the quick, there will be heat and tenderness in the hoof easily discovered. Tap the nails around carefully; when the part injured is struck there will be prompt resistance shown. Have the shoe taken off, and cut down to where the nail strikes the quick, enough to make room for any matter that may have formed to escape; then poultice with flax seed meal until the inflammation is reduced, when a little tar, resin, or tallow, or something of this kind, 
should be put on, and the opening filled up with a little tow to prevent gravel or dirt from getting in, and put the shoe on again.

\section{CORNS.}

Described in the article on Shoeing. The most difficult corns to treat are those in weak, broad heels. If in a high, strong heel, and contracted, all that is necessary to do is to trim out the corn, dress it with a little mild caustic to produce a healthy action, fitting the shoe so as to preclude all pressure upon the part, and the horse will go off all right. There is not horn enough to protect the heel from pressure when the heel is wide and weak, we nuust now accomplish two ends: remove pressure from the sole, and at the same time make the heels strong by growing strong, healthy horn. Put on a nicely fitting bar shoe, which will protect the heel by bringing pressure upon the frog.

The usual and scientific treatment is to apply a strong cantharides blister right over the seat of the corn, on the coronet. Stimulants of any kind will increase the action. Many remedies are used for this purpose with varied effects, but regular blistering really stands at the head of all. There is great danger of separation from the continued pressure of the shoe upon the affected part. The blacksmith may tell you it is a gravel, to shield himself from his inability to fit a shoe that will relieve pressure. In such a case it will be necessary to let the animal lie still and dress the part with an astringent, such as alum and water, sugar of lead and water. After the feet seem healthy, put on a bar shoe as before stated, and put the animal to work.

The following remedy seems to have a splendid effect in removing soreness and growing the feet. I know of its being sold for ten dollars. It is the best thing for the cure of weak, sore feet I ever saw. It softens the hoof and grows horn rapidly, as well as removes soreness.

\section{HOOF IINIMENT FOR CONTRACTED OR SORE FEET.}

Venice turpentine, $x / 2$ pint; aqua ammonia, 2 oz.; salts of niter, I oz.; benzine, I oz.; alcohol, 3 oz. Apply to the edge of the hair and all over the hoof once a day for a week; after that, for a week or two, three or four times a week, as may be necessary. 
The effect of this preparation on sore, weak feet, and upon contracted feet, in many cases, is wonderful, and is undoubtedly the best preparation for the feet yet published. It is well, however, to bear in mind that the primary condition of curing contraction is the use of mechanical means of expansion as given under that head.

\section{STEPPING ON NAILS, GLASS, OR ANYTHING THAT PUNCTURES THE SOLE OR FROG.}

The first thing to be attended to is to remove the nail, glass, or whatever it is, from the foot, carefully. See that no part remains, and remove a little of the hoof from around the opening. Drop a few drops of Friar's balsam into the orifice, and cover the part with a flax seed poultice. Friar's balsam can be obtained in almost any drug store. If this is not obtainable use the simple digestive ointment, given in another chapter.

\section{HIP LAMENESS}

Is a formidable disease. Its principal seat is in the whirlbone joint, and is usually caused by sprains or falls. The animal from this form of lameness will stand on the affected limb, and will not show lameness. The muscles are not called into action in elevating the limb. Then there is a dragging or swaying motion of the limb outwards. By placing the hand on the hip joint, an extra degree of heat will be found to invest this part.

- Treatment.-First, absolute rest; next, same treatment and remelies as given for shoulder lameness. Treatment should be repeated until recovered, which requires from one to two weeks.

\section{RETENTION OF URINE.}

The most common cause is keeping the animal at work, not giving time to urinate, and a spasm of the neck of the bladder or gravelly concretions; any cause of irritation may cause spasm. Symptoms are the same as in inflammation of the kidneys, except standing very wide behind, and when walking, a straddling gait resembling a cow with a very full bag. 
The most prompt treatment is to use the catheter, and scarcely anything more is necessary. But if one is not obtainable, bleed freely and give a strong opiate. 3 oz. tinct. opium, in half pint of water.

\section{SCOURS, OR PURGING.}

- This disease is generally produced by two causes: change of food or water, or unhealthy food, and sometimes through nervous excitement.

Cure.-Neutralize the acids in the bowels by giving an ounce and a half of prepared chalk and a dram and a half of powdered catechu, mixed in a pint of water. Give once or twice a day until purging ceases. Keep the animal without exercise, and do not give much water to drink.

If this disease should arise from nervous excitement, give a dram of powdered opium in the food once a day for three or four days.

\section{PROFUSE STALING.}

The causes of this disease are, the improper use of diuretic medicines, as saltpeter, resin, \&c. Unwholesome food will sometimes produce it.

Treatment.-Give one of the following balls every night: Powdered opium, $1 / 2$ oz. ; powdered kino, I oz. ; prepared chalk, I oz. Mix with molasses, and make six balls.

Or give the following powder once a day mixed in the food: gentian powdered, sulphate iron, a dram and a half of each.

\section{BLOODY URINE}

Is generally thie result of injuries of the loins, unwholesome food, violent exercise, \&c.

Treatment. - Give plenty linseed tea to drink; if the ani. mal refuses it, drench him. Give internally, once a day, one of the following pills: sugar of lead, $\mathrm{x}$ oz.; linseed meal, 2 oz. Mix with molasses and divide into eight parts.

\section{SPASMODIC ACTION OF THE DIAPHRAGM,}

Commonly called thumps, is caused by severe and long continued driving and hard work. Horses of a nervous 
temperament having too much cold water given to drink on a cold morring, nervous irritation, severe work or excitement from any cause, may excite this trouble.

Symptoms. - A sudden jerking or twitching of the rnuscles of the sides and flanks; pulse wiry, quick and low, more or less fever; extremities natural.

Cure.-This disease being of a purely spasmodic charac. ter, but in this case wholly of a nervous nature, bleeding must be omitted, and must be treated wholly by giving spasmodic remedies. Give assafoctida, in a dose of from I to 3 ounces of the tincture, mixed in a half pint of water. Given as a drench will stop it almost instantly.

If necessary, the medicine may be repeated in two hours. Keep the horse well clothed, and keep all exciting causes away from him. The bowels should be kept loose and regular, by giving bran mashes and moderate exercise.

\section{WORMS.}

The symptoms of worms are debility, feebleness, sluggish movements, emaciation, staring coat, hide bound, skin covered with blotches, irregular and capricious appetite, tucked up belly, pallid appearance of the lining membrane of the lip, badly digested freces, rubs the tail, and where fundament worms exist a whitish substance will be found about the fundament.

Give of calomel, 3 drams; tartar emetic, I dram. Mix and

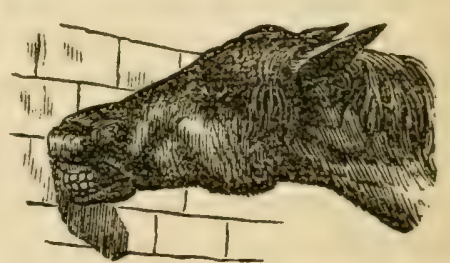

Symptoms of Worms. divide into three powders; one to be given at night for three successive nights. To be followed, in twenty-four hours, with a good purging ball.

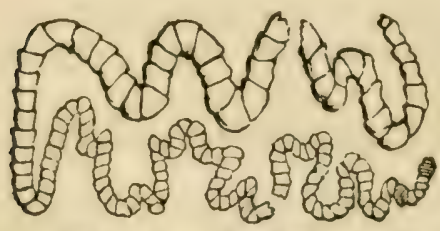

Tænia, or Tape Worm.

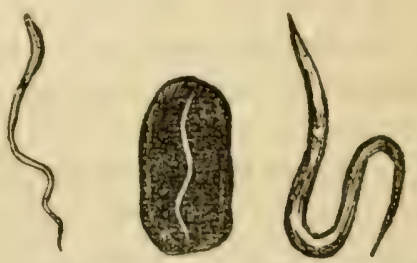

Different Kinds of Wormu. 


\section{INFLAMMATION OF THE EYES.}

Symptoms. - A watery discharge from the eye, eyelids partly closed, membrane of lid on under side much reddened.

In ordinary cases all that is necessary to do is to keep the horse quiet and bathe the eye with cold water. Either of the following will be found good:

Laudanum, I oz.; rain water, I pint. Mix. Or, acetate of lead, I dram; sulphate of zinc, I/2 dram; rain water, 3 pints. Mix for use.

Either of the above may be applied with a soft sponge two or three times a day.

Give on the tongue, three or four times a day, three or four drops of belladonna.

More thorough treatment would be a seaton below the eye, which of itself, will soon, in most cases, effect a cure.

The following is perhaps one of the very best eye washes used. It is a favorite remedy of great value. I insert it as given me.

\section{EXE WASH.}

Take three hen's eggs and break them into a quart of clear cold rain water; stir until a thorough mixture is effected; boil over a slow fire, stirring every few minutes; add half an ounce of sulphate of zinc, (white vitriol;) continue the boiling a short time, and the compound is ready for use. In this preparation a solid substance, or curd, is precipitated or thrown down, and a liquid solution rests upon the top. This is the best wash for sore eyes of either man or beast that was ever made. The curd applied to the inflamed eye at night will draw the fever and soreness nearly all out by morning. After two or three days the water should be strained from the curd, and put into a bottle for future use. This eye wash is invaluable. When applied to the human eye it should be diluted.

A gentleman who had a copy of my old edition, having this remedy in it, informed me that he was offered \$IO for the book on account of the value of this receipt, having used it in his neighborhood with great success, and that he would not sell it at any price. 


\section{CUTS OR WOUNDS-REMEDIES FOR.}

If the cut or wound is very bad, trim the hair off close around the edges, and wash out carefully with warm wates and castile soap. The object next is to produce a granulating process. There is hardly any use in sewing up cuts, as the stitches will sluff out. In treating deep wounds, or cuts or ulcers of any kind, bear in mind that the matter must be sponged or syringed out daily with castile soap and warm water, or what is termed a dependent opening must be made for the matter to run off. Matter alway burrows or pockets. The principle is the same in all cases,-using caustic to cut out fungous or other diseased growths; using for indolent ulcers proportionately more stimulating preparations than for those in a fresh, healthy condition.

\section{THE FOLLOWING DIGESTIVE OINTMENT}

is unrivaled for the cure of cuts or fresh wounds on horseflesh, and is alone worth more than the price of this book to any horseman.

For a healing ointment the following is unrivaled: $21 / 2$ lbs. palm oil, 2 lbs. lard, $1 / 2$ lb. gum turpentine, $1 / 4 \mathrm{lb}$. beeswax, I lb. calamine. Simmer all together over a slow fire, and it will be fit for use. Put a little in the wound once a day. Wash the wound with warn water and castile soap before applying the ointment.

\section{A GOOD SIMPLE HEALING PREPARATION.}

Blue vitriol, in the proportion of two drams to a pint of water is an excellent application for wounds. If a caustic effect is desired, increase the quantity to an ounce or more, and it will be found a fine preparation to rouse old ulcers to a healthy action. Good for poll evil or other ulcers.

A fine healing lotion is: Tincture myrrh, $\mathbf{I}$ oz.; tincture aloes, 2 oz. ; water, $1 / 2$ pint. Mix, and apply once a day. 
HEALYNG OINTMENT FOR CUTS, GALLS, ETC. GOOD.

Oxide of zinc, pulverized fine, 4 drams; carbolic acid, 6 grains; lard, I ounce. Melt the lard and stir in the zinc. Add the carbolic acid and mix thoroughly. Apply once or twice a day to the cut or injury. Will cause a healthy discharge from a foul ulcer.

\section{IINIMENT FOR OPEN WOUNDS. A FINE PREPARATION.}

Take sulphate of copper (copperas), I oz.; white vitriol, 2 Oz.; muriate of soda (salt), 2 oz.; oil linseed, 2 oz.; Orleans molasses, $8 \mathrm{oz}$. Boil over a slow fire fifteen minutes, in a pint of urine, all of the above ingredients. When nearly cold add I oz. of oil of vitriol and $4 \mathrm{oz}$. spirits of turpentine, and bottle for use. Apply to the wound with a quill, which will soon set the wound to discharging, and perform a cure in a few days. Be careful to keep the wound covered either with a bandage or a plaster. Should be applied once or twice a day until it discharges freely.

\section{WASH FOR FRESH WOUNDS. A FAVORITE REMEDY OF GREAT VALUE.}

One teaspoonful white vitriol, I teaspoonful copperas, 2 teaspoonfuls fine gunpowder; add to I quart of boiling water, and let it stand until cool. If the wound is deep, apply with a syringe. One of the best of remedies for the purpose recommended.

\section{IINIMENT FOR FOUL ULCERS. GOOD.}

Sulphate of copper, I oz.; nitric acid, I/2 oz.; water, 8 to $12 \mathrm{Oz}$.

COOLING LINIMENT FOR EXTERNAL INFLAMMATION. GOOD.

Goulard extract, I oz.; vinegar, 2 oz.; spiris of wine, 3 oz.; water, I I $/ 2$ pints. Apply with a bandage. 
FOR INFLAMED LEG, GALLED SHOULDERS OR BACK. A REALLY GOOD THING.

Sal ammoniac, I oz.; vinegar, 4 oz.; spirits of wine, 2 oz.; tincture arnica, 2 drams; water, $1 / 2$ pint. Mix, and bathe with it often and thoroughly.

\section{BUTTER OF ANTIMONY.}

For corns, canker, indisposition of the sole to secrete healthy horn, wounds in the foot not attended by healthy action, and for every case where the superficial application of a caustic is needed, the chloride of antimony (butter of antimony) is one of the very best.

\section{STICKING-PLASTER, FOR CUTS OR WOUNDS.}

Burgundy pitch, 4 oz.; tallow, 2 oz. Melt the articles together, and spread on linen or cloth while hot. Cut in strips of proper length and width, and draw the wound together; warm the strips and apply them. Clip the hair short where the plaster is to be applied.

\section{WASH FOR REDUCING AN INFLAMED WOUNV.}

One oz. sulphate of zinc, I oz. crotus martes, I/2 oz. sugar of lead, I pint water. A sore will not smell bad when this wash is used.

\section{SPRAINS AND BRUISES.}

It must be borne in mind, the first object in treating acute inflammation caused by injury of any kind is to lower the inflammation. Cold water, or one ounce of sugar of lead to a pint of water, would be better, and is a remedy of great value, to be used repeatedly until relief is afforded.

The following is excellent: Saltpeter, $4 \mathrm{oz}$.; sugar of lead, I oz.; muriate of ammonia, I oz.; common salt, I pint; cold water, 2 galls. Mix and bathe the parts affected; or keev constantly wet with the following, which is gond: 
Tincture arnica, 2 oz.; cold water, $x$ quart. This will prevent infiammation or swelling following a bruise or sprain.

\section{ANODYNE STIMULATING LINIMENT.}

Spirits of hartshorn, $\mathrm{I} I / 2$ oz.; sulphuric ether, $\mathrm{I} I / 2$ oz.; spirits of turpentine, $1 / 2 \mathrm{oz}$; sweet oil, $3 / 4 \mathrm{oz}$.; oil of cloves, $1 / 2$ oz., chloroform, I oz. Put into a strong 8 ounce bottle and cork tightly; keep in a dark place, or wrap with paper. This liniment relieves pain, and is good for lameness, etc., and for all cases of strains and soreness. To be well rubbed in.

Oil of turpentine, I oz.; tinc. opium, I oz.; soap liniment, I oz.; tinc. capsicum, $1 / 2$ oz. Stimulating liniment; good for rheumatism, sprains, etc.

\section{MAGIC IINIMENT.}

Used very generally; good not only for sprains, bruises, etc., after the acute stage, but a fine counter-irritant for pleurisy, inflammation, etc.: Oil of spike, 2 oz.; organum, 2 oz.; hemlock, 2 oz.; wormwood, 2 oz.; sweet oil, 4 oz.; spirits ammonia, 2 oz.; gum camphor, 2 oz.; spirits turpentine, 2 oz.; proof spirits, I quart-9o per cent. Mix well together, and bottle tight.

FOR FRESH STRAINS, ETC.

Carbonate ammonate, 2 ounces; apple vinegar, $1 / 2$ gill. Rub in well.

\section{TO ABATE SWELLING CAUSED BY AN INJURY.}

Take common wormwood, 2 oz.; New England rum, I quart. Steep the wormwood in the liquor and apply thor oughly.

A FINE SIMPLE LINIMENT.

Two parts ammonia to 4 parts of soft water, good tor strains, etc. 


\section{THRUSH,}

This is a rotting of the frog, with a discharge of matter from the cleft or division of the frog, occasionally producing lameness. The treatment is simple and effectual. Wash the parts well with soap and water, then apply powdered. sulphate of copper to the parts, and fill up all the cavities with cotton, packed in so as to keep out all dirt. This process should be repeated in a few days if necessary.

For Thrush or Canker: Burnt alum, 4 oz.; sulphate of iron, 2 oz.; sulphate of copper, I oz.; camphor, 2 drams. Mix.

\section{MAGIC HEALING PREPARATION.}

Burnt alum, I/2 oz.; prepared chalk, I oz.; pulverized gum camphor, I dram; calamine, pulverized, 2 drams. Mix.

Sprinkle on the sore. Its effect will be apparently wonderful, healing a simple wound in a few hours.

If it is desired to cicatrice a wound quickly, this is to be used. Good for fresh wounds, galls of collar, saddle, or in fact for any purpose requiring a fine healing astringent. This is the receipt for the wonderful healing powder so much advertised. Its effect will appear wonderful to those not accustomed to its use. It is just the thing for sore or lacerated mouths, or any such difficulty requiring great astringent healing properties.

TO REDUCE SWELLING OF THE LEGS AND STRENGTHEN THE TENDONS AFTER HARD DRIVING

A favorite remedy on Long Island. One pint alcohol, I ordinary sized beef gall, I ounce organum, I ounce oil of spike, I ounce gum myrrh, $1 / 2$ ounce camphor gum. First wash and rub clean and dry. Then bathe with the liniment and rub dry. Then apply again and bandage the leg, being careful not to bandage too tight.

This is the best liniment for the purpose recommended I have ever used. It should be kept in every stable.

This is a splendid remedy for the above purpose. 
TU RECRUIT A HORSE HIDE-BOUND OR OTHERWISE OUT OF SORTS.

Nitrate potassa (or saltpeter), 4 oz.; crude antimony, I oz.; sulphur, $3 \mathrm{oz}$. Nitrate of potassa and antimony should be finely pulverized, then add the sulphur, and mix the whole well together. Dose: A tablespoonful of the mixture in a bran mash daily, for a week or two.

This will be found an excellent remedy. It was given me ien years ago, by Dr. T. Burton, of Fultonville, N. Y., cone of the most successful of medical practitioners, and not only one of the best horsemen with whom, in my varied experience, I have become acquainted, but one of the best men I have ever met, and to whose interest and encouragement I am more than to any other single cause indebted for my great success. It was by this gentleman's advice that I made a series of models with which to illustrate the principles of shoeing, which have so often since been admired by horsemen. There are a few chance acquaintances I have made during the inception of a checkered career in my profession, the l -membrance of whom becomes at all times only a growing scurce of pleasure and encouragement, but chief of them all stands this gentleman, whose encouraging predictions I now take the liberty of acknowledging in this connection, as an assurance of my continued appreciation of his interest so long ago, and that I have done the best I could to prove worthy of his high, flattering assurance of my future success.)

\section{CRACKED HEELS.}

Two ounces resin, 2 ounces copperas, 2 ounces alum, I ounce beeswax, I pint tar, size hen's egg of tallow; boil over a slow fire, skim off the filth and add the scrapings of sweet elder a handful; when cool, fit for use.

This is the best local application for cracked heels or stuffing of the heels that I have ever used, and is in fact one of the very best of healing preparations.

Six years ago, in Ohio, Turco had an aggravated cracking and stuffing of heels of so bad a character that I feared stuffing of the hoofs. In defiance of all the treatment I could then think of for cure, I was compelled to poultice, al.d lid so continually, using a variety of preparations 
including charcoal and night soil as experiments. Of course, I could now manage such a case easily, but at that time all my efforts were baffled, and there was a strong prospect .f my favorite horse I then valued at three thousand dollars, being ruined.

At this time, an old gentleman who claimed some success as a "horse doctor," saw the case, and, against my judgment, insisted upon using this remedy, which he said would cure it in two weeks, and, to my surprise and gratification, there was a perfect cure in less than that time.

There was no internal treatment given. It will be fours? a remedy possessing great curative virtues for this purpose.

In treating scratches or grease heel, a local treatmen: will always be facilitated powerfully, and is almost indispensable, by giving a dose of physic.

\section{GREASE HEELS.}

This is a white, offensive, greasy discharge from the heels of the horse. The skin becomes hot, tender and swollen. The acrid character of the discharge often causes large portions of the skin to slough away, leaving an ugly sore behind.

Treatment.-Open the bowels with the following ball: Barbadoes aloes, I oz.; pulverized gentian root, 2 drams; pulverized ginger, I dram; water sufficient to make the ball. Wash the parts well, and poultice for two or three days with the following: Flax seed meal mixed with a solution of 2 drams sulphate of zinc to a pint of water, which keep clean, and bathe frequently with glycerine, or the solution of zinc; or a solution of the chloride of lime may be used; or the bichloride of mercury may be used in inveterate cases with good results, prowded it is not repeated oftener than once a week.

\section{CURE OF SCRATCERS.}

Four ounces tincture arnica, 4 ounces glycerine. If heels are cracked badly, add: I ounce iodine, 2 ounces tincture myrrh, $1 / 2$ ounce gun powder (powdered fine.) Put all into a bottle and shake thoroughly; put on two or three times a day. 
In treating scratches, first give a dose of physic, or a few bran mashes.

\section{CANKER,}

This is a more aggravated form of thrush, often proving very troublesome to manage. It is a continuation of the thrush between the horny frog and the internal structures of the foot, causing separation between them.

Treatment.-Cut away all the horn which has been separated from the soft structures of the foot, and apply the following ointment: 'Take equal parts $\mathrm{if}$ pine tar and lard, melt over a slow fire, and add sulphuric acid very slowly until ebullition (boiling) ceases, and apply to the parts. The foot must be protected from dirt by a bandage or a leathern boot.

\section{QUITTER.}

This is a formation of pus between the hoof and the soft structure within; a sore at the coronet or upper part of the foot, which at first is a hard, smooth tumor, soon becoming soft, and breaks, discharging quantities of pus.

Treatment.-Poultice the foot for several days with flax seed meal. As soon as the hoof becomes soft, cut away all loose portions, but no more, and inject with a syringe either of the following once a day: Chloride of zinc, 2 drams, dissolved in a pint of water; or, sulphate of zinc, $\mathbf{I} 1 / 2$ drams, in a pint of water; or, nitrate of silver, 2 drams, in a pint of water; or glycerine may be used with advantage. Before using the wash have the foot well cleaned with castile soap and water.

\section{MANGE.}

Take the horse in the sun and scrub him thoroughly all over with castile soap and water, then wash him well from head to tail with gas water, in which put 2 drams white hellebore to the gallon. He must now be put in another stall, distant from the one in which he has been standing. Thus treated, it rarely requires more than one washing to effect a permanent cure. The harness should be thoroughly scrubbed and put away for six or eight weeks. These precautions are necessary to success in this otherwise troublesome disease. 
No. 2.-Oil turpentine, 4 oz.; oil tar, 4 oz.; linseed oil, $6 \mathrm{oz}$. Mix.

\section{PREPARATION TO KILL LICE ON HORSES.}

One ounce of arsenic to a pail of soft water. The horse should be washed thoroughly in some warm place. It is not known to many that hen lice and common human body lice grow on horses with great rapidity. This remedy is a sure cure, and is invaluable.

\section{NASAL GLEET.}

This is a chronic discharge from one or both nostrils, of a whitish, muco-purulent matter, the result usually of neglected catarrh. The general health of the animal does not seem to suffer; he looks well, feeds well and works well, yet we have this discharge, which is caused by weakness in the secretory vessels of the lining membrane of the nose.

The successful treatment in all cases where this disorder has existed has been on tonic principle. Bleeding and purging are positively injurious. Give one of the following powders night and morning: Seaquin-chloride of iron, 2 oz.; powdered cinnamon, I oz. Mix and divide into four powders. Or: Carbonate of iron, pulverized gentian and pulverized quassia, of each $\mathbf{r}$ oz. Divide into four powders. Or: Nux vomica, pulverized, $1 / 2$ oz.; linseed meal, $2 \mathrm{oz}$. Divide into eight powders. Another good preparation 1s: Muriate of barytes, I/2 oz.; linseed meal, I oz. Divide into eight powders. The last is best.

\section{CAUSTICS}

Are substances which burn away the tissues of the body by decomposition of their elements, and are valuable to destroy fungous growth and set up healthy action.

Corrosive sublimate, in powder; acts energetically.

Nitrate of silver is excellent to lower granulation.

Sulphate of copper, not so strong as the above, but good.

Chloride of zinc is a powerful caustic. It may be used in sinuses, in solution, 7 drams in a pint of water. 


\section{MILDER CAUSTICS.}

Verdigris, either in powder or mixed with lard, as an ointment, in proportion of one to three.

If a wound or an ulcer will not heal so long as there is a foreign body, or unhealthy growth in it; hence, if a wound or puncture from any cause, there must be a removal of hair, pieces of wood, bone, etc. No matter what you do, if any foreign body remains in the wound, it will not heal. This done, wash it or inject with warm water and castile soap, after which the regular digestive ointment can be used, or a mild solution of any of the remedies recommended for the purpose. But if fungous growths cannot be removed with the knife, a caustic becomes necessary, a little of which is to be put on the part, or into the sinews. Carrying this treatment to extreme implies using a hot iron. (The actual cautery.)

\section{FARCY-CURE OF.}

One-quarter pound sulphur, I/8 pound saltpeter, I ounce black antimony. If acute, give one tablespoonful twice a day. If sub-acute, once or twice a week.

The sum of $\$ 50$ was repeatedly paid for this prescription, and it has made some marked cures. It is regarded as specific for farcy in the portion of Ohio in which I obtained it. In two instances, gentlemen who have used it in the treatment of farcy have informed me it cured, and expressed themselves as valuing it worth $\$ 50$.

The following is my regular treatment for this formidable disease :

Three drams of powdered sulphate of copper, given every night in the food, until the animal refuses to eat. After a few days repeat, but if the case is bad give the medicine in water as a drench, for ten days, if he will not take it in his food.

\section{CONDITION POWDERS.}

Take I pound of ginger, $\mathbf{I}$ ounce of anise seed, pulverized, I ounce of fenugreek seed, 2 ounces of ginseng root, pulverized, I ounce of the seed of sumach berries, pulverized, I ounce of antimony; $\operatorname{mix}$ it with one pound of 
brown sugar. This is excellent for coughs, colds, or to give a horse an appetite.

\section{TO CURE COUGH-NO. 2. EXCELLENT.}

Put all the tar into alcohol it will cut, and add one-third in quantity of tincture belladonna. Dose: From one to two teaspoonfuls once or twice a day. Very good.

TO CURE COUGH-NO. 3.

Take tartar emetic, I oz.; resin, 2 oz.; bloodroot, I oz.; salts of tartar, $2 \mathrm{oz}$; ginger, $2 \mathrm{oz}$. Mix, and give a teaspoonful three times a day, in the feed.

\section{COUGH POWDER.}

Fenugreek, ginger, licorice and bloodroot, equal parts Half proportion lobelia and camphor may be added. Dose, tablespoonful twice a day. For heaves, add more camphor.

\section{DIURETIC DROPS}

that are reliable for stoppage of water, foul water, or inflammation of the kidneys, in all cases:

Take of sweet spirits of nitre, 4 oz.; balsam copaiba, $2 \mathrm{oz}$; ; oil of juniper, $2 \mathrm{oz}$.; spirits of turpentine, $2 \mathrm{oz}$. ; gum camphor, pulverized, I oz. Mix all together, and shake well, bottle, and it is fit for use for man or beast, under all cirumcstances where a diuretic is required.

Dose: For a horse, $\mathbf{I} \mathrm{Oz}$. in half a pint of milk once in six hours; for a man, $\mathbf{I}$ teaspoonful in a tablespoonful of milk once in six hours.

Be sure to shake the ingredients up well before turning out for use.

\section{THE PULSE.}

The beating, as it is termed, of the heart, and that of an artery, tells the exact condition of the circulation and of the health, to the experienced practitioner.

In a state of health the pulse is from 36 to 40 in a minute. It will be felt easiest and best at the lower jaw, a 
little behind where the sub-maxiliary artery and vein come from the under jaw. Pass the finger down the jaw, up near the neck on the inner edge, and you will feel a cord-like ridge, and upon quietly but firmly pressing it you will feel it throb or beat. Each contraction of the heart forces a jet of blood through the arteries throughout the system. The arteries are strong elastic tubes, which expand as the blood is forced through them, but contract again as soon as the volume of blood passes, forming a beat which can be plainly felt under the finger at this point. It is highly important to understand the condition of the circulation to treat diseases, especially of an acute character, successfully.

Frequent reference is made to the state of the pulse in different diseases, such as colic, pneumonia, laminitis, \&c., \&c. Hence it should be studied carefully. For example, during the early stage of colic, the pulse will be hardly affected, and the ears and legs will be natural in temperature; while in inflammation of the bowels the pulse will be quick and wiry, ears and legs cold, \&c. In fever it is quick, wiry and light, indicating the extreme or not of obstruction in the circulation.

\section{BLEEDING.}

For general bleeding the jugular vein is selected. The horse is blindfolded, or his head turned away; the hair is smoothed along the course of the vein with a moistened

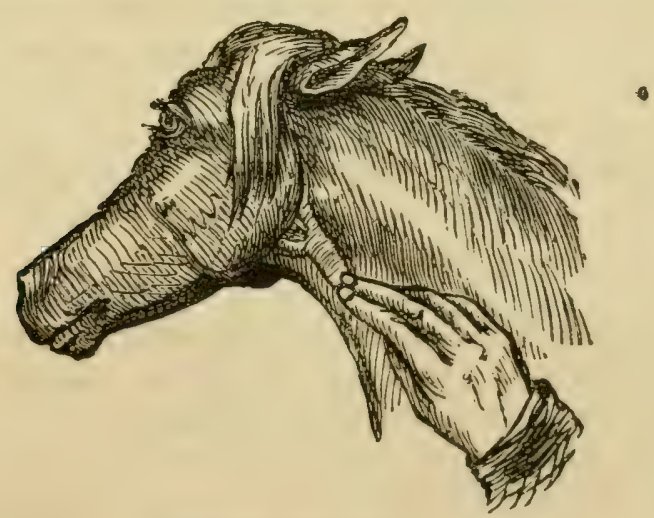

Raising the Vein. 
finger, then with the third and little fingers of the left hand, which holds the fleam, pressure is made on the vein sufficiently to bring it into view, but not to swell it too much. The point to be selected is about two inches below the

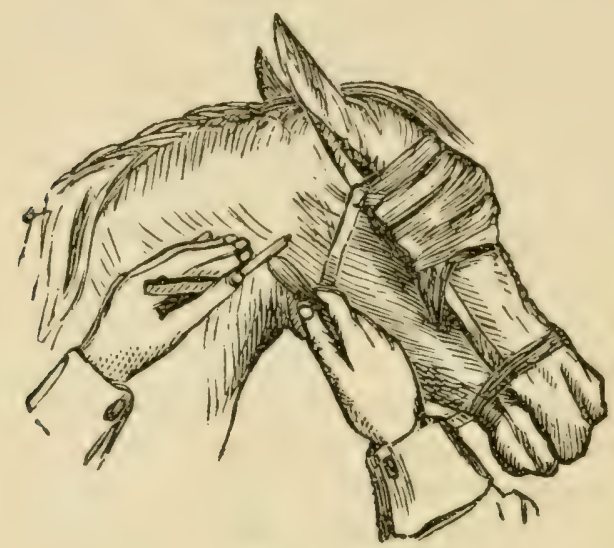

Bleeding from the Neck Vein.

union of the jugular vein at the angle of the jaw. (See cut.) The fleam is put in a direct line with the vein at the center, when it is to be hit sharply with a stick. See that the fleam is large, sharp and clean, for if rusty or dull, inflammation of the vein might result. It is of great importance that the blood be drawn quickly. When sufficient blood has been taken, the edges of the wound should be brought closely together, and kept together by a small sharp pin being passed through them. Around this a little tow or a few hairs from the mane of the horse should be wrapped, so as to cover the whole of the incision, and the head of the horse should be tied up for several hours, to prevent his rubbing the part against the manger. When the bleeding is to be repeated, if more than three or four hours have elapsed, it will be more prudent to make a fresh incision, rather than to open the old wound.

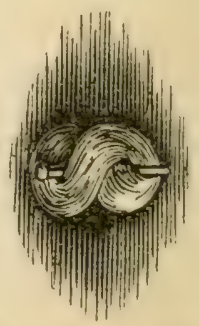

A pin is first stuck through the lips of the wound ; a portion of tow, thread or hair is then wrapped round the pin. 


\section{PHYSICING.}

It is always best, if possible, to prepare the horse for physic by giving a bran mash twenty-four hours previously, as the medicine will act more favorably and there is less danger of superpurgation. Five drams of aloes (Barbadoes aloes are always used for horses) will act as forcibly after a mash as seven without. Again, the quantity of physic should be adapted to age and size. The rule is to give one drain for each year up to seven. Eight drams is the largest given at one dose.

Physic Ball: Barbadoes aloes, pulverized, 7 drams; bar soap, 4 drams; ginger, I dram. The usual way is to mix the ingredients in this proportion, then reduce to the weight intended and give.

For Alterative Balls simply give from one to two or three ounces of mass, as above prepared, two or three times a week, for a week or two.

For Worms: Give 4 drams aloes, $x$ dram tartar emetic, 2 drams ginger, about the size of a bean of calomel, and molasses enough to make into a ball. To be given every morning for three days.

\section{VAI,UABLE MISCELLANEOUS RECEIPTS.}

The following remedies will be found excellent:

\section{DRENCH FOR DIARRHCFA.}

Opium, I dram; prepared chalk, I oz.; compound powder of tragacanth, I oz.; mint water, I pint.

\section{MERCURIAL ALTERATIVE BALLS.}

Calomel, I/2 dram; aloes, I dram; castile soap, 2 drams; oil of juniper, 30 drops; syrup to form a ball.

\section{ASTRINGENT BALLB.}

Catechu, I/2 ounce; alum, 3 drams; cascarilla, 2 drams ; flour, 2. drams; treacle. 


\section{DRENCHES TO PROMOTE PARTURITION}

Ergot of rye in fine powder, 2 or 3 drams; pennyroyal water or infusion of rue, I quart.

\section{FOR DIABETES.}

Opium, I dram; ginger, 2 drams; oak bark, p. I oz.; decoction of oak bark, I pint.

\section{CORDIAL AND ANODYNE BALL.}

Castile soap, 3 drams; camphor, 2 drams; ginger, $11 / 2$ dram, and Venice turpentine, 6 drams, made into 1 ball.

\section{AROMATIC POWDER.}

Caraway, 6 oz.; pimento, 4 oz.; ginger, 2 oz.; licorice, 2 oz. Mix. Dose, 6 to 8 drams.

\section{COOLING AND DIURETIC DRINK.}

Dissolve $\mathbf{r}$ ounce of nitre in a pail of water.

TONIC BALL (VEGETABLE TONIC).

Peruvian bark. I olnce; opium, $1 / 2$ dram; ginger, $\mathbf{x} 1 / 2$ dram; oil of caraway, 20 arops. Treacle to form a ball.

\section{DIURETTC ALTERATIVE BALLS.}

Dried common soda, s oz. : castile soap, 6 drams; resin, $2 \mathrm{oz}$; licorice powder, $1 \% \mathrm{oz}$.; Barbadues tar, to form 6 balls. One daily.

\section{LAXATIVE ALTERATIVF BALLS.}

Aloes, 4 oz.; soft soap, 4 oz.; common moss $212 \pi$ Mix. Dose I uz. 
BALLS FOR APPETITH.

Equal weights of assafcetida, saffron, bay berries, and aloes, made into a mass with extract of gentian. Dose $\mathbf{I} \mathbf{~} z$.

\section{ANODYNE BAII.}

Opium I/2 dram to I dram; camphor, I dram; anise seed, $1 / 2$ oz.; soft extract of licorice.

\section{CORDIAL BALLS.}

Ginger and gentian, equal parts; treacle to form a mass. Dose, I oz. to $\mathrm{I} / 2 \mathrm{Oz}$.

Ginger and caraway, each 4 lbs.; gentian, I lb.; palm oil, $4 \frac{1}{2}$ lbs. Beat together. Dose, I Oz. to $\mathrm{I}^{1 / 2} \mathrm{Oz}$.

MIXED BALLS, CORDIAL ASTRINGENT BALLS.

Catechu, I dram; opium, Io grains. To WASH HORSES BEFORE OR AFTEK A JOURNEY.

\section{DIURETIC BALLS.}

Resin soap and nitre, of each equal parts, beaten together into a mass. Dose, $\mathrm{I}$ oz. to $\mathrm{I} / 2 \mathrm{Oz}$.

White soap, 8 oz.; nitre, 3 oz. ; 3 resin, oz.; camphor, 3 drams; oil of juniper, 3 drams. For 6 balls, one every morning or every other morning.

\section{TONIC DIURETIC BAUL.}

Gentian, I dram; ginger, $1 / 2$ drani ; silphate of iron, 2 drams; nitre, $1 / 2$ oz.; resin, $1 / 2$ oz. Mix with molasses.

FEVER BALLS.

Emetic tartar, 1/2 dram; camphor, $1 / 2$ dram; nitre, 2 drams; ginger, 3 drams. Mix in ball. 
Antimonial powder, 2 drams; nitre, 3 drams; cream tirtar, 2 drams; honey to form a ball. In influenza twice a day, after a mild laxative.

\section{BALLS FOR FARCY AND GLANDERS.}

Sulphate of copper, $\mathbf{x}$ dram; calomel, 20 grains; common turpentine, 3 drams; licorice powder and syrup to form a ball.

Sulphate of iron, 2 drams; iodide of potassium, ro gr.; gentian, 2 drams; ginger, I dram, and treacle to form a ball.

\section{COUGH BALLS.}

Emetic tartar, $1 / 2$ dram; digitalis, $1 / 2$ dram; nitre, $\mathbf{I} / 2$ dram; tar enough to form a ball. One. every night.

Powdered squills, I dram; gum ammoniac, 3 drams; opium, $\mathrm{x} / 2$ dram; syrup to form a ball.

\section{FOR BLOODY URINE.}

Acetate of lead, Io gr.; sulphate of zinc, 40 gr.; catechu, 4 drams; conserve of roses to form a ball. One daily.

\section{FOR DIABETES.}

Catechu, I/2 oz.; alum, I/2 dram ; sugar of lead, Io gr.; with conserve of roses to form a ball.

\section{ANODYNE DRENCHES.}

Opium, I dram, dissolved in warm water, $1 / 2$ pint; add I quart of starch gruel.

Mix tincture of opium, I oz. with sweet spirits of nitre. I I/2. oz.; ess. peppermint, I dram. and water, I pint. 


\section{WORM POWDERS}

Sulphur, I oz.; tartar emetic, 4 drams; common salt, $8 \mathrm{oz}$., liver of antimony, I oz. Mix for 6 doses; I daily, in wetted corn.

\section{TO CURE AN INDOLENT ULCER.}

Take the green scum that gathers on the water in the frog ponds in the spring and summer; boil over a slow fire; then add fresh butter to the consistence of an ointment. This is an Indian remedy; cured an ulcer of seventeen years' standing that had resisted all other treatment.

The gentleman whom it cured deemed it so valuable, and desiring to benefit those that may be similarly afflicted, requested that I would put it in my book.

For a lacerated wound and bruise, I have found the following so effective a remedy that I insert it. It lias a peculiarly soothing, healing effect. I once had one of my big toes crushed by a heavy horse stepping upon it; under like circumstances, previously found even arnica or laudanum to afford the desired relief; by pouring some of this on the part, wetting the stocking, in fifteen minutes I had no pain, and had no trouble afterwards:

Simple tincture of marigold, called callendula, reduced one-third to one-half with soft water. Bathe the part repeatedly with it. It possesses remarkable healing qualities.

\section{GRAIN FOUNDER-CURE OF.}

Take three pints of vinegar, into which put six red pepper pods, and boil until reduced to one quart. When cool, give as a drench. Blanket the horse warmly. This will put the horse in a profuse perspiration, and perform a perfect cure. The gentleman of whom I got this, cured a valuable horse that got into his granary and ate so much grain that he was in the morning perfectly stiff. One dose made a perfect cure. He said he would not be without it for one hundred dollars. 


\section{CONDITION POWDER.}

One-half pound grains paradise, ground; $1 / 2 \mathrm{tb}$. ground ginger; $3 / 4 \mathrm{lt}$. powdered gentian; $6 \mathrm{oz}$. cumin seed, ground; 6 oz. fenugreek, ground; $6 \mathrm{oz}$. carbonate soda; 6 ltbs. common brown sugar; $13 / 4$ tbs. salt. Put in one hundred pounds of meal. Dose: one pint to be given with the usual food.

This is considered one of the best tonic condition powders ever used. It is sold in the eastern cities at a large. price, under the name of Condition Food, and is held as a secret of great value. I have known $\$ 50$ to be refused for the receipt. 


\section{APPENDIX.}

READ first the chapter "Preliminary Hints, etc.," on page 24 ; next the chapter on "Excessive Fear-the Causes of, etc.," page 57. In the school you were taught principles of subduing or taming horses. To aid still further, $\mathrm{I}$ include here a few additional hints.

The great stumbling-block to horsemen is the difference they say there is in horses. What will break one horse easily, will have scarcely any effect upon another, if not, indeed, make them more vicious and unmanageable. As I have shown, this trouble is the result of thoughtlessness or ignorance. This duty, above most all others, demands not only a knowledge of principles, but that, at the foundation of a knowledge of these principles, there must be firmness, delicacy and patience in feeling your way, when you are not sure of easy and direct success. And, besides, the instances of horses being very vicious and bad are really almost rare, and it is to the ntrol of such that we must bring to bear the advantage of skill.

But the well-meaning reader will often ask, won't your system break any horse without so many perplexing conditions? Rarey and others claimed they could make any horse gentle, and were very successful. And what do you mean by so many conditions if your system is an improvement?

It is eary enough to claim great skill and power in the subjection of horses, but this does not prove real skill. We should go back and examine and compare principles, and judge of their value and points of merit. In the first place, people were not so exacting and critical years ago as now. We are now required to do more, and the results we are able to show are so much greater than could be shown upon horses of the same disposition and habits by any and all old systems, that there is no comparison. The art of controlling and subduing wild or vicious horses I have shown to have reduced to an exact science, leaving nothing to be desired. But I would remind that we are acting upon fixed conditions, that these conditions are unalterable. Some horses are naturally gentle, others vicious. Some are dull and stupid, while others are quick to comprehend, and no matter how perfect the treatment, success must be regulated verv much by the character of the subject. But my object is to simplify tinese difficulties, and to do so would call your attention to what is said about dispositions on page 3o. But here you are simply reminded of extremes. 
In the first place, the dispositions of the different classes of domestic animals would seem to be, in a greater or less degree, developed in the horse, showing, as it were, peculiarities of strata, and in proportion as there is preponterance of any combination or peculiarity of strata, we have developed what we call disposition. Thus one horse will remind, by his temper, of the hog, the bear or mule, while another will show the reverse, of the sheep or gazelle, while another shows the elements of the feline nature. The first, if aroused, is sulky-a stolid, reckless sort of action, that goes headlong, regardless of consequences, or is stupidly sullen. The other is moved wholly by fear, and will not bear excitement or abuse. There is a timidity and fear underlying its actions that points to any sort of punishment or abuse as only increasing the resistance and fears of the animal. While the third would seem to work in nicely by ordinary, caretul treatment; but rouse its temper, the eyes become bloodshot and the whole nature would seem to be excited to fury. And here, we see, are endless modifications of these extremes. But if you will look at the eyes, ears and head carefully, there will be noticeable a singular correspondence of construction and expression to the disposition an ${ }^{\circ}$ character. The good disposition-a large brownish eye, the ear is short and tapering and the nostrils large; the head is broad between the eyes, and short from eyes to ears.

The sulky, stupid nature-eye medium or small, eye-lids heavy, the ears long and flabby; but if other features are even good, excitement will reveal a persistent, willful temper.

The third-a large and clear eye, eyelids thin, quick to learn but over-sensitive, ears pointed, nostrils open, full brain, texture dense and fine. The fourth has a stolid expression; no movement of eye or head but in a suspicious manner, that will not bear any trifling, or resists only when excited. And so I could go on, according to modification, to an endless degree. But these conditions you must study. Move slowly and carefully when you are not sure of what you have; never take any chances you can avoid. What you do, do well. I mean do not suppose a horse that seems to work gently after a course of subjection, can be always depended upon. Try the animal thoroughly for several days following, if necessary, until you find prompt, sure obedience.

A horse should be perfectly obedient to the bit, but not too tender. Be careful how you force the mouth much of a horse that will not pull against the bit, and be just as careful to know that you have the most thorough control over the mouth of a courageous, runaway horse. There is the widest latitude in the training necessary to the mouth. One horse will resist the bit with rare courage, while another will give up in a few minutes. But you should indirectly aim to overcome the cause of the resistance, and then carry out your point with the reins and bit.

In the training of colts especially you cannot be too thorough in overcoming all sense of fear of anything striking or touching the hind parts. If the tail is sensitive, disposed to catch the rein (has been spoiled), make the crouper large, as directed, and wear under 
the tail for at least a week. But if the colt is over-sensitive and vicious, subject carefully to subjective treatment first. Use the mildest treatment you can, and win the better nature by kindness. When the animal submits from necessity, at once give presents of apples, oats or anything else of which the horse is fond. This is a powerful point, especially in the management of those horses that are sensitive, but if excited that are recklessly obstinate.

\section{TAMING HORSES.}

It is not a little amusing to read the accounts of different writers of the powers exhibited by different persons at different times over vicious horses. Indeed, the simplest exhibitions of control over horses were regarded within the domain of the black art. And it is not a little singular that, in the broad sunlight of the present era of intelligence, there are many who believe that there can be but few in any age who can be gifted with such power.

Like the soothsayers and doctors of old times, who consulted the horoscope of the stars, or resorted to some complicated, mysterious humbugging, to have revealed the secret and means of cure, there has been an enchantment and mystery about the control of the horse, that has been regarded with open-mouthed wonder.

In IS25, a man named Bull, who lived in Stanton le Vale, in Lincolnshire, Eng., was renowned for his exhibitions of power over vicious horses. His art was a secret of the greatest importance. Mr. T. John son, a neighbor, owning a very vicious horse, was induced to take him to Bull to be tamed, and finally induced bull to teach him (Johnson) the secret, paying therefor a large price. Bull's secret was explained as lollows: First catch your horse, then strap the near fore leg up round the arm of the animal; lead him about on three legs until he becomes tired or weary. He will then allow you to handle him anywhere. Then attach a strap with a ring to the off fore fetlock; to this ring fasten anotherstrap, which, being brought over the horse's back to the near side, is put through the ring on the off fore fetlock. Return the end of the strap to the near side, keeping fast hold, and move the animal on and pull. He will then be thrown upon his knees, when, after struggling some time, by gentle usage, he will lie down. After unloosing the straps again, put him through the same process as before, when the horse will lie down whenever required. Dick Chislian's (also a noted horse-tamer) secret consisted of tying up the near fore foot, and so driving or riding him until entirely manageable. A man named Sullivan, who lived in Mallow, Ireland, in I820, by some means learned this secret. He pretended his secret was in a peculiar way of whispering into the horse's ear, and the most intelligent people of that town, even the parish priest, regarded his performances with more than wonder; and even yet, in that part of Ireland, Sullivan's exploits are referred to with a sort of awe, that is as surprising as it is amusing.

A man, Offut, who traveled mostly in the south and west, claimed the most wonderful powers over horses. His secret was the same, with slight variations, as Bull's, and it was claimed by Offut that he 
gave the secret to John S. Rarey, who afterwards became famous, and who received over $\$ 100,000$ in England alone, for this secret.

And now for the great secret medicine which has been sold through the country for large prices, and many a man will still tell you will do it every time. All you have to do is to get it and your success is sure:

Oil of rhodium, oil of cummin or oil of anise seed. These should be kept in air-tight bottles, ready for use. Next, the wart, or horn castor, as it is called, which grows on the inside of the horse's leg ; dry, and grate it very fine, and keep also in an air-tight bottle. To catch a horse: Smear the hand with a little of the castor and oils, going to the windward, and gradually approach until the nose can be touched, when by fondling and rubbing, putting at the same time some of the ingredients into the horse's nose, he will soon become gentle.

Catlin, the noted traveler among the Indians, states that the Indians breathe into the nostrils of young buffaloes to make them follow. I have heard a great deal said at different times, and by different parties, of the great things they could do with medicine and means, but I never saw any practical proofs that were at all satisfactory. I give above the great secrets of Rarey and others. Now, we see that all this is hardly worth the name of a secret or system. It is easy to talk about horses not doing anything bad if they were not badly treated, etc. We might just as well claim we would not be sick if we lived right, and that doctors were unnecessary, or that fire-engines would be unnecessary if proper precautions were taken to prevent fires. In one sense this is true, in another it is fallacious reasoning. We do not understand the horse's nature, and probably never will so that it will not be found necessary to resort to scientific principles of control. They are as necessary as the skillful physician's help in emergencies of sickness or accident, and as the well-equipped fire brigade to arrest and put out promptly what might result in fatal destruction. So, in like manner, we must study scientific principles of reaching and mastering the difficulties presented in the control and management of vicious or unmanageable horses, as modern research, based upon a higher and broader intelligence, has enabled clearer perceptions of principles and the introduction of remedies and inventions to more directly, and naturally aid nature when exposed to disease or accident; and as the difficulties of the firemen, with the old hand-pump and bucket were simplified and superceded by scientific means and the invention of steam-engines, by which the difficulties presented are reached and overcome with ease and power. In like manner we are now able to prevent and overcome the difficulties of educating and making wild and vicious horses gentle with an ease and directness which would be entirely impossible by the principles used formerly by Rarey and others. The feats of control I have shown by my treatment, and I show almost daily in illustrating my system, would be entirely impossible by such treatment. My system combines all the elements of success demanded, embodying welldefined principles that will make the difficulties presented easily reached and overcome. It demands also in a high degree fine, keen perception and great firmness of purpose, that really but calls out and develops the highest and finest qualities of our nature. 


\section{HARNESSING.}

Be very particular about the fitting of the harness. It should rest easy on every part, yet fit nicely. The belly-band should not be overtight; undue pressure stops the circulation, is uncomfortable and may chafe. Be specially particular about the bridle fitting nicely, not pulling the bit across the lips-should rest in the mouth naturally and easily when checked up; that the throat latch is not too tight. Many a horse is half choked, and often even spoiled, from this cause, without its being suspected. The fitting of the harness should be attended to as carefully as the fitting of a suit of clothes-that it is not at least uncomfortably tight anywhere. There are many horses that a little careful, encouraging management would work in so gently that they would not be suspected capable of much resistance or acting badly, that a little harsh, rough treatment will make act very badly. I don't like checking the head up high, especially a colt that don't $\mathrm{k}$ now what it means. The check at all times should be moderately loose, and if a horse drives well and naturally good action, better be left off, or just enough to keep the head in place.

Always work the colt slowly at first, teaching him to go right and left, and ahead, with reins, as directed in driving colts in harness, and if you will give little presents of oats, corn, or anything else of which the horse is fond, it will help your purpose very much and teaches yourself patience. Always be mindful how you would probably act yourself if in the horse's place, if jerked and pulled about, perhaps made to feel the whip keenly, and that it requires a little time for a horse to understand what is wanted to be done.

People get mixed up in these matters, and ask, how is it then that you drive a horse so quickly, and yet you tell us to work slow and careful; we don't understand this.

I make a horse or colt, by my process of training, so that he will submit to being harnessed, haridled and submit to shafts striking the hind parts very quickly. This is what we term taming a horse. If he happens to work in quickly to the control of the bit, he will drive afterwards gently. But very much of my success in this will depend upon the type of his temperament; a sulky, surly disposition always working in slowly, yet surely, if only patient. I can make any colt gentle by the simple course of subjection in from ten to twenty minutes, with very rare exceptions, but it will often require an hour or two to teach a colt to rein easily and nicely, and this comes under the head of details requiring this "knack" of teaching or winning into doing what is wanted, and is a matter of a little patience in teaching. In breaking colTs your point should be to make them entirely fearless and gentle, then teach slowly and carefully what to do. In breaking OLD HORSES, or those having bad habits fastened upon them, to overcome in the most thorough manner the weakness of resistance, whatever it is, drill on this one point until sure of success, let it be long or short. If the horse is moved by fear and determined in resistance, work sharp 
and quick until you make your point, and then all you will have to do will be to hold it until the horse becomes cool and the excitement to the nervous system wears off. There is what may appear to be a curious contradiction, but nevertheless it is true, that those horses most known and noted for their viciousness, that are called the worst horses, are in most instances easiest to break.

Wild Pete, of Petroleum Center, a nine-year-old horse, so wild and bad that he resisted all efforts to break him to harness, yielded to my treating in one hour, and has been used as a family carriage-horse since (over four years). The Bill Press horse, of Gowanda, N. Y., a wildish, reckless, runaway kicker, spoiled by bad management, resisted all efforts to subdue and control him in harness. Press, the owner, was incredulous when I proposed hitching him in harness in twenty minutes. He said he and four of the best horsemen of his township (Gowanda, which is noted for its sharp, skillful horsemen), worked a half a day' with him, and utterly failed; he said ten men could not put him in shafts. I drove him in fifteen minutes all alone, and in an hour's time broke him thoroughly. The Buffalo Omnibus Co. horse, referred to in paper, was completely subdued and reformed by me in twenty minutes. The famous Malone horse, of Cleveland, was under perfect control in loss than an hour. When in Columbus, O., a seven-year-old horse out of Cruiser, that had resisted all efforts to break, and was supposed to be worthless, yielded to my treatment in twenty minutes, and remained perfectly gentle afterwards. A seven-year-old Gold I)ust mare, owned by McVay in Mansfield, O., and purchased by him of L. L. Dorsey, the breeder of Kentucky. This mare was a natural kicker, was sold by Morsey to McVay, when three years old, as an incorrigible kicker. She had resisted the most persistent and skillful efforts to subdue and break her, and was truly a bad mare, all sorts of treatment having failed upon her, yet forty minutes' treatment, with careful, gentle handling and diving for a few days, completely reformed her. I could multiply cases of this kind in my long experience by the hundied, to show the curious extremes in horses, and I refer to them here to remind you that you are not to measure your success by the management of such cases. The most skill and the most effort will often be demanded in the management of cases that are not known to be bad or vicious.

It is the cool, almost calculating fighter-the mare that seems gentle in all places but one, and then she is, perhaps, lightning itself in hanging on, in contesting the efforts; perhaps it is the balker, that will resist only at one point, at all others a splendid worker. Some minor defect of character in an otherwise gentle, willing worker. One horse will, perhaps, pull on one rein. Another will kick if the rein is caught under the tail, can't be shod, etc. While the average of these minor habits yield readily to treatment-a matter, perhaps, of a few minutes' work-you may find cases that will call for more real skill and effort to break up than is necessary to break horses regarded and known to be very biad. If you find one of these give-and-take treacherous cases, you must make your point clear and sure; make your fight quick and decisive if you can, and always in the position and 
place of resistance. The moment you make your point, keep to work, requiring the horse to do over and over what is demanded, but rewarding liberally for obedience, with apples or anything of which the horse is fond; and once making your point, don't flatter yourself, make your success sure. These fellows (horses and mares) are treacherous; they will or may try you on, when not looking for it, hence make up your mind, if the horse is one of courage and bottom, to try him over and over most thoroughly, and if any inclination of resistance, contest it until the point is made sure ; but once beyond this be the careful, adroit manager, in a measure flattering and winning as you would a child. Now there is often, in horsemen of even much practical experience, manifested great lack of what I would call ordinary good sense or skill in this art of management. If they learn a system, the system must do it all; break the horse down on the kill or cure principle, without thinking that working along, carefully feeling their way as it were, is indispensable. When a careful engineer lets on steam, he does it at first slowly, that he may gradually get momentum without needless strain. To put on full head of power, because he can and knows how to do it, would be exposing to great hazard of spoiling and breaking down the machinery; and if the machinery is highly tempered and nicely balanced there is the more danger of this. It is the tact, the gentleness, the firmness, the clear conception of the whole duty and of the possible consequences that makes success here. And so it is as a master of this duty, for no machine was ever made by man more complex, more fully and perfectly balanced and more necessary that its laws and principles of government should be regarded in its management, than that of a finely organized horse, or-success in the management of which more clearly shows the value of skill.

When about leaving New York, a well known gentleman, a personal friend, requested that I would remain a day and show a horse breaker, a man who attended all the horse-taming schools in that city, a naturally good fellow, but crude in his ideas, how to manage a trotting mare he had just purchased. She was high-toned, eager, courageous and plucky, and had been subjected to severe treatment, but she would resent the drudgery of any heavy pulling or rough handling, and was acting badly. This man worked her and insisted upon hitching her to a heavy express wagon. That is just what you should not do with this mare, I insisted, and you will only spoil her by persisting in doing so. I obtained a light sulky, walked her gently at first, then let her out on a trot and soon could let her out as I pleased under any excitement without trouble. The mare only needed working up slowly and carefully, and with, perhaps, a few tnuches at the right time and place, would have worked in nicely; but worked as she had been, and by such a man, I should regard it almost a miracle to make her work successfully without breaking down her constitution, or spoiling her.

A three-year-old thorough-bred colt, of a very high-strung, bad disposition, was presented in New York to be driven in harness. I subjected the colt to treatment and soon had her in harness, but knew 
nothing of the bit or rein, being overworked and limited in time ; told a man, who had been with me for years and worked well, to hitch up and drive this colt gently, and by all means must not excite her-to take his time, work her slow, that on any account he must not excite her. But treating her as he would a common colt and getting her mad, she resisted the most severe and abusive treatment, which he, by losing his temper, inflicted in his effort to drive her in this way. The consequence was the colt was not fit to be seen or handled for two weeks. The owner generously overlooking the matter, and when over the effects of the abuse, in twenty minutes I was able to drive her as I desired gently, and did successfully in the presence of her owner, without the least excitement or abuse.

I refer to these cases, out of hundreds I could mention, to show that assumed experience and practice is not all that is necessary. Behind all this, firm, sound judgment is necessary, and this is what makes true success in this or any other field of effort.

This sort of nameless knack or skill, I will call it, is always called for in working in some horses; those, I mean, of a really courageous, determined resistance. But at the foundation of it is being careful and patient. A colt or horse that is sensitive, especially colts, must be worked along slowly, first with the harness only. If the colt will not go straight ahead at first, pull the near rein out of the shaft loop or terret, shorten your hold of it and he will come around you in a circle freely. Reverse this and gradually let out until you can drive on a straight line, but do not go any further until there is prompt, free obedience to the reins. The next step should be driving to poles, as explained on page 5r. A little slow, careful work now will lay the foundation of making your after-work easy and sure. Rough, careless work now may start the colt in kicking, balking, resisting in some way that will require very careful, thorough handling to thoroughly overcome.

Always make the point first of making the colt gentle to be handled and touched all over, behind and before. From this proceed to train as desired. The constantly varying conditions of disposition and habit call for much genius to attain success. It demands, anyhow, strong control of the passions and a firm resolution to be patient, in fact the highest qualities of good sense and manhood are demanded back of all your efforts. There is often required great hazard and great firmness and courage. But this does not imply foolhardy rashness. Nothing should be trusted to chance that precautionary measures can prevent. It is no evidence of skill to get hurt, run away with or kicked, or that you had such and such accidents. It is true skill to anticipate such trouble and guard against it, or overcome it. You should study those causes that are at the foundation in spoiling horses. For example, in exciting undue fear, in making horses vicious, your lesson and other parts of this work will aid in giving a knowledge of this duty in its complexity of bearing. Following out these analogies, you will notice changes of expression peculiar to disposition and habit. The leerish expression of the kicker, the sulky expression of the 
balker, the lop ears of the sulker, the prompt, wiry expression and pointed ear of the eager, intelligent, courageous character, and learn to adapt your efforts to the control of each with increased success as you get practice.

\section{SHOEING.}

In the first place the object of trimming and fitting the foot for the shoe is to bring it back to its natural shape and bearing. If the foot is healthy, the safest course is not to touch the frog or sole, but cut down the wall from the heel to the toe until the bearing is natural. The bearing of the shell or hoof should be level. The shoe should be made to fit the foot, only so much longer as the foot will grow in the time it is expected to be on. The bearing surface of the shoe should be level and fit exactly all the way round to the foot. This means just what is said, and the owner should see that the shoe is level at the heels and not beveled in cup shape as shoes will usually be found when ready to be nailed on. Next see that the shoe is as big as the foot. The best way is to sternly object to allowing the foot to be touched with a red hot shoe and never on any conditions to allow the shoe to be burned into the foot to fit it.

Let the nail holes be as well forward in the toe as possible, at all events do not allow the nails to go into but one heel.

Do not, under any circumstances, allow any rasping under nail clenches, and none over them; no filing at all on the outside of the hoof, not even below the clinches, excepting enough down near the shoe to round the edge, but on no account should the hoof be cut down to the shoe, because the shoe happens to be small or short. This sort of work must not be allowed, yet it is just what all country shoers will insist on doing. Simply let the nails be cut off with nippers, clenched down upon the outside of the horn and if there is any soreness or tenderness the hammering should be light, and carefully done. As to corks, \&c., their object is to prevent slipping. In a state of health the nearer the foot is to the ground the better. If the feet are getting dry and hard, you should take measures to keep them damp. Flax seed wet with water, stuffing or buckling a couple of thicknesses of wet blanket around the foot. The simplest way is to throw some water on the bedding under fore feet during the day.

\section{CONTRACTION.}

If in a state of health, the object should be to keep the feet natural and healthy, the object now should be to bring the foot back to its natural shape. If one heel is drawn in, then, this only heel should be brought back natural. If both heels are drawn in, then both should be spread back. Two conditions now become necessary, first that the foot is prepared properly, and second that we have mechanical means that will enable spreading the heels without injury, yet as desired. The practice of sawing between the heels and frog, and then putting 
on an expansion shoe and spreading the quarters outward violently, is exceedingly cruel and dangerous. In the first place if the object is to weaken the horn between bar and frog it can be done but very imperfectly with a saw and violently spreading the heels, and thus, in a measure, bursting the shell apart will produce violent inflammation and lameness. Spreading the heels even in some cases a quarter of an inch, but little resistance may be shown, the horse may walk to his stable all right, but in a few hours, if examined, he may be in great pain, possibly in a high state of fever. It is really very doubtful policy for you to intrust a good horse in the hands of doubtful men who travel the country assuming to cure all sorts of lameness by this system of treatment.

The first thing to be done in the way of curing contraction, is to thoroughly soak the feet, either by poulticing by tying two or three thicknesses of blanket around the feet and keeping wet for 24 hours, or standing the feet in a tub in which is some mud. When the horn is soft, cut down the feet level to the point of removing the superfluous horn ; now, with a knife adapted to the purpose, weaken the horn between the heel and point of the frog, especially back, near and at the point of the heel. This done properly on both sides, fit a shoe of the simple flat kind accurately to the shell. Well back at the turn on each side, cut or file out enough, as shown in the Tyrrell shoe, but further back, so that it will bend as desired, about at the widest part. Now lay on the shoe as intended to be nailed and mark on the outside over the inside of the bar at the point of the heel; punch or drill two holes through, if you can obliquely the direction of the bar; make and drive two strong spikes from the ground surface up. Now bend and file these spikes so that they will extend up and back inside the bar at the point of the heels. The shoe must fit all round, there must be special attention to having those spikes fit, resting against the bar, but not so long as to come against the sole above. Nail on now, carefully, do not, by any means, allow the nails to be large, or rasping of the shell outside. This done, spread the shoe not over three-sixteenths of an inch, if shoe is fitted close. The heels, it is seen, are spread so far as the shoe is opened. This spreading should be repeated once every one or two days, but never more than an eighth of an inch at a time, but follow it up until the foot is brought back to its natural shape.

This is the Tyrrell principle, but it is next to impossible to fit a Tyrrell shoe. If too large or small, in the least, it will not do. The improvement I give makes it simple and entirely practical. Experience teaches the writer that not one horseman in fifty and not one shoer in a hundred can, or will, carry out properly and make a success with the aid and the hints given here and in the chapter on shoeing.

If the HEELS are WEAK, do not grow horn enough, do not cut away any when paring for the shoe. Simply level the foot, being as careful as you can not to waste by undue cutting where there is none to spare. 'The shoe should be fitted carefully, and in this case must, in a measure, protect the foot. For where the horn is light at the heel the sole is also usuall: light and will not bear pressure. 
If there is a CORN, you must protect that part from pressure, and this is done best by bringing pressure on the frog with a bar shoe, but if there is weakness or inflammation in the coffin-joint this is not by any means advisable, as it would aggravate the difficulty; you must now use an ordinary open shoe with middling high heel-corks, with no toecork, on the contrary, you should round the toe to imitate an old shoe, by bending or turning up the toe. If the horse is stiff and sore, in all cases round the toe, so that the foot will naturally roll a little, and thus in a measure relieve the strain upon the machinery of the foot and joint above it. To make the heels stronger, that is, have more horn, stimulate coronary ring at the upper edge of the hoof, using a mild blister, just enough to stimulate sharply, twice a week, or use the Hoof Liniment, but you must grow horn from the top down, and you will not see benefit until you have grown the foot down pretty well. If you have contraction, open the feet as directed, minding to keep the feet stuffed when in stable, at all events the feet must not be allowed to get dry and hard.

\section{QUARTER CRACK.}

The only practical way to cure quarter crack is to open the heel on that side, between bar and frog, cutting well down but not to bleed, until the quarter will give freely, then put on the shoe for expanding the heels. In this case you are to open or spread only the inner heel. The hoof is simply too small for the foot, and doing this properly reaches the point directly. In addition burn with a firing iron a crease across at the upper edge of the hoof. If this is done properly the hoof will not split any more. You may now grow the hoof more rapidly if you desire, but opening the foot and shoe is the point of success.

Mr. Bonner is the most profound and practical student of the foot in this or any other country. The writer is indebted to him for many valuable hints on the care and management of the feet, but does not feel at liberty to publish details of his treatment. He is a man of rare, round common sense, in all that he says and does, who goes to the bottom of a thing. His industry and research is in fact wonderful, in all that pertains to the care and management of horses.

\section{MR. BONNER'S SYSTEM OF FEEDING.}

In the morning, at five o'clock in summer, and six o'clock in winter, each horse is given two quarts of oats. At nine o'clock two quarts more are given, and the same quantity is given again at one o clock. Before feeding, each horse is given all the water he will take, unless he is to be driven, in which case the allowance is cut short a little. At five o'clock in the afternoon the allowance of hay is given, usually about ten pounds to each horse, and none is given at any other time during the twenty-four hours. At nine in the evening, each horse is given a hot supper prepared as follows: For the ten horses twenty quarts of oats are put into a large kettle and boiled after which is 
added about the same quantity of wheat bran by measurement, with the proportion of a teaspoonful of salt to each horse. The whole is thoroughly mixed, and when sufficiently cool each is given his share. If not driven, each horse is walked from half an hour to an hour daily, and the greatest care is taken not to expose them needlessly for a moment without clothing.

\section{INGENIOUS ARR ANGEMENT}

For sifting, cleansing and measuring the grain for feeding. The grain is conducted from the loft to the feeding floor by a spout in which are two slides. Pulling one of them out a few inches permits the escape of two quarts and the other one four quarts of grain, which is deposited in a drawer beneath, in the bottom of which is a screen with the handle projecting from the side of the spout. Moving this handle right and left a few times removes all dirt and dust, and leaves the grain clean and fresh, ready for use.

\section{WHERE MEDICINES CALLED FOR IN THIS BOOK CAN BE OBT AINED.}

Anti-Fever Medicine, for Chills and Fevers, or Lung FEvers, called for in this book under that head (page 152).

This medicine is unequaled for the treatment of inflammation of the lungs, chills or fever of any kind. It is also just the thing for staggers or inflammation of the brain. It has been used with great success for colic and inflammation of the bowels-lately it is a specially valuable remedy for the cure of inflammatory rheumatism in man. As an external application, the writer has used it with great success in acute inflammation of the eyes. Put 30 to 40 drops in half a tumbler of soft water, and bathe the eye four or five times a day, more or less, according to severity of case.

Black Ointment, for cure of blood and bone spavin, curb, ringbone, and all external enlargements.

Address Wm. Somerville, V. S., I27 Erie st., Buffalo, N. Y.

Anti-Fever Medicine, price $\$ 8.00$ dozen, $\$ 5.00$ half doz. $\$ 1.00$ bottle. Black Ointment same rates, C. O. D. or cash with order.

Dr. Somerville is a graduate of two colleges in Europe, 45 years' practice, a scientific practitioner of a high order. 


\section{MISCELLANEOUS RECEIPTS.}

THERE are chance receipts here that will be found valuable. At all events, I give such plain, practical explanations, and include the best remedies, obtained by me in various ways during my experience, as I believe best and most reliable. Dr. Somerville informs the writer that he is having the best of success lately in treating colic and inflammation of the bowels with the fever medicine. He gives about a teaspoonful every thirty minutes until there is relief.

You will, however, find the regular treatment under those special heads, colic, pneumonia, inflammation of bowels, founder, to be, if available, the hest the writer has found, and in fact he gives the best treatment he can. Altogether, this edition will be found much better than any former one.

\section{TO CURE A FISTULA, POLL EVIL OR ANY INDOLENT ULCER.}

Burn corn cobs to ashes, fill the sore to the bottom with the ashes. It may be necessary to repeat two or three times, until a cure is effected.

A countryman who claimed he could cure any fistula, poll evil, etc., with one or two applications of a certain remedy, brought forward several neighbors who fully endorsed his assertions. One man said he had a horse that had been doctored for fistula for two years without doing any good, and at large expense. He was advised by this man to treat as above directed, and a cure was effected in a few weeks. Others who had used it endorsed the statement in the strongest terms. In the cases referred to there was no effort at dressing the ulcer. The ashes were stuffed to the bottom, when a granulating process set in and gradually healed up. Being simple and safe it is worthy a trial, and persons using it will confer a favor by reporting result to me at Buffalo, N. Y., from which point all mail matter will be received.

\section{TO CURE WEAK BACK.}

O. J. Madison, livery keeper and large dealer in horses, of Massillon, Ohio, a few years ago, cured several very bad cases. One horse was so weak that he would fall down and could not get up; said it would cure any case of weak back, and that he never knew it to fail. 
Give one grain of strychnine night and morning; next take equal parts of pine tar and pitch, warm until it spreads easily, and spread over the small of the back, from the hip furward ten inches, and across to almost the points of the hips; then spread on cantharicles (should be well pulverized) until the pitch is thoroughly covered; then cover with two thicknesses of cotton flannel.

A stiff sticking plaster of this nature is called a charge, and the following is one of the best formulas:

Burgundy pitch or common pitch, 5 ounces; tar, 6 ounces; yellow wax, I ounce, melted together, and when they are becoming cool, half a dram of powdered cantharides well stirred in. This must be partially melted afresh when applied, and put on the part with a large spatula as hot as it can be without giving too much pain. Tow or cotton should be scattered over it while it is warm; this forms a thick, adhesive covering, which cannot be separated from the skin for months. This is applied for old sprains of the loins, and also strains of the back sinews. The charge acts in three ways-by the slight stimulating power which it possesses, gradually removes all deepseated infammation; it promotes absorption of any thickening beneath, and gives general strength to the parts.

\section{DR. SHELDON'S TREATMENT FOR WORMS.}

1)r. Sheldon says it never fails to clean the worms out of a horse.

rst. Bran mash. In 24 hours give I drachm of santonine, which should be dissolved in water; then mix in a quart of starch, and give as a drench; in 30 minutes give aloes in solution sufficient to more the bowels promptly. The rule, as to the amount of aloes to be given, is explained on page $\mathbf{I 9 7}$, under the head of Physicking.

The same authority claimed such success in the cure of Tetanus, which is among the most difficult diseases to control, that I include his treatment. He claimed that it never failed to cure :

Take a large handful of lobelia (about 1 11).); steep in a gallon of water; give one quart of the infusion; put poultice of same over the hack of the head; same on the cut, or part injured, and continue repeating, at first in thirty minutes; repeating at longer intervals, as there is improvement. Blanket warmly and keep in a quiet place.

Dr. Sheldon practices near Canandaigua, N. Y.; a man of experience He claims the most perfect success by this treatment. He was ior several years, Surgeon in charge of 7 th Avenue R. R. stables, in New York city. [Regular treatment on page I65.]

I would remind that the veterinary practice is mixed and doubtful in the treatment of tetanus. Prof. Somerville said, I have tried all kinds of treatment and failed. It is a hard disease to control. 


\section{STICKING PLASTER-THE VERY BEST.-BY AN OID PHYSICIAN.}

Burgundy pitch, I oz. ; dragon's blood, I oz. ; oxcoro, I oz.; Venice turpentine, I oz. Put in a cup ; melt together. Spread, while warm, on leather or cloth.

\section{OLD MR. GOULD'S PREPARATION FOR PUTTING ON THE CLAMPS FOR CASTRATING HORSES.}

Mr. Gould is a resident near Bath, Steuben Co., N. Y. He is known in that and surrounding counties for his success in castrating horses, claiming to have never lost a case, and but little swelling after the operation.

The writer took particular pains to see the old man operate, and learn his secret.

The horse was laid down and tied in the usual manner. He washed the parts thoroughly with warm water, and then greased with lard. The clamps were of the usual $k$ ind. It is the preparation he put on the clamps that made his success, he said.

He put on the clamp, first rye flour paste; on this sifts on equal portions of red precipitate and corrosive sublimate, mixed together in powder. In 24 hours the clamps were taken off. This method of ireatment has been pursued for many years by a friend of the author, and he claims, with unfailing success, by never having lost a case, and is followed by no appreciable swelling.

\section{WIND-BROKEN, WHEEZING, OR WHISTLING.}

On page 165 is given a remedy for the cure of whistling, and authority. This proof, when set $u p$, I was unable to read, but arranged, as I supposed, for its being made according to copy. The printers, however made a bad blunder. Instead of "sponga fosta," it should read "Spongia, and Fowler's" solution, 20 drops each, or 20 drops of one in the morning, and the same of the other on the tongue at night, and so repeating until a cure was effected, requiring from four 10 six weeks. Mr. Conklin referred to, of 25 Jackson street, of that city, informed the writer recently, after being carefully questioned about it, after an experience of nearly five years, that his success has been enrirely satisfactory. Instead of dividing and giving alternately night and morning, as before stated, he unites the medicines, and gives of both, so united, 20 drops, night and morning. He said further, that filling a sponge with spongia and pushing it up the nostrils of the horse until thoroughly absorbed into the system, would give marked immediate relief to a heavy or wheezy horse; that he depended upon it for relief to show up a horse well.

The above medicines are not on sale at the drug stores. Go to a Homœopathic Repository to get them or you will be annoyed and disappointed. 
TO CURE WEAKNESS AND WEEPING OF THE EYES-THE LIDS SWOLLEN AND THE FYES WEAK.-FOR HORSES.

An old man's Remedy. Claimed that he never failed in curing with it.

Take saltpetre, I $1 / 2 \mathrm{oz}$; : sulphate of zinc, I oz.; sugar of lead, y oz. Mix all with a pint of vinegar and a quart of soft water. Take a small sponge: fill with it and squeeze in the hollow over the eye once a day until a cure is effected.

NOTE.-Would bathe not only the part named, but the eye itself, sponging around and into it.

\section{CURE OF BIG LEG AND BLOOD SPAVIN.}

Mr. James Brown of Troopsville, Cayuga Co., N. Y., cured a Blood Spavin, by rubbing on at night a simple blister (I part Spanish flies to 4 parts lard).

Ie put on the blister at night. and washed it off in the morning and applied a liniment of salalmoniac and vinegar (reduced one-half with water), rubbed in thoronghly, using the liniment two days and blister one. It took nearly six weeks to make a cure.

For Big Leg, this treatment was kept up for eight weeks, to make a cure.

\section{BRUISE AND CUT ON MAN OR HORSE.}

A favorite prescription of great value.

Laudanum, I o\%.; arnica tinc., I oz.; sassafras oil, r oz. Mix, bandagre lightly, when possible, and keep wet. Said the gentleman who gave the above prescription, I bruised one of my fingers terribly, literally smashing nail and flesh. I was in the greatest pain. When, after hours of suffering, a gentleman from New York accosted me, and learning my trouble, said for thirty cents I can relieve and cure you. He gave me this prescription. I had it put up, kept my finger wet with it during the night, and next day there was no pain, and in two days my finger was well. It removes all fire and pain and heals by first intention.

There are two prescriptions in this book that are above all price for cuts and bruises. One is the tincture of marigold, called callendula, described on page 20I, and the above. For man or horse they are unrivaled and are worth far more to any family than the cost of this book. One of my horses (Tommy), was kicked and seriously injured, deep holes being made in the shoulder by the corks of the shoe. Severe swelling and soreness followed immediately, making the horse seriously lame and sore. Bathing thoroughly rluring the same evening and night, following with the first-named remedy removed all soreness and he went to work next day apparently as well as ever, and the cuts were healed in two days. 
Mr. James Bennet, of Cleveland, a gentleman of great skill as a horseman, and of the highest integrity, called my attention to the callenclula preparation. Said he, I never saw anything that would take out soreness like it. A stallion bit me on the back. I was in great pain. A gentleman obtained some of it which he poured upon my shirt over the part, and in twenty minutes I was relicved from pain. The writer, in Painesville, Ohio, had a mare offered that pulled, on a walk, six men by the bit around the ring. It was an exhibition of the most desperate pluck imaginable. 'The result was the animal's tongue was cut fully half off, and the mouth was badly bruised and became terribly swollen in a short time. I had a few ounces of callendula with me, wirich I had previously obtained to try it, if opportunity presented. I reduce $I$ some of it one-third to one-half with water, and bathed the mouth with it thoroughly, repeating at first every hour, and next day every two to three hours. In the course of a few houtrs the swelling went down and within three days the tongue was healed and the mouth was entirely well.

Sou can make callendula by filling a bottle with marigold blows and filling it with good whisky, and let stand until the strength is taken up by the liquor. Reduce this one-third to one-half for use. Or you can gret it at a homœopathic repository. It is not usually kept in ordinary drug stores.

\section{COUGH DROPS, FOR COLD AND COUGH.}

Fluid extract belladonna, ro to $\mathrm{I} 5$ drops in a tablespoonful of water on the tongue three or four times a day. If there is swelling of the glands of the neck, and especially if the attack is acute, apply any stimulating liniment or mild blister-anything that will act well as a counter-irritant. This works splendidly in most cases. In fact you will find it just the thing, as we have found and proved by long experience.

An excellent remedy.

\section{COUGH POWDERS.}

Liquorice root powdered, fenugreek, lobelia, blood root, camphor gum, equal parts. Dose-tablespoonful two or three times a day in feed. In all cases of acute or chronic cough, if thickening of glands of neck, stimulate outside neck sharply.

\section{EYE WASH.}

A remedy of great value for inflammation of the eyes or sores of any kind.

Crotus martes and white vitriol, equal parts; dissolve in a half-pint of snow water or pure soft water. Dissolve thoroughly, and when settled pour off and arld half as much more water. If too sensitive, or m'ich inflammation, reduce.

This has cured fever sores when all nther treatment failed. Alzerah Williams, Mrs. Waite of Jamestown, N. Y., and John Woodford of West Hickory, $\mathrm{Pa}$., were cured by it. 


\section{FOR DEEP WOUNDS.}

Prevents inflammation or tendency to sloughing or mortification.

One lb. saltpetre, I gallon water, I quart best whisky. Inject into the wound with a syringe three times a day until a cure is effected.

A gun-shot wound, a fout deep, in the thigh of a horse (the ball could not be found, remaining in the leg) was perfectly cured in two weeks by this treatment.

In treating deep and dangerous wounds, especially if the animal is plethoric or fat, take away the grain, give a dose of physic, feed bran, carrots, etc. If grass is available substitute it for hay. You can also omit physic if grass is given freely. The acid on the grass neutralizes physic and makes it unnecessary.

\section{FOR REMOVING CALLOUSES OR THICKENING, CURBS OR BUNCHES UF ANY KIND.}

Oil origanum, oil spike, oil amber, spirits turpentine and camphor, I ounce each. Rub on thoroughly two or three times a week.

When in Ohio, the writer bought a fine work horse very cheap, on account of having a very bad curb on one of his legs, making a very disagreeable blemish. He was purchased late in June and kept constantly to the hardest pulling as a wheel horse. A little of the above medicine was rubbed on about once a week, sometimes oftener, and again would frequently neglect doing so for more than that time. By fall the enlargement was all gone, and the leg was as smooth and well as the one opposite.

\section{SLOW BUT SURE CURE FOR SPAVINS.}

Spirits of turpentine and hog's lard, simmer in the sun three or four days. Apply three or four times a week until well. By this treatment the horse may be kept to his work.

\section{TO CURE FITS.}

Put as much valerian root, and the castor or wart from a horse's leg, which is to be cleaned and cut into small pieces, as will be digested in a pint of whisky. Dose-three teaspoonfuls each day, and repeated until a cure is effected. A son of Mr. Hoyer's, of Shelby, Niagara county, N.Y., twelve years old, was subject to fits terribly, being in a fit sometimes, Mr. Hoyer stated, for two hours. Dr. Failing, of Royalton, next town, obtained the above remedy in Canada, which cured the boy in six months. Mr. Henderson, hotel keeper of Otisco, N. Y., claimed to have been cured by this prescription. 
THE CURE OF SPAVINS, RINGBONES, SPLINTS, ETC.

On page 168 , the nature of spavins, ringbone, etc, are explained and the prescriptions for cure are given on pages I7O and I7I. Great imposition has been, and is practiced upon the public by extravagant pretensions of ability to take off spavin, etc. Of having just the "secret cure all" that will annihilate spavins, ringbones, etc., as by magic. These pretended great secrets, are no secrets at all, and is the most unblushing quackery to a veterinary surgeon. They are usually combinations of the most powerful medicines modified by others of the ordinary character, that will kill and destroy the skin and subtissue of the part applied to if put on with any freedom, thereby causing a bad sore and blemish.

The formulas on page I 70 have been prepared with special care, and are among the very best.

The point is, first, with a shears clip the hair from a large surface, not as is generally done from the enlarged part, but considerable surface surrounding. Rub the blister in thoroughly with the hand for at least ten minutes. If a blister is not very strong, it can be made to act quite well by rubbing it in well, and if strong it may act well by merely rubbing it a few minutes. The rule should be to rub in well. The lamer the animal, and more serious the spavin or the ringbone, the stronger the remedy, and more thoroughly should it be rubbed in, but not so strong as to dissolve the skin. 'This is to be avoided and prevented. You can stop the action of a blister by greasing with lard.

When a blister after two or three days ceases to act, you will be governed in this by the strength of the blister, and the thoroughness with which it has been rubbed in. Grease over with lard next day, or in the course of twenty-four hours, wash with castile soap and water. Rub dry, and put on more blister, and repeat in this way three, four, five or more times, as the severity of the case may require. if you stop short of enabling sufficient action to produce ancholosis, there will be danger of failure. The animal must be kept up while under treatment, and the tail should be so tied that the parts inflamed will not be switched or touched by it. You must always clip off the hair before applying a blister that is at all strong, if not it will be raised and have a blemish.

The "Sweating Liniment," foot of page r 70 , the very strong sweating blister, and the one headed "A Fine Absorbent," on head of page $x>1$, are adapted more especially for taking off bunches, such as curb splints, capped hocks, or other enlargements of such character. The two other prescriptions following for spavin, ringhone, etc., are given as good samples of the heroic blistering believed to be among the socalled great secrets. The first, I have the best assurance, has been sold repeatedly for $\$ 50$. The second is among the great secrets in Vestern Pennsylvania and Ohio for the same purpose, and the secret sold repeatedly for $\$ 100$. 
A spavined horse will travel better if the inside heel-cork is ham. mered down, or the inside of the shoe is perceptibly thimmer, so as to relieve pressure upon the inside of the leg. If ringboned before, hammer down the toe-cork, and turn the toe up like a well worn down shoe, rounding up like a sled crook with medium crooks behind. The object is to enable the foot to roll or turn on the ground easily, and thus bring less strain upon the joint which is sore and sensitive.

\section{TO CURE CUTS OR BRUISES OF THE CHEEKS.}

Use inside I dram tannin to $1 / 2 \mathrm{oz}$. borax, three or four parts water; swab once a day inside of wound. For outside dressing, use tincture myrh and aloes (described on foot page 1 $S_{4}$ ). All wounds or injuries before being dressed should be washed or sponged clean with castile soap and tepid water, then dress with medicine. Wounds or sores should not be dressed oftener than once in 24 hours.

\section{MAGIC LINIMENT.}

Two oz. oil of spike, $2 \mathrm{oz}$. origanum, $2 \mathrm{oz}$. hemlock, 2 oz. wormwood, 4 oz. sweet oil, 2 oz. spirits ammonia, 2 oz. gum camphor, 2 oz. spirits turpentine, and I quart proof spirits-90 per cent. Mix well together, and bottle tight. For sprains, bruises, lameness, etc., in man, this liniment, without turpentine, is unrivaled.

Note. - This prescription was obtained by the writer twelve years ago, in On ondaga Co., N. Y. Much was claimed for it; that it would cure lame back, bruises, sprains, etc., and with the turpentine worked well upon horse flesh. My attention has been particularly called to it during the past two years by parties who used it. In Niagara Co., N. Y., a gentleman, in louking over his book after the school, pointed to it, saying: "There is a receipt I would not take $\$ 50$ for." He said a very fine horse in that neighborhood a few years ago got strained in the back so badly that he could not get up in consequence. A negro from Syracuse, took the horse in charge, made and applied a liniment to the back, bathing it in thoroughly twice daily. There was rapid improvement; the animal being soon able to get up, and got entirely well. He offered the negro \$1o for the receipt, without avail, that he made the nigger drunk and stole the receipt from him, "and," said he, "that's it exactly." He took down a bottle from a shelf in the sitting-room (in Charlotte, Niagara Co., N. Y.), saying: "Here is some of it ; they could not keep house without it here. For toothache, neuralgic pains, sprains, etc., the landlady said it was indispensable; that they kept it always in the house." "This was corroborated by others.

At Clifton Springs, Ontario Co., N. Y., during my last tour through that section in 1874 , a gentleman pointed out the same prescription taken from my ola book, and said he would not take \$roofor it; that he had cured 40 cases of neuralgia with it: that he put up the medicine as a specialty for that purpose, at $\$ 1.00$ a bottle; first making it up for his wife, who was troubled with neuralgia, curing her. It was used by others with the same result. The demand becoming so great that he put it up as a specialty and had thus secured a large !ocal sale of it. 
TO GROW HAIR.

Add as much sulphur to sweet oil as will make it thick as cream ; rub thoroughly into the tail or mane twice a week. This will grow hair on a tail rapidly. One of my horses rubbed the hair off his tail so as to spoil it. The skin was smooth and glossy, but no hair would grow there. Some one told me to apply the above; in a short time a thick heavy growth of hair started and grew to full length. Gifford lost all the hair from his tail, falling out (in 1873), in defiance of all that could be done. The above was rubbed well into the dock twice a week, and a heavy growth of hair soon started, making a fine tail.

FOR SCRATCHES, SADDLE GALLS, ETC., SORE TEATS, CAKED BAGS, ETC., IN COWS.

Two oz. Goulard's extract ; 2 oz. sulphate zinc ; 8 oz. lard.

Ur. D. Van Camp, a resident of Theresa, Jefferson Co., N. Y., in I86I, with whom the writer became acquainted at that time, made a sort of specialty of this medicine, to dairymen, claimerl that it would cure sore teats, caked bags, etc. Dairymen regarded it through that section with special favor, as the merlicine sold reaclily for such use, and the receipt was sold to quite a number of farmers, after the medicine was used by them, for $\$ 10$ to each. The Doctor gave the receipt to the writer on condition of not giving it to any one in that sectiun.

\section{SURE CURE FOR NEURALGIA (SELECTED).}

The Norwalk Gazette says: "A friend of ours who suffered horrible pains from neuralgia, hearing of a noted physician in Germany who invariably cured that disease, crossed the ocean and visited Germany for treatment. He was permanently cured after a short sojourn, and the doctor freely gave him the simple remedy used, which was nothing but a poultice and tea made from our common field thistle. The leaves are macerated and used on the parts afflicted as a poultice, while a small quantity of the leaves are boiled clown to the proportion of a quart to a pint, and a small wine-glass of the decoction drank before each meal. Our friend says he has never known it to fail of giving relief, while in almost every case it has effected a cure."

\section{TO STOP HAIR FALLING OUT.}

Fill a bottle with lobelia (roots and stems). Fill the bottle now with whisky; scent with anything desirable; wet the hair, rubling well into the scalp, once a day for a week or two. This is as good as it is simple. The writer's hair was coming out badly: this was used with perfect success. 


\section{BOTS.}

There has been and is so much misconception about bots and their destructiveness to horses, that a few words aloout them seems advisable. All horses that are exposed to the bot-fly, must, as a result, have bots in their stomachs. But the question of interest is, what can you do for the cure of bots. In a report by Dr. Adams, published in the "Medical and Agricultural Register," he stated, having made the following experiments at different times on bots three-fourlhs growun:

When immersed in rum, they live, 25 hours; decoction of tobacco, II hours; strong oil of vitriol, 2 hours, I 8 minutes; essential oil of mint, 2 hours, 5 minutes. Were immersed, without apparent injury, in spirits of camphor Io hours; fish oil, 49 hours; tinct. aloes, Io hours; in brine, Io hours; solution indigo, Io hours. A number of small bots, with one that was full grown, were immersed in a strong solution of corrosive sublimate, one of the most powerful poisons; the small ones died in one hour, but the full-grown one was taken out of the solution, six hours after its immersion, apparently unhurt.

Bots hang to the muscular coating of the stomach, on the upper side. We see very plainly that we cannot put any medicine into the stomach that will affect the bot, that will not destroy the coating of the stomach, and injure or destroy the horse. In the second place, there is no veterinary surgeon of any pretension to skill, or being authority, who can tell the symptoms of bots from colic. No attention in fact is given to the subject of bots in practice. The symptoms usually indicate colic, the case is treated accordingly, and cured, and the presumption of the diagnosis is supposed to be correct. No man can tell the symptoms of bots from colic, and if he could, he could do nothing for their expulsion; this is the opinion of the best veterinary surgeons in the country. I have been led to take up time and space with this matter to aid the reader should he have occasion to treat an attack of "bellyache" or colic. The majority of horsemen will doctor anyhow for bots without, in fact, knowing but little about the difficulty. Do not be misled; follow the treatment laid down for colic on pages $\mathrm{x}_{4} 6$ and $\mathrm{x} 48$, and follow it rigidly. Do not be misled by persons who may assume to know just what to "give to cure." The treatment given has been used by the writer in hundreds of cases with success, and it is the standard treatment of one of the best practitioners in the country.

\section{A CURE FOR RHEUMATISM.}

The berry of the common scoke-weed, or scoke-root-often called poke root. The berries when ripe should be put into spirits-gin is the best-at the rate of two ounces to the pint. Of the tincture thus made, a tablespoonful is given three times a day. This simple remedy, persinted in for a week or more, has effected some remarkable cures. IIas been published by the press as a rem dy of value and is thrown in. 


\section{FEVER MEDICINE ON PAGE 152.}

This is all that is given for the cure of Pneumonia, and no other is necessary. It is invaluable not only for acute inflammations in the chest, but it is one of the best of remedies for acute rheumatism. It possesses also some remarkable properties as a local application externally.

Twice the writer has been relieved by it when, by exposure and wet, he was entirely disabled by rheumatism, by taking 6 to 8 drops on the tongue three times a day, and in three days each time a cure was effected. When you feel indications of rheumatism, take from 6 to 8 drops on the tongue, three times a day until well.

Years agro, the writer, on two occasions, was kicked on the shin, causing serious ulceration, which was most difficult to cure; at another time, from the same cause, the skin was barely broken, but in spite of the best medical çare, ulceration followed and annoyed for several weeks to cure. In I873. had the same part of the shin most seriously cut, causing much pain and inflammation. As a mere matter of chance experiment, or want of anything else, about 40 drops of this medicine was put into a half tumbler of soft water, a piece of cotton cloth was saturated with it and tied around the part at 7 P. M. ; at 9 the cloth was again saturated, before going to bed. The inflammation and soreness had about all subsided by morning. But I wet the cloth again when getting up, and again at noon. The infammation and soreness all disappeared, the injury, in a word, healed by first intention, and had no trouble afterwards. I have used it in acute inflammation of the eye from injury, in several bad cases with the most marked success. The simple facts are stated and the reader is simply offered the benefit. Medical men know the great difficulty of "ontrolling inflammation of the periosteum when badly cut or bruised at the point named, and keep on the feet. I had previously used the best cooling astringents without avail, yet in this case, a bad injury at that, the effect was most marked, though on my feet as usual.

\section{WORTH TRYING.}

An experienced physician, who has himself been afflicted with rheu. matism, informs one of our exchanges that the disease is almost certain to give way to a remedy he has discovered. As it can now not only be procured at the drug store, but in the fields, we give it publicity. It is the berry of the common smoke-weed, or scoke-root-more commonly called "poke-root." These berries are put into spirits-gin is the best-at the rate of two ounces to the pint. Of the tincture thus made a tablespoonful is given three times a day. We are told that this simple remely, persisted in for a week or more, has effected some remarkable cures of this common and distressing complaint. This has been extensively published in press, and is included for what it is worth. 


\section{ITCH OINTMENT (FOR MAN).}

I oz. red precipitate: I oz. spirits of turpentine; 2 oz. Burgundy pitch; $1 / 2 \mathrm{lb}$. fresh butter. Melt the butter and pitch, and add the other ingredients, stirring until cold.

\section{VEGETABLE CAUSTIC.}

Make a strong lye of hickory or oak ashes, put into an iron kettle, and evaporate to the consistence of thin molasses; then remove into a sand bath, and continue the evaporation to the consistency of honey. Keep it in a ground stopped glass jar.

This caustic is very valuable in fistulas, cancers, scrofulas and indolent ulcers, particularly where there are sinuses, necrosis (or decay of bone), and in all cases where there is proud flesh; andalso to excite a healthy action of the parts. It removes fungous flesh without exciting inflammation, and acts but little except on spongy or soft flesh.

\section{A VAlUABLE REMEDY (CLIPPED FROM THE PRESS).}

Every family should keep a quantity of chlorate of potash. We have never found anything equal to it for a simple ulcerated sore throat. Dissolve a small teaspoonful of it in a tumbler of water, and then occasionally take a spoonful of the solution so as to gargle the throat. It is nearly tasteless and not at all offensive to take, and is hence well adapted to children. Nothing is better than this for chapped or cracked hands. Wash then in a weak solution and they will soon he well. It is also good for a rough, pimply or chapped face. It may he procured at any druggist's.

\section{SORE MOUTH.}

The lips frequently become sore at the angles of the mouth, from cutting or bruising of the bit. Tincture of myrrh and alocs, equal parts, applied to the sore, will soon cause it to heal.

\section{A VERY FINE HEALING PREPARATION FOR CUTS.}

Equal parts tinc. myrrh and balsam copaiba. To be used once a day. This is the favorite remedy of one of the most successful horsemen, a man of good sense and remarkably successful. It is one of the best of healing remedies.

\section{TO CURE BOILS.}

Two parts cream tartar, one part sulphur, one pint whisky. (About four cents' worth of each of the two.)

Take one tablespoonful three mornings; then skip three mornings, and so on, for nine mornings. Obtained by an ald man, and claimed to be an infallible cure. 


\section{CONTENTS.}

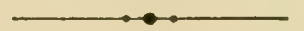

PAGE.

Aciaptation of Horses for different uses ............... 37

Appliances for Subjection ....................... 99

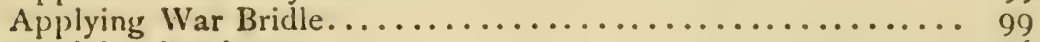

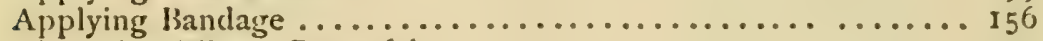

Absorbing Blister, Powerful ...................... I 7 I

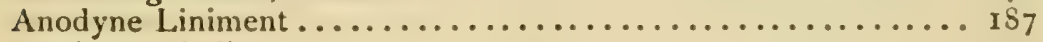

Astringent Balls . ........................... 197

Aromatic Powder ............................ 19

Anodyne Ball ................................ 199

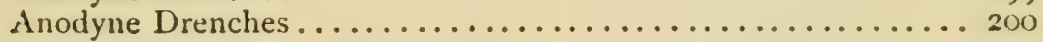

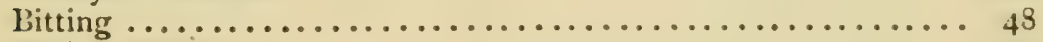

Bitting IIarness............................ 49

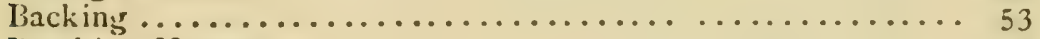

Breaking IIorses............................ 72

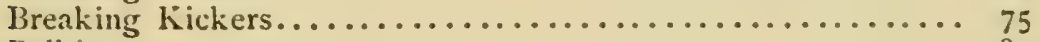

Balking $\ldots \ldots \ldots \ldots \ldots \ldots \ldots \ldots \ldots \ldots \ldots \ldots \ldots \ldots . \ldots \ldots . \ldots \ldots 8_{3}$

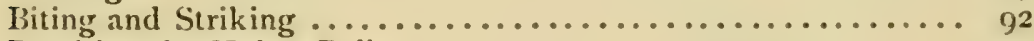

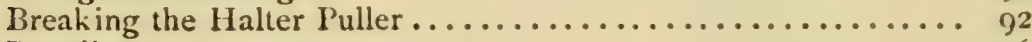

Breeling............................... 106

Bonner's Plan of Feeding Dexter ................... 116

Bar Shoe for Corns......................... : 37

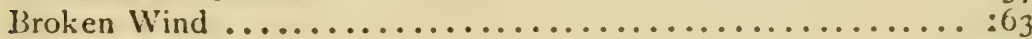

Bone Spavin ............................. 65

Blisters for Spavin, etc. ....................... : 70

Blood Spavin................................

Bog Spavin ........................

Bloody Urine............................... S1 $_{1}$

Butter of Antimony .......................... $\$ 86$

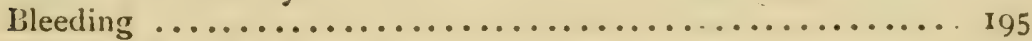

Balls for Appetite........................... I99

Balls for Farcy and Glanders ...................... 200

Conditions of Success ................................ 2 4

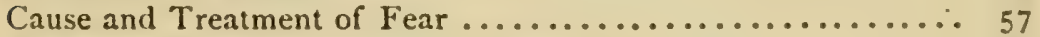

Chilian and South American Methods................. 66

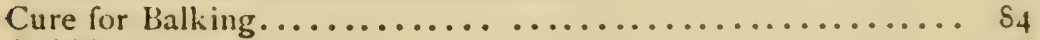

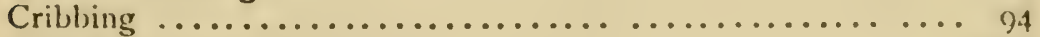

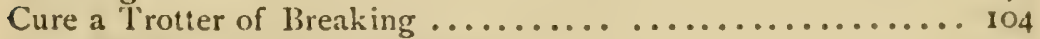

Cuts, Showing Formation of Foot................... I 24

Contraction of the feet....................... 132 
CUN'TEN'TS.

PAGE.

Convex Shoe for Contracted Feet .................. I35

Corns................................................ 179

Certificate from Dr. William Somerville................ I 43

Colic.................................... I46

Colic and Inflammation of Bowels Contrasted............. It 6

Congestion of the Lungs......................... I49

Catarrh or Cold.............................. I 55

Cure for Heaves ................................ I 64

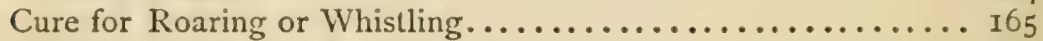

Cure for Spavin and Ringbone...................... I I

Curbs ..................................... I

Coffin Joint Lameness .......................... I 75

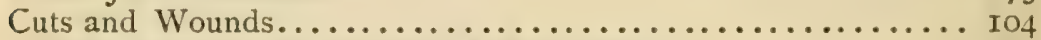

Cooling Liniment for External Inflammation............. I $8_{5}$

Cracked Heels ............................... I 89

Cure of Scratches............................ Igo

Canker................................ IgI

Caustics .................................... I92

Condition Powders ...................... I93 and 202

Cure of Farcy.............................. I93

Cough Powder............................... I94

Cure for Cough, No. 2 and $3 \ldots \ldots \ldots \ldots \ldots \ldots \ldots \ldots$ I9 94

Cordial and Anodyne Ball....................... I98

Cooling and Diuretic Drink ...................... I9

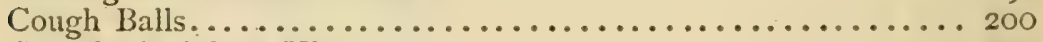

Cure for Indolent Ulcers........................ 20 I

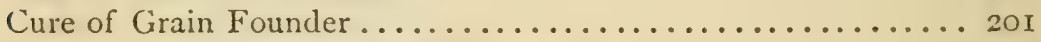

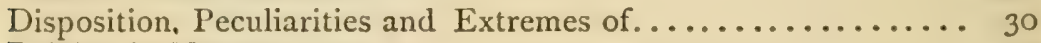

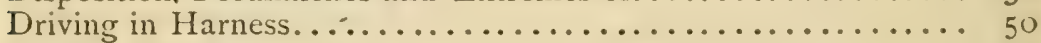

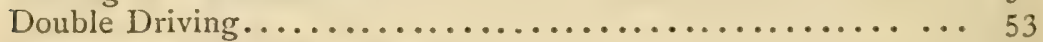

Diseases and their Treatment..................... I43

Dr. Burton's Remedy for Colic....................... I 47

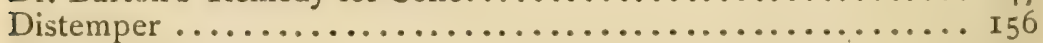

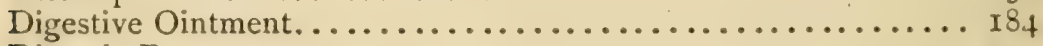

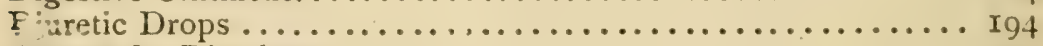

Ḋrench for Diarrhœa ........................... I97

Drenches tc Promote Parturition..................... I98

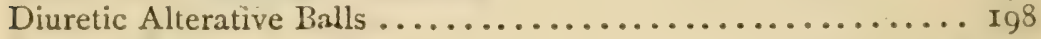

Diuretic Balls ............................ I99

Educated Horses ............................ 5

Education of Horses, New System of................ IC

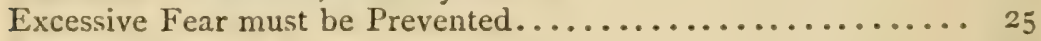

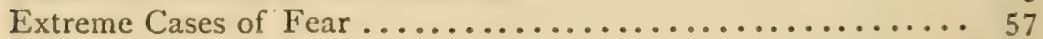

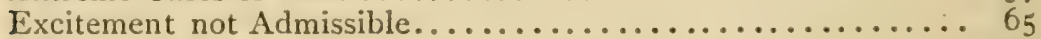

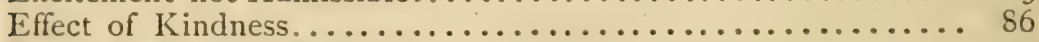

Excessive Rasping Bad ......................... I30

Eight-tailed Bandage ......................... I52

Eye Wash, Excellent .......................... I $8_{3}$

First Impressions are Strongest ................... 26

Fear, Causes and Treatment of .............. . : 57 


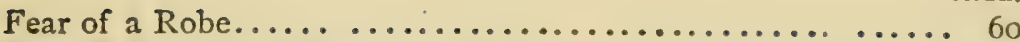

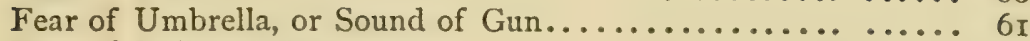

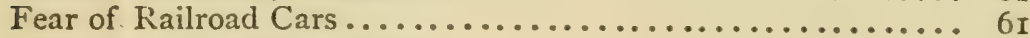

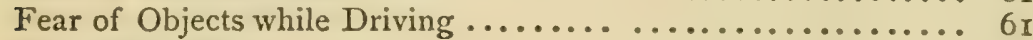

Four Ring Bit............................... Ioo

Foot Strap ................................. Ioo

Feeding $\ldots \ldots \ldots \ldots \ldots \ldots \ldots \ldots \ldots \ldots \ldots \ldots \ldots \ldots \ldots \ldots \ldots \ldots \ldots \ldots$

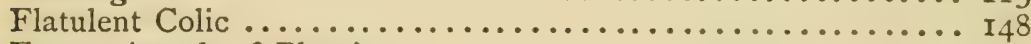

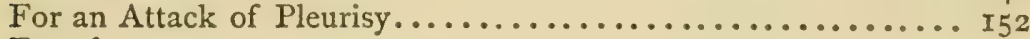

Founder................................. I6I

Favorite Remedies for Heaves.................... I64

Fistula of the Withers........................ I66

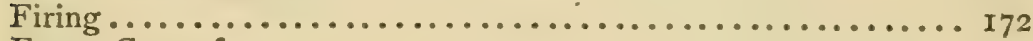

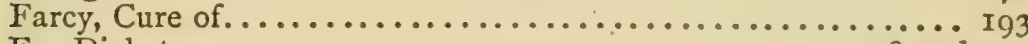

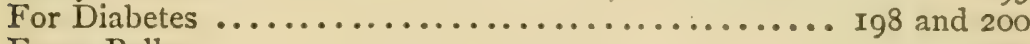

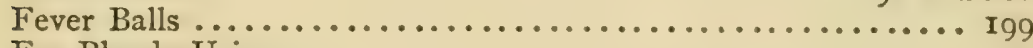

For Bloody Urine........................... 200

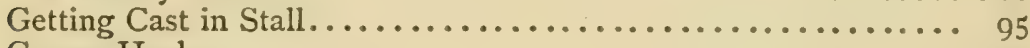

Grease Heels ................................ I53

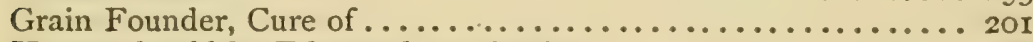

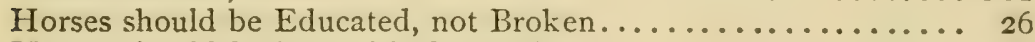

Horses should be Proved before Using................ 36

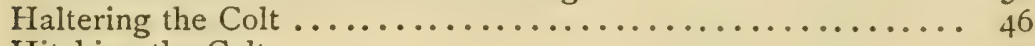

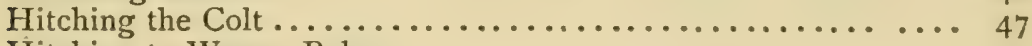

Hitching to Wagon Poles ..................... 5 I

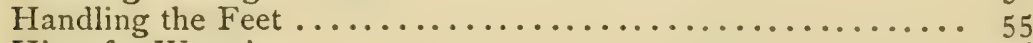

Hints for Watering.......................... I 6

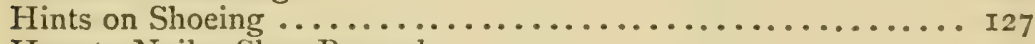

How to Nail a Shoe Properly....................... I3I

Heaves ................................... I6

Hoof Liniment for Contracted or Sore Feet . . . . . . . . . . . . I79

Hip Lameness.............................. I80

Healing Ointment, for Cuts, Galls, etc................... I 85

How to Bleed a Horse.......................... Ig6

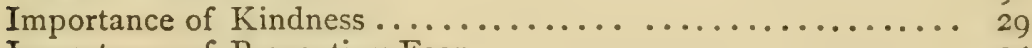

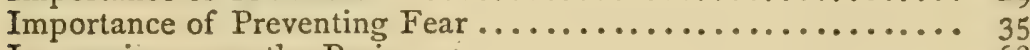

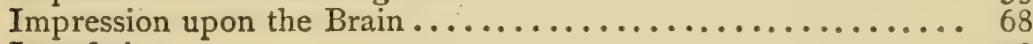

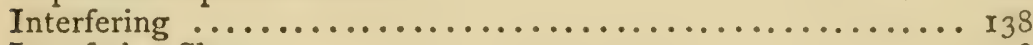

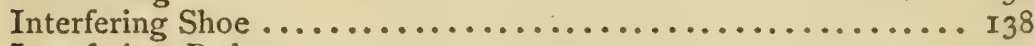

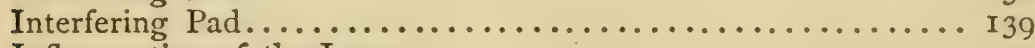

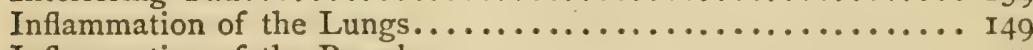

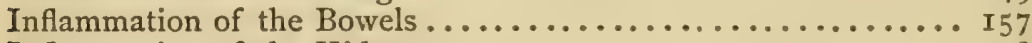

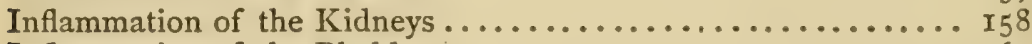

Inflammation of the Bladder ................... I60

Inflammation of the Brain ..................... I60

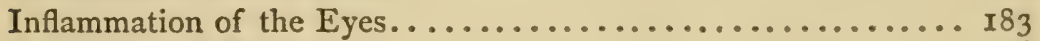

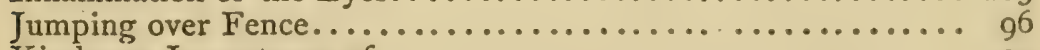

Kindness, Importance of ...................... 29

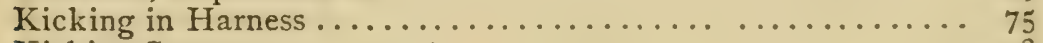

Kicking Straps .............................. $7^{8}$ 


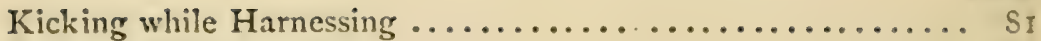

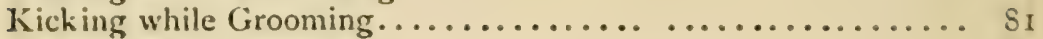

Kicking while Shoeing $\ldots \ldots \ldots \ldots \ldots \ldots \ldots \ldots \ldots \ldots \ldots \ldots$ S I $_{1}$

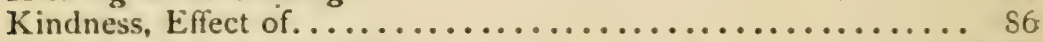

Kicking while in the Stall........................ So

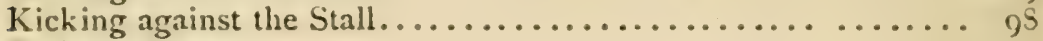

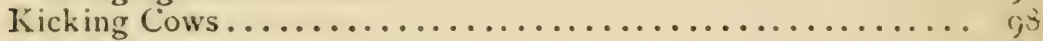

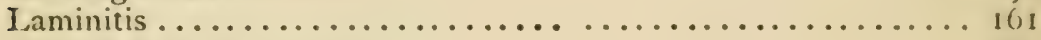

Locked Jaw, or Tetanus ......................... I6 $6_{5}$

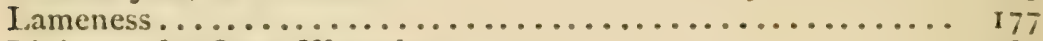

Liniment for Open Wounds .................... I $S_{5}$

Liniment for Foul Ulcers ..................... I $8_{5}$

Liniment for Galled Shoulders or Back............... IS6

Liniment for Strains, etc........................ IS7

Laxative Alterative Balls .......................... I9s

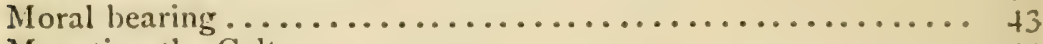

Mumting the Colt ............................ 54

Must See Objects from Different Positions............... 63

Mare.................................. 10

Make Follow with Whip...................... I IS

Mad Staggers............................. If,o

Magic Liniment .......................... I 87

Magic Healing Preparation..................... I $\$ 8$

Mange ............................... I

Milder Caustics.............................. 193

Miscellaneous Receipts ......................... 197

Mercurial Alterative Balls ........................ 197

Mixed Balls, Cordial Astringent Balls................... I99

New System of Educating Horses.................. In

Notices of the Press and People.................... II

Natural Adaptation Regarded ..................... 35

Not Being Afraid of Horses.................... 39

Nailing the Shoes ........................... 132

Nasal Gleet ............................... I1) 2

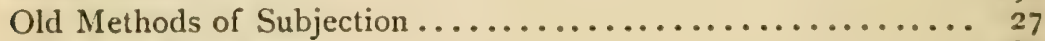

Overdraw Check............................. So

Oats vs. Corn for Feed .......................... IIt

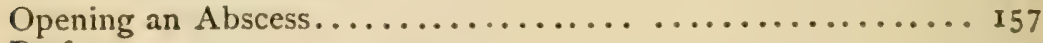

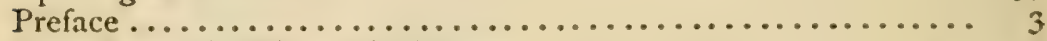

Prof. Magner's Educated Horses ................... 5

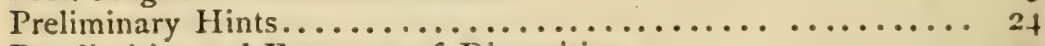

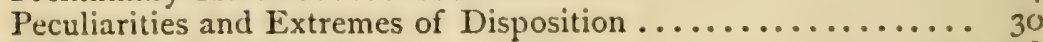

Pole Applied for Balkers....................... SS

Pulling on the Halter............................ 9 I

Prevent Getting Cast in Stall .................... 95

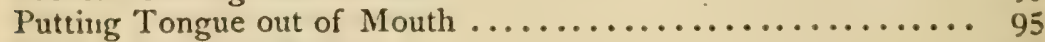

Prevent Jumping Fences .......................... 97

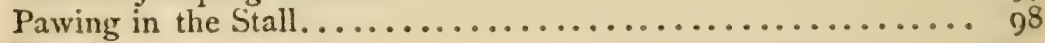

Pleurisy................................. 149

Poll Evil and Fistula of the Withers................... I66 


\section{CONTENTS.}

Powder for Spavin and Ringbone .................. I 7 I

l'owerful Absorbing Blister...................... I 7 I

Pricking in Shoeing ........................ 177

Profuse staling........................... Is I

Preparation to Kill Lice on Horses.................... I92

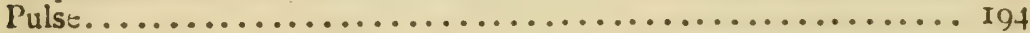

Physicing .................................... I97

Quarter Crack.................................. I 38

Quitter .................................. I9I

Subjection, Old Methods of...................... 27

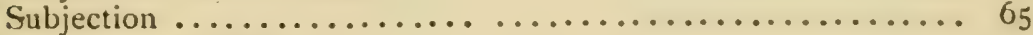

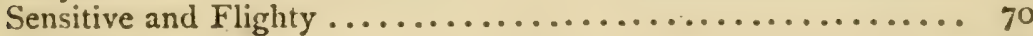

Stabling ................................ I Io

Shoeing................................ I 23

Structure of the Foot......................... I 24

Shoes Made Concave ........................... I 28

Shoes Concave are Injurious. .................... 133

Shoes ................................... 140

Spasmodic Colic ............................. I 45

Symptoms of Colic............................ I 46

Symptoms of Pneumonia........................ I5 I

Symptoms of Inflammation of Bowels ............... I5

Strangles ................................ I 56

Staggers ................................. 160

Sweeny ................................. 167

Spavin................................... 168

Strong Blister for Spavins, Ringbone, etc. .............. I 70

Sweating Liniment for Windgalls, etc. ................ I 70

Sweating Blister for Curbs, Splints, etc. ................ I 7 I

Splints ............................. I 74

Sprain of the Back Sinews ................... I75

Shoulder Strains .......................... I 78

Shoulder Lameness. ........................... I 78

Stepping on Nails, Glass, etc..................... I8o

Scours, or Purging .......................... I 8 I

Spasmodic Action of the Diaphragm ................ I8

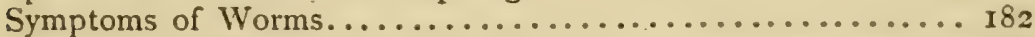

Sprains and Bruises ............................ I 86

Sticking Plaster for Cuts, Wounds, etc.................. I86

Thoroughness Necessary ..................... 4 I

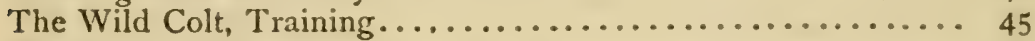

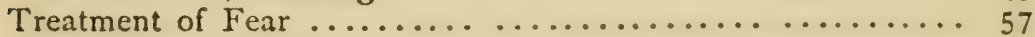

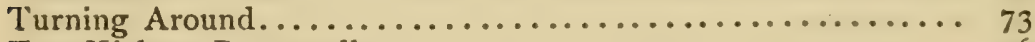

Test Kickers Repeatedly ...................... 76

To Work a Balker Single....................... 89. 89

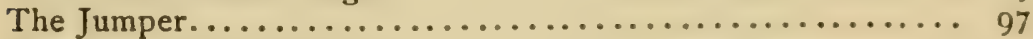

Treating a Halter Puller........................ 92

Training in the Trot ......................... IO2

Trotting ................................. I02

To Force on the Trut ........................ 104 


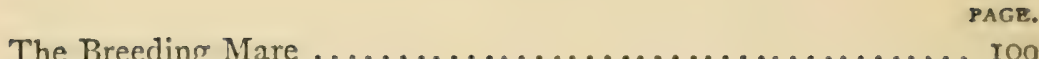

Tenching Tricks.............................. If

Teaching to Follow ........................ I 8

To make Follow with Whip ..................... I Is

Teaching to Lie Down.......................... I20

Teaching to Sit Up .......................... I20

Teaching to Make a Bow ........................ I2

Teaching to say Yes and No..................... I 2 I

Teaching to Kiss You ........................ I 2 I

Teaching Horse to Dance....................... I 22

Teaching Horse to Waltz ...................... I 22

The Foot ................................. I23

The Hoofs, Cuts of............................ I24

Tyrrel's Patent Shoe for Contracted Feet................ 136

Treatment for Corns ........................... I37

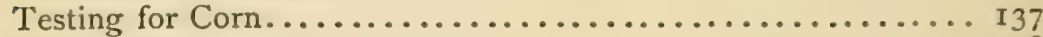

Tympanites ............................... I 48

Typhoid Pneumonia.......................... I 5 ]

Treatment for Inflammation of the Kidneys ............. I59

Treatment for Founder .......................... I62

Tetanus, or Locked Jaw........................ I6 65

Treatment for Bone Spavin....................... I69

Thoroughpin ........................... I 74

Treatment for Ringbone ...................... I 76

Thumps ............................... Is

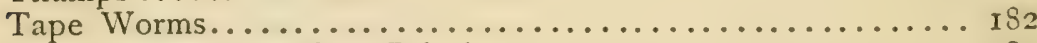

To Abate Swellings from Injuries ................. I87

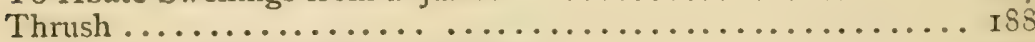

To Recruit a Horse Hide-bound, etc. ................... Isg

The Pulse................................ I9t

Tonic Ball (Vegetable) ......................... Igs

Tonic Diuretic Ball ........................... r 99

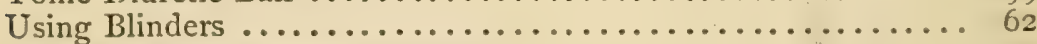

Valuable Miscellaneous Receipts ..................... I97

Worst Horses .............................. 69

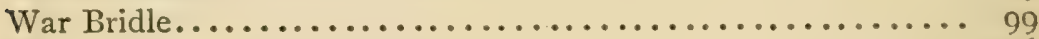

Watering .................................... II6

Weak Heels.................................. I39

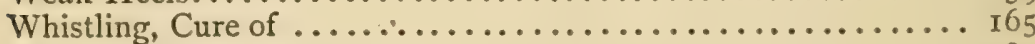

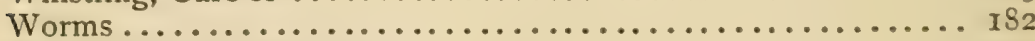

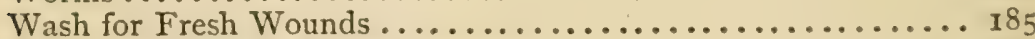

Wash for Inflamed Wounds ....................... I86

Worm Powders.............................. 201 







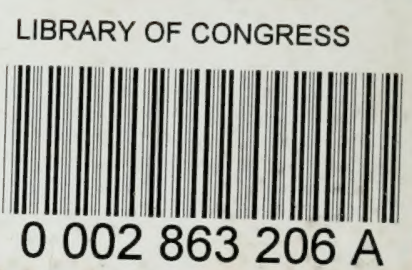

